\title{
One stop shop IV: taxonomic update with molecular phylogeny for important phytopathogenic genera: 76-100 (2020)
}

\author{
Ruvishika S. Jayawardena $a^{1,2,7} \cdot$ Kevin D. Hyde ${ }^{1,2,3,18} \cdot$ Yi Jyun Chen ${ }^{2,7} \cdot$ Viktor Papp ${ }^{4}$ Balázs Palla ${ }^{4}$ Dávid Papp ${ }^{5,6}$. \\ Chitrabhanu S. Bhunjun ${ }^{2,7} \cdot$ Vedprakash G. Hurdeal ${ }^{2,7}$. Chanokned Senwanna ${ }^{2,8} \cdot$ Ishara S. Manawasinghe ${ }^{2,9,18}$. \\ Dulanjalee L. Harischandra ${ }^{2,7,9}$. Ajay Kumar Gautam ${ }^{10}$ • Shubhi Avasthi ${ }^{11}$ • Boontiya Chuankid ${ }^{2,7}$. \\ Ishani D. Goonasekara ${ }^{2,7} \cdot$ Sinang Hongsanan ${ }^{12} \cdot$ XiangYu Zeng $^{2,7,19} \cdot$ Kapila K. Liyanage $^{2,17,20} \cdot$ NingGuo Liu $^{2}$. \\ Anuruddha Karunarathna ${ }^{2,8} \cdot$ Kalani K. Hapuarachchi ${ }^{2} \cdot$ Thatsanee Luangharn $^{2,3}$. Olivier Raspé el, $^{2,}$ \\ Rashika Brahmanage ${ }^{2,7,9} \cdot$ Mingkwan Doilom $^{3,16,17} \cdot$ Hyang B. Lee $^{13} \cdot$ Liu Mei $^{9} \cdot$ Rajesh Jeewon $^{14}$. \\ Naruemon Huanraluek ${ }^{2} \cdot$ Napalai Chaiwan ${ }^{2,7} \cdot$ Marc Stadler $^{15} \cdot$ Yong Wang $^{1}$
}

Received: 20 May 2020 / Accepted: 7 August 2020 / Published online: 24 September 2020

(c) The Author(s) 2020

\begin{abstract}
This is a continuation of a series focused on providing a stable platform for the taxonomy of phytopathogenic fungi and fungus-like organisms. This paper focuses on one family: Erysiphaceae and 24 phytopathogenic genera: Armillaria, Barriopsis, Cercospora, Cladosporium, Clinoconidium, Colletotrichum, Cylindrocladiella, Dothidotthia,, Fomitopsis, Ganoderma, Golovinomyces, Heterobasidium, Meliola, Mucor, Neoerysiphe, Nothophoma, Phellinus, Phytophthora, Pseudoseptoria, Pythium, Rhizopus, Stemphylium, Thyrostroma and Wojnowiciella. Each genus is provided with a taxonomic background, distribution, hosts, disease symptoms, and updated backbone trees. Species confirmed with pathogenicity studies are denoted when data are available. Six of the genera are updated from previous entries as many new species have been described.
\end{abstract}

Keywords Disease $\cdot$ Plant pathology $\cdot$ Phylogeny $\cdot$ Taxonomy $\cdot$ Symptoms

\section{Contents and contributors (main contributors underlined)}

Newly discussed genera and family

76. Armillaria - B Chuankid, M Stadler

77. Barriopsis - IS Manawasinghe, RS Jayawardena

78. Cercospora - ID Goonasekara

79. Clinoconidium - $\underline{\mathrm{AK} \text { Gautam}}, \underline{\mathrm{S} \text { Avasthi }}$

80. Cylindrocladiella - D Harischandra, RS Jayawardena

81. Dothidotthia - $\mathrm{C}$ Senwanna

82. Erysiphaceae - KKLiyanage, RS Jayawardena, KD Hyde

83. Fomitopsis - V Papp, B Palla, D Papp

84. Ganoderma-KK Hapuarachchi, TLuangharn, ORaspe

85. Golovinomyces - RS Jayawardena

86. Heterobasidium - V Papp, B Palla, D Papp

87. Meliola $-\underline{S}$ Hongsanan, $\underline{X Y}$ Zeng

Yong Wang

yongwangbis@aliyun.com

Extended author information available on the last page of the article
88. Neoerysiphe - RS Jayawardena

89. Nothophoma - IS Manawasinghe, RS Jayawardena

90. Phellinus - V Papp, B Palla, D Papp

91. Pseudoseptoria - A Karunarathna, RS Jayawardena

92. Stemphylium - RS Jayawardena, KD Hyde

93. Thyrostroma - C Senwanna, KD Hyde

94. Wojnowiciella - D Harischandra, RS Jayawardena

Updated genera

95. Cladosporium - NG Liu, RS Jayawardena

96. Colletotrichum - RS Jayawardena, KD Hyde

97. Mucor - VG Hurdeal, HB Lee

98. Phytophthora - CS Bhunjun, RS Jayawardena

99. Pythium - CS Bhunjun, RS Jayawardena

100. Rhizopus - VG Hurdeal, $\underline{\text { HB Lee }}$ 


\section{Introduction}

This is the fourth paper in the One Stop Shop series focusing on providing a stable platform for the taxonomy of plant pathogenic fungi and fungus-like organisms. Genera included in this series are associated with plant diseases, and when the data are available we discuss the species that have been established as pathogens using Koch's postulates. Some genera, however, are not well-known plant pathogens and some may be emerging pathogens, and need further studies to confirm their pathogenicity. Hyde et al. (2014) launched this series and stated its specific aims.

Three issues of One Stop Shop (OSS) have been published treating 73 genera and two families of plant pathogenic fungi and fungus-like organisms (Hyde et al. 2014; Jayawardena et al. 2019a, b, Table 1). In this fourth contribution, a further 24 genera and one family are treated, providing clarification of their taxonomy and classification. Six of the entries are updates from previous entries as many changes have occurred in these genera. For each entry, the background of the genus, disease symptoms, host distribution, pathogen biology and epidemiology, morphological based identification, molecular-based identification, updated phylogeny and recommended genetic markers are provided and discussed. All contributed entries will be placed in the database, http://www.onestopshopfungi.org. The main outcome of this series is to enhance the current understanding of plant pathogens and gain better insights into the current classification, providing a stable taxonomy and phylogeny for plant pathogens. This will provide a definitive classification for mycologists and plant pathologists to accurately identify causal agents of disease and to implement accurate control strategies.

\section{Materials and methods}

Photo plates of the symptoms of the disease and morphological characters are given, when available. Classification follows Wijayawardene et al. (2020).

For the treated taxa, all species that have been published until 30 March 2020 are included in the phylogenetic analyses. Sequence data from ex-type, ex-epitype or authentic or reference/voucher strains for each species were retrieved from GenBank. Sequence data from single gene regions

Table 1 All entries treated in One stop shop (OSS) series

\begin{tabular}{|c|c|c|c|}
\hline OSS1 (Hyde et al. 2014) & OSS2 (Jayawardena et al. 2019a) & OSS3 (Jayawardena et al. 2019b) & OSS4 (This paper) \\
\hline Bipolaris & Alternaria & Alternaria (update) & Armillaria \\
\hline Botryosphaeriaceae & Bipolaris (update) & Capnodium & Barriopsis \\
\hline Botryosphaeria & Boeremia & Chaetothyrina & Cercospora \\
\hline Botrytis & Botryosphaeria (update) & Cytospora & Cladosporium (update) \\
\hline Choanephora & Calonectria & Cyphellophora & Clinoconidium \\
\hline Colletotrichum & Coniella & Cyttaria & Colletotrichum (update) \\
\hline Curvularia & Corticiaceae & Dactylonectria & Cylindricladiella \\
\hline Diaporthe & Curvularia (update) & Diplodia (update) & Dothidotthia \\
\hline Diplodia & Elsinö̈ & Dothiorella (update) & Erysiphaceae \\
\hline Dothiorella & Entyloma & Entoleuca & Fomitopsis \\
\hline Fusarium & Erythricium & Eutiarosporella & Ganoderma \\
\hline Gilbertella & Fomitiporia & Fusarium (update) & Golovinomyces \\
\hline Lasiodiplodia & Fulviformes & Ilyonectria & Heterobasidium \\
\hline Muсоr & Laetisaria & Lasiodiplodia (update) & Meliola \\
\hline Neofusicoccum & Limonomyces & Macrophomina & Mucor (update) \\
\hline Pestalotiopsis & Neofabraea & Medeolaria & Neoerysiphe \\
\hline Phyllosticta & Neofusicoccum (update) & Neonectria & Nothophoma \\
\hline Phytophthora & Phaeoacremonium & Neopestalotiopsis & Phellinus \\
\hline Puccinia & Phellinotus & Pestalotiopsis (update) & Phytophthora (update) \\
\hline Pyrenophora & Phyllosticta (update) & Plasmopara & Pseudoseptoria \\
\hline Pythium & Plenodomus & Pseudopestalotiopsis & Pythium (update) \\
\hline Rhizopus & Pseudopyricularia & Rosellinia & Rhizopus (update) \\
\hline Stagonosporopsis & Tilletia & Sphaeropsis & Stemphylium \\
\hline Ustilago & Venturia & Stagonosporopsis (update) & Thyrostroma \\
\hline Verticillium & Waitea & Verticillium (update) & Wojnowiciella \\
\hline
\end{tabular}


were aligned using Clustal Xv.1.81 (Thompson et al. 1997) and further alignment of the sequences carried out using the default settings of MAFFT v.7 (Katoh and Toh 2008; http://mafft.cbrc.jp/alignment/server/), and manual adjustment was conducted using BioEdit where necessary. Gene regions were also combined using BioEdit v.7.0.9.0 (Hall 1999). Primers for each gene locus can be found in the bibliography related to the phylogeny presented in each genus. Phylogenetic analyses consisted of maximum likelihood (ML), maximum parsimony (MP) and Bayesian posterior probability (BYPP). Maximum parsimony analysis was performed using PAUP (Phylogenetic Analysis Using Parsimony) v. 4.0b10 (Swofford 2002) to obtain the most parsimonious trees. Maximum likelihood analyses were also performed in raxmlGUIv.0.9b2 (Silvestro and Michalak 2010) or RAxML-HPC2 on XSEDE (8.2.8) on the CIPRES science gateway platform (http://www.phylo.org; Miller et al. 2010). Bayesian inference was conducted using MrBayes v. 3.2.6 on the CIPRES science gateway platform (http:// www.phylo.org; Miller et al. 2010) or stand-alone MrBayes v.3.1.2 (Ronquist and Huelsenbeck 2003). MrModeltest v. 2.3 (Nylander 2004) or jModeltest v. 2.1.4 (Darriba et al. 2012) was used for the statistical selection of the best-fit model of nucleotide substitution to parametrize the analyses.

\section{Results}

76. Armillaria (Fr.) Staude, Schwämme Mitteldeutschl. 28: xxviii, 130 (1857)

\section{Background}

Armillaria is a plant pathogenic genus in the phylum Basidiomycota, family Physalacriaceae (He et al. 2019), collectively referred to as shoestring root-rot fungi or honey mushrooms. Armillaria can cause root-rot disease in a wide variety of woody hosts worldwide. Armillaria has undergone significant revision in the past 20 years. The genus once accommodated any white-spored agaric with broadly attached gills and an annulus (Volk et al. 1996). Armillaria mellea is the type species. Most Armillaria species have the potential to infect healthy and stressed trees, they differ in their pathogenicity to their hosts and under certain circumstances, they behave as obligate saprobes. Most Armillaria species are facultative necrotrophs causing root and butt rot on a broad range of woody plants affecting a variety of forest, shade, ornamental and orchard trees and shrubs. Some Armillaria species cause significant economic losses to forest trees and in nursery plantations. Armillaria root disease is found in many temperate and tropical forests throughout the world. This fungus spreads mainly through the interaction of tree roots. As saprotrophs, Armillaria species are important wood decomposers that contribute to nutrient cycling in forest ecosystems. As pathogens, they infect and eventually kill susceptible trees, which impacts forest structure, composition and succession. Trees that are used for fibre or lumber production, as well as trees located in recreation sites, are affected by these diseases. Such Armillaria infections may cause yield reduction and tree mortality in silvicultural and agricultural tree plantations and provoke economic losses.

Armillaria species are expected to become more aggressive during drought and thus enhance root rot (La Porta et al. 2008; Kolb et al. 2016; Kubiak et al. 2017). The incidence of Armillaria related root disease is likely to increase as temperatures increase and precipitation decreases due to climate change (Sturrock et al. 2011). Whilst the ability of the pathogen to sporulate, spread and infect is affected by temperature and moisture, factors that stress host trees directly may be just as critical to a successful invasion of host tissues. It seems likely that the disease will become more severe in the future, wherever Armillaria susceptible tree species are subjected to increased levels of climate stress (Klopfenstein et al. 2009). Currently, Armillaria root disease causes large growth/volume losses (e.g., 16-55\%) in areas of western and North America (Filip and Goheen 1984; Cruickshank et al. 2011; Lockman and Kearns 2016). Armillaria root disease is typically more severe in trees that are maladapted to climateinduced stress (Ayres and Lombardero 2000; Kliejunas et al. 2009; Sturrock et al. 2011). Thus, it is likely that climate change will further exacerbate damage from Armillaria root disease, which can further predispose trees to beetle attack (e.g. Hertert et al. 1975; Tkacz and Schmitz 1986; Goheen and Hansen 1993).

Armillaria mellea is an edible species that has long been used as a Traditional Chinese Medicine. Some of Armillaria species are is believed to be able to improve health and prevent various diseases, such as insomnia, pain, and neurasthenia. Extracts of A. mellea exhibit anti-oxidative, antiinflammatory and immune-modulatory activities. Armillaria mellea can also induce maturation of human dendritic cells. The chemical constituents isolated from A. mellea include sesquiterpenoids, steroids, triterpenoids, adenosine and resin acids. Armillariol $\mathrm{C}$ is a furan-based natural product isolated from Armillaria species. A xylosyl 1,3-galactofucan (AMPS-III) was isolated and identified as a novel antiinflammatory agent from this species.

Classification-Basidiomycota, Agaricomycotina, Agaricomycetes, Agaricomycetidae, Agaricales, Physalacriaceae (He et al. 2019)

Type species-Armillaria mellea (Vahl) P. Kumm.

Distribution-Worldwide, mostly in temperate areas (northern and southern hemisphere) and some in tropical areas.

Disease symptoms-Armillaria root disease, shoestring root rot 
Symptoms caused by this fungus can be categorized into two categories:

Crown symptoms-branch dieback, crown thinning, chlorosis, reddening of foliage or heavier than normal production of cones.

Basal symptoms - the fungus can grow up from the roots in the inner bark in some tree species and causes basal cankers above the infected roots. Resinosis (exudation of resin) can be observed in resinous conifers. In some plants, decayed roots or decay in the inner wood of stem bases can be observed. Species cause a white rot of wood. In white rot, wood often has a bleached, whitish appearance and are spongy or stringy, and maybe wet. Black lines called "zone lines" are usually seen in the decayed wood. These lines are curved planes in the wood, sometimes called "pseudosclerotial plates", composed of thickened, dark fungal cells. They may play a role in the protection of Armillaria from unfavourable conditions or other fungi that attempt to invade its territory, including other individuals of the same species. Actively decaying wood may be luminescent, producing a faint glow in the dark (Baumgartner and Rizzo 2002; Worrall 2004; Klopfenstein 2009).

There are three major signs of Armillaria root disease in the field.

Mycelial fans can always be seen in infected and recently killed trees. These are white mats of fungal mycelium between the inner bark and wood that are generally substantial and have a mushroom odour.

Rhizomorphs are commonly associated with infection and are often attached to infected roots, but they may also be attached to the surface of uninfected roots. Depending on the species these may be few, small, fragile, hard to find or abundant and robust. Rhizomorphs can be cylindrical in soil or flattened under bark, reddish-brown to black branched and have a cream-coloured tip when actively growing (Guillaumin and Legrand 2013).

Mushrooms that have honey-brown caps can be seen in clusters near or on the base of trees.

Hosts-Many angiosperms and gymnosperms (especially conifers) in native, planted forests, orchards and vineyards (Farr and Rossman 2020).

\section{Pathogen biology, disease cycle and epidemiology}

Sexual reproduction results in the diploid mycelium. Such a mycelium is the dominant phase that is found growing in wood, growing through the soil as rhizomorphs, and killing trees. Armillaria species can be dispersed through airborne sexual basidiospores which will establish a new infection center. These taxa do not reproduce asexually but disperse by growing mycelium which is the most common source of infection, through root contacts or root grafts or by growing through the soil as rhizomorphs. Mycelium in colonized roots and the rhizomorphs produced serve as the most common mode of infection and may survive for up to 50 years or more in stumps, depending on the climate, size of the stump, and other factors (Baumgartner and Rizzo 2002; Worrall 2004; Klopfenstein 2009).

\section{Morphology-based identification and diversity}

Armillaria has included only white-spored wood-inhabiting agarics with broadly attached to decurrent gills and macroscopic black to reddish-brown rhizomorphs. Armillaria basidiomes are easily recognized by their caespitose habit, annulus and honey colour. It is, however, extremely difficult to identify some species due to the lack of morphological apomorphies (Watling et al. 1991; Pegler 2000). Besides, basidiomata are often not available to differentiate species, which further complicates the taxonomy of Armillaria (Harrington and Wingfield 1995). In this regard, Armillaria provides a clear example of where a phylogenetic approach can contribute significantly to its taxonomy. Until the late 1970s, Armillaria mellea was considered by most researchers to be a polymorphic species with a wide host range and distribution. Herink (1973), among others, suspected that this single species might be a species complex. However, since the morphology of basidiomata is difficult to study because of overlapping and inconsistent traditionally used morphological characters, other avenues of research were pursued. Hintikka (1973) developed a technique that allowed the determination of mating types in Armillaria. Using a modification of this method, Korhonen (1978a) was able to distinguish five European biological species. The cumbersome nature of the mating-type method of species identification prompted a search for other techniques for identifying collections. They were able to separate all North American species (NABS) of Armillaria except for A. calvescens and $A$. gallica, which are apparently very closely related (Anderson and Stasovski1992). Ten species of Armillaria in North America have been confirmed from multiple studies utilizing a combination of morphological, biological and phylogenetic species concepts (Anderson and Ullrich 1979; Anderson and Stasovski 1992; Burdsall and Volk 1993; Kim et al. 2006; Ross-Davis et al. 2012). Before, A. mellea shows great variability in morphology and hosts. These species were first separated using interfertility tests using cultures of Armillaria haploid tester strains and morphology. Now, A. mellea is considered as an independent species, with two North American biological species (Bérubé and Dessureault 1989; Volk et al. 1996) (Fig. 1).

\section{Molecular-based identification and diversity}

Problems surrounding the identification of Armillaria have led to important advances in developing robust but rapid DNA techniques. Such techniques have initially included DNA-base composition (Jahnke et al. 1987) DNADNA hybridization (Miller et al. 1994), sequence analyses of 


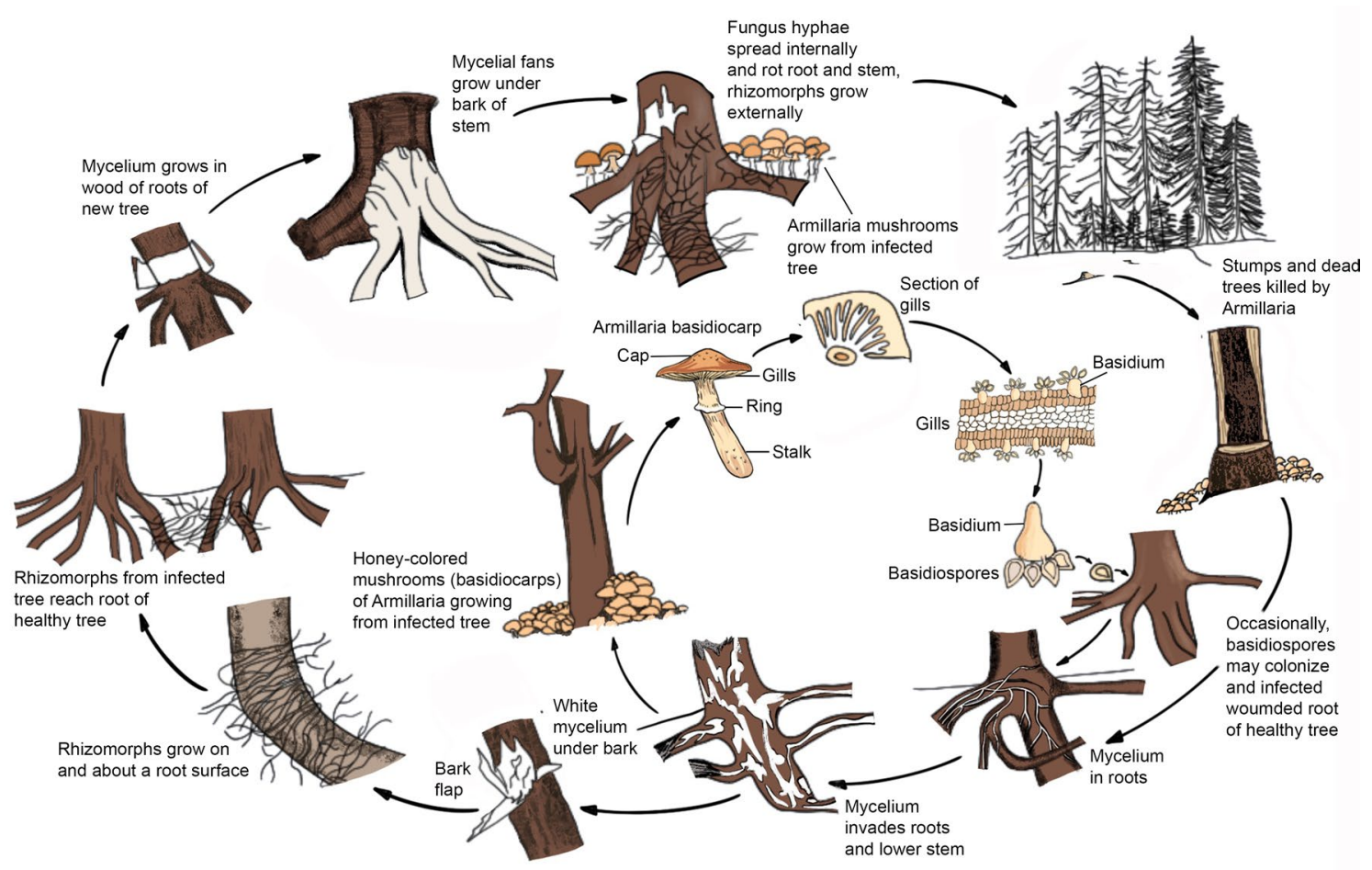

Fig. 1 Disease cycle of Armillaria mellea (redrawn from Agrios 2005)

the IGS-1(Anderson and Stasovski 1992) and ITS (Coetzee et al. 2001a, b), RFLPs without PCR (Smith and Anderson 1989) and RFLPs of IGS-1 amplicons (Harrington and Wingfield 1995). Although several of these techniques might pose some problems (Pérez-Sierra et al. 2000), by their relative simplicity they have gradually replaced traditional, morphological methods.

The amount of DNA sequence data on Armillaria species has increased substantially since the first publication on the phylogeny of the genus in the northern hemisphere (Anderson and Stasovski 1992). As with many other fungal genera, the focus of such studies initially was set on species of Europe and North America (Chillali et al. 1998; Coetzee et al. 2000b). Later, substantial datasets for species in Africa, Australasia and southeast Asia have become available (Terashima et al. 1998; Coetzee et al Coetzee et al. 2000a, 2001a). At present, ITS, IGS-1 and tefl sequences are available in GenBank for the best-known species of Armillaria. However, there are disjunctions in data sets and relatively little is known about species from Indo-Malaysia and South America. Armillaria fruiting bodies are produced seasonally and not every year; they are, therefore, often not available during fieldwork (Kile et al. 1991).

Identification using the biological species concept with species identification based on sexual compatibility tests (Korhonen 1978a) has been examined for its utility by some mycologists, but its application was soon abandoned. This was because of complications due to the absence of known tester strains, lack of haploid strains, ambiguous mating interactions and degeneracy of cultures. For these reasons, DNA-based molecular techniques have finally been preferred in Armillaria taxonomy, either complementing other methods or on their own. The techniques utilized for the taxonomy of Armillaria species include comparisons of RFLPs (Harrington and Wingfield 1995), AFLPs (PérezSierra et al. 2004), and the use of sequences from the ITS, IGS-1 and tefl gene in phylogenetic studies (Coetzee et al. 2000b, 2001a; Maphosa et al. 2006; Kim et al. 2006). Phylogenetic methods have made it possible to differentiate the lineages of the genus in southern Argentina (Pildain et al. 2009). Lineages I and II grouped with A. novae-zelandiae and A. luteobubalina, respectively, while Lineages III and IV represented unique taxa that were closely related to $A$. hinnulea, Armillaria 4th species from New Zealand (established by Coetzee et al. 2001a, b) and Armillaria Group III from Kenya (Mwenje et al. 2006). Modern approaches to identification of Armillaria species are mostly based on the analyses of DNA sequences. The present study reconstructs the phylogeny of Armillaria based on a combined ITS, IGS and tefl sequence data (Fig. 2, Table 2). However, insufficient data are available for the LSU gene region in GenBank. Then, it is difficult to have comparative phylogenetic analyses but the single gene analysis of each gene was carried out to compare the topology of the tree and clade stability. 


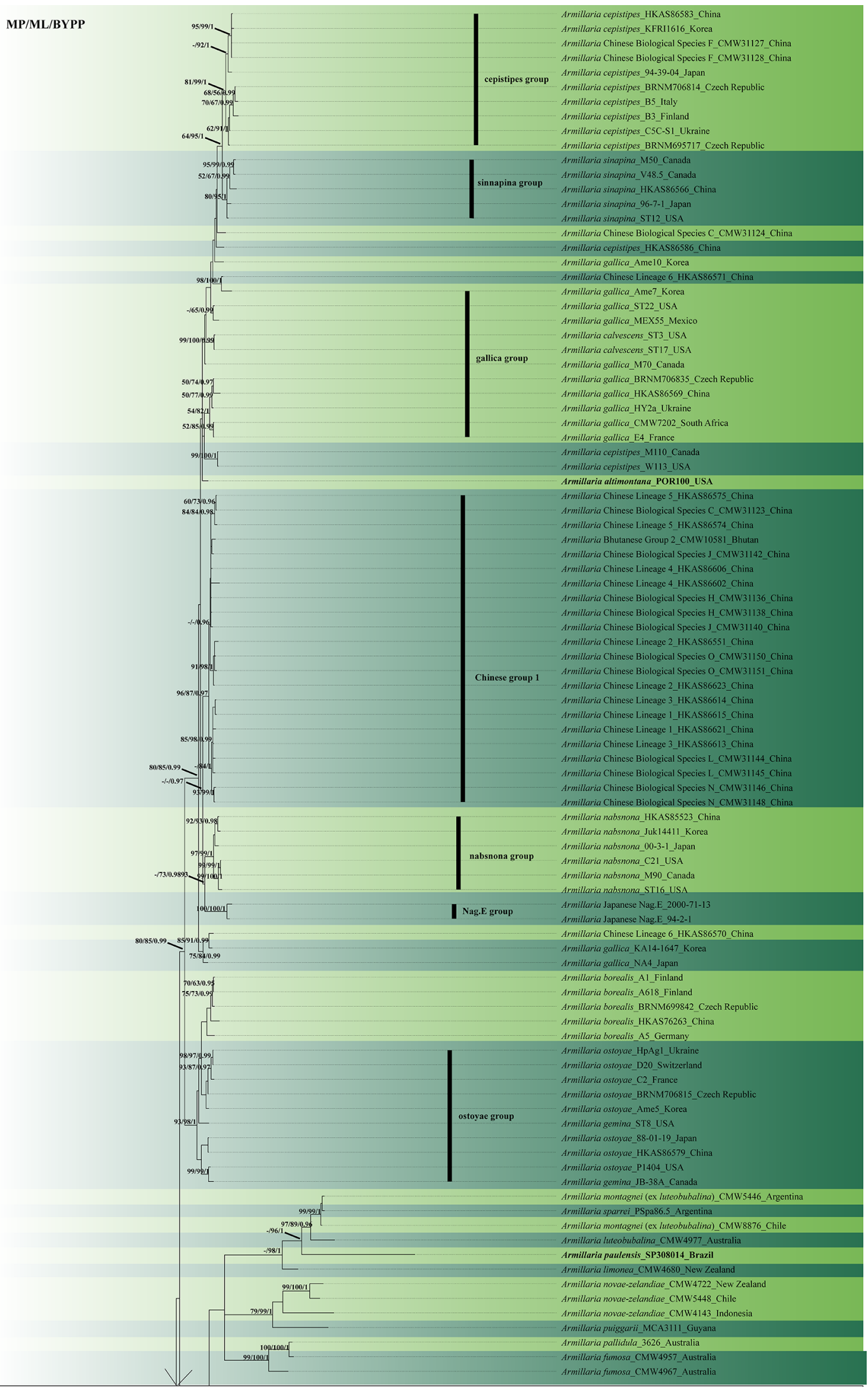


4 Fig. 2 Phylogenetic tree generated by maximum likelihood analysis of combined ITS-IGS-tefl sequence data of Armillaria species. Related sequences were obtained from GenBank. One hundred and thirty-nine strains are included in the analyses, which comprise 4557 characters including gaps. The tree was rooted with Guyanagaster lucianii (G31.4) and Guyanagaster necrorhizus (MCA 3950). Single gene analyses were carried out to compare the topology of the tree and clade stability. Tree topology of the ML analysis was similar to the MP and BYPP. ML phylogenetic tree inference was performed using RAxML version 8.2.12 on the CIPRES web server, using a mixed-model analysis and the GTRCAT model of substitution. The four partitions were defined as ITS, IGS, tef 1 exons and tef 1 introns. The best scoring RAxML tree with a final likelihood value of 25308.198187 is presented. The matrix had 1957 distinct alignment patterns, with $65.74 \%$ of undetermined characters or gaps. Estimated base frequencies of ITS were as follows: $\mathrm{A}=0.227071, \mathrm{C}=0.203923$, $\mathrm{G}=0.235701, \quad \mathrm{~T}=0.333305 ; \quad$ substitution rates $\mathrm{AC}=0.628852$, $\mathrm{AG}=3.751709, \quad \mathrm{AT}=1.365607, \quad \mathrm{CG}=1.467905, \quad \mathrm{CT}=2.788595$, $\mathrm{GT}=1.000000$. Estimated base frequencies of IGS were as follows: $\mathrm{A}=0.244624, \mathrm{C}=0.196588, \mathrm{G}=0.242370, \mathrm{~T}=0.316418$; substitution rates $\mathrm{AC}=0.954911, \mathrm{AG}=3.055115, \mathrm{AT}=1.041498, \mathrm{CG}=1.278095$, $\mathrm{CT}=3.421100, \mathrm{GT}=1.000000$. Estimated base frequencies of tef 1 exons were as follows: $\mathrm{A}=0.228587, \mathrm{C}=0.301128, \mathrm{G}=0.255865$, $\mathrm{T}=0.214420 ; \quad$ substitution rates $\mathrm{AC}=0.905728, \quad \mathrm{AG}=3.660986$, $\mathrm{AT}=1.564184, \quad \mathrm{CG}=0.648739, \quad \mathrm{CT}=28.048363, \mathrm{GT}=1.000000$. Estimated base frequencies of tef 1 introns were as follows: $\mathrm{A}=0.215042, \mathrm{C}=0.222693, \mathrm{G}=0.185633, \mathrm{~T}=0.376631$; substitution rates $\mathrm{AC}=1.170263, \mathrm{AG}=5.878084, \mathrm{AT}=0.847943, \mathrm{CG}=1.087990$, $\mathrm{CT}=5.095797, \mathrm{GT}=1.000000$; gamma distribution shape parameter $\alpha=0.1000000000$. The maximum parsimonious dataset consisted of 2908 constant, 1172 parsimony-informative and 477 parsimonyuninformative characters. The parsimony analysis: $\mathrm{CI}=0.610$, RI $=0.861, \mathrm{RC}=0.525, \mathrm{HI}=0.390$ in the first tree. Bayesian posterior probability was performed using the Markov chain Monte Carlo (MCMC) method implemented in MrBayes 3.2.6 with a mixed-model partition identical to the ones defined in the ML analysis. The best-fit nucleotide substitution model was separately determined for each partition with jModeltest version 2.1.10 on CIPRES, using the Akaike Information Criterion. $\mathrm{K} 80+\mathrm{I}, \mathrm{K} 80+\mathrm{I}, \mathrm{SYM}+\mathrm{G}$ and $\mathrm{HKY}+\mathrm{G}$ were selected as best-fit models for ITS, IGS, tef1 exons and tef 1 introns, respectively. At the end of the runs, the average deviation of split frequencies was 0.016675 . MP and RAxML bootstrap support value $\geq$ $50 \%$ and BYPP $\geq 0.95$ are shown, respectively, near the nodes. Holotype or ex-type strains are in bold

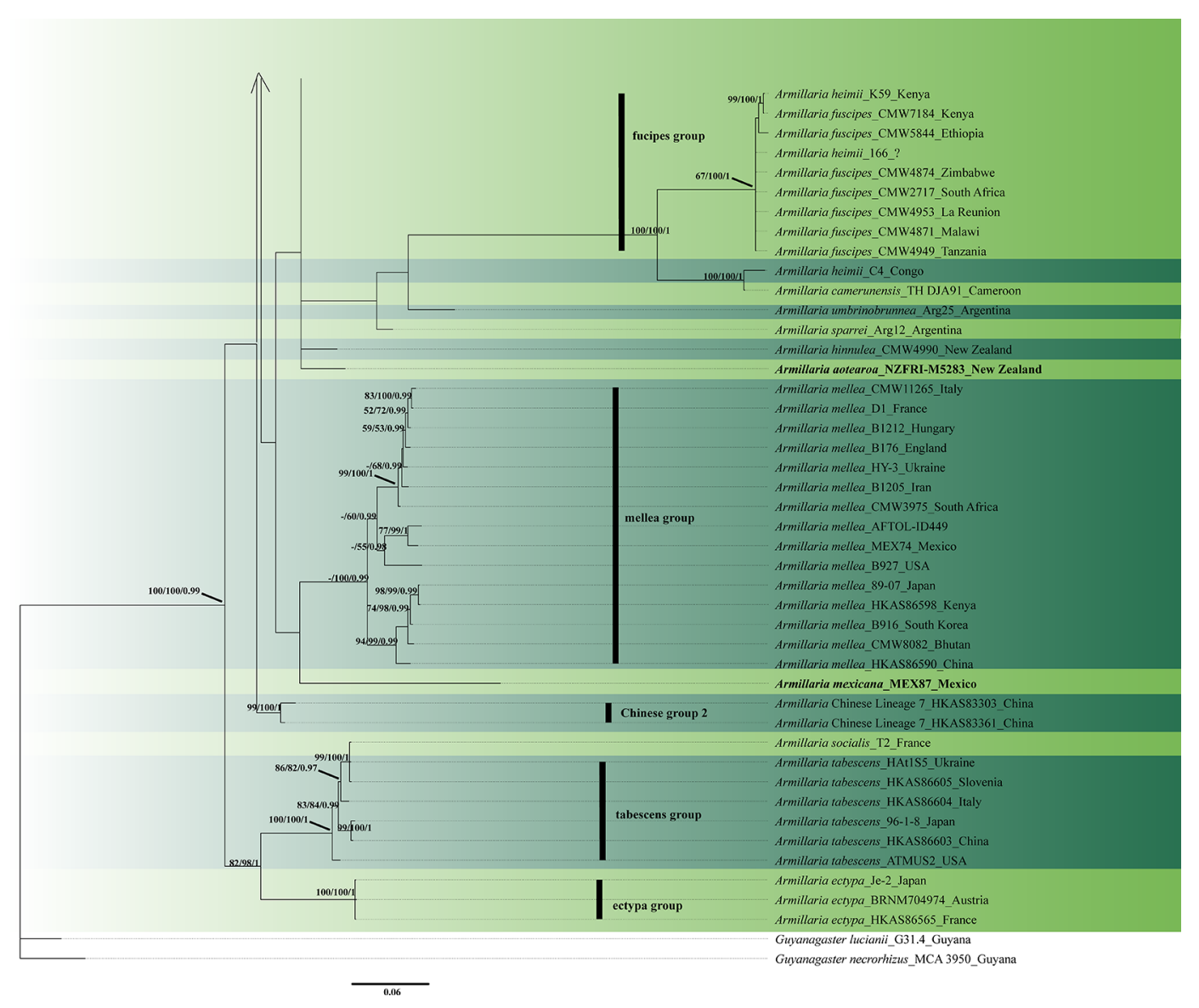

Fig. 2 (continued) 
Table 2 DNA barcodes available for Armillaria

\begin{tabular}{|c|c|c|c|c|c|c|}
\hline Species & Sources & Country & ITS & LSU & tefl & IGS1 \\
\hline Armillaria affinis & JMCR.126 & Central America? & - & AF261356 & - & - \\
\hline A. altimontana & POR100* & USA & $\begin{array}{l}\text { AY213579, } \\
\text { AY213580 }\end{array}$ & - & $\begin{array}{l}\text { JN944606, } \\
\text { JF313117 }\end{array}$ & AY509181 \\
\hline A. aotearoa & NZFRI-M 5283* & New Zealand & NR_151846 & - & KU295542 & - \\
\hline \multirow[t]{8}{*}{ A. borealis } & CMW31075 & Belarus & - & - & KM205252 & KM205305 \\
\hline & CMW31072 & China & - & - & KM205251 & KM205304 \\
\hline & $\begin{array}{l}\text { HKAS 76263, } \\
\text { Gt571 }\end{array}$ & China & KT822294 & - & KT822426 & - \\
\hline & $\begin{array}{l}\text { BRNM 699842, } \\
\text { MUAF } 501\end{array}$ & Czech Republic & EU257713 & - & EU251402 & EU257708 \\
\hline & CMW3172 & Finland & - & DQ338540 & DQ435623 & - \\
\hline & A1 & Finland & JN657467 & - & JN657494 & JN657440 \\
\hline & A5 & Germany & JN657468 & - & JN657495 & JN657441 \\
\hline & A618 & Switzerland & JN657469 & - & JN657496 & JN657442 \\
\hline \multirow[t]{3}{*}{ A. calvescens } & ST3 & USA & AY213559 & JF895899 & $\begin{array}{l}\text { JF313138, } \\
\text { JF895835 }\end{array}$ & AY509163 \\
\hline & ST17 & USA & $\begin{array}{l}\text { AY213560, } \\
\text { AY213561 }\end{array}$ & JF895900 & $\begin{array}{l}\text { JF313130, } \\
\text { JF895836 }\end{array}$ & AY509164 \\
\hline & $\begin{array}{l}\text { TH DJA 91/PUL } \\
\text { F2895 }\end{array}$ & Cameroon & KU170952 & KU170942 & KU289112 & - \\
\hline \multirow[t]{12}{*}{ A. cepistipes } & $\begin{array}{l}\text { BRNM 706814, } \\
\text { MUAF } 516\end{array}$ & Czech Republic & EU257715 & - & EU251395 & EU257709 \\
\hline & M110 & Canada & AY213581 & - & JF313121 & AY509182 \\
\hline & $\begin{array}{l}\text { HKAS 86583, } \\
01108 / 1\end{array}$ & China & KT822290 & - & KT822417 & - \\
\hline & B3 & Finland & JN657445 & - & JN657472 & JN657418 \\
\hline & B5 & Italy & JN657446 & - & $\begin{array}{l}\text { JN657473 } \\
\text { KJ414321 }\end{array}$ & JN657419, KJ414318 \\
\hline & $94-39-04$ & Japan & AB510853 & - & AB510786 & AB510809 \\
\hline & SY1Ra & UK? & - & - & JF746917 & JF288720 \\
\hline & C5C-S1 & Ukraine & JN657450 & - & JN657477 & JN657423 \\
\hline & W113 & USA & AY213583 & - & JF313115 & AY509184 \\
\hline & BRNM 695717 & Czech Republic & EU257716 & - & EU251396 & EU257710 \\
\hline & $\begin{array}{l}\text { HKAS 86586, } \\
\text { 97033/1 }\end{array}$ & China & KT822263 & - & KT822416 & - \\
\hline & KFRI1616 & Korea & MG543860 & - & MG544785 & - \\
\hline \multirow[t]{4}{*}{ A. ectypa } & BRNM 704974 & Austria & EU257720 & - & EU251403 & EU257712 \\
\hline & CMW15693 & France & - & DQ338547 & FJ875698 & - \\
\hline & $\begin{array}{l}\text { HKAS 86565, } \\
70011 / 13\end{array}$ & France & KT822340 & - & KT822438 & - \\
\hline & TFM27105, Je-2 & Japan & AB559000 & - & AB558992 & - \\
\hline A. fumosa & CMW4957, 123 & Australia & AF329917 & DQ338552 & DQ435646 & - \\
\hline \multirow[t]{7}{*}{ A. fuscipes } & $\begin{array}{l}\text { CBS 118122, } \\
\text { CMW5844, WG1I }\end{array}$ & Ethiopia & AY882969 & - & - & AY172032 \\
\hline & CMW7184 & Kenya & AY882973 & - & - & AY882965 \\
\hline & CMW4953 & La Reunion & AY882974 & DQ338556 & DQ435622 & AY882963 \\
\hline & CMW4871 & Malawi & AY882976 & - & - & AY882959 \\
\hline & CMW2717 & South Africa & AY882971 & - & - & AF204821 \\
\hline & CMW4949 & Tanzania & AY882978 & - & - & AY882961 \\
\hline & CMW4874 & Zimbabwe & AY882967 & - & - & AF489481 \\
\hline \multirow[t]{2}{*}{ A. gallica } & M70 & Canada & AY213568 & - & JF313123 & AY509171 \\
\hline & CMW31087 & China & - & - & KM205260 & KM205313 \\
\hline
\end{tabular}


Table 2 (continued)

\begin{tabular}{|c|c|c|c|c|c|c|}
\hline Species & Sources & Country & ITS & LSU & tefl & IGS1 \\
\hline & $\begin{array}{l}\text { HKAS } 86569, \\
93421 / 1\end{array}$ & China & KT822277 & - & KT822414 & - \\
\hline & $\begin{array}{l}\text { BRNM } 706835, \\
\text { MUAF } 575\end{array}$ & Czech Republic & EU257718 & - & EU251390 & EU636240 \\
\hline & E4 & France & JN657452 & - & JN657479 & JN657425 \\
\hline & $86-016 / 3$ & Germany & - & - & KJ200952 & KJ200946 \\
\hline & $86-008 / 2$ & Iran & - & - & KJ200954 & KJ200948 \\
\hline & NA4 & Japan & AB510881 & - & AB510761 & AB510834 \\
\hline & MEX55 & Mexico & JX281809 & - & KC111014 & JX281799 \\
\hline & CMW7202 & South Africa & AY190247 & - & - & AY190245 \\
\hline & HY2a & Ukraine & JN657455 & - & JN657482 & JN657428 \\
\hline & Aga235 & USA & - & JF895911 & JF895847 & - \\
\hline & ST22, EL-1 & USA & $\begin{array}{l}\text { AY213569, } \\
\text { AY213570 }\end{array}$ & JF895912 & $\begin{array}{l}\text { JF313126, } \\
\text { JF895848 }\end{array}$ & AY509172 \\
\hline & Ame10 & Korea & MG543850 & - & MG544774 & - \\
\hline & KA14-1647 & Korea & MG543859 & - & MG544784 & - \\
\hline & Ame7 & Korea & MG543852 & - & MG544777 & - \\
\hline \multirow[t]{2}{*}{ A. gemina } & JB-38A & Canada & FJ664586 & FJ618757 & FJ618670 & - \\
\hline & ST8 & USA & AY213555 & - & JF313136 & $\begin{array}{l}\text { AY509158, } \\
\text { AY509159 }\end{array}$ \\
\hline \multirow[t]{3}{*}{ A. heimii } & $\mathrm{C} 4$ & Congo & AY333917 & - & - & AY330630 \\
\hline & 166 & - & AY333913 & - & - & AY330634 \\
\hline & K59 & Kenya & AY333916 & - & - & AY330627 \\
\hline \multirow[t]{2}{*}{ A. hinnulea } & CMW4980 & Australia & - & DQ338555 & DQ435648 & AF445077 \\
\hline & CMW4990 & New Zealand & AF329905 & DQ338555 & DQ435648 & - \\
\hline A. jezoensis & HUA9116 & Japan & - & - & - & D89921 \\
\hline A. limonea & CMW4680 & New Zealand & AF329930 & DQ338560 & DQ435655 & AF445073 \\
\hline A. lutea & 90-4 (Alut) & USA & - & - & - & AF243066 \\
\hline A. luteobubalina & CMW4977 & Australia & AF329912 & DQ338559 & DQ435657 & AF445069 \\
\hline \multirow[t]{16}{*}{ A. mellea } & AFTOL-ID449 & USA & AY789081 & AY700194 & AY881023 & - \\
\hline & B176 & England & AF163578 & - & - & AF163602 \\
\hline & $\begin{array}{l}\text { HKAS } 86590, \\
00020 / 6\end{array}$ & China & KT822251 & - & KT822354 & - \\
\hline & D1 & France & JN657464 & - & JN657491 & JN657437 \\
\hline & $\begin{array}{l}\text { B1212, CMW4615, } \\
94056 / 1\end{array}$ & Hungary & AF163581 & - & - & AF163605 \\
\hline & $\begin{array}{l}\text { B1205, CMW4613, } \\
86009 / 1\end{array}$ & Iran & AF163583 & - & DQ435637 & AF163606 \\
\hline & $\begin{array}{l}\text { CBS122232, } \\
\text { CMW11265, } 426\end{array}$ & Italy & FJ875692 & FJ875694 & DQ435636 & - \\
\hline & $\begin{array}{l}\text { FFPRI420861, } \\
\text { WD2588, 89-07 }\end{array}$ & Japan & AB510852 & - & AB510796 & AB510808 \\
\hline & $\begin{array}{c}\text { HKAS 86598, } \\
\text { PFD84-103 }\end{array}$ & Kenya & KT822248 & - & KT822348 & - \\
\hline & MEX74 & Mexico & JX281807 & - & KC111011 & JX281797 \\
\hline & CMW3975 & South Africa & AF310329 & - & - & AF310327 \\
\hline & $\begin{array}{l}\text { B916, CMW4610, } \\
\text { A-5 }\end{array}$ & South Korea & AF163592 & - & DQ435639 & AF163612 \\
\hline & HY-3 & Ukraine & JN657466 & - & JN657493 & JN657439 \\
\hline & Am115 & USA & - & JF895920 & JF895856 & - \\
\hline & B927 & USA & AF163595 & FJ875695 & DQ435634 & AF163608 \\
\hline & CMW31161 & China & - & - & KM205267 & KM205320 \\
\hline
\end{tabular}


Table 2 (continued)

\begin{tabular}{|c|c|c|c|c|c|c|}
\hline Species & Sources & Country & ITS & LSU & tefl & IGS1 \\
\hline & CMW8082 & Bhutan & AY554333 & - & - & AY554335 \\
\hline & HUA93110 & Japan & - & - & - & D89922 \\
\hline A. mexicana & MEX87* & Mexico & KR061310 & - & KR061314 & KR061306 \\
\hline $\begin{array}{l}\text { A. montagnei (ex } \\
\text { luteobublina) }\end{array}$ & CMW5446 & Argentina & AF448422 & DQ338562 & DQ435650 & AF445068 \\
\hline $\begin{array}{l}\text { A. montagnei ( } \mathrm{ex} \\
\text { luteobublina) }\end{array}$ & CMW8876 & Chile & AF448423 & - & DQ435658 & AF445065 \\
\hline $\begin{array}{l}\text { A. montagnei (Line- } \\
\text { age II) }\end{array}$ & $\operatorname{Arg} 309$ & Argentina & FJ660939 & FJ711625 & - & - \\
\hline $\begin{array}{l}\text { A. montagnei (Line- } \\
\text { age II) }\end{array}$ & $\operatorname{Arg} 270 *$ & Argentina & FJ711609 & - & - & - \\
\hline \multirow[t]{7}{*}{ A. nabsnona } & ST16 & USA & AY213574 & - & JF313124 & AY509178 \\
\hline & $\begin{array}{l}\text { HKAS } 85523, \\
\text { Gt798 }\end{array}$ & China & KT822333 & - & KT822411 & - \\
\hline & M90 & Canada & AY213573 & - & JF313122 & $\begin{array}{l}\text { AY509176, } \\
\text { AY509177 }\end{array}$ \\
\hline & $00-3-1$ & Japan & AB510899 & - & AB510766 & AB510850 \\
\hline & $\mathrm{C} 21$ & USA & AY213572 & - & JF313119 & $\begin{array}{l}\text { AY509174, } \\
\text { AY509175 }\end{array}$ \\
\hline & CMW6905 & USA & - & DQ338542 & DQ435631 & - \\
\hline & Juk14411 & Korea & MG543857 & - & MG544782 & - \\
\hline \multirow[t]{5}{*}{ A. novae-zelandiae } & CMW4967 & Australia & AF329921 & - & DQ435651 & - \\
\hline & CMW5448 & Chile & AF448417 & DQ338554 & DQ435653 & - \\
\hline & CMW4143 & Indonesia & AF448421 & DQ338564 & DQ435654 & - \\
\hline & CMW3951 & Malaysia & AF448419 & DQ338553 & - & - \\
\hline & CMW4722 & New Zealand & AF329926 & DQ338551 & DQ435652 & - \\
\hline $\begin{array}{l}\text { A. novae-zelandiae } \\
\text { (Lineage I) }\end{array}$ & $\operatorname{Arg} 49$ & Argentina & FJ660935 & FJ711629 & - & - \\
\hline \multirow[t]{11}{*}{ A. ostoyae } & SP308014* & Brazil & EF639348 & - & - & - \\
\hline & BRNM706815 & Czech Republic & EU257717 & - & EU251400 & EU257711 \\
\hline & CMW31102 & China & - & - & KM205272 & KM205325 \\
\hline & $\begin{array}{l}\text { HKAS 86579, } \\
96043 / 11\end{array}$ & China & KT822310 & - & KT822428 & - \\
\hline & $\mathrm{C} 2$ & France & JN657459 & - & JN657486 & JN657432 \\
\hline & 88-01-19 & Japan & AB510859 & - & AB510784 & AB510815 \\
\hline & D20 & Switzerland & JN657463 & - & JN657490 & JN657436 \\
\hline & HpAg1 & Ukraine & JN657462 & - & JN657489 & JN657435 \\
\hline & P1404 & USA & AY213554 & - & JF313140 & AY509157 \\
\hline & Ame5 & Korea & MG543851 & - & MG544776 & - \\
\hline & 3626 & Australia & FJ664607 & FJ618752 & FJ618665 & - \\
\hline A. puiggarii & $\begin{array}{l}\text { MCA 3111/PUL } \\
\text { F2896/BRG } 41295\end{array}$ & Guyana & KU170954 & KU254228 & KU289104 & - \\
\hline \multirow[t]{7}{*}{ A. sinapina } & V48.5 & Canada & FJ664609 & FJ618763 & FJ618676 & - \\
\hline & M50 & Canada & $\begin{array}{l}\text { AY213563, } \\
\text { AY213564 }\end{array}$ & - & JF313114 & AY509167 \\
\hline & CMW31112 & China & - & - & KM205277 & KM205330 \\
\hline & $\begin{array}{l}\text { HKAS 86566, } \\
96015 / 39\end{array}$ & China & KT822323 & - & KT822422 & - \\
\hline & $96-7-1$ & Japan & AB510873 & - & AB510774 & AB510827 \\
\hline & P2-7 & USA & - & JF895916 & JF895850 & - \\
\hline & ST12 & USA & AY213565 & - & JF313132 & AY509168 \\
\hline A. singula & HUA9101* & Japan & - & - & - & D89926 \\
\hline
\end{tabular}


Table 2 (continued)

\begin{tabular}{|c|c|c|c|c|c|c|}
\hline Species & Sources & Country & ITS & LSU & tefl & IGS1 \\
\hline A. socialis & $\mathrm{T} 2$ & France & DQ784801 & - & - & - \\
\hline \multirow[t]{2}{*}{ A. solidipes } & MS2-11 & USA & - & JF895918 & JF895852 & - \\
\hline & CMW31107 & Finland & - & - & KM205275 & KM205328 \\
\hline \multirow[t]{2}{*}{ A. sparrei } & PSpa86.5 & Argentina & FJ664612 & FJ618750 & - & - \\
\hline & $\operatorname{Arg} 12$ & Argentina & FJ660948 & FJ711618 & - & - \\
\hline A. umbrinobrunnea & $\operatorname{Arg} 25$ & Argentina & FJ660946 & FJ711621 & - & - \\
\hline \multirow[t]{9}{*}{ A. tabescens } & CMW31118 & China & - & - & KM205280 & KM205333 \\
\hline & $99122 / 13$ & China & KT822339 & - & KT822441 & - \\
\hline & CMW3165 & France & - & DQ338546 & DQ435642 & - \\
\hline & CMW31119 & Italy & - & - & KM205281 & KM205334 \\
\hline & $\begin{array}{l}\text { HKAS 86604, } \\
\text { CT1097.3 }\end{array}$ & Italy & KT822338 & - & KT822440 & - \\
\hline & $96-1-8$ & Japan & AB510867 & - & AB510804 & AB510823 \\
\hline & $\begin{array}{l}\text { HKAS } 86605, \\
901582\end{array}$ & Slovenia & KT822337 & - & KT822439 & - \\
\hline & HAt1S5 & Ukraine & HQ232292 & - & HQ285906 & HQ232284 \\
\hline & ATMUS2 & USA & AY213588 & - & JF313113 & $\begin{array}{l}\text { AY509189, } \\
\text { AY509190 }\end{array}$ \\
\hline Bhutanese Group 2 & CMW10581 & Bhutan & AY554329 & - & FJ875699 & AY624365 \\
\hline \multirow{2}{*}{$\begin{array}{l}\text { Chinese Biological } \\
\text { species C }\end{array}$} & CMW31123 & China & - & - & KM205284 & KM205337 \\
\hline & CMW31124 & China & - & - & KM205285 & KM205337 \\
\hline \multirow{2}{*}{$\begin{array}{l}\text { Chinese Biological } \\
\text { species F }\end{array}$} & CMW31127 & China & - & - & KM205286 & KM205339 \\
\hline & CMW31128 & China & - & - & KM205287 & KM205340 \\
\hline \multirow{2}{*}{$\begin{array}{l}\text { Chinese Biological } \\
\text { species H }\end{array}$} & CMW31136 & China & - & - & KM205293 & KM205346 \\
\hline & CMW31138 & China & - & - & KM205294 & KM205347 \\
\hline \multirow{2}{*}{$\begin{array}{l}\text { Chinese Biological } \\
\text { species J }\end{array}$} & CMW31140 & China & - & - & KM205296 & KM205349 \\
\hline & CMW31142 & China & - & - & KM205297 & KM205350 \\
\hline \multirow{2}{*}{$\begin{array}{l}\text { Chinese Biological } \\
\text { species L }\end{array}$} & CMW31144 & China & - & - & KM205298 & KM205351 \\
\hline & CMW31145 & China & - & - & KM205299 & KM205352 \\
\hline \multirow{2}{*}{$\begin{array}{l}\text { Chinese Biological } \\
\text { species N }\end{array}$} & CMW31146 & China & - & - & KM205300 & KM205353 \\
\hline & CMW31148 & China & - & - & KM205301 & KM205354 \\
\hline \multirow{2}{*}{$\begin{array}{l}\text { Chinese Biological } \\
\text { species O }\end{array}$} & CMW31150 & China & - & - & KM205302 & KM205355 \\
\hline & CMW31151 & China & - & - & KM205303 & KM205356 \\
\hline \multirow[t]{2}{*}{ Chinese Lineage 1} & HKAS 86615 & China & KT822315 & - & KT822384 & - \\
\hline & HKAS 86621 & China & KT822306 & - & KT822386 & - \\
\hline \multirow[t]{2}{*}{ Chinese Lineage 2} & HKAS 86623 & China & KT822318 & - & KT822363 & - \\
\hline & HKAS 86551 & China & KT822279 & - & KT822367 & - \\
\hline \multirow[t]{2}{*}{ Chinese Lineage 3} & HKAS 86613 & China & KT822319 & - & KT822388 & - \\
\hline & HKAS 86614 & China & KT822305 & - & KT822391 & - \\
\hline \multirow[t]{2}{*}{ Chinese Lineage 4} & HKAS 86602 & China & KT822308 & - & KT822378 & - \\
\hline & HKAS 86606 & China & KT822281 & - & KT822359 & - \\
\hline \multirow[t]{2}{*}{ Chinese Lineage 5} & HKAS 86574 & China & KT822324 & - & KT822361 & - \\
\hline & HKAS 86574 & China & KT822327 & - & KT822364 & - \\
\hline \multirow[t]{2}{*}{ Chinese Lineage 6} & HKAS 86570 & China & KT822320 & - & KT822402 & - \\
\hline & HKAS 86571 & China & KT822288 & - & KT822404 & - \\
\hline
\end{tabular}


Table 2 (continued)

\begin{tabular}{lllllll}
\hline Species & Sources & Country & ITS & LSU & tef1 & IGS1 \\
\hline Chinese Lineage 7 & HKAS 83303 & China & KU378047 & - & KT822437 & - \\
& HKAS 83361 & China & KU378048 & - & KT822436 & - \\
Japanese Nag. E & $94-2-1$ & Japan & AB510888 & - & AB510768 & AB510840 \\
& 2000-71-13 & Japan & AB510879 & - & AB510773 & AB510832 \\
\hline
\end{tabular}

Ex-type/ex-epitype/ex-neotype/ex-lectotype strains are in bold and marked with an asterisk (*). Voucher strains are also in bold

This phylogenetic tree is largely in accordance with earlier studies from Coetzee et al. (2018) and provides the most conclusive phylogeny of the genera to date. Genealogical concordance phylogenetic species recognition (GCPSR) using the concordance among several gene trees (Taylor et al. 2000; Dettman et al. 2003) to delineate species has become standard in fungal taxonomy. However, except for a few studies (Guo et al. 2016; Tsykun et al. 2013), this taxonomic method has not been widely implemented in Armillaria taxonomy. Sequences of the genomes of key species are already providing prospects to study the evolution and systematics of Armillaria. They are certain to lead to important breakthroughs regarding not only the taxonomy but the biology and ecology of these fungi in the future (Sipos et al. 2017).

\section{Recommended genetic marker (genus level)_ITS}

Recommended genetic markers (species level)_ITS, IGS1, tefl

Additional genetic markers (species level)—LSU, tub2

Accepted number of species-There are 278 epithets in Index Fungorum (2020) listed for this genus. However, sequence data are only available for $\mathbf{3 1}$ species including 16 groups of unnamed species (Table 2).

References-Watling et al. (1991), Pegler (2000), Harrington and Wingfield (1995) (morphology); Coetzee et al. (2000a, b, 2001a, b), Maphosa et al. (2006), Mwenje et al. (2006), Kim et al. (2006), Coetzee et al. (2018) (molecular phylogeny).

77. Barriopsis A.J.L. Phillips, A. Alves \& Crous, in Phillips et al., Persoonia 21: 39 (2008)

\section{Background}

Stevens (1926) originally described the type species of Barriopsis in Physlospora as Physlospora fusca and Petrak and Deighton (1952) transferred it to Phaeobotryosphaeria. The fungus that was considered by Stevens (1926), and Petrak and Deighton (1952) did not have apiculi on its ascospores and was not similar to Phaeobotryosphaeria which had small, hyaline apiculi on the ascospores. von Arx and Müller (1954) considered Phaeobotryosphaeria as a synonym of Botryosphaeria. Based on morphological difference and molecular sequence data, Phillips et al. (2008) introduced Barriopsis. Species of Barriopsis are mostly saprobic and weak pathogens (Phillips et al. 2013).

Classification-Ascomycota, Dothideomycetes, Incertae sedis, Botryosphaeriales, Botryosphaeriaceae

Type species-Barriopsis stevensiana A.J.L. Phillips \& Pennycook

Distribution-Species appear to be confined to regions with tropical or subtropical climates including Australia, Cuba, Iran and Thailand (Phillips et al. 2008; Abdollahzadeh et al. 2009; Liu et al. 2012; Phillips et al. 2013; Doilom et al. 2014; Konta et al. 2016; Dissanayake et al. 2016; Hyde et al. 2018b; Burgess et al. 2019).

Disease symptoms-Barriopsis species can be weak pathogens and their pathogenicities are uncertain (Phillips et al. 2008; Dissanayake et al. 2016). Barriopsis stevensiana and $B$. iraniana were isolated from infected branches, fruits and leaves with various disease symptoms, including dieback, canker, rot and necrosis, from Cupressus sempervirens, Mangifera indica, Citrus sp. and Olea sp. in northern and southern provinces of Iran (Abdollahzadeh et al. 2009). Species of this genus may be future emerging pathogens.

Hosts-Archontophoenix alexandrae, Cassia sp., Citrus sp., Mangifera indica, Olea sp. Tectona grandis (Phillips et al. 2008, 2013; Abdollahzadeh et al. 2009; Liu et al. 2012; Doilom et al. 2014; Konta et al. 2016; Dissanayake et al. 2016; Hyde et al. 2018b, 2020b).

\section{Pathogen biology, disease cycle and epidemiology}

Barriopisis in this article is considered as an emerging pathogen. Further studies to identify the biology, disease cycle and epidemiology are needed.

\section{Morphological based identification and diversity}

The sexual morph is characterized by brown aseptate ascospores that are widest in the center and lack terminal apiculi (Phillips et al. 2008, 2013; Doilom et al. 2014; Dissanayake et al. 2016; (Fig. 3)). Barriopsis archontophoenicis forms the sexual morph in culture medium after long 
Fig. 3 Barriopsis stevensiana MFLU 19-1560. a Ascomata on dead twigs of Cassia sp. b Ascomata cut through horizontally showing the white contents with dark spots. $\mathbf{c}, \mathbf{d}$ Sections through ascomata. e, f Ascospores. $\mathbf{g}$ Germinated ascospore. Scale bars: $\mathbf{c}, \mathbf{d}=$ $200 \mu \mathrm{m}, \mathbf{e}, \mathbf{f}=20 \mu \mathrm{m}, \mathrm{g}=100$ $\mu \mathrm{m}$
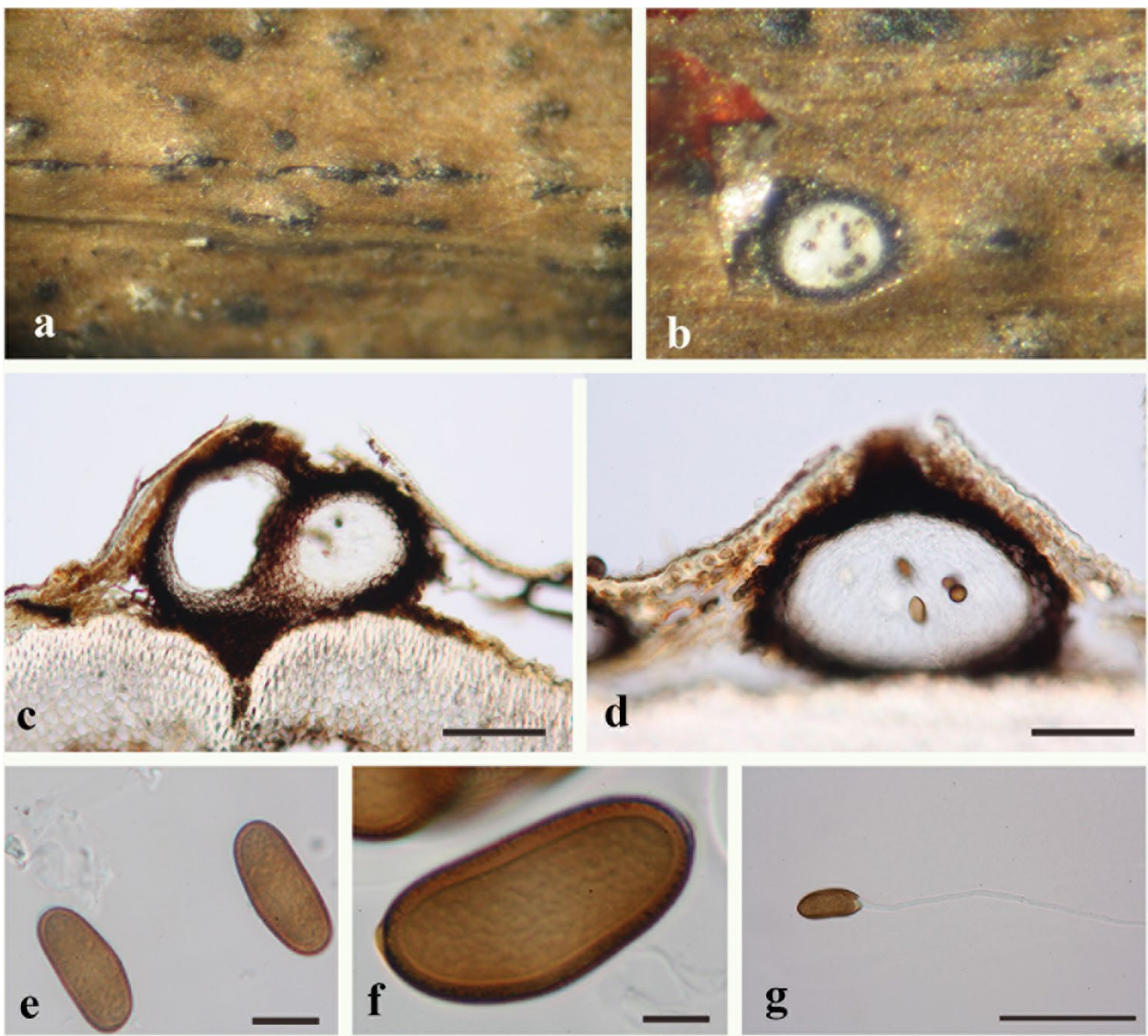

periods of incubation (up to 6 months, Konta et al. 2016). The asexual morph is lasiodiplodia-like with hyaline conidia that become dark-brown and septate with irregular longitudinal striations (Stevens 1926). Abdollahzadeh et al. (2009) observed the asexual morphs of B. fusca and B. iraniana and confirmed that the morphology is similar to the description given by Stevens (1926). In their study, they revealed that this genus can be distinguished from other genera of Botryosphaeriaceae by the presence of visible striations on conidia at an early stage of development.

However, using morphology alone in identifying these species is not wise due to the overlapping of morphological characters within the genus. Therefore, the use of multi loci phylogeny along with morphology is recommended for this genus. Very little is known about the diversity and pathogenicity of this botryosphaeriaceous genus and future studies are needed to confirm its pathogenic nature.

\section{Molecular based identification and diversity}

Phillips et al. (2008) using SSU, ITS, LSU, tef1 and tub2 sequence data established Barriopsis which is sister to Phaeobotryon. Based on ITS and tefl sequence data, Abdollahzadeh et al. (2009) introduced B. iraniana. Doilom et al. (2014) introduced $B$. tectonae based on ITS, tub2 and tefl sequence data. In this study, it was mentioned that ITS and tub2 sequence data have lesser variation, while tefl sequence data have considerable variation. Konta et al. (2016) added a new species, B. archontophoenicis with the use of ITS, LSU, SSU and tefl sequence data. In this study, we construct the phylogenetic tree for the accepted species based on ITS and tefl sequence data (Fig. 4).

Recommended genetic marker (genus level)_ITS

Recommended genetic marker (species level)_tefl

Accepted number of species-There are six species epithets in Index Fungorum (2020), however only five species have DNA sequence data (Table 3 ).

References-Phillips et al. (2008), Abdollahzadeh et al. (2009) (morphology and phylogeny); Dissanayake et al. (2016) (accepted number of species, phylogeny); Doilom et al. (2014), Konta et al. (2016) (new species).

78. Cercospora Fresen. ex Fuckel, Hedwigia 2(15): 133 (1863)

\section{Background}

Cercospora includes pathogens, saprobes and endophytes. Species are widely distributed, occurring on numerous flowering and ornamental plants, ferns, other fungi (as parasites), gymnosperms, grasses and other monocotyledons such as lilies, magnoliids and palms, mostly causing leaf spots. The well-known asexual morph, which is hyphomycetous, are 
Fig. 4 Phylogram generated from maximum likelihood analysis based on combined ITS, and tefl sequence data of Barriopsis species and closely related taxa. Fifteen strains are in the combined sequence analyses, which comprise 865 characters including gaps. Diplodia mutila (CBS 112553 and CBS 230.30) was used as the outgroup taxa. Tree topology of the ML analysis was similar to the one generated from BI. The best scoring RAxML tree with a final likelihood value of -2372.487246 is presented. The matrix had 201 distinct alignment patterns, with $12.30 \%$ of undetermined characters or gaps. Estimated base frequencies were as follows: $\mathrm{A}=0.207721, \mathrm{C}$ $=0.288041, \mathrm{G}=0.271092$, $\mathrm{T}=0.233145$; substitution rates $\mathrm{AC}=1.068561, \mathrm{AG}=$ 2.489613, $\mathrm{AT}=0.682766, \mathrm{CG}$ $=1.417925, \mathrm{CT}=4.236517$, GT $=1.000000$; gamma distribution shape parameter $\alpha$ $=1.343820$. RAxML bootstrap support value $\geq 50 \%$ and BYPP $\geq 0.95$ are shown respectively, near the nodes. Ex-type strains are in bold

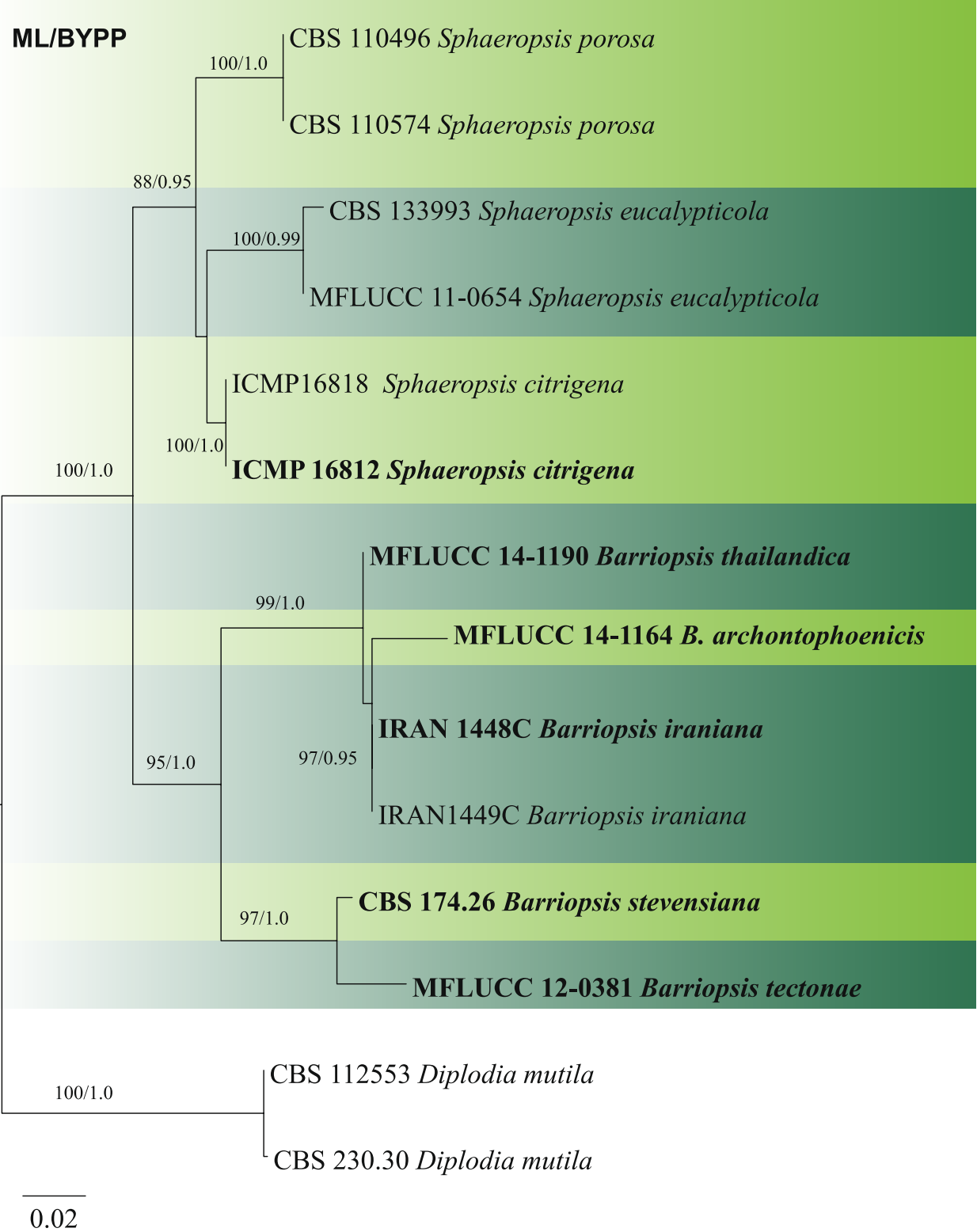

Table 3 DNA barcodes available for Barriopsis

\begin{tabular}{|c|c|c|c|}
\hline Species & Isolate & ITS & tef1 \\
\hline $\begin{array}{l}\text { Barriopsis } \\
\text { archontophoe- } \\
\text { nicis }\end{array}$ & MFLUCC 14-1164* & KX235306 & KX23530 \\
\hline \multirow[t]{2}{*}{ B.iraniana } & IRAN 1448C* & FJ919663 & FJ919652 \\
\hline & IRAN1449C & FJ919665 & FJ919654 \\
\hline B.tectonae & MFLUCC 12-0381* & KJ556515 & KJ556516 \\
\hline B. thailandica & MFLUCC 14-1190* & KY115675 & KY115676 \\
\hline B. stevensiana & CBS 174.26* & NR119698 & - \\
\hline
\end{tabular}

Ex-type/ex-epitype/ex-neotype/ex-lectotype strains are in bold and marked with an asterisk (*). Voucher strains are also in bold among the largest groups of plant pathogenic fungi causing leaf spots, leading to diseases on many economically important crops (Agrios 2005; To-Anun et al. 2011; Groenewald et al. 2013; Guatimosim et al 2016; Park et al. 2017). Comparatively only a few sexual morphs have been studied (Hyde et al. 2013). A photosensitizing toxic compound named 'cercosporin' is responsible for Cercospora species inhabiting such a wide host range (Daub et al. 2005; Thomas et al. 2020).

Classification-Ascomycota, Dothideomycetes, Dothideomycetidae, Capnodiales, Mycosphaerellaceae

Type species-Cercospora apii Fresen., Beitr. Mykol. 3: 91 (1863)

Distribution-Worldwide Disease symptoms — Leaf blights and spots 
This disease affects the leaves, petioles, stems and peduncles of the tree. Infection and lesion formation initially occur on older leaves before progressing to newer ones. Small, brown flecks develop with a reddish border, expanding to circular spots with an ashy-grey centre. Concentric rings may be observed as individual lesions expand. This tissue becomes thin and brittle, and often drops out, leaving a ragged hole. These lesions often resemble frogeyes, giving this disease its common name. Severely affected leaves wither and die from coalescing lesions (Shane and Teng 1992; Steddom et al. 2005).

Species of Cercospora cause blights and spots on the leaves, petioles, stems and peduncles of trees. Often infection and lesion formation occurs on older leaves before progressing to newer ones. Common symptoms include small, brown lesions that develop with a reddish border, eventually expanding to larger circular or angular spots. Concentric rings may be observed as individual lesions expand. The tissue becomes thin and brittle, and often drops out, leaving a ragged hole. Severely affected leaves wither and die from coalescing lesions (Shane and Teng 1992; Steddom et al. 2005).

Hosts-Wide host range including plant genera in Amaranthaceae, Apiaceae, Asteraceae, Arecaceae, Chenopodiaceae, Convolvulaceae, Cryptogammaceae, Cucurbitaceae, Cyatheaceae, Dennstaedtiaceae, Dioscoreaceae, Euphorbiaceae, Fabaceae, Gunneraceae, Hydrangeaceae, Lamiaceae, Lygodiaceae, Musaceae, Myrtaceae, Onagraceae, Plumbaginaceae, Poaceae, Pteridaceae, Scrophulariaceae, Solanaceae, Thelypteridaceae and Urticaceae (Farr and Rossman 2020).

Cercospora apii causes leaf spot disease on celery and $C$. beticola on sugar beet (Braun et al. 2013; Guatimosim et al. 2016). The pathogen Cercospora cf. sigesbeckiae infects various plant families, including economically valuable crops such as soybean, causing 'Cercospora leaf blight', a disease characterized by leaf bronzing (Albu et al. 2016, 2017). Some other species identified as causative organisms of the leaf blight are C. kikuchii and C. cf. flagellaris (Soares et al. 2015; Rezende et al. 2020). The yield losses related to Cercospora disease have been reported from Canada, China, India and other regions in the USA and South America (Almeida et al. 2005; Cai et al. 2009; Hershman 2009; Wrather et al. 2010; Geisler 2013; Albu et al. 2017; Bandara et al. 2020). Cercospora is among the leading fungal pathogens that cause a severe threat to soybean, which is an important grain legume crop, by reducing seed production and quality (Arantes et al. 2020). Two notable pathogens on soybean are $C$. kikuchii (leaf blight and purple seed stain) and $C$. sojina (frogeye leaf spot) (Soares et al. 2015)

Other notable reports include Cercospora leaf spots, which are the most common and destructive of the Hibiscus diseases, often resulting in complete crop loss (Park et al. 2017) and more than 200 fungal species in association with various diseases of 'kenaf' (Hibiscus cannabinus) worldwide (Park et al. 2017). Key proteins and expression of genes that could inhibit the pathogen $C$. kikuchii in soybean (Arantes et al. 2020) have been investigated. However, based on previous reports, morphological characters, phylogeny and pathogenicity of Cercospora cf. nicotianae was identified as one of several cryptic species causing Cercospora leaf blight (Sautua et al. 2019, 2020). Thomas et al. (2020) proposed the expression of fungal cercosporin auto resistance genes and silencing of the cercosporin pathway as effective strategies to combat Cercospora diseases.

\section{Pathogen biology, disease cycle and epidemiology}

The taxa survive on undecomposed residues in soil, on weed hosts and seeds. Leaf spot disease is favoured by warm, wet weather. Severe outbreaks generally require a period of showery weather. Infection from germinating fungal spores occurs via penetration of leaf stomata by fungal hyphae. Spores spread in wind, rain, irrigation or via mechanical tools (Vereijssen 2004; Lin and Kelly 2018).

\section{Morphological based identification and diversity}

Cercospora has been widely applied to all kinds of dematiaceous hyphomycetous asexual morphs characterized by holoblastic conidiogenesis and some associated with "Mycosphaerella"-like sexual morphs (Hyde et al. 2013; Groenewald et al. 2013). Species resembling the genus type, C. penicillata, characterized by pigmented conidiophores, thickened and darkened conidiogenous loci and singly formed colourless conidia are identified as Cercospora sensu stricto (Ellis 1971, 1976). Chupp (1954) published a worldwide monograph of this group which listed 1,419 species. A vast number of studies related to Cercospora are based on morphology or confined to specific regions or hosts (Phengsintham et al. 2013a, b). Hence, more than 3000 species of Cercospora have been described (Pollack 1987), often as a result of taxa being considered as hostspecific at a genus or family level (Crous and Braun 2003; Groenewald et al. 2005). However, based on morphological features of the structure of conidiogenous loci and hila, absence or presence of pigmentation in conidiophores and conidia, Crous and Braun (2003) revised the generic circumscription of Cercospora, resulting in the reduction of the number of species to 659. A series of publications related to Cercospora and its allied genera in Mycosphaerellaceae, along with illustrations and descriptions of sexual morphs was published by Braun et al. (2013, 2014, 2015a, b, 2016).

\section{Molecular based identification and diversity}

Cercospora is monophyletic (Stewart et al. 1999; Hyde et al. 2013). Groenewald et al. (2013) provided a comprehensive phylogenetic analysis of 360 isolates which included ITS, 
and protein-coding genes; translation elongation factor 1-alpha (tefl), actin (act), calmodulin (cal) and histone 3 (his). This provided a basis for the identification of Cercospora species, indicating most to be host-specific (Park et al. 2017). Bakhshi et al. (2018) subjected 170 Cercospora isolates to an eight-gene analysis (tefl, act, cal, his, $t u b 2, r p b 2$, gapdh) which resulted in several new clades within the $C$. apii, $C$. armoraciae, $C$. beticola, $C$. cf. flagellaris and Cercospora sp. G. complexes. The combination of tef1, cal, tub2, rpb2 and gapdh provided high phylogenetic resolution for distinguishing Cercospora species with gapdh being the gene effective in distinguishing the species complexes (Bakhshi et al. 2018). The genomes for several species-Cercospora arachidicola, $C$. aff. canescens, $C$. cf. sigesbeckiae, C. kikuchii, C. sojina and C. zeae-maydis have been published, of which $C$. cf. sigesbeckiae and $C$. sojina are important soybean pathogens (Albu et al. 2017; Sautua et al. 2019). The mating-type genes of some asexual Cercospora species have been characterised (Groenewald et al. 2013), of which C. beticola, C. zeae-maydis and C. zeina are heterothallic, while only one mating type was discovered in populations of $C$. apii and C. apiicola (Groenewald et al. 2006, 2010).

In soybean cultivation regions such as China, Latin America or the USA, C. sojina occurs as several pathotypes named as races, and their existence differs from soybean cultivar-to-cultivar (Athow et al. 1962; Yorinori and Henechin 1978; Mian et al. 2008; Gu et al. 2020). Apart from being differentiated physiologically, several molecular genetic tools such as AFLPs (Amplified Fragment Length Polymorphisms), SSR markers and SNP markers have been utilized to characterize their population diversity (Gu et al. 2020). The combination of DNA sequence data with ecology, morphological and cultural characteristics named as the Consolidated Species Concept (Quaedvlieg et al. 2014) is an effective method for delimiting Cercospora species (Groenewald et al. 2013; Bakhshi et al. 2015, 2018). Here we provide an updated phylogenetic tree of combined ITS, tef1, act, cal, his, tub2, rpb2 and gapdh (Fig. 5).

\section{Recommended genetic markers (genus level)—LSU, ITS} Recommended genetic markers (species level)_-ITS, tefl, act, cal, his, tub2, rpb2, gapdh

Accepted number of species-There are over 3100 epithets listed in Index Fungorum (2020), however, only 93 have DNA sequence data (Table 4).

References-Braun et al. (2013, 2014, 2015a, b, 2016) (morphology), Groenewald et al. (2013) (morphology, phylogeny), Albu et al. (2017) (morphology, phylogeny), Guatimosim et al. (2016) (morphology, phylogeny), Bakhshi et al. $(2015,2018)$ (morphology, phylogeny).
Fig. 5 The most parsimonious tree generated by MP analysis of combined ITS, tef1, act, cal, his, tub2, rpb2 and gapdh sequence data of Cercospora species is presented. Related sequences were obtained from previous publications and GenBank. One hundred and fourteen strains are included in the analysis comprising 4222 characters including gaps, of which 2942 characters are constant, 514 characters are parsimony-uninformative and 766 are parsimony-informative. The parsimony analysis of the data matrix resulted in the maximum of 84 equally most parsimonious trees with a length of 3092 steps $(\mathrm{CI}=$ $0.557, \mathrm{RI}=0.678, \mathrm{RC}=0.382, \mathrm{HI}=0.443$ ) in the first tree. The tree was rooted with Septoria provencialis (CBS 118910). Tree topology of the MP analysis was similar to the ML and BYPP analyses. ML and MP bootstrap support values $\geq 70 \%$ and BYPP $\geq 0.95$ (ML/ MP/ BYPP) are shown respectively near the nodes. Ex-type strains are in bold.

79. Clinoconidium Pat., Bulletin de la Société Mycologique de France 14: 156 (1898)

\section{Background}

Clinoconidium is an important genus that causes smut disease on plants in the family Lauraceae. This genus was established by Patouillard (1898) and typified with Clinoconidium farinosum. Taxonomically, Clinoconidium is placed in Cryptobasidiaceae (Exobasidiales, Exobasidiomycetes, Basidiomycota) and characterized by aseptate, colourless, and globose to ovoid basidiospores which are dispersed individually. The name Clinoconidium was considered illegitimate because of the designation of an illegitimate type species name; however, it was later validated by Saccardo (1902).

Clinoconidium is a gall producing genus which was once named as Ustilago by Ito $(1935,1936)$ due to the presence of a powdery spore mass on the surface of the galls. This genus was also transferred to another gall producing genus $\mathrm{Mel}$ anopsichium by Kakishima (1982). However, it was renamed as Clinoconidium as its sorus structure and spore features are quite different from those of Ustilago (Saccardo 1902). The spores of Ustilago species are formed from sporogenous hyphae, whereas this fungus produces spores from hymenial layers in the galls. Spore walls are comparatively thinner than those of Ustilago. The differentiation from Melanopsichium, a gall producing taxon on plants in Polygonaceae (Vánky 2013) includes variation in gall structures and sporulation. Melanopsichium produces spores in chambers formed inside of gall tissues, while this genus produces spores in peripheral lacunae on the surface of gall tissues. The morphological characters of these taxa showed its close similarity to Clinoconidium.

Classification-Basidiomycota, Ustilaginomycotina, Exobasidiomycetes, Exobasidiomycetidae, Exobasidiales, Cryptobasidiaceae

Type species-Clinoconidium farinosum Pat. ex Sacc. \& P. Syd

Distribution -Brazil, China, Costa Rica, India, Japan, Panama, Spain, Taiwan and Venezuela 
MP/ML/BYPP

C. achyranthis CBS 123613

90/89/-- L. polygonacea CBS 132614

100/77/-- [- C. campi-silii CBS 132625

70/74/- [ C. sojina CBS 132615

C. punctiformis CBS 132626

C. euphorbiae-sieboldianae CBS 113306 C. apiicola CBS 116457

C. vignigena CBS 132611

C. gamsiana CCTU 1074

91/--/0.99-C. uwebrauniana CCTU 1200

C. apii CBS 116455
C. beticola CBS116456

C. plantaginis CBS 252.67

C. cf. resedae CBS 118793

[CBS 131.32 $\mid$ C. cf. nicotianae

70/-/1.00 CBS 132632

70/97/0.99-C. cf. brunkii CBS 132657

C. convolvulicola CCTU 1083

C. cf. flagellaris CCTU 1172

C. cf. flagellaris CCTU 1154

$\stackrel{100 / 91 / 1.00}{ }{ }^{C}$ C. cf. flagellaris CCTU 1204

C. cf. flagellaris CBS 132667

C. cf. flagellaris CCTU 1070

C. cf. flagellaris CCTU 1159

C. cf. flagellaris CBS 132653

C. brachiata COAD 2593

C. agavicola CBS 117292

${ }_{L}$ C. cf. coreopsidis CBS 132598

$\left[{ }_{\text {CBS } 111133}^{C P C} \mid C\right.$ aff. canescens

$\left[\begin{array}{l}\text { CBS } 132624 \\ \text { CCTU } 1003\end{array} \mid\right.$ C. cf. zinniae

C. bidentis COAD 1018

C. brassicicola Cer $68-18$

C. tezpurensis NFCCI 3067

C. kikuchii CBS 128.27

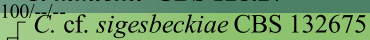

C. malayensis KUSF 27687

C. rodmanii CBS 113123

C. cf. richardiicola CCTU 1004

C. ariminensis CBS 137.56

C. tetragoniae HL-Tt-1

C. zinniicola LIPIMC 0771

C. sesami Cers 52-10

C. cocciniae IPBCC 13.1008

C. chrysanthemoides $\mathrm{CPC} 20529$

C. asparagi AS16 01

C. broussonetiae isolate $\mathrm{P} 610$

C. chrysanthemi LIPIMC 0759

C. codiaei LIPIMC 0779

Cercospora sp. P CBS 116365

C. sidicola $\mathrm{P} 500$

C. arecacearum $\mathrm{P} 521$

C. capsicigena $\mathrm{P} 289$

C. artemisiae LIPIMC 0769

Cercospora sp. P CPC 5262

C. cf. malloti MUCC 575

$\stackrel{4 / 0.98}{\longrightarrow}$ C. iranica CCTU 1137

Cercospora sp. T CCTU 1148

C. alchemillicola CPC 5259

C. cf. ipomoeae CBS 132639

C. fagopyri CBS 132623

C. cf. physalidicola SN150520

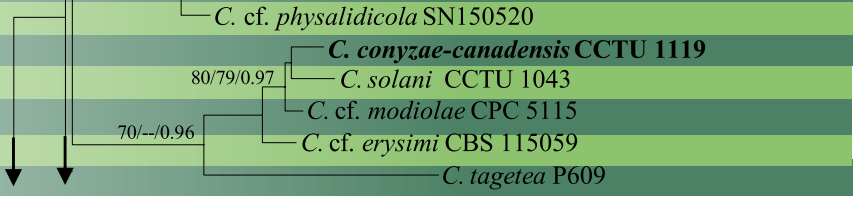




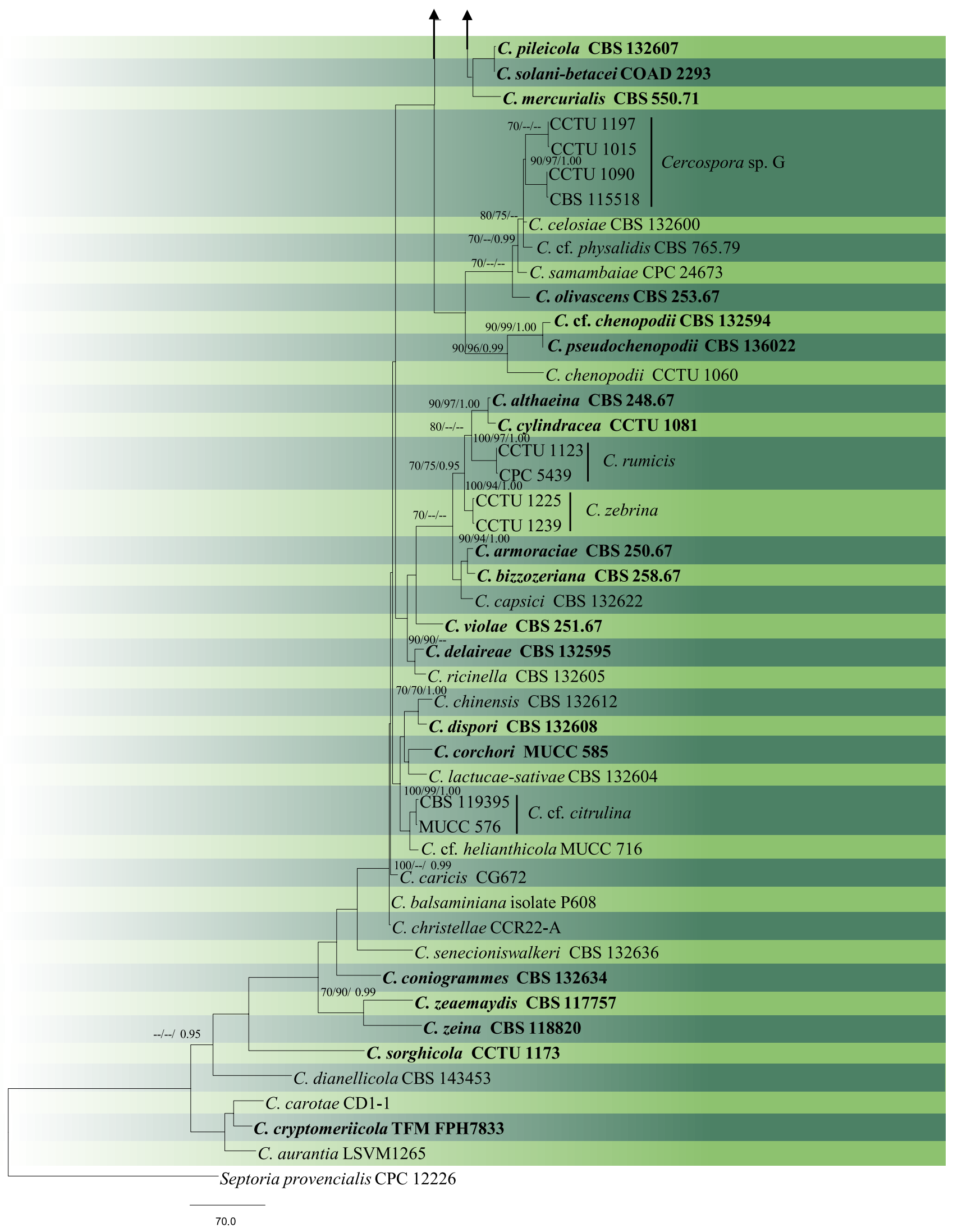

Fig. 5 (continued) 
Disease symptoms - mainly observed as powdery pappus gall in fruits. Infection initiates on very young fruits, converted into round, wrinkled galls. The fruit galls are then covered with a powdery mass of spores during early days of infection, withering in the rainy season, leaving behind hard, earthy, brown galls. On Cinnamon, entire young fruits are molded with buff and spongy smut like taxa in the full bloom of disease. Interestingly this infection is restricted to fruits only (Fig. 6).

Hosts-different plants of Lauraceae including, Apollonias barbujana, Cinnamomum burmannii, C. camphora, $C$. daphnoides, C. tamala, C. tenuifolium, Nectandra sp., Octea sp., Oreodaphne sp. and Phoebe neurophylla (Farr and Rossman 2020).

\section{Morphological based identification and diversity}

This is an important pathogenic genus; producing galls on shoot buds of host plants belonging to the family Lauraceae. Fruits of the host are completely or partially transformed into reddish-brown to dark brown, irregularly malformed, enlarged, globose to subglobose galls; larger than normal fruits. Hymenia formed in peripheral lacunae of the galls are pale yellow to whitish and covered by the host epidermis. Inner tissues of galls consist of hyphae and deformed plant cells. Hyphae are intercellular, hyaline, compact, septate, smooth-walled and lack clamp connections, while haustoria are intercellular, slightly lobed to irregular and observed in deformed host cells. Upon maturation, galls rupture, exposing orange to dark brown or creamish white spore masses which cover the entire infected young fruits. Sterile hyphae can be found intermingled between the basidia in some species and are indistinguishable from young basidia or absent in some species of Clinoconidium. Basidia are clavate, hyaline, depressed, difficult to observe and gastroid, densely aggregated in masses, formed in irregular fascicles from basally agglutinated hyphae and the wall is densely foveolate when mature. Basidiospores are ellipsoid, clavate, pyriform, fusoid, globose, subglobose to oval, aggregated in a creamish white to brown coloured masses on the surface of the galls, hyaline or wall pale brown to brown, rugose when mature; producing long branched hyphae with septa when germinated on culture media and proliferating sympodially.

\section{Molecular based identification and diversity}

There are seven epithets of Clinoconidium recorded on various plant hosts. Sequence data for Clinoconidium bullatum, C. cinnamomi, C. onumae and $C$. sawadae are available in GenBank, including sequence data for LSU and ITS. Clinoconidium farinosum and C. globosum lack sequence data in GenBank. ITS and LSU are the most suitable loci for $f$ (Fig. 7).

Recommended genetic markers (genus level)_ITS, LSU Recommended genetic markers (species level)_ITS, LSU Accepted number of species-There are seven species epithets in Index Fungorum (2020), however, only four species have DNA molecular data (Table 5).

References-Hendrichs et al. (2003), Jiang and Kirschner (2016), Kakishima et al. (2017a, b) (morphology, phylogeny)

80. Cylindrocladiella Boesew., Canadian Journal of Botany 60 (11): 2289 (1982)

$=$ Nectricladiella Crous \& C.L. Schoch, Studies in Mycology 45: 54 (2000)

\section{Background}

Boeswinkel (1982) established Cylindrocladiella to accommodate five Cylindrocladium-like species producing small, cylindrical conidia. Even though the generic status of Cylindrocladiella was initially opposed by Crous and Wingfield (1993), later studies on morphological comparisons by Crous et al. (1994) and molecular data (Victor et al. 1998; Schoch et al. 2000) supported the establishment of Cylindrocladiella as a genus. This genus is commonly confused with the asexual morph of Calonectria but can be distinguished by clear morphological differences, such as aseptate stipe extensions, different branching patterns of the conidiophores and comparatively small, aseptate conidia. Although species are generally not regarded as important plant pathogens, correct identification is essential for disease control and biosecurity implications.

Classification-Ascomycota, Sordariomycetes, Hypocreomycetidae, Hypocreales, Nectriaceae

Type species-Cylindrocladiella parva (P.J. Anderson) Boesew.

Distribution-as a soil-borne fungus, the species in Cylindrocladiella have a cosmopolitan distribution in various geographically and climatically distinct regions around the world (Farr and Rossman 2020).

Disease symptoms-black-foot disease, damping-off, leaf spot, root rot and shoot die-back

Many species belonging to Cylindrocladiella are opportunistic plant pathogens but they are not considered as primary pathogens. They can be isolated associated with disease symptoms such as leaf spot, damping off and shoot die-back (Scattolin and Montecchio 2007; Pham 2018). Chocolate brown lesions around the shoots spread primarily to be followed by wilting of the shoot tip, reddish 
discolouration, dropping of leaves, and finally plant death (Brielmaier-Liebetanz et al. 2013). Characteristic symptoms of the black-foot disease include a reduction in root biomass and root hairs with sunken and necrotic root lesions (Agustí-Brisach and Armengol 2013). Symptoms of Cylindrocladiella root rot are black lesions on the tap and lateral roots, wilting and foliar necrosis, and the outer bark of the seedlings will crack and become loose (Sinclair and Lyon 2005).

Hosts - Species are soil-borne, weak pathogens of forestry, agricultural and horticultural crops. There are 270 records of Cylindrocladiella associated with different plant species (Farr and Rossman 2020). Among them, different Vitis species and Eucalyptus species are common hosts associated with different species of Cylindrocladiella.

\section{Morphological based identification and diversity}

Cylindrocladiella can be distinguished from related species by penicillate and/or subverticillate symmetrically branched conidiophores which produce small, cylindrical, 1-septate conidia and aseptate stipe extensions (Lombard et al. 2012). The generic status of Cylindrocladiella was earlier strongly contested (Sharma and Mohanan 1991), however, based on morphological evaluation and comparisons by Crous and Wingfield (1993) and Crous et al. (2017) confirmed its generic status. Victor et al. (1998) and Schoch et al. (2000) provided molecular data to support generic status. Lombard et al. (2012) in his revision of Cylindrocladiella mentioned that only two species have been recognized with their respective Nectricladiella sexual morph. Rossman et al. (2013) proposed that the generic name Cylindrocladiella be used rather than Nectricladiella. Lombard et al. (2015) showed that Cylindrocladiella formed a monophyletic group in Nectriaceae (Wijayawardene et al. 2020).

\section{Molecular based identification and diversity}

Using RFLPs and AT-DNA data, Victor et al. (1998) recognised seven species in the genus. Schoch et al. (2000) added another species based on ITS and partial $t u b 2$. Van Coller et al. (2005) introduced the use of his 3 sequence data for this group. A combined multilocus phylogeny of his, tefl, tub2 and ITS was used by Lombard et al. (2012) which resulted in 18 new Cylindrocladiella species and several unresolved species complexes. Lombard et al. (2017) introduced six new species based on a combined ITS, tefl and tub2 dataset. Pham (2018) introduced five new species based on his, tefl, tub2 and ITS sequence data and Marin-Felix et al. (2019) introduced two new species based on ITS, tefl and $t u b 2$ sequence data. Here we reconstruct the phylogenetic analyses of these species based on ITS, tefl and tub2 sequence data (Fig. 8).
Recommended genetic markers (genus level)_-ITS, LSU Recommended genetic markers (species level)_his, tefl, tub2

Accepted number of species-There are 47 species epithets in Index Fungorum (2020). However, only 46 species have DNA sequence data (Table 6).

References-Crous and Wingfield (1993), Lombard et al. (2012) (morphology); Victor et al. (1998), Schoch et al. (2000), Lombard et al. (2015) (morphology, phylogeny).

81. Dothidotthia Höhn., Berichte der Deutschen Botanischen Gesellschaft 36: 312 (1918)

\section{Background}

Dothidotthia was assigned to Botryosphaeriaceae, because of its coelomycetous asexual morph, and characteristic peridium, pseudoparaphyses and asci (Barr 1989). Ramaley (2005) reported that Thyrostroma is the asexual morph of Dothidotthia based on the production of hyphomycetes in culture. Phillips et al. (2008), introduced a new family Dothidotthiaceae to accommodate Dothidotthia and considered Thyrostroma as the asexual morph of Dothidotthia. However, the links between the sexual and asexual morphs are not supported by molecular evidence. Recent molecular and morphology studies (Marin-Felix et al. 2017; Crous et al. 2019; Senwanna et al. 2019), based on a taxon sampling of current species indicates that Dothidotthia does not cluster near Thyrostroma. Thus, Dothidotthia is a distinct genus.

Classification-Ascomycota, Pezizomycotina, Dothideomycetes, Pleosporomycetidae, Pleosporales, Dothidotthiaceae Type species—Dothidotthia symphoricarpi (Rehm) Höhn. Distribution-in both temperate and tropical countries (Italy, Russia, Thailand, Ukraine and the USA)

Disease symptoms - species cause canker, dieback and leaf spot diseases on twig, branch, bark and leaf

Hosts-Pathogens of Acer negundo, Diapensia lapponica, Fendlera rupicola, Euonymus alatus, Robinia pseudoacacia, Verbena asparagoides (Barr 1989; Farr and Rossman 2020; Index Fungorum 2020).

\section{Morphological based identification and diversity}

In previous studies, the asexual morphs of Dothidotthia have been reported as Thyrostroma (Ramaley 2005), however, phylogenetic analyses indicated that Dothidotthia can be separated from Thyrostroma (Marin-Felix et al. 2017; Crous et al. 2016; Senwanna et al. 2019). Dothidotthia is characterized by fusiform to obclavate or obpyriform, 0 -3-transversely septate conidia and a sexual morph with clavate, short pedicellate asci, ellipsoid, 1-septate ascospores (Fig. 9). The sexual morphs of Dothidotthia and Thyrostroma have similar morphological characteristics in shape and overlapping 
Table 4 DNA barcodes available for Cercospora

\begin{tabular}{|c|c|c|c|c|c|c|c|c|c|}
\hline Species & Isolate no & ITS & tefl & act & cal & his & tub2 & $r p b 2$ & gapdh \\
\hline \multirow[t]{2}{*}{ Cercospora achyranthis } & CBS 132613 & JX143523 & JX143277 & JX143031 & JX142785 & JX142539 & - & - & - \\
\hline & СРC 10091 & JX143524 & JX143278 & JX143032 & JX142786 & JX142540 & - & - & - \\
\hline C. agavicola ${ }^{\#}$ & CBS 117292* & AY647237 & AY966897 & AY966898 & AY966899 & AY966900 & - & - & - \\
\hline C. alchemillicola & CPC 5259* & JX143525 & JX143279 & JX143033 & JX142787 & JX142541 & - & - & - \\
\hline C. althaeina & CBS 248.67* & JX143530 & JX143284 & JX143038 & JX142792 & JX142546 & MH496340 & - & MH496170 \\
\hline C. apii ${ }^{\#}$ & CBS 116455* & AY840519 & AY840486 & AY840450 & AY840417 & AY840384 & MH496343 & - & MH496173 \\
\hline C. apiicola ${ }^{\#}$ & CBS 116457* & AY840536 & AY840503 & AY840467 & AY840434 & AY840401 & - & - & - \\
\hline C. arecacearum & P 521 & KC677879 & - & - & - & - & - & - & - \\
\hline C. ariminensis & CBS 137.56 & KF251297 & KF253245 & KF253606 & KF253960 & - & KF252779 & KF252303 & - \\
\hline C. armoraciae $^{\#}$ & CBS 250.67* & JX143545 & JX143299 & JX143053 & JX142807 & JX142561 & MH496351 & - & MH496181 \\
\hline C. artemisiae & LIPIMC 0769 & KC776169 & - & - & - & - & - & - & - \\
\hline C. asparagi & ICMP 21630 & KY549097 & KY549101 & KY549091 & KY549093 & - & - & - & - \\
\hline C. aurantia & LSVM12 65 & MG956773 & - & - & - & - & - & - & - \\
\hline C. balsaminiana & P608 & KC677880 & - & - & - & - & - & - & - \\
\hline C. beticola ${ }^{\#}$ & CBS 116456* & AY840527 & AY840494 & AY840458 & AY840425 & AY840392 & MH496355 & KT216555 & MH496185 \\
\hline C. bidentis & COAD 1018 & JX117826 & - & - & - & - & - & - & - \\
\hline C. bizzozeriana ${ }^{\#}$ & CBS 258.67* & JX143546 & JX143300 & JX143054 & JX142808 & JX142562 & MH496368 & - & MH496198 \\
\hline C. brachiata & COAD 2593 & - & MK118086 & MK118087 & - & - & - & - & - \\
\hline C. brassicicola & Cer $68-18$ & MN209932 & - & - & - & - & - & - & - \\
\hline C. broussonetiae & P610 & KC677882 & - & - & - & - & - & - & - \\
\hline C. cf. brunkii & CBS 132657 & JX143559 & JX143313 & JX143067 & JX142821 & JX142575 & - & - & - \\
\hline C. campi-silii & CBS 132625 & JX143561 & JX143315 & JX143069 & JX142823 & JX142577 & - & - & - \\
\hline \multirow[t]{2}{*}{ C. canescens ${ }^{\#}$} & CPC 15871 & JX143567 & JX143321 & JX143075 & JX142829 & JX142583 & - & - & - \\
\hline & CBS 111133 & AY260065 & DQ835084 & DQ835103 & DQ835130 & DQ835157 & - & - & - \\
\hline C. capsici $^{\#}$ & CBS 132622 & JX143568 & JX143323 & JX143077 & JX142831 & JX142585 & - & - & - \\
\hline C. capsicigena & P289 & KC677884 & - & - & - & - & - & - & - \\
\hline C. caricis & CG672 & AF284390 & - & - & - & - & - & - & - \\
\hline C. carotae & CD1-1 & KF941306 & - & - & - & KF941303 & - & - & - \\
\hline C. celosiae & CBS 132600 & JX143570 & JX143326 & JX143080 & JX142834 & - & - & - & - \\
\hline \multirow[t]{2}{*}{ C. chenopodii ${ }^{\#}$} & CBS 132594* & JX143572 & JX143328 & JX143082 & JX142836 & JX142590 & - & - & - \\
\hline & CCTU 1060 & KJ886438 & KJ886277 & KJ885955 & KJ885794 & KJ886116 & MH496371 & MH511862 & MH496201 \\
\hline C. chinensis & CBS 132612 & JX143578 & JX143334 & JX143088 & JX142842 & JX142596 & - & - & - \\
\hline C. christellae & $\begin{array}{l}\text { CCR22 isolate } \\
\text { A }\end{array}$ & FJ460222 & - & - & - & - & - & - & - \\
\hline C. chrysanthemi & LIPIMC 0759 & KC776154 & - & - & - & - & - & - & - \\
\hline C. chrysanthemoides & СРC 20529 & KC005779 & KC005813 & КC005764 & KC005767 & - & - & - & - \\
\hline \multirow[t]{2}{*}{ C. citrullina ${ }^{\#}$} & CBS 119395 & EU514222 & JX143335 & JX143089 & JX142843 & - & - & - & - \\
\hline & MUCC 576 & JX143579 & JX143337 & JX143091 & JX142845 & - & - & - & - \\
\hline C. cocciniae & $\begin{array}{l}\text { IPBCC } \\
13.1008\end{array}$ & KC776158 & - & - & - & - & - & - & - \\
\hline C. codiaei & LIPIMC 0779 & KC776170 & - & - & - & - & - & - & - \\
\hline C. coniogrammes & CBS 132634* & JX143583 & JX143341 & JX143095 & JX142849 & JX142603 & - & - & - \\
\hline C. convolvulicola & CCTU 1083* & KJ886441 & KJ886280 & KJ885958 & KJ885797 & KJ886119 & MH496374 & MH511865 & MH496204 \\
\hline C. conyzae-canadensis & CCTU 1119* & KJ886445 & KJ886284 & KJ885962 & KJ885801 & KJ886123 & MH496377 & MH511868 & MH496207 \\
\hline C. corchori & MUCC 585* & JX143584 & JX143342 & JX143096 & JX142850 & JX142604 & - & - & - \\
\hline C. cf. coreopsidis & CBS 132598 & JX143585 & JX143343 & JX143097 & JX142851 & JX142605 & - & - & - \\
\hline C. cryptomeriicola & TFM:FPH7833 & AB277789 & - & - & - & - & - & - & - \\
\hline C. cylindracea & CCTU 1081* & KJ886449 & KJ886288 & KJ885966 & KJ885805 & KJ886127 & MH496381 & MH511872 & MH496211 \\
\hline C. delaireae & CBS 13259* & JX143587 & JX143345 & JX143099 & JX142853 & JX142607 & - & - & - \\
\hline C. dianellicola & CBS 143453* & MG386075 & - & MG674152 & MG674153 & - & - & - & - \\
\hline C. dispori & CBS 13260* & JX143591 & JX143349 & JX143103 & JX142857 & JX142611 & - & - & - \\
\hline C. cf. erysimi & CBS 115059 & JX143592 & JX143350 & JX143350 & JX142858 & JX142612 & - & - & - \\
\hline C. euphorbiaesieboldianae & CBS 113306* & JX143593 & JX143351 & JX143105 & JX142859 & JX142613 & - & - & - \\
\hline C. fagopyri & CBS 132623* & JX143594 & JX143352 & JX143106 & JX142860 & JX142614 & - & - & - \\
\hline
\end{tabular}


Table 4 (continued)

\begin{tabular}{|c|c|c|c|c|c|c|c|c|c|}
\hline Species & Isolate no & ITS & tef1 & act & cal & his & $t u b 2$ & $r p b 2$ & gapdh \\
\hline \multirow[t]{6}{*}{ C. cf. flagellaris } & CCTU 1159 & KJ886493 & KJ886332 & KJ886010 & KJ885849 & KJ886171 & MH496388 & MH511879 & MH496218 \\
\hline & CBS 132653 & JX143603 & JX143361 & JX143115 & JX142869 & JX142623 & MH496390 & MH511881 & MH496220 \\
\hline & CCTU 1204 & KJ886505 & KJ886344 & KJ886022 & KJ885861 & KJ886183 & MH496399 & MH511890 & MH496229 \\
\hline & CBS 132667 & JX143604 & JX143362 & JX143116 & JX142870 & JX142624 & MH496401 & MH511892 & MH496231 \\
\hline & CCTU 1172 & KJ886501 & KJ886340 & KJ886018 & KJ885857 & KJ886179 & MH496409 & MH511900 & MH496239 \\
\hline & CCTU 1154 & KJ886489 & KJ886328 & KJ886006 & KJ885845 & KJ886167 & MH496410 & MH511901 & MH496240 \\
\hline C. gamsiana & CCTU 1074* & KJ886426 & KJ886265 & KJ885943 & KJ885782 & KJ886104 & MH496446 & MH511937 & MH496276 \\
\hline C.cf. gossypii & CCTU 1070 & KJ886467 & KJ886306 & KJ885984 & KJ885823 & KJ886145 & MH496452 & MH511943 & MH496282 \\
\hline C. helianthicola ${ }^{\#}$ & MUCC 716 & JX143615 & JX143374 & JX143128 & JX142882 & JX142636 & - & - & - \\
\hline C. ipomoeae & CBS 132639 & JX143616 & JX143375 & JX143129 & JX142883 & JX142637 & - & - & - \\
\hline C. iranica & CCTU 1137* & KJ886513 & KJ886352 & KJ886030 & KJ885869 & KJ886191 & MH496455 & MH511946 & MH496285 \\
\hline C. kikuchii & CBS 128.27* & DQ835070 & DQ835088 & DQ835107 & DQ835134 & DQ835161 & - & - & - \\
\hline C. lactucae-sativae & CBS 132604 & JX143621 & JX143380 & JX143134 & JX142888 & JX142642 & - & - & - \\
\hline C. malayensis & KUS-F27687 & KR400012 & KY082663 & KY082664 & KY082665 & KY082666 & - & - & - \\
\hline C. cf. malloti & MUCC 575 & JX143625 & JX143384 & JX143138 & JX142892 & JX142646 & - & - & - \\
\hline C. mercurialis & CBS 550.71* & JX143628 & JX143628 & JX143141 & JX142895 & JX142649 & - & - & - \\
\hline C. cf. modiolae & СРC 5115 & JX143630 & JX143389 & JX143143 & JXJX142897 & JX142651 & - & - & - \\
\hline \multirow[t]{2}{*}{ C. cf. nicotianae } & CBS 131.32 & DQ835073 & DQ835099 & DQ835119 & DQ835146 & DQ835173 & - & - & - \\
\hline & CBS 132632 & JX143631 & JX143390 & JX143144 & JX142898 & JX142652 & - & - & - \\
\hline C. olivascens & CBS 253.67* & JX143632 & JX143391 & JX143145 & JX142899 & JX142653 & - & - & - \\
\hline C. cf.physalidicola & SN150520 & - & KT275242 & KT223391 & KT275241 & KT275240 & - & - & - \\
\hline C. cf. physalidis ${ }^{\#}$ & CBS 765.79 & JX143633 & JX143392 & JX143146 & JX142900 & - & - & - & - \\
\hline C. pileicola & CBS 132607* & JX143634 & JX143393 & JX143147 & JX142901 & JX142655 & - & - & - \\
\hline C. plantaginis & CBS 252.67* & DQ233318 & DQ233342 & DQ233368 & DQ233394 & DQ233420 & МH496461 & - & MH496291 \\
\hline C. polygonacea & CBS 132614 & JX143637 & JX143396 & JX143150 & JX142904 & JX142658 & - & - & - \\
\hline C.pseudochenopodii & CBS 136022* & KJ886516 & KJ886355 & KJ886033 & KJ885872 & KJ886194 & MH496464 & MH511954 & MH496294 \\
\hline C. punctiformis & CBS 132626 & JX143638 & JX143397 & JX143151 & JX142905 & JX142659 & - & - & - \\
\hline C. cf. resedae & CBS 118793 & JX143639 & JX143398 & JX143152 & JX142906 & JX142660 & - & - & - \\
\hline C. cf. richardiicola ${ }^{\#}$ & CBS 132627 & JX143640 & JX143399 & JX143153 & JX142907 & JX142661 & MH496465 & MH511955 & MH496295 \\
\hline C. ricinella ${ }^{\#}$ & CBS 132605 & JX143646 & JX143405 & JX143159 & JX142913 & JX142667 & - & - & - \\
\hline C. rodmanii & CBS 113123 & DQ835076 & AF146136 & DQ835122 & DQ835149 & DQ835176 & - & - & - \\
\hline C. rumicis & CCTU 1123 & KJ886521 & KJ886360 & KJ886038 & KJ885877 & KJ886199 & MH496466 & MH511956 & MH496296 \\
\hline C. rumicis & СРC 5439 & JX143648 & JX143407 & JX143161 & JX142915 & JX142669 & - & - & - \\
\hline C. samambaiae & СРC 24673 & KT037514 & KT037474 & KT037596 & KT037463 & KT037555 & - & - & - \\
\hline C. senecioniswalkeri & CBS 132636 & JX143649 & JX143408 & JX143162 & JX142916 & JX142670 & - & - & - \\
\hline C. sesami & Cers52-10 & MK027103 & - & - & - & - & - & - & - \\
\hline C. sidicola & P500 & KC677888 & - & - & - & - & - & - & - \\
\hline C. cf. sigesbeckiae & CBS 132675 & JX143655 & JX143414 & JX143168 & JX142922 & JX142676 & - & - & - \\
\hline C. sojina & CBS 132615 & JX143659 & JX143419 & JX143173 & JX142927 & JX142681 & - & - & - \\
\hline C. solani & CCTU 1043 & KJ886523 & KJ886362 & KJ886040 & KJ885879 & KJ886201 & MH496469 & MH511959 & MH496299 \\
\hline C. sorghicola & CCTU 1173* & KJ886525 & KJ886364 & KJ886042 & KJ885881 & KJ886203 & MH496471 & MH511961 & MH496301 \\
\hline Cercospora sp. P & CBS 116365* & AY752141 & AY752176 & AY752204 & AY752235 & AY752266 & - & - & - \\
\hline Cercospora sp. $\mathrm{P}$ & JZG-2013 & JX143714 & JX143473 & JX143227 & JX142981 & JX142735 & - & - & - \\
\hline Cercospora sp. G & CCTU 1197 & KJ886540 & KJ886379 & KJ886057 & KJ885896 & KJ886218 & MH496472 & MH511962 & MH496302 \\
\hline Cercospora sp. G & CCTU 1015 & KJ886528 & KJ886367 & KJ886045 & KJ885884 & KJ886206 & MH496473 & MH511963 & MH496303 \\
\hline Cercospora sp. G & CCTU 1090 & KJ886536 & KJ886375 & KJ886053 & KJ885892 & KJ886214 & МH496476 & MH511965 & MH496306 \\
\hline Cercospora sp. G & CBS 115518 & JX143681 & JX143441 & JX143195 & JX142949 & JX142703 & MH496480 & - & MH496310 \\
\hline Cercospora sp. T & CCTU 1148 & KJ886541 & KJ886380 & KJ886058 & KJ885897 & KJ886219 & MH496488 & MH511976 & MH496318 \\
\hline C. tagetea & P609 & KC677890 & - & - & - & - & - & - & - \\
\hline \multirow[t]{2}{*}{ C. tetragoniae } & HL_Tt-1 & MT095118 & - & - & - & - & - & - & - \\
\hline & NFCCI3067* & KC351743 & KC513746 & KC355808 & KC513745 & KC355807 & - & - & - \\
\hline C. uwebaruniana & CCTU 1200* & KJ886408 & KJ886247 & KJ885925 & KJ885764 & KJ886086 & MH496489 & MH511977 & MH496319 \\
\hline C. vignigena & CBS 132611* & JX143734 & JX143493 & JX143247 & JX143001 & JX142755 & - & - & - \\
\hline
\end{tabular}


Table 4 (continued)

\begin{tabular}{llllllllll}
\hline Species & Isolate no & ITS & tef1 & act & cal & his & tub2 & rpb2 & gapdh \\
\hline C. violae $^{\#}$ & CBS 251.67* & JX143737 & JX143496 & JX143250 & JX143004 & JX142758 & MH496492 & - \\
${\text { C. } \text { zeae-maydis }^{\#}}_{\text {C. } \text { zebrina }^{\#}}$ & CBS 117757* & DQ185074 & DQ185086 & DQ185098 & DQ185110 & DQ185122 & - & MH496322 \\
& CCTU 1225 & KJ886550 & KJ886389 & KJ886067 & KJ885906 & KJ886228 & MH496495 & MH511981 & MH496325 \\
C. zeina & CCTU 1239 & KJ886551 & KJ886390 & KJ886068 & KJ885907 & KJ886229 & MH496504 & MH511987 & MH496334 \\
C. cf. zinniae & CBS 118820* & DQ185081 & DQ185093 & DQ185105 & DQ185117 & DQ185129 & - & - & - \\
& CBS 132624 & JX143756 & JX143518 & JX143272 & JX143026 & - & - & - \\
C. zinniicola & CCTU 1003 & KJ886552 & KJ886391 & KJ886069 & KJ885908 & KJ886230 & MH496505 & MH511988 & MH496335 \\
\hline
\end{tabular}

Ex-type/ex-epitype/ex-neotype/ex-lectotype strains are in bold and marked with an asterisk $(*)$. Voucher strains are also in bold. Species confirmed with pathogenicity studies are marked with ${ }^{\#}$

Fig. 6 Clinoconidium sp. on Cinnamomum sp. a host plant with infected and healthy fruits, b healthy fruits, $\mathbf{c}, \mathbf{d}$ infected fruits at various stages of infection

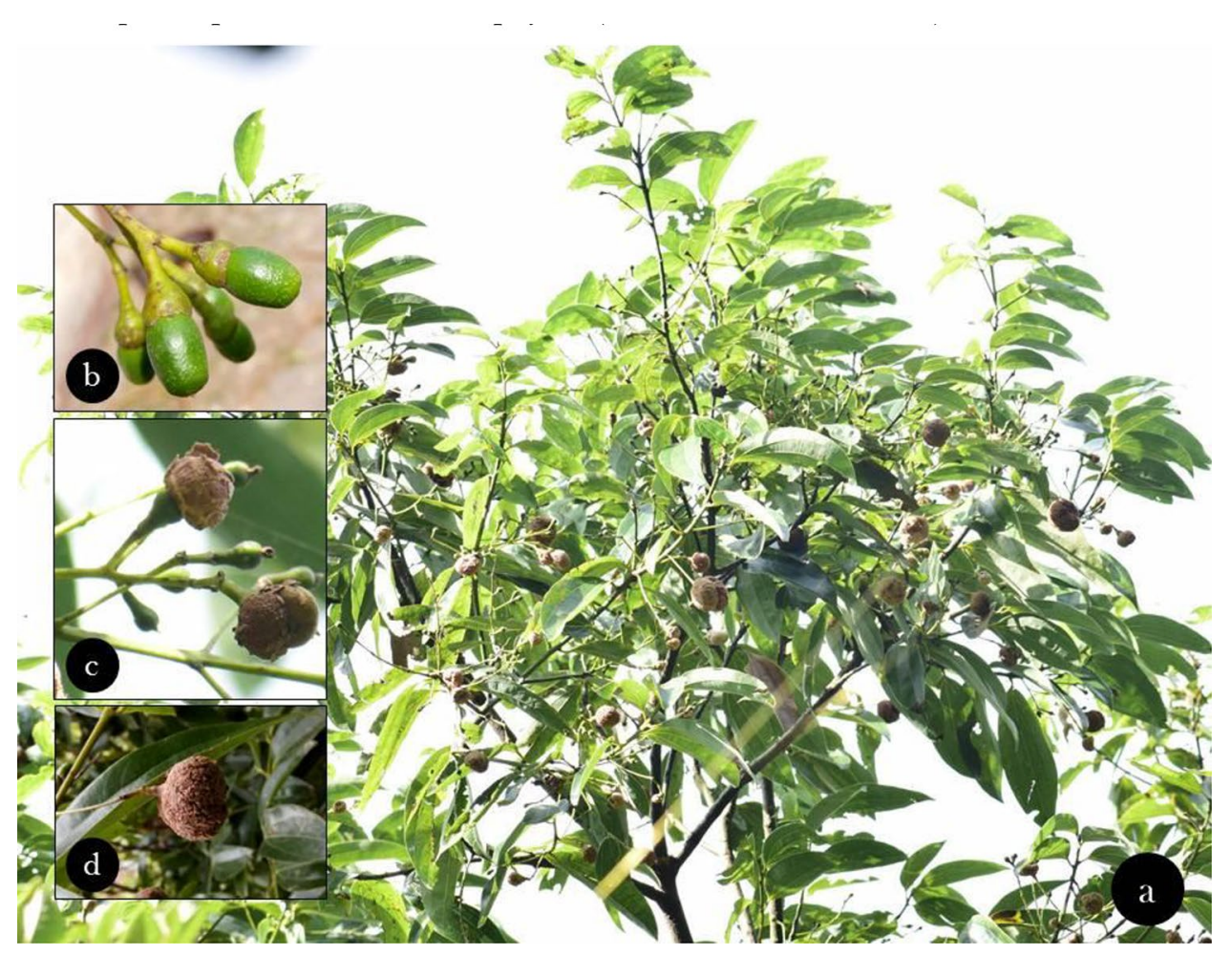

dimensions of asci and ascospores (Barr 1989; Ramaley 2005; Phillips et al. 2008; Hyde et al. 2013; Senwanna et al. 2019). However, Dothidotthia can be differentiated from Thyrostroma by peridium structure and conidial morphology and molecular phylogeny (Senwanna et al. 2019). Crous et al. (2019) introduced Neodothidotthia to accommodate N. negundinicola and Dothidotthia aspera was synonymized under $N$. negundinis based on analysis of LSU sequence data. However, Senwanna et al. (2019) showed that Neodothidotthia negundinicola and $N$. negundinis group with $D$. robiniae and $D$. symphoricarpi (type species). Furthermore, the conidial morphology of Neodothidotthia is similar to Dothidotthia symphoricarpi (Pseudotthia symphoricarpi) and D. robiniae (Phillips et al. 2008; Zhang et al. 2012; Crous et al. 2019; Senwanna et al. 2019). Therefore, Neodothidotthia had been treated as a synonym of Dothidotthia.

\section{Molecular based identification and diversity}

Dothidotthia species can be separated from Thyrostroma based on LSU sequence data (Marin-Felix et al. 2017; Crous et al. 2019). Multigene phylogenetic analyses of a combined LSU, SSU, ITS and tefl dataset for Dothidotthia is presented in this study, which is similar to Senwanna et al. (2019) (Fig. 10).

Recommended genetic markers (genus level)—LSU, SSU Recommended genetic markers (species level)_ITS, tefl, $r p b 2$ and $t u b 2$

Accepted number of species-There are 14 epithets listed in Index Fungorum (2020), however only four species have DNA molecular data (Table 7).

References-Barr (1989), Ramaley (2005) (morphology); Phillips et al. (2008), Zhang et al. (2012), Hyde et al. (2013), 


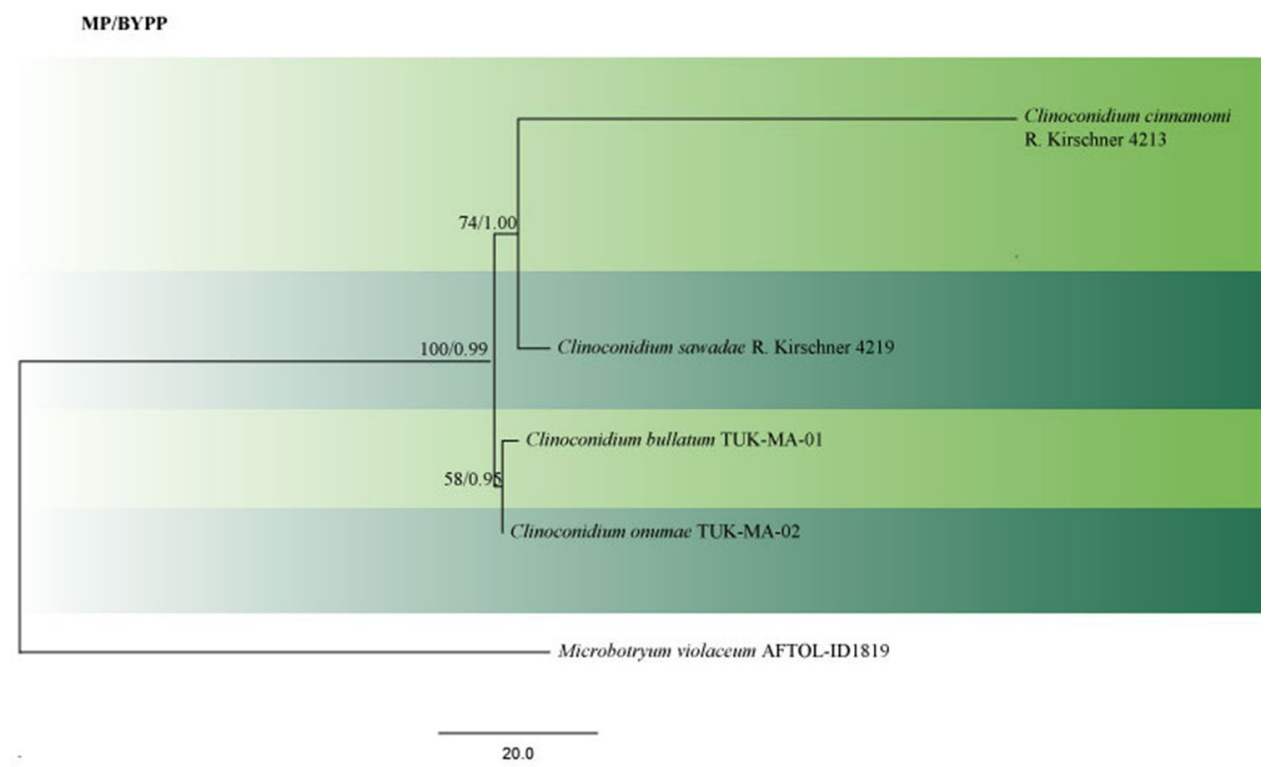

Fig. 7 Phylogram generated from MP analysis based on combined sequences of LSU and ITS sequences of all the species of Clinoconidium with molecular data. Related sequences were obtained from GenBank. Five taxa are included in the analyses, which comprise 1100 characters including gaps, of which 910 characters are constant, 182 characters are parsimony-uninformative, eight characters parsimony-informative. The parsimony analysis of the data matrix

Table 5 DNA barcodes available for Clinoconidium

\begin{tabular}{llll}
\hline Species name & Strain Name & ITS & LSU \\
\hline $\begin{array}{l}\text { Clinoconidium bul- } \\
\text { latum }\end{array}$ & TUK-MA-01 & - & AB178259 \\
C. cinnamomi & R. Kirschner 4213 & KX196602 & KX196604 \\
C. onumae & TUK-MA-02 & - & AB178260 \\
C. sawadae & R. Kirschner 4219 & KX196600 & KX196603 \\
\hline
\end{tabular}

Marin-Felix et al. (2017), Crous et al. (2019), Senwanna et al. (2019) (morphology and phylogeny)

82. Erysiphaceae Tul. \& C. Tul. [as 'Erysiphei'], Select. fung. carpol. (Paris) 1: [191] (1861)

\section{Background}

Powdery mildews belong to Erysiphales of Ascomycota (Mori et al. 2000). Powdery mildews are one of the most prevalent and easily recognizable of plant diseases (Glawe 2008). Mucor erysiphe, published by Linnaeus (1753), was the first binomial referring to powdery mildew (now known as Phyllactinia guttata) (Braun and Cook 2012). Infections are often conspicuous owing to the profuse production of conidia that give them their common name. Powdery mildews are also models for basic research on host-parasite interactions, developmental morphology, cytology, and molecular biology (Glawe 2008). Erysiphaceae is obligately parasitic and as such, their life cycle depends completely on living hosts, from which they resulted in the maximum of two equally most parsimonious trees with a length of 202 steps $(\mathrm{CI}=0.980, \mathrm{RI} 0.500, \mathrm{RC}=0.490, \mathrm{HI}=0.020)$ in the first tree Single gene analyses were carried out and compared with each species, to compare the topology of the tree and clade stability. The tree was rooted with Microbotryum violaceum (AFTOLID1819). Maximum parsimony bootstrap support value $\geq 50 \%$ and BYPP $\geq 0.9$ are shown respectively near the nodes

obtain nutrients without killing host cells and without which they are unable to survive. As they are obligate plant pathogens, researchers have not had the advantage of routinely cultivating these taxa on artificial media. However, many powdery mildews have been grown on detached leaves of their hosts (Hirose et al. 2005). Powdery mildews seldom kill their host, but are responsible for water and nutrient loss and impaired growth and development. They can increase respiration and transpiration and interfere with photosynthesis and reduce yields.

Changes in host range directly cause the niche separation of powdery mildews and thus may become a trigger of speciation in their evolution. It is possible that studying the evolutionary history of powdery mildews will not only reveal facts on fungal evolution but may also lead us to consider the evolutionary history of angiosperm plants (Takamatsu 2004; Matsuda and Takamatsu 2003; Hirata et al. 2000; Mori et al. 2000).

The first systematic trial to identify the conidial states of powdery mildews at the species level was made by Ferraris (1910), who grouped species of Oidium according to the size and shape of their conidia and provided a key to its species. Foex (1913), Jaczewski (1927), and Brundza (1934) contributed to the classification of the conidiophore types. Jaczewski (1927) introduced the terms 'Euoidium and Pseudoidium' for Oidium states with catenate and solitary conidia, respectively. Yarwood (1957) provided a survey on the Erysiphaceae, including the asexual morphs. 


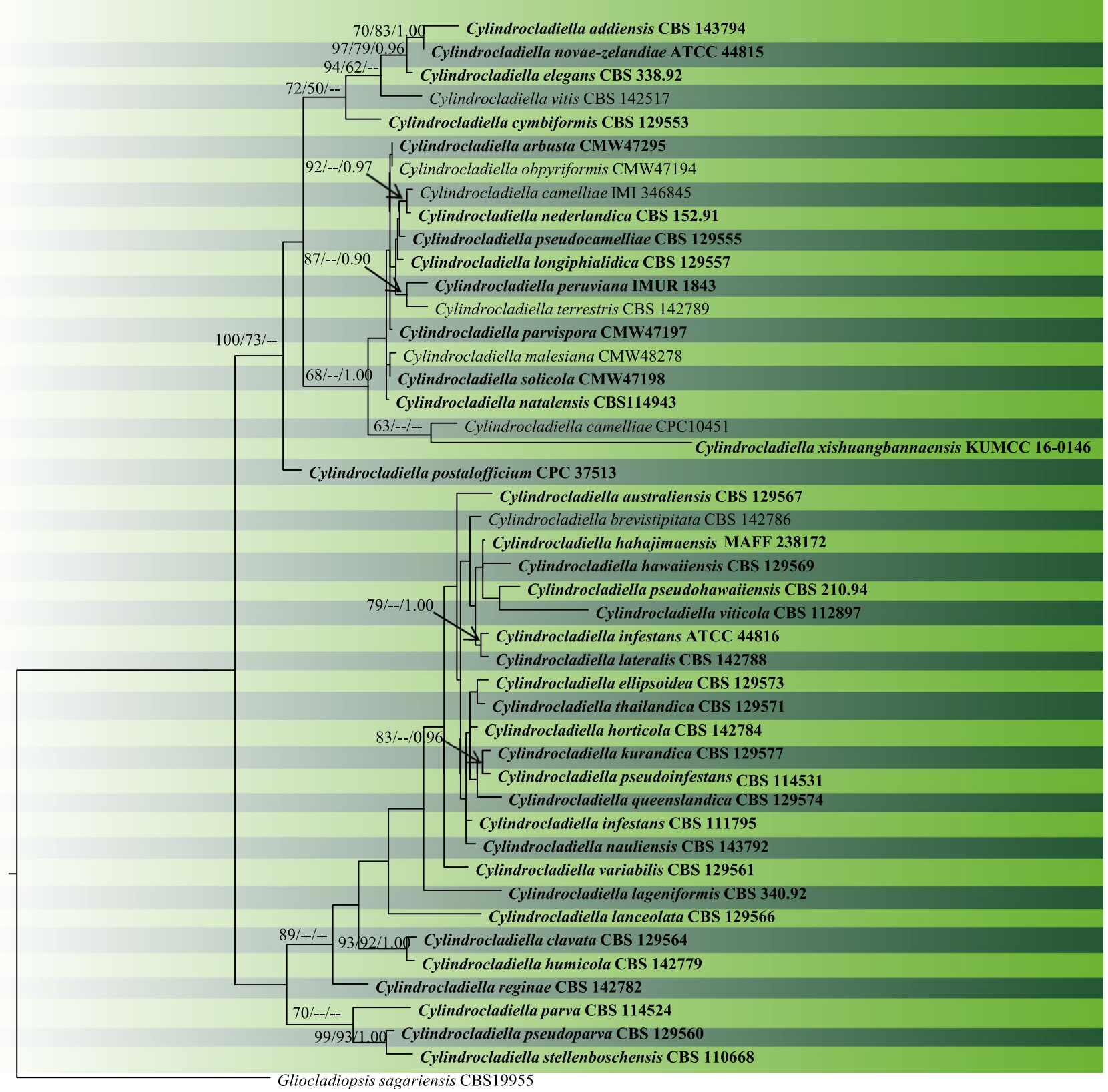

Fig. 8 Phylogram generated from MP analysis based on combined sequences of ITS, tef1 and tub2 sequences of all the accepted species of Cylindrocladiella. Related sequences were obtained from GenBank. Fourty-six taxa are included in the analyses, which comprise 2460 characters including gaps. Single gene analyses were carried out and compared with each species, to compare the topology of the tree and clade stability. The tree was rooted with Gliocladiopsis sagariensis (CBS 19955). The best scoring RAxML tree with a final

Boesewinkel (1980) provided the first comprehensive key based on a combination of more than 12 morphological characteristics observed on conidia, conidiophores, appressoria, haustoria, fibrosin bodies, and mycelium. Braun likelihood value of -6772.195394 is presented. The matrix had 261 distinct alignment patterns, with $0.96 \%$ of undetermined characters or gaps. Estimated base frequencies were as follows: $\mathrm{A}=0.230657$, $\mathrm{C}=0.279364, \mathrm{G}=0.252128, \mathrm{~T}=0.237852 ;$ substitution rates $\mathrm{AC}$ $=1.388608, \mathrm{AG}=2.845402, \mathrm{AT}=2.389715, \mathrm{CG}=0.838197, \mathrm{CT}$ $=7.220493, \mathrm{GT}=1.000000 ;$ gamma distribution shape parameter a $=0.650385$. Maximum likelihood and MP bootstrap support value $>$ $50 \%$ are shown respectively near the nodes. Ex-type strains are in bold

(1987) issued a second comprehensive monograph of the Erysiphales encompassing all powdery mildew taxa known at that time. Shin and La (1993) and Shin and Zheng (1998) introduced some new morphological features of taxonomic 
Table 6 DNA barcodes available for Cylindrocladiella

\begin{tabular}{|c|c|c|c|c|}
\hline Species & Isolate No & ITS & tefl & $t u b 2$ \\
\hline Cylindrocladiella addiensis & CBS 143794* & MH111383 & MH111393 & MH111388 \\
\hline C. arbusta $^{\#}$ & CMW 47295* & MH017015 & МH016977 & MH016958 \\
\hline C. australiensis & CBS 129567* & JN100624 & JN099060 & JN098747 \\
\hline C. brevistipitata & CBS 142786* & - & MF444940 & MF444926 \\
\hline C. camelliae & IMI 346845 & AF220952 & JN099087 & AY793471 \\
\hline C. clavata & CBS 129564* & JN099095 & JN098974 & JN098752 \\
\hline C. cymbiformis & CBS 129553* & JN099103 & JN098988 & JN098753 \\
\hline C. elegans & CBS 338.92* & AY793444 & JN099039 & AY793474 \\
\hline C. ellipsoidea & CBS 129573* & JN099094 & JN098973 & JN098757 \\
\hline C. hahajimaensis & MAFF 238172* & JN687561 & JN687562 & - \\
\hline C. hawaiiensis & CBS 129569* & JN100621 & JN099057 & JN098761 \\
\hline C. horticola & CBS 142784* & MF444911 & MF444938 & MF444924 \\
\hline C. humicola & CBS 142779* & MF444906 & MF444933 & MF444919 \\
\hline C. infestans & CBS 111795* & AF220955 & JN099037 & AF320190 \\
\hline C. kurandica & CBS 129577* & JN100646 & JN099083 & JN098765 \\
\hline C. lageniformis & CBS 340.92* & AF220959 & JN099003 & AY793481 \\
\hline C. lanceolata & CBS 129566* & JN099099 & JN098978 & JN098789 \\
\hline C. lateralis & CBS 142788* & MF444914 & MF444942 & MF444928 \\
\hline C. longiphialidica & CBS 129557* & JN100585 & JN098966 & JN098790 \\
\hline C. longistipitata & CBS 116075* & AF220958 & JN098993 & AY793506 \\
\hline C. malesiana & CMW 48278* & MH017019 & MH016981 & MH016962 \\
\hline C. microcylindrica & CBS 111794* & AY793452 & JN099041 & AY793483 \\
\hline C. natalensis & CBS 114943* & JN100588 & JN099016 & JN098794 \\
\hline C. nederlandica & CBS 152.91* & JN100603 & JN099033 & JN098800 \\
\hline C. novazelandica & CBS 486.77* & AF220963 & JN099050 & AY793485 \\
\hline C. nauliensis & CBS 143792* & MH111387 & MH111397 & MH111392 \\
\hline C. obpyriformis ${ }^{\#}$ & CMW 47194* & MH017022 & - & MH016966 \\
\hline C. parva & CBS 114524 & AF220964 & JN099009 & AY793486 \\
\hline C. parvispora & CMW 47197* & MH017025 & МH016987 & MH016968 \\
\hline C.peruvianum & IMUR 1843* & AF220966 & JN098968 & AY793500 \\
\hline C. postalofficium & СРC 37513* & MN562148 & - & MN556845 \\
\hline C.pseudocamelliae & CBS 129555* & JN100577 & JN098958 & JN098814 \\
\hline C.pseudohawaiiensis & CBS 210.94* & JN099128 & JN099012 & JN098819 \\
\hline C.pseudoinfestans & CBS 114531* & AF220957 & JN099004 & AY793508 \\
\hline C.pseudoparva & CBS129560* & JN100620 & JN099056 & JN098824 \\
\hline C. queenslandica & CBS 129574* & JN099098 & JN098977 & JN098826 \\
\hline C. reginae & CBS 142782* & MF444909 & MF444936 & MF444922 \\
\hline C. solicola ${ }^{\#}$ & CMW47198* & МH017021 & МH016983 & MH016964 \\
\hline C. stellenboschensis & CBS 110668* & JN100615 & JN099051 & JN098829 \\
\hline C. terrestris & CBS 142789* & MF444915 & MF444943 & MF444929 \\
\hline C. thailandica & CBS 129571* & JN100582 & JN098963 & JN098834 \\
\hline C. variabilis & CBS 129561* & JN100643 & JN099080 & JN098719 \\
\hline C. viticola ${ }^{\#}$ & CBS 112897* & AY793468 & JN099064 & AY793504 \\
\hline C. vitis ${ }^{\#}$ & CBS 142517* & KY979751 & KY979891 & KY979918 \\
\hline C. xishuangbannaensis & KUMCC 16-0146* & МH388337 & MH388372 & - \\
\hline
\end{tabular}

Ex-type/ex-epitype/ex-neotype/ex-lectotype strains are in bold and marked with an asterisk $(*)$. Voucher strains are also in bold. Species confirmed with pathogenicity studies are marked with ${ }^{\#}$ relevance. A progressive report was provided by the work of Cook et al. (1997), who examined the surface of conidia by scanning electron microscopy and separated Oidium into eight subgenera. Braun (1999) discussed the classification of Erysiphaceae as proposed by Cook et al. (1997) and introduced some corrections and alterations. Fundamental 


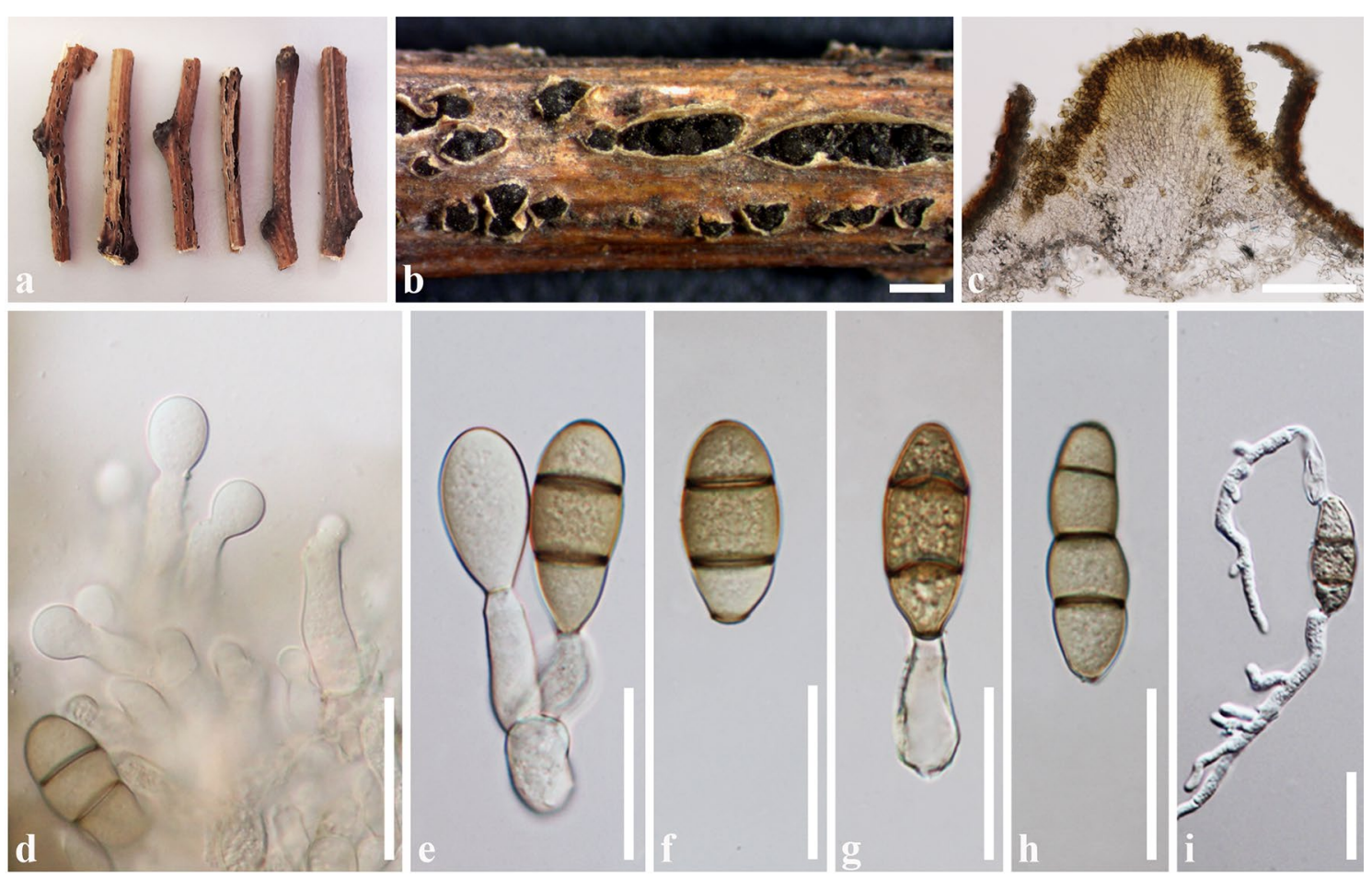

Fig. 9 Dothidotthia robiniae (MFLU 16-1704). a, b Sporodochia on the host surface. c Vertical section of sporodochium. d Conidiogenesis. e, $\mathbf{g}$ Conidia attached with the conidiogenous cells. f, h Conidia. i Germinated conidium. Scale bars: $\mathbf{b}=1000 \mu \mathrm{m}, \mathbf{c}=200 \mu \mathrm{m}, \mathbf{d}-\mathbf{i}=30 \mu \mathrm{m}$

innovations in the generic taxonomy of the group based on molecular and SEM examination and a better insight into the phylogeny are results of comprehensive investigations over the last decade (Takamatsu et al. 1998, 1999, 2000, 2005a, b, 2008; Matsuda and Takamatsu 2003; Hirose et al. 2005; Liberato et al. 2006; Braun and Cook 2012).

Classification-Ascomycota, Pezizomycotina, Leotiomycetes, Leotiomycetidae, Erysiphales

Type genus-Erysiphe R. Hedw. ex DC.

Distribution-worldwide

Disease symptoms - powdery mildew

The initial signs of infection appear on young leaves in the form of small, raised blisters, which cause the leaves to curl and expose the under surfaces. As the disease progresses, round, pinpoint powdery white spots dusting the upper surfaces of leaves, as well as stems and occasionally fruiting occurs. As the disease becomes severe, the spots will become larger, and more interconnected and irregular in shape. Over time they progress from younger to older leaves and the undersides of leaves. However, mature leaves are usually much less severely infected than new or young leaves. If the white patches (which have a granular, powdery texture) are wiped away, the growths will return in a matter of days. Severely infected leaves will turn yellow, dry out and drop from the plant. Buds and growing tips of shoots can also become infected, eventually becoming distorted and stunted (Bushnell and Allen 1962; Davis et al. 2001; Romero et al. 2003; Oberti et al. 2014; Saharan et al. 2019).

Hosts- The host range of this fungal group is strictly confined to angiosperms and powdery mildews have never been reported to infect ferns or gymnosperms (Amano 1986; Hirata et al. 2000; Takamatsu et al. 2010). They affect a wide range of angiosperms such as cereals and grasses, vegetables, ornamentals, weeds, shrubs, fruit trees, and broadleaved shade and forest trees. Powdery mildews are considered as host-specific.

\section{Pathogen biology, disease cycle and epidemiology}

Powdery mildews tend to grow superficially, or epiphytically, on plant surfaces. During the growing season, hyphae are produced on both the upper and lower leaf surfaces, although some species are restricted to one leaf surface. Infections can also occur on stems, flowers or fruit. Specialized absorption cells, termed haustoria, extend into the plant epidermal cells to obtain nutrition. While most powdery mildews produce epiphytic mycelium, a few genera produce hyphae that are within the leaf tissue; this is known as endophytic growth. Conidia are produced on plant surfaces during the growing season. They develop either singly or in chains on conidiophores. Conidiophores arise from the epiphytic hyphae, or in the case of endophytic hyphae, the conidiophores emerge through leaf stomata. At the end of the growing season, powdery mildews produce ascospores, 


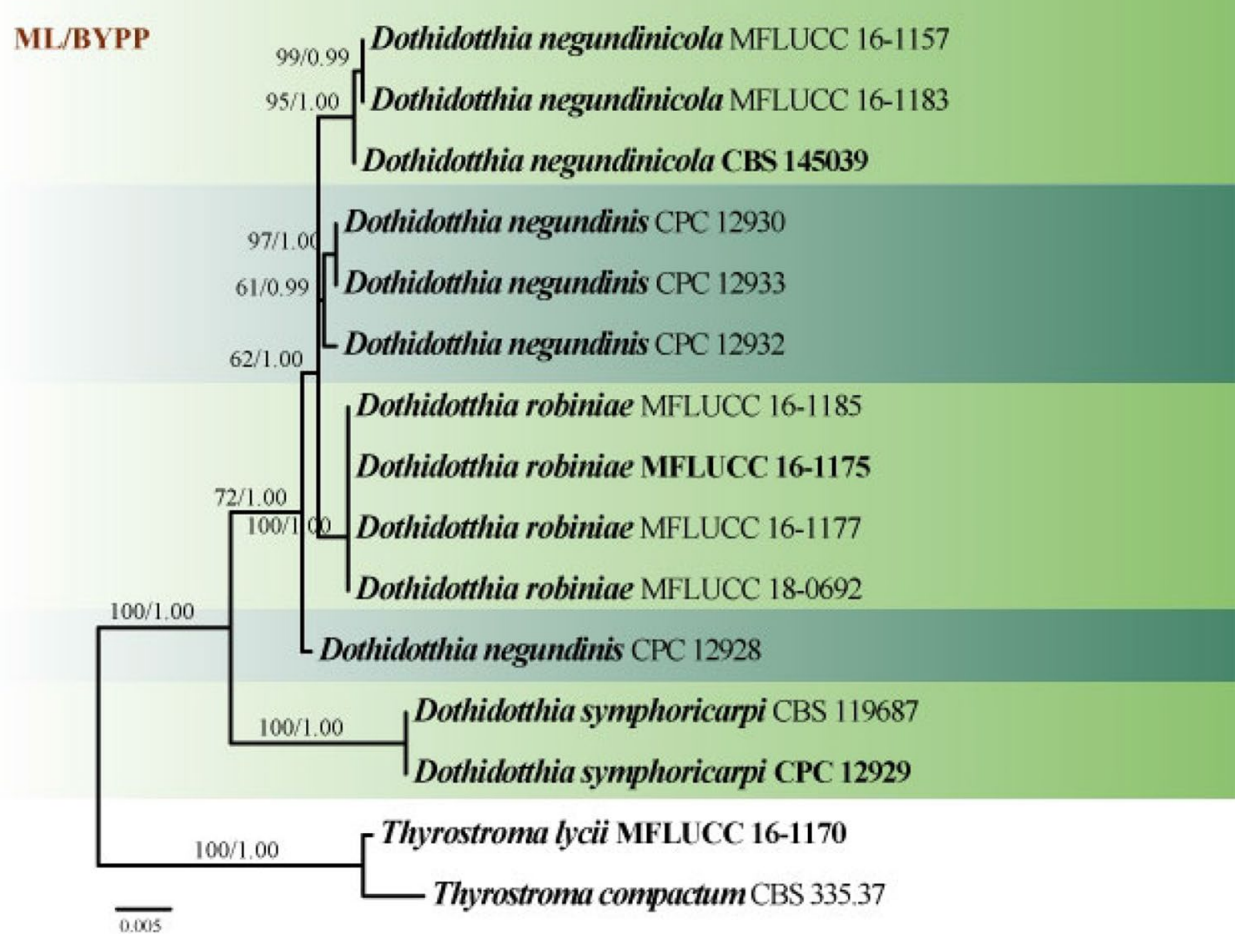

Fig. 10 Phylogenetic tree generated by ML analysis of LSU, SSU, ITS and tefl sequence data of Dothidotthia species. Related sequences were obtained from GenBank. The tree was rooted with Thyrostroma compactum (CBS 335.37) and T. lycii (MFLUCC 16-1170). Tree topology of the ML analysis was similar to the Bayesian analysis. The best scoring RAxML tree with a final likelihood value of - 5116.933762 is presented. The matrix had 115 distinct alignment patterns, with $25.41 \%$ of undetermined characters or gaps. Estimated base frequencies were as follows: $\mathrm{A}=0.245094, \mathrm{C}=0.237101, \mathrm{G}=0.269739, \mathrm{~T}=0.248067$; substitution rates $\mathrm{AC}=3.925871, \mathrm{AG}=7.445430$, $\mathrm{AT}=2.745308$, $\mathrm{CG}=2.728664, \mathrm{CT}=20.049514, \mathrm{GT}=1.000000$; gamma distribution shape parameter $\alpha=0.790240$. Maximum likelihood bootstrap support values greater than $60 \%$ and BYPP probabilities $\geq 0.95$ are indicated above the nodes. Ex-type (ex-epitype) and voucher strains are in bold
Table 7 DNA barcodes available for Dothidotthia

\begin{tabular}{llllll}
\hline Species & Isolate no & LSU & SSU & ITS & tef1 \\
\hline Dothidotthia negundinicola & CBS 145039* & MK442537 & - & MK442597 & - \\
& MFLUCC 16-1157 & MK751815 & MK751760 & MK751725 & MK908015 \\
& MFLUCC 16-1183 & MK751816 & MK751761 & MK751726 & MK908016 \\
D. negundinis & CPC 12930 & EU673274 & EU673226 & MK442599 & - \\
& CPC 12932 & EU673275 & EU673227 & MK442600 & - \\
& CPC 12933 & EU673276 & EU673228 & MK442601 & - \\
D. robiniae & MFLUCC 16-1175* & MK751817 & MK751762 & MK751727 & MK908017 \\
& MFLUCC 16-1177 & MK751818 & MK751763 & MK751728 & MK908018 \\
& MFLUCC 16-1185 & MK751819 & MK751764 & MK751729 & MK908019 \\
& MFLUCC 18-0692 & MK751821 & MK751766 & MK751731 & MK908021 \\
D. symphoricarpi & CPC 12929* & EU673273 & EU673224 & - & - \\
& CBS 119687 & MH874618 & - & MH863064 & - \\
\hline
\end{tabular}

Ex-type/ex-epitype/ex-neotype/ex-lectotype strains are in bold and marked with an asterisk (*). Voucher strains are also in bold in a sac-like ascus enclosed in a fruiting body called a chasmothecium. The chasmothecium is generally spherical with no natural opening; asci with ascospores are released when a crack develops in the wall of the fruiting body. A variety of appendages may occur on the surface of the chasmothecia.
These appendages are thought to act as the hooks of a velcro fastener, attaching the fruiting bodies to the host, particularly to the bark of woody plants, where they overwinter. They can survive winter conditions as dormant mycelia within the buds and other plant tissue of the host. These infected parts 
of the host can be the source of primary inoculum that can initiate further infection when conditions are right (Misra 2001; Amsalem et al. 2006; Heffer et al. 2006; Te Beest et al. 2008; Saharan et al. 2019; Fig. 11).

\section{Morphological based identification and diversity}

Members of Erysiphaceae cause powdery mildew disease on about 10,000 angiosperm species (Takamatsu et al. 2010). The Erysiphaceae are divided into five tribes and two basal genera (Cook et al. 1997). Both tree-parasitic and herb-parasitic species are included in three of the five tribes: Cystotheceae, Erysipheae and Phyllactinieae. Tree-parasitic species usually take basal positions in these tribes and herb-parasitic species have derived positions. The tribe, Golovinomycetea is a group derived from a single ancestor (Mori et al. 2000). The monophyly of the tribe is also supported by the common characteristics, i.e., ectophytic parasitism, polyascal ascomata, and Euoidium asexual morphs, with the latter producing conidia in chains without distinct fibrosin bodies. Of these five lineages, four consists of taxa infectious to dicotyledons. Blumeria graminis, which is infectious to monocotyledon plants, formed an independent lineage. Therefore, Blumeria graminis was accommodated in a monotypic tribe Blumerieae in the new system (Inuma et al. 2007).

The powdery mildew belonging to the tribe Cystotheceae have both herbaceous and woody plants as hosts and consist of three genera, Cystotheca, Podosphaera and Sawadaea, of which Cystotheca and Sawadaea are restricted to a narrow range of host families (Meeboon et al. 2013). Podosphaera consists of two sections, Podosphaera and Sphaerotheca. Section Podosphaera parasitizes woody plants (Takamatsu et al. 2000). The tribe Golovinomyceteae consists of three genera, Golovinomyces, Neoerysiphe, and Arthrocladiella. Arthrocladiella is a monotypic genus consisting of a single species $A$. mougeottii and has only the host genus Lycium. Neoerysiphe is also a small genus composed of four species and has about 300 herbaceous host species ranging across five plant families including Lamiaceae. Golovinomyces is a large genus comprising 27 species (Braun 1987), and it is widely distributed in the world. The tribe Phyllactinieae comprises the genera Phyllactinia, Leveillula, Pleochaeta and Queirozia which typically have hemi-endophytic (partly external and partly internal mycelia in common (Braun 1987; Liberato 2007; Liberato et al. 2006; Khodaparast et al. 2001; Ramos et al. 2013).

The tribe Erysipheae forms a separate, monophyletic clade, which is characterized by asexual morphs belonging to Oidium subgen. Pseudoidium Jacz (Takamatsu et al. 1999; Mori et al. 2000). This clade comprises Erysiphe and its sections Erysiphe, Microsphaera and Uncinula. Uncinula forestalis differs from the species of Erysiphe sect. Uncinula in having terminal, fasciculate, septate, ascoma appendages and Euoidium-like asexual morph (conidia catenate) and therefore it was placed in Caespitotheca (Takamatsu et al. 2005b).
Because of the lack of asexual morphs in Uncinula septata and $U$. curvispora and multiseptate chasmothecial appendages arising from the upper half the fruiting body, the two species were assigned to Parauncinula (Braun and Takamatsu 2000; Takamatsu et al. 2005a). A unique taxon, Oidium phyllanthi, on Phyllanthus acidus, P. amarus and P. reticulatus produces a germination type designated as Microidium-type and was placed in a new genus Microidium (To-anun et al. 2005). With these new classifications, Erysiphales contains 17 accepted genera, 16 based on the holomorph and one on the asexual morph (Braun and Cook 2012). With the descriptions of several new species, the number of recognized powdery mildew species has increased from 515 (including 435 sexual morphs/ holomorphs) in Braun (1987), to about 820 species (including about 685 sexual morphs/holomorphs) (Braun and Takamatsu 2000; Braun et al. 2002; Takamatsu et al. 2005a, b; Liberato et al. 2006; Braun and Cook 2012).

\section{Molecular based identification and diversity}

Molecular data have proven useful in reassessing species and clarifying the taxonomic significance of morphology and host data. Only a few of the described species have been reassessed using molecular data (Braun and Cook 2012). Reports began appearing in the 1990s, that used ITS and 18S rDNA sequences to infer phylogenetic relationships of Erysiphales and other major ascomycete groups (Saenz and Taylor 1999; Saenz et al. 1994). Analyses of 18S rDNA, ITS1-5.8S-ITS2, and 28S rDNA sequences led to the opinion that Erysiphales can be placed in Leotiomycetes along with Cyttariales, Helotiales, and Rhytismatales (Wang et al. 2006). Phylogenetic analyses demonstrated that Erysiphaceae formed a distinct monophyletic group (Hirata et al. 2000). Thus, Erysiphaceae is derived from a single ancestral taxon that may have acquired parasitism just once (Mori et al. 2000a; Takamatsu 2004; Wang et al. 2006). Shirouzu et al. (2020) using nrDNA and $\mathrm{mcm} 7$ sequence data showed that Phyllactinieae is not monophyletic. However, there is a need to re-assess the tribes in this family to establish them as subfamilies or genera. In this paper, we present a phylogenetic tree with combined ITS and LSU sequences obtained from available type material and voucher specimens (Table 8, Fig. 12). This can be used as a backbone in the identification of powdery mildew species.

Recommended genetic markers (genus level)_ITS, LSU and SSU

Recommended genetic markers (species level)—tub2, chs, tef1

The ITS region of the precursor molecules of rRNA was revealed to form a secondary structure including several stemloop structures, and some conserved sequences are found in the stem regions (Takamatsu et al. 1998). This makes it possible to design PCR primers that work for a wide range of the powdery mildews. Takamatsu and Kano (2001) designed 
Fig. 11 The life cycle of a powdery mildew fungus on roses. Redrawn from Agrios (2005) and Mulbrhan et al. (2016)

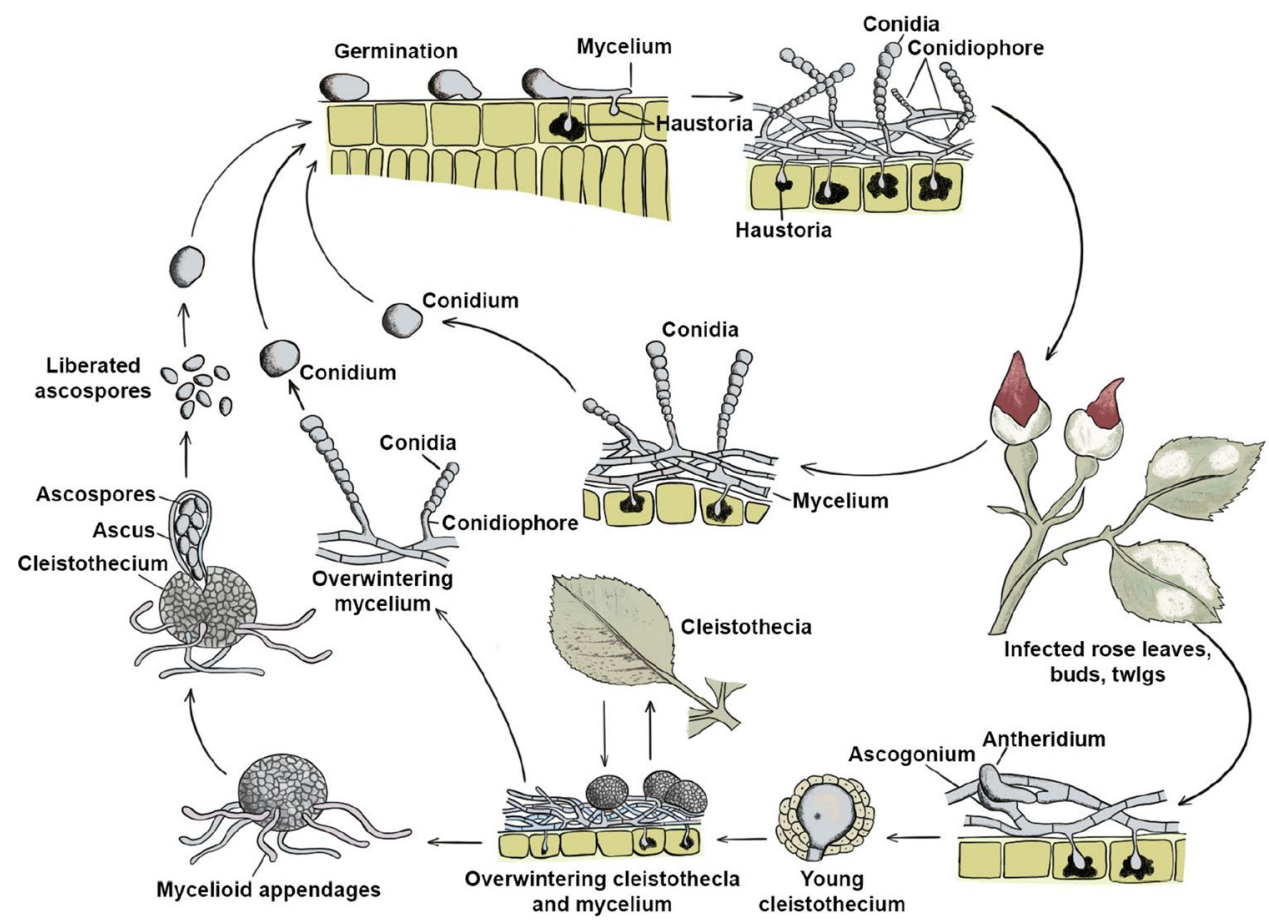

four new PCR primers that are useful to determine the nucleotide sequences of the rDNA of the powdery mildews. These primers provide stability to work on a wide range of powdery mildews and specificity to eliminate contaminating DNA by PCR. Primer sets PM3/P3, ITS1/PM4, PM5/P3, and ITS1/ PM6 were tested with universal primer set ITS1/ITS4 (White et al. 1990) covering all major clades of Erysiphales. Meeboon and Takamatsu (2013a) used LSU, ITS and IGS (Inter generic spacer) sequences to identify two different genetic groups of Erysiphe japonica (= Typhulochaeta japonica), powdery mildew on Quercus species based on the differences in host range. Cho et al. (2014) used ITS and 28S rDNA for the introduction of the powdery mildew species Erysiphe magnoliicola in Erysiphe sect. Microsphaera. Wang et al. (2014) also used ITS differences for phylogenetic analysis of powdery mildew disease on mulberry in Yunnan Province. Meeboon and Takamatsu (2013b) also used the 28S rDNA sequences and a combined alignment of the $28 \mathrm{~S}$, ITS, and IGS (Intergeneric spacer) rDNA sequences to construct a phylogeny of Erysiphe sect. Uncinula on Carpinus species and showed the cryptic species Erysiphe paracarpinicola. de Oliveira et al. (2015) used ITS sequences of Erysiphe platani on Platanus $\times$ acerifolia in Brazil as new records of taxa. Liyanage et al. (2017) used ITS, SSU and LSU sequences to identify E. quercicola infected rubber trees. Phylogenetic analyses of $B$. graminis based on the DNA sequences of four DNA regions, i.e. ITS, 28S rDNA, chitin synthase 1 , and ß-tubulin were conducted by Inuma et al. (2007) to revealed distinct groups in the $B$. graminis isolates from a single host genus belonged to a single group.
83. Fomitopsis P. Karst., Meddn Soc. Fauna Flora fenn. 6: 9 (1881)

\section{Background}

Fomitopsis was established by Karsten (1881) based on four species, with $F$. pinicola as the generic type (Murrill 1903; Donk 1960). The genus has a cosmopolitan distribution and comprises species causing brown rot on both living and dead trees (Han et al. 2016). Fomitopsis species also contribute to the decomposition of coarse woody debris in forest communities (Gilbertson 1980; Haight et al. 2019). There are certain instances of their pathogenic role in orchards of cultivated species where they cause heart rot on Citrus (Roccotelli et al. 2014) and Prunus species (Adaskaveg 1993). A Fomitopsis sp. was also recorded in oil palm (Elaeis guineensis) as an endophyte (Rungjindamai et al. 2008; Pinruan et al. 2010).

Classification-Basidiomycota, Agaricomycetes, Incertae sedis, Polyporales, Fomitopsidaceae

Type species-Fomitopsis pinicola (Sw.) P. Karst.

Distribution-Worldwide

Disease symptoms-Fomitopsis causes brown cubical rot on both living and dead trees (Mounce 1929). The basidiospores can be dispersed by wind, or by vectors such as bark beetles (Castello et al. 1976; Pettey and Shaw 1986; Lim et al. 2005; Persson et al. 2011; Jacobsen et al. 2017; Vogel et al. 2017). Upon infecting standing trees, stumps, or logs through wounds, or through the tunnels of penetrating vectors, the fungus establishes itself in the xylem (Mounce 1929). The growth rate of Fomitopsis species in the substrata 
can differ depending on their ecological requirements (Markovic et al. 2011; Haight et al. 2019). When the decay starts, the wood turns yellowish-brown, which later splits into cubical fragments. The colour is generally lighter in case of $F$. pinicola than other agents of brown rot decay (Markovic et al. 2011). White mycelial felts can also develop in shrinkage cracks of the decayed wood (Ryvarden and Gilbertson 1993). After establishment, the perennial basidiome appears relatively rapidly (Mounce 1929, Fig. 13). The infection results in the breakage of treetops, or further infection of the base of the trees and weakening of larger roots, which may lead to eventual windthrow of standing trees.

Hosts-The type species, F. pinicola mostly appears on gymnosperms, such as Abies, Larix, Picea and Pinus, but can also be found on angiosperms such as Acer, Alnus, Betula, Carpinus, Corylus, Elaeagnus, Fagus, Fraxinus, Malus, Populus, Prunus, Pyrus, Quercus, Salix, Sorbus, Tilia, Ulmus (Ryvarden and Gilbertson 1993; Dai 2012). The North American species in the Fomitopsis pinicola species complex have also been reported from Pseudotsuga, Sequioa and Tsuga (Haight et al. 2019). Other Fomitopsis species can be found on Ginkgo, Pinus and various angiosperm genera, such as Betula, Castanopsis, Cinamomum, Citrus, Delonix, Fagus, Eucalyptus Ligustrum, Prunus, Quercus and Tilia (Ryvarden and Gilbertson 1993; Dai 2012; Li et al. 2013; Han et al. 2016; Liu et al. 2019).

\section{Morphological based identification and diversity}

Based on morphological evidence, over 40 species were accepted in Fomitopsis (e.g. Ryvarden and Johansen 1980; Gilbertson and Ryvarden 1986; Ryvarden and Gilbertson 1993; Núñez and Ryvarden 2001; Hattori 2001). However, phylogenetic studies showed that the morphologically defined Fomitopsis was polyphyletic and taxa clustered with other brown-rot genera in the antrodia clade (Ortiz-Santana et al. 2013; Han et al. 2016). Han et al. (2016) showed that Pilatoporus and Piptoporus are synonyms of Fomitopsis sensu stricto, while the segregation of Rhodofomes was confirmed and five new genera were proposed. Fomitopsis sensu stricto is characterized by annual to perennial, mostly sessile, occasionally effused-reflexed or substipitate, soft, corky, tough to woody basidiocarps, a dimitic hyphal system with clamped generative hyphae and cylindrical to ellipsoid, hyaline, thin-walled, smooth basidiospores which are negative in Melzer's reagent, and cause brown rot (Fig. 13).

\section{Molecular based identification and diversity}

Comprehensive multigene analyses by Han et al. (2016) accepted ten species in Fomitopsis sensu stricto. Two new Fomitopsis species were described from Brazil, F. flabellata and $F$. roseoalba (Tibpromma et al. 2017). Fomitopsis flabellata was transferred to Rhodofomitopsis and the new combination Fomitopsis bondartsevae was proposed (Soares et al.
2017). Mating studies and molecular phylogenetic analyses resolved four cryptic lineages in the $F$. pinicola species complex (Haight et al. 2016), that represents three North American species ( $F$. mounceae, $F$. ochracea and $F$. schrenkii), and $F$. pinicola sensu stricto, which is restricted to Eurasia (Ryvarden and Stokland 2008; Haight et al. 2019). Three new species were proposed by Liu et al. (2019) from Australia (F. eucalypticola), Puerto Rico ( $F$. caribensis), and China ( $F$. ginkgonis).

The phylogenetic tree of Fomitopsis presented here is based on analyses of a combined ITS, LSU, tefl and $r p b 2$ sequence data (Fig. 14). In our analyses, it appears that the type of $F$. bondartsevae is identical to $F$. iberica and $F$. hemitephra sensu stricto (Han et al. 2016), which are grouped close to $F$. palustris and other species formerly discussed in Pilatoporus. Therefore, a thorough revision of the pilatoporus clade is recommended to clarify the status of these species.

\section{Recommended genetic marker (genus level)—LSU} Recommended genetic markers (species level)_-ITS, tefl, $r p b 2$

Accepted number of species-There are 104 epithets listed in Index Fungorum (2020). However, only 17 species have DNA sequence data (Table 9).

References-Li et al. (2013) (phylogeny, new species), Han et al. (2016) (phylogeny), Haight et al. 2019 (phylogeny, new species), Floudas et al. (2012) (genome, F . pinicola), Hong et al. (2017) (genome, F. palustris), Liu et al. (2019) (phylogeny, new species).

84. Ganoderma P. Karst., Revue mycol., Toulouse 3(no. 9): 17 (1881)

\section{Background}

Ganoderma was established by Karsten (1881) based on $G$. lucidum and characterized by double-walled basidiospores with truncate apices and ornamented endospores, and a crusty or shiny pileus surface (Moncalvo and Ryvarden 1997). This genus was divided into two subgenera, Ganoderma and Elfvingia by Karsten (1889). Various authors used different taxonomic characters for the identification of species (e.g., Murrill 1902, 1903; Atkinson 1908; Coleman 1927; Corner 1947), which resulted in an intricate taxonomy, with 344 species names in speciesfungorum.org, but an estimated 180 species (He et al. 2019) and Steyaert (1972, 1980) worked extensively on the genus and introduced many new species, transferred many to the genus and removed several synonyms. Ryvarden (1985) and Gottlieb and Wright (1999a,b) studied the macro- and micromorphology. Ganoderma presently comprises sections Amauroderma and Ganoderma, subgenera: Ganoderma and Trachyderma (Index Fungorum 2020, Wijayawardene et al. 2020).

Relevant characteristics for Ganoderma species delimitation are based on the macro and micromorphological characteristics (see in Fig. 15). The basidiomes are annual or 
Table 8 Genera in Erysiphaceae

\begin{tabular}{|c|c|c|c|c|c|}
\hline Genera & Species name & Strain no & Host & ITS & LSU \\
\hline Arthrocladiella & Arthrocladiella mougeotii & SqGq-1 & Lycium chinense & JX546296 & AB022379 \\
\hline Blumeria & Blumeria graminis & MUMH1723 & Festuca arundinacea & AB273556 & AB103065 \\
\hline Brasiliomyces & Brasiliomyces malvastri & NA & $\begin{array}{l}\text { Malvastrum coromandeli- } \\
\text { anum }\end{array}$ & NA & NA \\
\hline Caespitotheca & Caespitotheca forestalis & MUMH1461 & Schinopsis balansae & AB193466 & AB193467 \\
\hline Cystotheca & $\begin{array}{l}\text { Cystotheca wrightii } \\
\text { Cystotheca lanestris }\end{array}$ & $\begin{array}{l}\text { KUS-F27309 } \\
\text { NA }\end{array}$ & $\begin{array}{l}\text { Quercus glauca } \\
\text { Quercus agrifolia }\end{array}$ & $\begin{array}{l}\text { KF735066 } \\
\text { AB000933 }\end{array}$ & $\begin{array}{l}\mathrm{AB} 022355 \\
\mathrm{AB} 022353\end{array}$ \\
\hline Erysiphe & $\begin{array}{l}\text { Erysiphe polygoni } \\
\text { Erysiphe heraclei } \\
\text { Erysiphe monascogera } \\
\text { Erysiphe blasti } \\
\text { Erysiphe juglandis } \\
\text { Erysiphe hedwigii } \\
\text { Erysiphe pulchra var. } \\
\text { japonica } \\
\text { Erysiphe symphoricarpi } \\
\text { Erysiphe asiatica } \\
\text { Erysiphe monoperidiata } \\
\text { Erysiphe japonica var. } \\
\text { crispulae } \\
\text { Erysiphe adunca } \\
\text { Erysiphe aphananthes } \\
\text { Erysiphe flexuosa } \\
\text { Erysiphe mori } \\
\text { Erysiphe kenjiana } \\
\text { Erysiphe prunastri var. } \\
\text { prunastri } \\
\text { Erysiphe wadae }\end{array}$ & $\begin{array}{l}\text { UTC206 } \\
\text { NA } \\
\text { MUMH4190 } \\
\text { MUMH2 } \\
\text { MUMH48s } \\
\text { VPRI 22225 } \\
\text { MUMH90 } \\
\text { MUMH1428 } \\
\text { MUMH } 4992 \\
\text { MUMH } 4987 \\
\text { NA } \\
\text { MUMH40 } \\
\text { MUMH 4648 } \\
\text { MUMH1429 } \\
\text { NA } \\
\text { KW:34760F } \\
\text { MUMH776 } \\
\text { MUMH1534 }\end{array}$ & $\begin{array}{l}\text { Polygonum arenastrum } \\
\text { Daucus carota } \\
\text { Styrax japonica } \\
\text { Lindera umbellata } \\
\text { Microsphaera juglandis } \\
\text { NA } \\
\text { Cornus controversa } \\
\text { Symphoricarpos albus } \\
\text { Castanopsis diversifolia } \\
\text { Castanopsis argyrophylla } \\
\text { Quercus cuspidata } \\
\text { NA } \\
\text { Aphananthe aspera } \\
\text { Aesculus hippocastanum } \\
\text { Morus bombycis } \\
\text { Ulmus minor } \\
\text { Prunus domestica } \\
\text { Fagus crenata }\end{array}$ & $\begin{array}{l}\text { AF011307 } \\
\text { AB000942 } \\
\text { AB331647 } \\
\text { AB015918 } \\
\text { AB015928 } \\
\text { AF298539 } \\
\text { AB000941 } \\
\text { AB078970 } \\
\text { AB622218 } \\
\text { AB622213 } \\
\text { AB022416 } \\
\text { D84383 } \\
\text { AB69396 } \\
\text { AB091774 } \\
\text { AB000946 } \\
\text { AB475118 } \\
\text { AB046984 } \\
\text { AB091776 }\end{array}$ & $\begin{array}{l}\text { NA } \\
\text { AB103371 } \\
\text { NA } \\
\text { NA } \\
\text { NA } \\
\text { NA } \\
\text { AB022389 } \\
\text { NA } \\
\text { JQ220158 } \\
\text { JQ220154 } \\
\text { AB022415 } \\
\text { AB022374 } \\
\text { NA } \\
\text { NA } \\
\text { AB022418 } \\
\text { AB475109 } \\
\text { AB709961 } \\
\text { NA }\end{array}$ \\
\hline Golovinomyces & $\begin{array}{l}\text { Golovinomyces } \\
\text { cichoracearum } \\
\text { Golovinomyces adenop- } \\
\text { horae } \\
\text { Golovinomyces cynoglossi } \\
\text { Golovinomyces fischeri } \\
\text { Golovinomyces leuceriae }\end{array}$ & $\begin{array}{l}\text { MUMH623 } \\
\text { MUMH144 } \\
\text { MUMH3196 } \\
\text { MUMH1343 } \\
\text { MUMH1406 } \\
\text { MUMH683 }\end{array}$ & $\begin{array}{l}\text { Mycelis muralis } \\
\text { Adenophora triphylla var. } \\
\text { japonica } \\
\text { Cynoglossum asperrimum } \\
\text { Senecio doronicum } \\
\text { Leuceria thermarum }\end{array}$ & $\begin{array}{l}\text { AB077661 } \\
\text { AB077633 } \\
\text { AB769454 } \\
\text { AB769450 } \\
\text { AB246765 }\end{array}$ & $\begin{array}{l}\text { NA } \\
\text { AB077632 } \\
\text { AB077683 } \\
\text { AB769452 } \\
\text { NA }\end{array}$ \\
\hline Golovinomyces & $\begin{array}{l}\text { Golovinomyces orontii } \\
\text { Golovinomyces sonchicola } \\
\text { Golovinomyces sordidus } \\
\text { Golovinomyces sparsus } \\
\text { Golovinomyces valerianae }\end{array}$ & $\begin{array}{l}\text { MUMH2433 } \\
\text { BCRU934 } \\
\text { MUMH938 } \\
\text { HMNWAFU-CF2011034 }\end{array}$ & $\begin{array}{l}\text { Cirsium japonicum } \\
\text { Sonchus arvensis } \\
\text { Plantago sp. } \\
\text { Euphorbia collina } \\
\text { Valeriana officinalis }\end{array}$ & $\begin{array}{l}\text { AB769413 } \\
\text { AB077673 } \\
\text { AB769467 } \\
\text { AB769461 } \\
\text { AB769471 }\end{array}$ & $\begin{array}{l}\text { AB077678 } \\
\text { AB077672 } \\
\text { AB077657 } \\
\text { NA } \\
\text { NA }\end{array}$ \\
\hline Leveilluta & $\begin{array}{l}\text { Leveilluta taurica } \\
\text { Leveillula elaeagni } \\
\text { Leveillula lactucae-serri- } \\
\quad \text { olae }\end{array}$ & $\begin{array}{l}\text { WSP71133 } \\
\text { IRAN11138 } \\
\text { NA }\end{array}$ & $\begin{array}{l}\text { Triglochin maritime } \\
\text { Elaeagnus angustifolia } \\
\text { Hexinia polydichotoma }\end{array}$ & $\begin{array}{l}\text { AY912077 } \\
\text { AB048350 } \\
\text { HQ821500 }\end{array}$ & $\begin{array}{l}\text { NA } \\
\text { NA } \\
\text { HQ821501 }\end{array}$ \\
\hline Microidium & Microidium phyllanthi & MUMH(JPN)3361 & Phyllanthus acidus & AB719943 & AB120758 \\
\hline Neoerysiphe & $\begin{array}{l}\text { Neoerysiphe cumminsiana } \\
\text { Neoerysiphe galeopsidis } \\
\text { Neoerysiphe galii } \\
\text { Neoerysiphe geranii } \\
\text { Neoerysiphe joerstadii } \\
\text { Neoerysiphe kerribeeensis } \\
\text { Neoerysiphe nevoi }\end{array}$ & $\begin{array}{l}\text { MUMH } 522 \\
\text { MUMH4680 } \\
\text { MUMH } 4682 \\
\text { MUMH4665 MUMH } 4668 \\
\text { DAR } 33493 \\
\text { MUMH } 4671\end{array}$ & $\begin{array}{l}\text { Cacalia delphiniifolia } \\
\text { Chelonopsis moschata } \\
\text { Galium aparine } \\
\text { Geranium sp. } \\
\text { Phagnalon rupestre } \\
\text { Senecio glossanthus } \\
\text { Scolymus hispanicus }\end{array}$ & $\begin{array}{l}\text { AB329669 } \\
\text { AB498949 } \\
\text { AB498951 } \\
\text { AB498956 AB498976 } \\
\text { GU356546 } \\
\text { AB498975 }\end{array}$ & $\begin{array}{l}\text { NA } \\
\text { AB022369 } \\
\text { AB103365 } \\
\text { AB498952 } \\
\text { NA } \\
\text { NA } \\
\text { NA }\end{array}$ \\
\hline Parauncinula & Parauncinula septata & MUMH585 & $\begin{array}{l}\text { Quercus cuspidata var. } \\
\text { horikawae }\end{array}$ & AB 183533 & AB022420 \\
\hline
\end{tabular}


Table 8 (continued)

\begin{tabular}{|c|c|c|c|c|c|}
\hline Genera & Species name & Strain no & Host & ITS & LSU \\
\hline Phyllactinia & $\begin{array}{l}\text { Phyllactinia guttata } \\
\text { Phyllactinia actinidiae } \\
\text { Phyllactinia alni } \\
\text { Phyllactinia betulae } \\
\text { Phyllactinia- broussonetiae- } \\
\text { kaempferi } \\
\text { Phyllactinia enkianthi } \\
\text { Phyllactinia eupteleae } \\
\text { Phyllactinia fraxini } \\
\text { Phyllactinia guttata } \\
\text { Phyllactinia juglandis } \\
\text { Phyllactinia magnoliae } \\
\text { Phyllactinia mali } \\
\text { Phyllactinia moricola }\end{array}$ & $\begin{array}{l}\text { MUMH927 } \\
\text { MUMH497 } \\
\text { MUMH449 } \\
\text { MUMH506 } \\
\text { MUMH531 } \\
\text { MUMH527 } \\
\text { MUMH165 } \\
\text { MUMH907 } \\
\text { MUMH927 } \\
\text { TUAMH2072 } \\
\text { MUMH531 } \\
\text { MUMH619 } \\
\text { MUMHn36 }\end{array}$ & $\begin{array}{l}\text { Corylus sp. } \\
\text { Actinidia arguta } \\
\text { Alnus japonica } \\
\text { Betula platyphylla var. } \\
\text { japonica } \\
\text { Broussonetia kazinoki } \\
\text { Lyonia ovalifolia var. } \\
\text { elliptica } \\
\text { Euptelea polyandra } \\
\text { Syringa vulgaris } \\
\text { Corylus sp. } \\
\text { Juglans mandshurica var. } \\
\text { sachalinensis } \\
\text { Magnolia quinquepeta } \\
\text { Crataegus sp. } \\
\text { Morus cathayana }\end{array}$ & $\begin{array}{l}\text { AB080565 } \\
\text { AB080508 } \\
\text { AB080502 } \\
\text { AB080507 } \\
\text { AB080510 } \\
\text { AB080504 } \\
\text { AB080498 } \\
\text { AB080543 } \\
\text { AB080565 } \\
\text { AB080531 } \\
\text { AB080526 } \\
\text { AB080523 } \\
\text { AB080518 }\end{array}$ & $\begin{array}{l}\text { AB080456 } \\
\text { HQ821501 } \\
\text { AB080393 } \\
\text { AB080398 } \\
\text { AB080445 } \\
\text { AB080408 } \\
\text { AB080402 } \\
\text { AB080453 } \\
\text { AB080394 } \\
\text { AB080422 } \\
\text { AB080416 } \\
\text { AB080414 } \\
\text { AB080373 }\end{array}$ \\
\hline Pleochaeta & $\begin{array}{l}\text { Pleochaeta indica } \\
\text { Pleochaeta shiraiana }\end{array}$ & $\begin{array}{l}\text { MUMH3208 } \\
\text { MUMH20 }\end{array}$ & $\begin{array}{l}\text { Celtis australis } \\
\text { NA }\end{array}$ & $\begin{array}{l}\text { AB243757 } \\
\text { D84380 }\end{array}$ & $\begin{array}{l}\mathrm{NA} \\
\mathrm{AB} 022403\end{array}$ \\
\hline Podosphaera & $\begin{array}{l}\text { Podosphaera myrtillina } \\
\text { Podosphaera leucotricha } \\
\text { Podosphaera spiraeae } \\
\text { Podosphaera cercidiphylli } \\
\text { Podosphaera clandestine } \\
\text { Podosphaera astericola } \\
\text { Podosphaera balsaminae } \\
\text { Podosphaera carpesiicola } \\
\text { Podosphaera elsholtziae } \\
\text { Podosphaera euphorbiae- } \\
\text { hirtae } \\
\text { Podosphaera fusca } \\
\text { Podosphaera fuliginea } \\
\text { Podosphaera hibiscicola } \\
\text { Podosphaera intermedia } \\
\text { Podosphaera phtheiros- } \\
\text { permi } \\
\text { Podosphaera pseudofusca } \\
\text { Podosphaera xanthii }\end{array}$ & $\begin{array}{l}\text { NA } \\
\text { HMLAC120001 } \\
\text { MUMH } 2490 \\
\text { MUMHS67 } \\
\text { MUMH } 2535 \\
\text { MUMH333 } \\
\text { NA } \\
\text { MUMH344 } \\
\text { MUMHS131 } \\
\text { MUMH319 } \\
\text { NA } \\
\text { MUMH809 } \\
\text { MUMH605 } \\
\text { MUMH331 } \\
\text { MUMH774 } \\
\text { MUMH346 } \\
\text { MUMH74 }\end{array}$ & $\begin{array}{l}\text { Vaccinium myrillus } \\
\text { Photinia serrulata } \\
\text { Spiraea cantoniensis } \\
\text { Cercidiphyllum japonicum } \\
\text { Spiraea japonica } \\
\text { Aster ageratoides subsp. } \\
\text { ovatus } \\
\text { Impatiens balsamina } \\
\text { Carpesium abrotanoides } \\
\text { Ajuga reptans } \\
\text { Acalypha australis } \\
\text { NA } \\
\text { Verbena spicata } \\
\text { Hibiscus mutabilis } \\
\text { Clerodendrum trichotomum } \\
\text { Melampyrum nemorosum } \\
\text { Fatoua villosa } \\
\text { Youngia denticulata }\end{array}$ & $\begin{array}{l}\text { NA } \\
\text { JQ999954 } \\
\text { AB525940 } \\
\text { AB026140 } \\
\text { AB525941 } \\
\text { AB040335 } \\
\text { FJ625796 } \\
\text { AB040350 } \\
\text { AB026142 } \\
\text { AB040306 } \\
\text { AF154324 } \\
\text { AB046986 } \\
\text { AB040308 } \\
\text { AB026145 } \\
\text { AB040332 } \\
\text { AB040320 } \\
\text { AB040351 } \\
\text { NA }\end{array}$ & $\begin{array}{l}\text { NA } \\
\text { NA } \\
\text { AB022384 } \\
\text { NA } \\
\text { AB103367 } \\
\text { AB462779 } \\
\text { AB462788 } \\
\text { NA } \\
\text { AB462794 } \\
\text { AB462770 } \\
\text { AB103369 } \\
\text { AB462761 } \\
\text { NA } \\
\text { AB462777 } \\
\text { NA } \\
\text { NA } \\
\text { JX512556 } \\
\text { NA } \\
\text { NA }\end{array}$ \\
\hline Queirozia & Queirozia turbinata & VIC 26558 & Platycyamus regnellii & AB218773 & NA \\
\hline Sawadaea & $\begin{array}{l}\text { Sawadaea bicornis } \\
\text { Sawadaea nankinensis } \\
\text { Sawadaea polyfida } \\
\text { Sawadaea tulasnei }\end{array}$ & $\begin{array}{l}\text { MUMH904 } \\
\text { MUMH4232 } \\
\text { MUMH486 } \\
\text { MUMHS112 }\end{array}$ & $\begin{array}{l}\text { Acer pseudoplatanus } \\
\text { Acer buergerianum } \\
\text { Acer amoenum var. mat- } \\
\quad \text { sumurae } \\
\text { Acer mono var. marmora- } \\
\text { tum }\end{array}$ & $\begin{array}{l}\text { AB193380 } \\
\text { AB353762 } \\
\text { AB193358 } \\
\text { AB193388 }\end{array}$ & $\begin{array}{l}\text { AB103370 } \\
\text { NA } \\
\text { AB193393 } \\
\text { AB193400 }\end{array}$ \\
\hline Takamatsuella & Takamatsuella circinata & NA & Stachys distans & NA & NA \\
\hline
\end{tabular}

Type strains are in bold

perennial, dimidiate, sessile or substipitate to stipitate, with distinctive non-laccate (dull) or weakly to strongly laccate, glossy, shiny, smooth, spathulate, furrows, which are sulcate on the pileus surface. Some strains have several layers of thick, dull cuticles or shiny, with thin cuticle or cuticle of clavate end cells. The context is cream to dark purplish brown, brown to dark brown, sometimes spongy to firmfibrous. Pores are 4-7 per mm, angular, entire, subcircular to circular, regular, mostly cream or white when young, light yellow to brown when mature, which are usually white to cream when fresh, turning pale yellow on drying, with bruising brown of pore surface. The tube layer is single or stratified, with pale to purplish brown, hard, and becomes woody when dry. The stipe is central or lateral when present.

The Ganoderma hyphal system is di-trimitic and generative hyphae are thin-walled or occasionally thick-walled, with clamp connections. Skeletal hyphae are hyaline to brown, thick-walled, often long, unbranched. Binding hyphae are almost colourless, thin to thick-walled, branched and with clamp connections. Basidiospores are 7-30 $\mu \mathrm{m}$ 


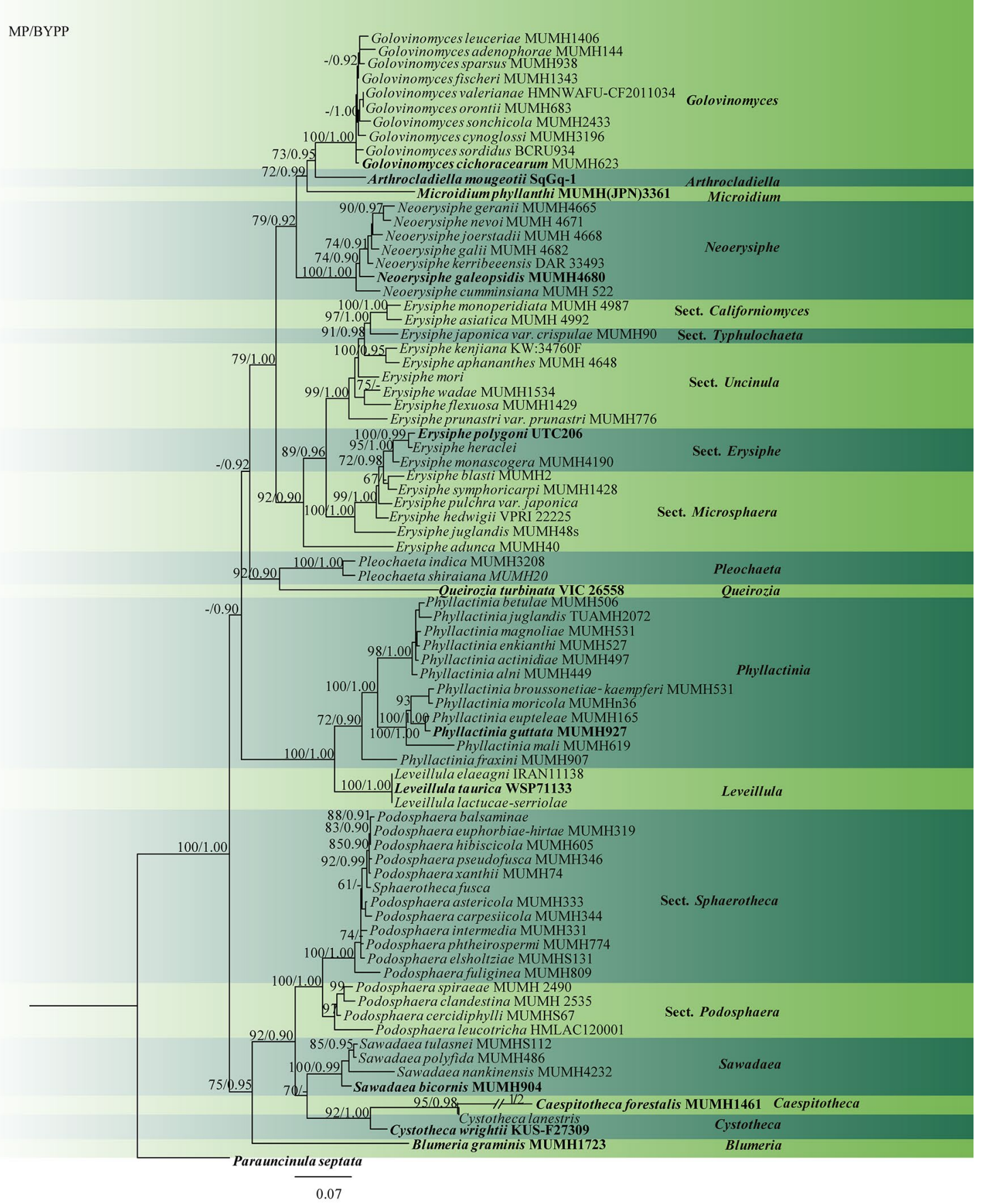

Fig. 12 Phylogram generated from parsimony analysis based on combined ITS and LSU sequenced data Erysiphaceae. Maximum parsimony bootstrap support values greater than $60 \%$ and BYPP greater

long, usually broadly to narrowly ellipsoid, truncate, double-walled, and with an apical germ pore. The endosporium is brown and separated from the hyaline exosporium by inter-wall pillars, negative in Melzer's reagent (Núñez and Ryvarden 2000; Ryvarden 2004). Basidia are broadly ellipsoid, tapering abruptly at the base, and cystidia are lacking. than 0.90 are indicated above the nodes. The type specimens (ex-epitypes) are in bold. The tree is rooted with Parauncinula septata

Ganoderma species are widely distributed in temperate, subtropical and tropical regions, and appear to thrive in hot and humid conditions (Pilotti et al. 2004; Hapuarachchi et al. 2019a, b; Luangharn et al. 2019). Basidiomes are commonly in the form of a bracket (Pilotti et al. 2004). Ganoderma is cosmopolitan and an important wood-decaying genus. Some 
Fig. 13 Fomitopsis pinicola a basidiomes on living European spruce, $\mathbf{b}$ causing brown-rot decay on narrow-leafed ash, c, $\mathbf{d}$ basidiomes on dead standing conifer tree, e young basidiome on hardwood log, $\mathbf{f}$ hyphal structure in the trama, $\mathbf{g}, \mathbf{h}$ basidiospores. Scale bars: $\mathbf{f}=$ $20 \mu \mathrm{m}, \mathbf{g}, \mathbf{h}=5 \mu \mathrm{m}$
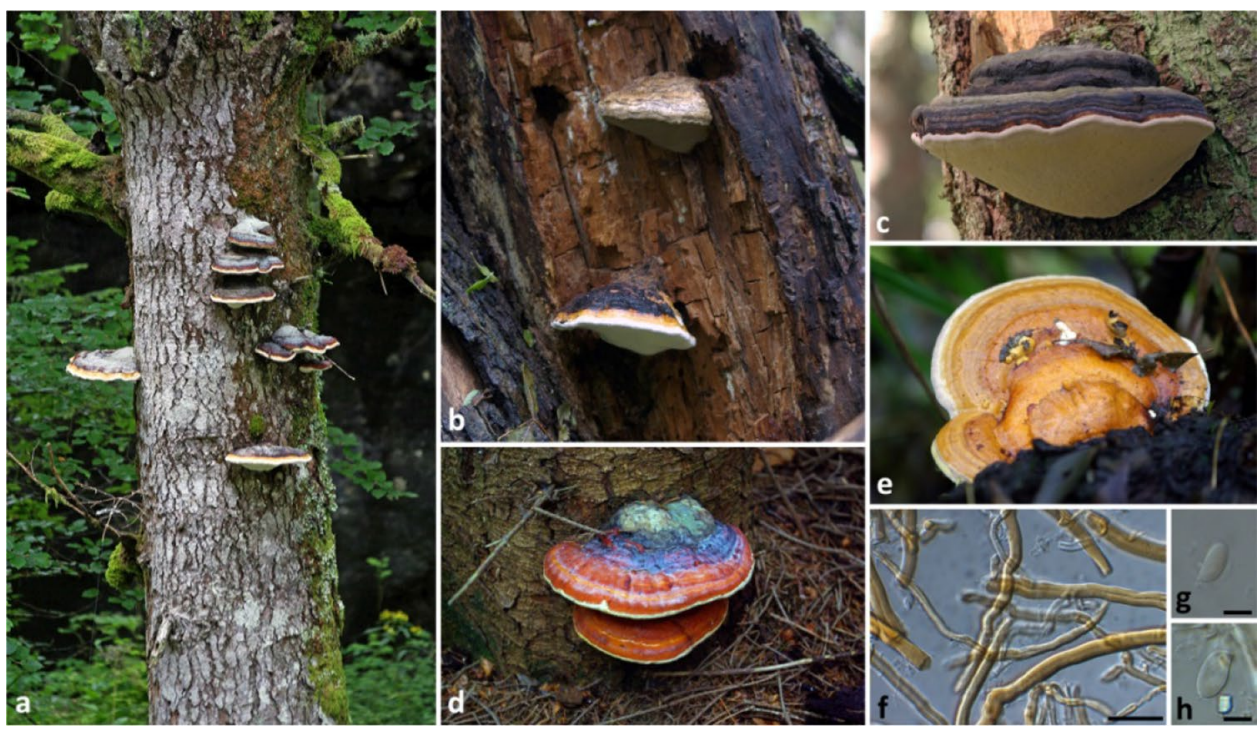

species of Ganoderma are pathogenic, causing root and stem rot on a variety of monocotyledons, dicotyledons and gymnosperms, including a wide range of economically important trees and perennial crops which results in the death of affected trees (Hapuarachchi et al. 2018b). Ganoderma grows as facultative parasites of trees but can also live as saprobes on rotting stumps and roots (Turner 1981; Pilotti et al. 2004). Hence, they have ecological importance in the breakdown of woody plants for nutrient mobilization. Taxa also possess effective machinery of lignocellulose-decomposing enzymes which may be useful for bioenergy production and bioremediation (Hepting 1971; Kües et al. 2015; Hyde et al. 2019).

Several Ganoderma species are prolific sources of highly active bioactive compounds such as polysaccharides, proteins, steroids and triterpenoids. These bioactive compounds show a huge structural and chemical diversity (Shim et al. 2004; Qiao et al. 2005; Wang and Liu 2008; Teng et al. 2011; De Silva et al. 2012a, b; 2013; Hapuarachchi et al. 2017; Li et al. 2018; Hyde et al. 2019). The bioactive constituents have anti-cancer, anti-inflammatory, anti-tumour, anti-oxidant, immunomodulatory, immunodeficiency, anti-diabetic, anti-viral, anti-bacterial, anti-fungal, anti-hypertensive, anti-atherosclerotic, anti-ageing, anti-androgenic, hepatoprotective and radical scavenging properties. They are also promising in neuroprotection, sleep promotion, cholesterol synthesis inhibition, preventing hypoglycemia, inhibition of lipid peroxidation/oxidative DNA damage, maintenance of gut health, prevention of obesity, and stimulation of probiotics (De Silva et al. 2012a; Hapuarachchi et al. 2016a, b, Hapuarachchi et al. 2017).

Current studies are identifying secondary metabolites, developing models for prediction or early detection of diseases, finding biological control methods as well as understanding genomes. Using artificial neural network spectral analyses and foliage of four disease levels, Ahmadi et al. (2017) provided an early detection method for Ganoderma basal stem rot of oil palm. Sitompul and Nasution (2020) suggested that to control Ganoderma diseases non or weakly pathogenic fungi can be considered as biological control agents. These agents could break down woody debris faster than the pathogen and occupy the same resource as the pathogen (compete for nutrients) as well as producing inhibitory secondary metabolites (Paterson 2007; Sitompul and Nasution 2020). Utomo et al. (2018) sequenced the nuclear genome of $G$. boninense, the main pathogen of basal stem rot, and the draft genome comprised of 79.24 megabases and 26,226 predicted coding sequences. Ramzi et al. (2019) conducted a study to understand the plant cell wall degradation and pathogenesis of $G$. boninense via comparative genome analysis. In their study, they found that similarly to G. lucidium, G. boninense was enriched with carbohydrate-active and cell wall degrading enzymes. Following plant-host interaction analysis, several candidate genes including polygalacturonase, endo $\beta$-1, 3-xylanase, $\beta$-glucanase and laccase were identified as potential cell wall degrading enzymes that contribute to the plant host interaction and pathogenesis. The study provided fundamental knowledge on the fungal genetic ability and capacity to secrete carbohydrateactive and cell wall degrading enzymes. Agudelo-Valencia et al. (2020) pointed out that information regarding the biotechnological importance of Ganoderma species (other than G. lucidium) is quite limited. Therefore, in their study they obtained and studied the genome of G. australe, resulting in gene prediction for the 84-megabase genome, prediction of 22,756 protein-coding genes, prediction of five putative genes and two enzyme complexes from a ganoderic acid pathway.

Most Ganoderma species are pathogenic or facultatively pathogenic, causing root and stem rot on a variety of monocotyledons, dicotyledons, and gymnosperms, including a wide range of economically important trees and perennial crops, which may result in death (Hapuarachchi et al. 2018a). Some species are saprobic and cause white-rot 


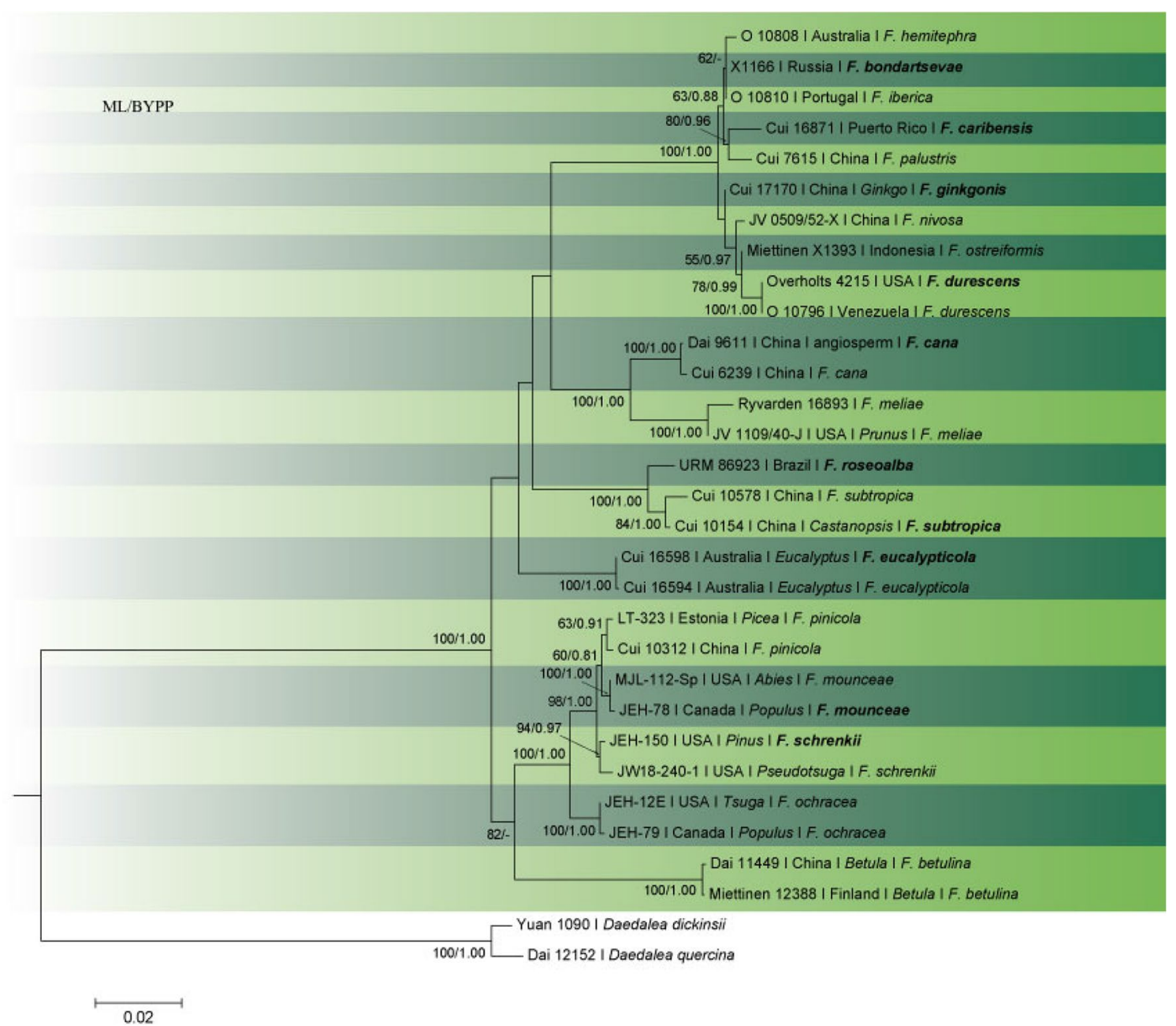

Fig. 14 Phylogram generated from RAxML analysis based on combined ITS, LSU, nSSU, tef1 and rpb2 sequence data of Fomitopsis species. Related sequences were obtained from GenBank. Thirty-one strains are included in the analyses, which comprised 4143 characters

decay of wood (Muthelo 2009). Hence, they have ecological importance in the breakdown of woody plants for nutrient mobilization. They possess effective machinery of lignocellulose-decomposing enzymes useful for bioenergy production and bioremediation (Hepting 1971; Adaskaveg et al. 1991; Kües et al. 2015).

Classification-Basidiomycota, Agaricomycotina, Agaricomycetes, Incertae sedis, Polyporales, Ganodermataceae

Type species-Ganoderma lucidum (Curtis) P. Karst. 1881 Distribution-worldwide

Disease symptoms-basal stem, butt and root rot in economically important trees and perennial crops, especially in tropical regions. Ganoderma disease development is affected by environmental factors and tree death could be either slow or rapid depending on water availability and temperature (Coetzee et al. 2015). including gaps. The tree was rooted with Daedalea quercina (Dai 12152) and D. dickinsii (Yuan 1090). Tree topology of the ML analysis was similar to the Bayesian analysis. ML bootstrap values > $50 \%$ and BYPP > 0.80 are shown respectively near the nodes

Basal stem rot: Symptoms of basal stem rot disease can take several years to develop, and the presence of the pathogen is often only visible when the fungus is well-established and more than half of the tissue has been decayed. Soils with poor drainage and water stagnation during rainy seasons favour the disease (Kandan et al. 2010).

Butt rot and root rot: The primary symptoms include wilting, mild to severe, of either all leaves or just the lowest leaves in the canopy, premature death of the oldest leaves or a general decline of the tree. The advanced decay of the larger roots is evident after leaves are blown down. Decay may extend from several $\mathrm{cms}$ to over a metre into the lower (butt) portion of the tree, depending on the species of Ganoderma. It is quite common for basidiomes not to appear before the severe decline and death of a tree (Glen et al. 2009). Therefore, the only way to determine if Ganoderma butt rot is the cause is to cut cross-sections through the lower 
Table 9 DNA barcodes for accepted species of Fomitopsis

\begin{tabular}{|c|c|c|c|c|c|c|}
\hline Species & Strain & ITS & LSU & $\mathrm{nSSU}$ & tefl & $r p b 2$ \\
\hline Fomitopsis betulina & Dai 11449 & KR605798 & KR605737 & KR605895 & KR610726 & KR610816 \\
\hline F. betulina & Miettinen 12388 & JX109856 & JX109856 & - & JX109913 & JX109884 \\
\hline F. bondartsevae & X1166* & JQ700276 & JQ700276 & - & - & - \\
\hline F. cana & Dai 9611* & JX435776 & JX435774 & KR605825 & KR610660 & KR610762 \\
\hline F. cana & Cui 6239 & JX435777 & JX435775 & KR605826 & KR610661 & KR610761 \\
\hline F. caribensis & Cui 16871* & MK852559 & MK860108 & MK860124 & MK900482 & MK900474 \\
\hline F. durescens & Overholts 4215* & KF937293 & KF937295 & KR605835 & - & - \\
\hline F. durescens & O 10796 & KF937292 & KF937294 & KR605834 & KR610669 & KR610766 \\
\hline F. eucalypticola & Cui 16598* & MK852562 & MK860113 & MK860129 & MK900484 & MK900479 \\
\hline F. eucalypticola & Cui 16594 & MK852560 & MK860110 & MK860126 & MK900483 & MK900476 \\
\hline F. ginkgonis & Cui 17170* & MK852563 & MK860114 & MK860130 & MK900485 & MK900480 \\
\hline F. ginkgonis & Cui 17171 & MK852564 & MK860115 & MK860131 & MK900486 & MK900481 \\
\hline F. hemitephra & O 10808 & KR605770 & KR605709 & KR605841 & KR610675 & - \\
\hline F. iberica & O 10810 & KR605771 & KR605710 & KR605842 & KR610676 & KR610771 \\
\hline F. meliae & Ryvarden 16893 & KR605776 & KR605715 & KR605849 & KR610681 & KR610775 \\
\hline F. meliae & JV 1109/40-J & KY264030 & - & - & - & - \\
\hline F. mounceae & JEH-78* & KF169629 & - & - & KF178354 & KF169698 \\
\hline F. mounceae & MJL-112-Sp & KF169636 & - & - & KF178361 & KF169705 \\
\hline F. nivosa & JV 0509/52-X & KR605779 & KR605718 & - & KR610686 & KR610777 \\
\hline F. ochracea & JEH-12E & KF169597 & - & - & KF178322 & KF169666 \\
\hline F. ochracea & JEH-79 & KF169604 & - & - & KF178329 & KF169673 \\
\hline F. ostreiformis & Miettinen X1393 & KC595918 & KC595918 & - & - & - \\
\hline F. palustris & Cui 7615 & KR605780 & KR605719 & - & KR610688 & KR610779 \\
\hline F. pinicola & Cui 10312 & KR605781 & KR605720 & KR605856 & KR610689 & KR610780 \\
\hline F. pinicola & LT-323 & KF169651 & - & - & KF178376 & KF169720 \\
\hline F. roseoalba & URM 86923* & KT189139 & KT189141 & - & - & - \\
\hline F. schrenkii & JEH-150* & KU169365 & - & - & MK236356 & MK208858 \\
\hline F. schrenkii & JW18-240-1 & KF169648 & - & - & KF178373 & KF169717 \\
\hline F. subtropica & Cui 10154* & JQ067652 & JX435772 & - & - & - \\
\hline F. subtropica & Cui 10578 & KR605787 & KR605726 & KR605867 & KR610698 & KR610791 \\
\hline
\end{tabular}

Ex-type/ex-epitype/ex-neotype/ex-lectotype strains are in bold and marked with an asterisk (*). Voucher strains are also in bold meter or so of the trunk after the tree is felled and examine the cross-sections for the typical pattern of rot: greatest near the soil line, decreasing in sections further from the soil line.

Ganoderma root rot may cause yellowing, wilting, or undersized leaves and dead branches. Tree vigour may decline as the decay of the sapwood advances. The first visible sign of infection is often the formation of basidiomes (solitary or in clusters) on the lower trunk and exposed root areas. There are two types: varnished and unvarnished. The upper surface of varnished fungus rot is typically red-brown with a white edge, shiny, and lacquered. Conks of the unvarnished fungus rot are brown with a white edge weathering to grey (Pilotti et al. 2004). When fresh, both have a white, porous surface on the underside. The rate of decay can lead to death in as little as 3 to 5 years from the time of infection and appears to be determined by tree vigour, which is often influenced by environmental stresses (Nirwan et al. 2016).
Hosts - Ganoderma has a wide host range, with more than 44 species from 34 potential host genera identified (Venkatarayan 1936). The root and stem rots caused by Ganoderma species, result in decreased forestry yields of e.g. Areca catechu (Palanna et al. 2020), Camellia sinensis, Cocos nucifera, (Kinge and Mih 2014), Elaeis guineensis, (Glen et al. 2009) and Hevea brasiliensis (Monkai et al. 2017) worldwide.

\section{Pathogen biology, disease cycle and epidemiology}

The fungus is spread by spores produced in the prominent basidiomes that form on the outside of the tree (conks). New spores released from the conks are dispersed throughout the summer during humid periods and infect open wounds on root flares and lower trunk areas of susceptible trees. The spores germinate, and the infection progresses to attack the sapwood of major roots and the lower tree trunk. Over the years, the number of decayed wood increases leading to 

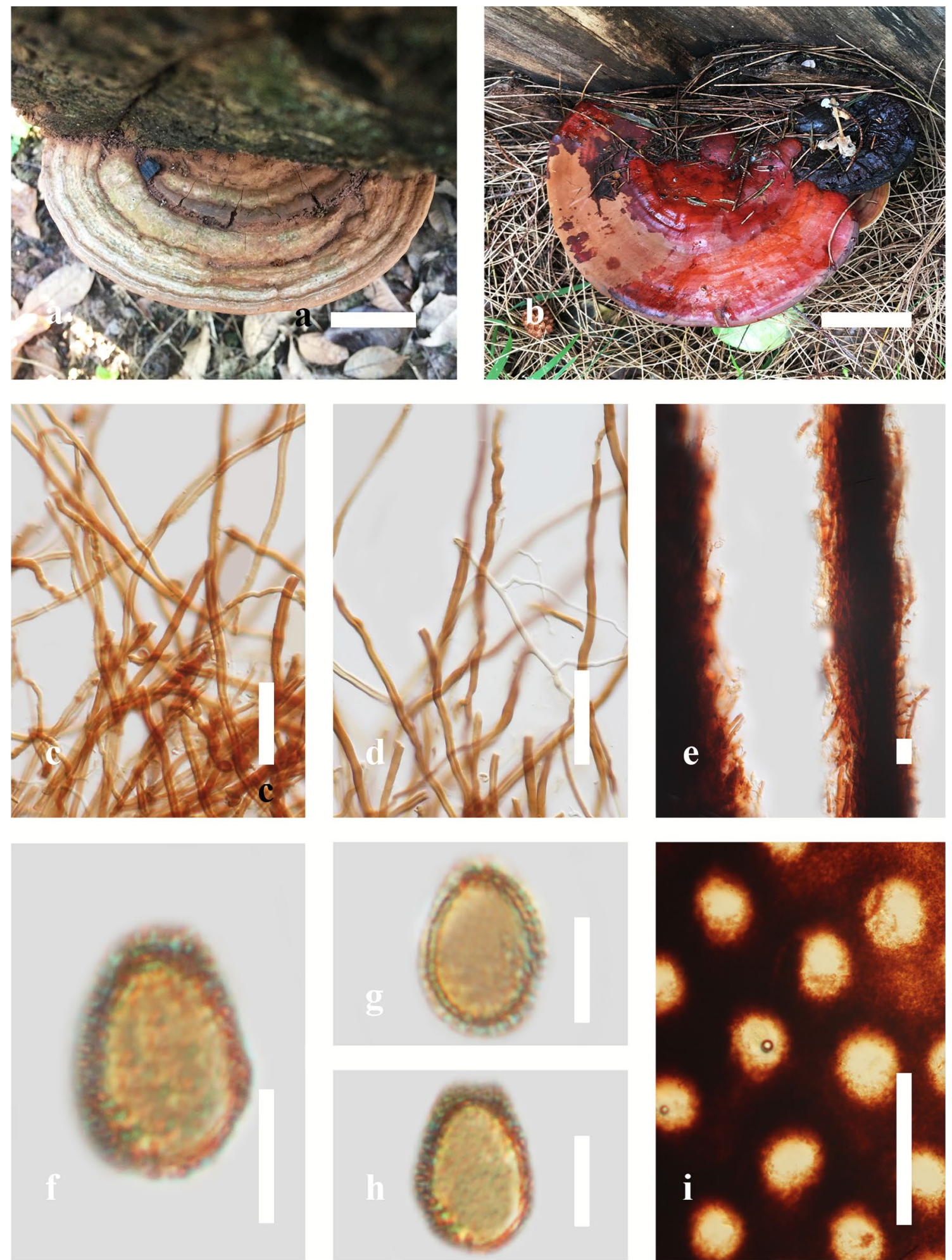

Fig. 15 Morphology of Ganoderma species. a An old basidiome of Ganoderma australe, b Mature basidiome of G. casuarinicola, c, d hyphae, e tube layer hyphae, $\mathbf{f}-\mathbf{h}$ Basidiospores, i Pore characteristics. Scale bars: $\mathrm{a}, \mathrm{b}=2 \mathrm{~cm} ; \mathrm{c}, \mathrm{d}=3 \mu \mathrm{m} ; \mathrm{e}=15 \mu \mathrm{m} ; \mathrm{f}, \mathrm{g}, \mathrm{h} .=5 \mu \mathrm{m} ; \mathrm{i}=500 \mu \mathrm{m}$ 
dangerously soft, spongy wood in the part of the tree that functions as its anchor (Paterson 2007).

\section{Morphology-based identification and diversity}

Ganoderma species identification, limitations and their taxonomic segregation have been unclear and recently being debated (Moncalvo et al. 1995; Wang et al. 2009; Cao et al. 2012; Yao et al. 2013; Richter et al. 2015; Zhou et al. 2015a, b). Many Ganoderma collections and species have been misnamed because of the presence of heterogenic forms, taxonomic obstacles and inconsistencies in the way the genus has been subdivided (Mueller et al. 2007). Ganoderma species are genetically heterogeneous, hence a wide range of genetic variation has been reported and caused by outcrossing over generations and different geographical origins (Pilotti et al. 2004). This has led to variation in their listed morphological characteristics, even within the same species (Hong et al. 2001). Environmental factors, variability, inter hybridization and individual morphological bias, mean identification of Ganoderma species is difficult (Zheng et al. 2007a). Hence, naming a species is confused and traditional taxonomic methods based on morphology are inconclusive for establishing a stable classification system for Ganoderma species (Hseu et al. 1996; Hong et al. 2001) which in turn result in an uncertain nomenclature. This confusing situation is mainly the result of various criteria used in identification by different authors. Some authors strictly only focus on hostspecificity, geographical distribution and macro morphology of basidiomes, while other authors only focus on spore characteristics as the primarily taxonomic characteristics (Sun et al. 2006; Ekandjo and Chimwamurombe 2012). Richter et al. (2015) suggested using a combination of morphological, chemotaxonomic and molecular methods to develop a more stable taxonomy for this genus.

\section{Molecular identification and diversity}

Isoenzyme analysis was the first molecular technique used to separate Ganoderma species (Park et al. 1994; Gottlieb et al. 1995, 1998; Gottlieb and Wright 1999a, b; Smith and Sivasithamparam 2000). Then, DNA sequences of the internal transcribed spacer (ITS), partial large subunit rDNA (Moncalvo et al. 1995, 2000; Cao et al. 2012; Yao et al. 2013; Richter et al. 2015) and nearly complete small subunit rDNA sequences (Hong and Jung 2004; Douanla-Meli and Langer 2009) were used. Later, multigene phylogenetic analyses with protein-coding genes such as $\beta$-tubulin (tub2), the largest subunit of RNA polymerase II gene ( $r p b 1)$, the secondlargest subunit of RNA polymerase II ( $r p b 2)$, and translation elongation factor 1- $\alpha$ (tef1) were performed to resolve the taxonomic confusions within Ganoderma (Park et al. 2012; Zhou et al. 2015a, b; Hennicke et al. 2016; Jargalmaa et al. 2017). However, many problems remain in the resolution of phylogenetic relationships within the genus. As a result of the intricate taxonomy of Ganoderma, 65\% of the Ganoderma sequences available in GenBank were reported to be wrongly identified or ambiguously labelled, (Jargalmaa et al. 2017). In this study, we reconstruct the phylogenetic tree based on ITS, tef 1 and $r p b 2$ sequence data (Table 10, Fig. 16).

Recommended genetic marker (genus level)_ITS Recommended genetic markers (species level)—rpb2, tef 1 Accepted number of species-There are 456 species and infra-species epithets in Index Fungorum (2020), for 224 accepted species. However, only $\mathbf{6 4}$ species have DNA sequence data.

References-Coetzee et al. (2015); Xing et al. (2016, 2018); Tchoumi et al. (2019), Luangharn et al. (2019), Ye et al. (2019) (phylogeny, new species), Cabarroi-Hernández et al. (2019) (phylogeny).

85. Golovinomyces (U. Braun) V.P. Heluta, Biol. Zh. Armenii 41: 357 (1988)

\section{Background}

Braun (1978) introduced Golovinomyces as a section of Erysiphe sensu lato and Heluta (1988a) raised it to genus rank. Braun (1999) and Braun and Takamatsu (2000) accepted Golovinomyces as a distinct genus and established a new tribe, Golovinomyceteae. This is a strictly herb-parasitic genus in the Erysiphaceae. Host-parasite co-speciation was reported between Golovinomyces and Asteraceae hosts using molecular phylogenetic analyses (Matsuda and Takamatsu 2003). It was suggested that Golovinomyces first acquired parasitism on Asteraceae and then diverged to the host tribes Astereae, Cardueae, Heliantheae and Lactuceae. Bremer (1994) pointed out that Golovinomyces may have originated in South America and the geographic distribution expanded into the Northern Hemisphere. However, Takamatsu et al. (2006) suggest that Golovinomyces originated in the Northern Hemisphere, and not in South America. Fabro et al. (2008) profiled genome-wide expression on haustorium formation of G. cichoracearum in Arabidopsis. Research to understand pathogenesis towards plants has been undertaken. A draft whole genome of G. magnicellulatus, the causal agent of phlox powdery mildew was provided by Farinas et al. (2019). McKernan et al. (2020) identified 82 genes associated with resistance to $G$. chicoracearum, the causal agent of powdery mildew in cannabis.

Classification-Ascomycota, Pezizomycotina, Leotiomycetes, Leotiomycetidae, Erysiphales, Erysiphaceae

Type species-Golovinomyces cichoracearum (DC.) V.P. Heluta

Distribution-Worldwide (Mainly in northern hemisphere) Disease symptoms—powdery mildew 
Hosts-Has a wide range of hosts including Asteraceae, Boraginaceae, Cucurbitaceae, Malvaceae, Fabaceae, Lamiaceae, Polygonaceae, Scrophulariaceae, Solanaceae and Verbenaceae.

\section{Pathogen biology, disease cycle and epidemiology}

Discussed under Erysiphaceae.

\section{Morphological based identification and diversity}

Golovinomyces is characterized by chasmothecia with mycelioid appendages, several, mostly 2 -spored asci, an asexual morph with catenescent conidia that lack fibrosin bodies, and mostly nipple-shaped appressoria (Braun 1978; Qiu et al. 2020a). Heluta (1988a) reallocated Erysiphae cichoracearum to Golovinomyces and now nearly all species of E. cichoracearum are assigned to Golovinomyces. Braun (1987) confined E. cichoracearum to powdery mildews on hosts of Asteraceae and assigned specimens on hosts belonging to other plant families to Erysiphe orontii. Braun and Cook (2012) split G. cichoracearum into several species based on molecular analyses of this complex which suggested a co-evolutionary relationship between Golovinomyces species and tribes of Asteraceae (Matsuda and Takamatsu 2003). Golovinomyces cynoglossi sensu lato, a complex of morphologically similar powdery mildews on the plant family Boraginaceae, was reassessed by Braun et al. (2018) and split into G. asperifoliorum, G. asperifolii and G. cynoglossi based on sequence analyses, biological aspects and morphological differences. Braun et al. (2019) revisited $G$. orontii and Qiu et al. (2020b) epitypfied and confirmed Erysiphe cucurbitacearum was a synonym of G. tabaci.

\section{Molecular based identification and diversity}

A comprehensive phylogenetic analysis by Takamatsu et al. (2013) resulted in a polyphyletic complex that split into three genetically distinct clades. Golovinomyces ambrosiae and $G$. spadiceus were considered as separate species by Braun and Cook (2012). However, phylogenetic analyses of ITS and 28S rDNA sequences by Takamatsu et al. (2013), including Golovinomyces species on Asteraceae, found that these two species that occur on Asian species of Eupatorium and a multitude of other hosts, including those on other plant families, formed a single large, unresolved clade (lineage III in Takamatsu et al. (2013)). The taxonomic interpretation posed a serious problem as $G$. ambrosiae and $G$. spadiceus were treated as two morphologically differentiated species. Hence, the resolution based only on ITS sequence data was considered insufficient to distinguish closely allied species. Most subsequent authors followed the taxonomic treatments in Braun and Cook (2012) and recognized G. ambrosiae and $G$. spadiceus as separate species, within lineage III, based on morphological differences (Qiu et al. 2020a). However, there is minimal multi loci data for the powdery mildews currently available. Most of the research involves the intra-specific genetic diversity in species such as Blumeria graminis (Walker et al. 2011), Erysiphe necator (de Oliveira et al. 2015), Golovinomyces orontii (Pirondi et al. 2015a) and Podosphaera xanthii (Pirondi et al. 2015b). Based on ITS and D1/D2 domain of 28S sequence data, Braun et al. (2019) introduced G. bolayi and G. vincae. Nayak and Bandamaravuri (2019) developed species-specific PCR primers $\mathrm{CgF} 2$ and $\mathrm{CgR} 2$ for $G$. orontii (the causal agent of powdery mildew in cucurbits), based on partial ITS and 5.8S rDNA, which resulted in a $233 \mathrm{bp}$ fragment of $G$. orontii.

Recommended genetic markers (genus level)_ITS, LSU Recommended genetic markers (species level)-Comprehensive applications of multi loci approaches to solve complex taxonomic-phylogenetic problems connected with the species level classification of the powdery mildews are lacking. The phylogenetic analyses of multi loci sequence data, including ITS and LSU, IGS, $t u b 2, c h s$, and consideration of morphological characters resolve species delimitation in a heterogeneous complex within Golovinomyces.

Accepted number of species-There are 81 epithets listed in Index Fungorum (2020), however, only 41 have molecular data (Table 11, Fig. 17).

References-Braun (1978, 1987), Heluta (1988a, b) (morphology); Braun and Cook (2012), Takamatsu et al. (2013), Braun et al. (2019), Qiu et al. (2020a, b) (morphology and phylogeny).

86. Heterobasidion Bref., Unters. Gesammtgeb.Mykol. (Liepzig) 8: 154 (1888)

\section{Background}

Heterobasidion was introduced by Brefeld (1888) and is typified by $H$. annosum (三 Polyporus annosus). Certain Heterobasidion species are important forest pathogens of the Northern Hemisphere, causing root and butt rot, mainly in conifers (Woodward et al. 1998). In coniferous plantations, Heterobasidion is one of the most widespread of wood decay agents, especially when the host is under intensive management. Heterobasidion greatly reduces site productivity and the amount of harvestable timber; estimated financial losses caused by Heterobasidion species in Europe were around 800 million euro per year (Korhonen et al. 1998; Garbelotto 2004; Asiegbu et al. 2005). On the other hand, these taxa have a relatively moderate pathogenic role in natural forest ecosystems. They affect stand species composition, density and structure, and they contribute to forest succession, nutrient recycling and even regeneration (Goheen and Otrosina 1998; Garbelotto 2004; Dai et al. 2006). 
Table 10 DNA barcodes available for Ganoderma

\begin{tabular}{|c|c|c|c|c|}
\hline Species & Voucher no & ITS & $r p b 2$ & tefl \\
\hline Ganoderma adspersum & GACP15061220 & MK345425 & MK371437 & MK371431 \\
\hline G. angustisporum & Cui 13817* & MG279170 & MG367507 & MG367563 \\
\hline G. applanatum & FIN131R610 & EF060004 & - & - \\
\hline G. aridicola & Dai 12588* & KU572491 & - & KU572502 \\
\hline G. australe & GACP14081671 & MH106871 & - & - \\
\hline G. australe & MFLU 13-0534 & KP142173 & - & MN423152 \\
\hline G. austroafricanum & CBS138724 & KM507324 & - & - \\
\hline G. boninense & WD 2028 & KJ143905 & KJ143964 & KJ143924 \\
\hline G. carocalcareus & DMC 322* & EU089969 & - & - \\
\hline G. casuarinicola & Dai 16336* & MG279173 & MG367508 & MG367565 \\
\hline G. casuarinicola & HKAS104639 & MK817650 & MK840868 & MK871328 \\
\hline G. chocoense & QCAM3123 & MH890527 & - & - \\
\hline G. curtisii & CBS 100132 & JQ781849 & KJ143967 & KJ143927 \\
\hline G. destructans & CMW43670* & KR183856 & - & - \\
\hline G. ecuadoriense & ASL799 & KU128524 & - & - \\
\hline G. eickeri & CMW49692* & MH571690 & - & MH567287 \\
\hline G. ellipsoideum & GACP14080966* & MH106867 & - & - \\
\hline G. enigmaticum & CBS 139792* & KR183855 & - & - \\
\hline G. enigmaticum & Dai 15970 & KU572486 & MG367513 & KU572496 \\
\hline G. flexipes & Wei 5494 & JN383979 & - & - \\
\hline G. gibbosum & SFC20150630-23 & KY364264 & - & - \\
\hline G. hoehnelianum & Dai11995 & KU219988 & MG367497 & MG367550 \\
\hline G. knysnamense & CMW47755* & MH571690 & - & MH567287 \\
\hline G. leucocontextum & GDGM 40200* & KF011548 & - & - \\
\hline G. lingzhi & Wu 1006-38* & JQ781858 & JX029980 & JX029976 \\
\hline G. lobatum & JV1212/10J & KF605676 & - & KU572501 \\
\hline G. lucidum & Rivoire 4195 & KJ143909 & KJ143969 & - \\
\hline G. lucidum & Cui 14404 & MG279181 & MG367519 & MG367573 \\
\hline G. martinicense & LIP SWMart08-55* & KF963256 & - & - \\
\hline G. mbrekobenum & UMN7-3GHA* & KX000896 & - & - \\
\hline G. mizoramense & UMN-MZ4* & KY643750 & - & - \\
\hline G. multiplicatum & Dai 13122 & KU572488 & - & KU572498 \\
\hline G. multipileum & CWN 04670 & KJ143913 & KJ143972 & KJ143931 \\
\hline G. mutabile & Yuan 2289* & JN383977 & - & - \\
\hline G. nasalanense & GACP17060211* & MK345441 & - & - \\
\hline G. nеојаропісит & ASI 7032 & JQ520193 & - & - \\
\hline G. orbiforme & Cui 13918 & MG279186 & MG367522 & MG367576 \\
\hline G. orbiforme & GACP14061420 & MK345447 & - & - \\
\hline G. oregonense & CBS 265.88 & JQ781875 & KJ143974 & KJ143933 \\
\hline G. philippii & E7098 & AJ536662 & - & - \\
\hline G. podocarpense & QCAM6422* & MF796661 & - & - \\
\hline G. resinaceum & CBS 194.76 & KJ143916 & - & KJ143934 \\
\hline G. ryvardenii & HKAS 58053* & HM138671 & - & - \\
\hline G. ryvardenii & HKAS 58054 & HM138672 & - & - \\
\hline G. sandunense & GACP18012501* & MK345450 & - & - \\
\hline G. sandunense & GACP18012502 & MK345451 & - & - \\
\hline G. sessile & JV 1209/9 & KF605629 & - & KJ143936 \\
\hline G. shandongense & Dai 15785 & MG279190 & MG367526 & MG367580 \\
\hline G. sichuanense & HMAS 42798* & JQ781877 & - & - \\
\hline G. sinense & Wei 5327 & KF494998 & MG367529 & KF494976 \\
\hline G. steyaertanum & MEL:2382783 & КР012964 & - & - \\
\hline
\end{tabular}


Table 10 (continued)

\begin{tabular}{lllll}
\hline Species & Voucher no & ITS & rpb2 & tef1 \\
\hline G. steyaertanum & 6 WN 20B & KJ654462 & - & - \\
G. subresinosum & 7-SU-3-C-70(M)-B & KJ654472 & - & - \\
G. thailandicum & HKAS104640* & MK848681 & MK875831 & MK875829 \\
G. tropicum & Dai 16434 & MG279194 & MG367532 & MG367585 \\
G. tropicum & HKAS 97486 & MH823539 & MH883621 & - \\
G. tsugae & Dai12751b & KJ143919 & KJ143977 & KJ143939 \\
G. valesiacum & CBS428.84 & JQ520218 & - & - \\
G. weberianum & CBS219.36 & JQ520219 & - & - \\
G. wiiroense & UMN-20-GHA & KT952361 & - & - \\
G. williamsianum & Dai 16809 & MG279183 & MG367535 & MG367588 \\
G. wuzhishanensis & GACP14081689 & KU994772 & - & - \\
G. zonatum & FL-02 & KJ143921 & KJ143979 & KJ143941 \\
\hline
\end{tabular}

Ex-type/ex-epitype/ex-neotype/ex-lectotype strains are in bold and marked with an asterisk (*). Voucher strains are also in bold

Classification-Basidiomycota, Agaricomycotina, Agaricomycetes, Incertaesedis, Russulales, Bondarzewiaceae

Type species-Heterobasidion annosum (Fr.) Bref., Unters. Gesammtgeb. Mykol. (Liepzig) 8: 154 (1888)

Distribution-North America, Europe, Asia, Australia and Oceania

Disease symptoms-There are two Heterobasidion species complexes $-H$. insulare sensu lato and $H$. annosum sensu lato-they cause the same symptoms. The $H$. annosum species complex is one of the major root-rot pathogenic genera of the northern temperate hemisphere (Garbelotto and Gonthier 2013; Kärhä et al. 2018). After the primary infection through stump tops, or stem and root wounds, the taxa can vegetatively infect uninjured trees (secondary infection) by the growth of the mycelium through root contacts (Rishbeth 1950, 1951a, b; Asiegbu et al. 2005; Garbelotto and Gonthier 2013). Heterobasidion could be considered both necrotrophs and saprotrophs; though some species in the $H$. insulare species complex (e.g. H. austral, H. araucariae) are mainly saprotrophs (Niemelä and Korhonen 1998; Dai and Korhonen 2009; Chen et al. 2014). In contrast to Europe, the pathogenicity of $H$. annosum sensu lato in China and Japan is uncertain; the complex seems to occur mostly on dead trees, and no symptoms of tree decline are usually visible near infected trees. These observations could be due to different, less intensive forest management strategies in the East-Asian regions, or lack of data on the butt rot symptoms (Dai et al. 2006; Tokuda et al. 2007).

The infection causes white pocket rot and heart rot in the roots and the butt of living trees (Korhonen and Stenlid 1998; Asiegbu et al. 2005). Resin, containing mycelium, may also exude from the infected roots, or the bark-scales (Rishbeth 1950). In invaded roots and the basal portions of the trunk, $H$. annosum sensu lato taxa colonize different plant tissues depending on the host. Heart rot is mainly caused in trees more susceptible to the colonization of the heartwood, e.g. Picea abies. In the case of Pinus, cambium and sapwood are the most severely colonized, while the sapwood of Calocedrus or Sequoiadendron trees is the most colonized (Garbelotto 2004; Asiegbu et al. 2005; Garbelotto and Gonthier 2013).

After establishment, the basidiomata of $H$. annosum sensu lato appear. The localization of the sporocarps is governed by the species, environmental conditions and infection strategy. Some species prefer the root collar for fruiting ( $H$. annosum, $H$. irregular). Some also produce sporocarps in decay pockets in stumps and fallen trees $(H$. parviporum, $H$. abietinum and $H$. occidentale), or under the intact surface of stumps $(H$. irregulare, $H$. occidentale). The sporocarps are sometimes located on the higher parts of the trunk. When moisture is limited, the fungi fruit inside stumps; if the climate is moist and humid, the basidiomata can be found near the ground in the duff at the base of diseased trees. If during primary infection the stump surface is infected, the basidiomata form under an intact top layer. During active pathogenesis, if the standing trees are infected the sporocarps could be found within decay columns in the sapwood (Rishbeth 1950; Otrosina and Garbelotto 2010).

The infection kills the functioning sapwood, cambium and heart wood in the roots and at the basal portions of the trunk, resulting in white rot, reduced growth rate, crown dieback (Omdal et al. 2004), and eventually mortality and windthrow of infected trees (Rishbeth 1950; Oliva et al. 2008; Garbelotto and Gonthier 2013).

Hosts - The host range of Heterobasidion is extremely wide. The genus has been reported from approximately 200 host species (Korhonen and Stenlid 1998). Taxa mostly occur on gymnosperms, such as Abies, Agathis, Araucaria, Calocedrus, Juniperus, Keteleeria, Larix, Picea, Pinus, 


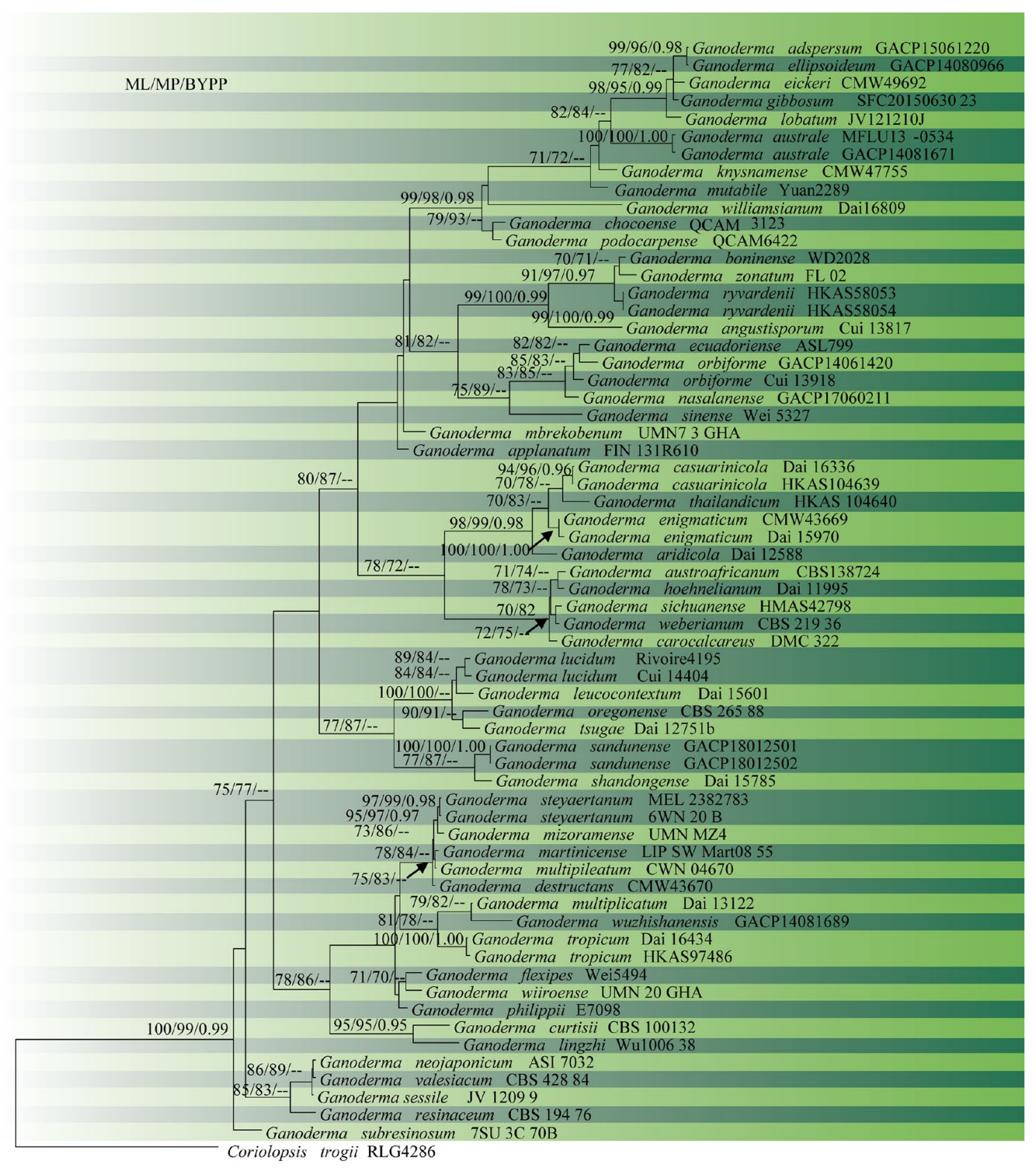

0.60

Fig. 16 Phylogram of 64 recognized Ganoderma species, obtained from ML of combined ITS, $r p b 2$, and tef 1 datasets. Bootstrap values from ML (left) and MP (middle) greater than 70\% and BYPP, greater

Podocarpus, Pseudolarix, Pseudotsuga, Sequoia, Sequoiadendron, Thuja and Tsuga (Buchanan 1988; Corner 1989; Dai and Korhonen 2009; Otrosina and Garbelotto 2010; Garbelotto and Gonthier 2013; Garbelotto et al. 2017). Occasionally, certain Heterobasidion species grow on broadleaved trees of various angiosperm genera (Garbelotto and Gonthier 2013; Ryvarden and Melo 2014). than 0.95 , are indicated above the nodes. The tree is rooted with Coriolopsis trogii. Type specimens are indicated in bold

\section{Morphological based identification and diversity}

There are 33 Heterobasidion epithets listed in Index Fungorum (2020). Of these, eight are related to other polypore genera, based on type studies and morphological observations (Ryvarden 1972, 1985; Buchanan and Ryvarden 1988; Dai and Niemelä1995; Hattori 2003). Besides, the taxonomic status of three further species described from Asia is 
unclear: viz. $H$. arbitrarium, $H$. perplexum and $H$. insulare (Corner 1989; Ryvarden 1989; Stalpers 1996; Hattori 2001; Dai et al. 2002; Tokuda et al. 2009). Given that no sequence data (H. arbitrarium, $H$. perplexum) or authentic sequences (H. insulare sensu stricto) are available for the molecular resolution, further studies are needed to clarify their status.

Formerly, Heterobasidion was considered as a group consisting of only the generic type, $H$. annosum and $H$. araucariae and H. insulare (Buchanan 1988; Chase 1989). However, mating studies on Eurasian and North American Heterobasidion collections revealed several intersterile groups, which later became the basis for designating separate taxonomic species within the $H$. annosum and $H$. insulare species complexes. Mating experiments revealed three intersterile groups of $H$. annosum sensu lato in Europe (Korhonen 1978b, Capretti et al. 1990) and two in North America (Otrosina et al. 1993). All intersterile groups have been recognised in the $H$. annosum species complex are now formally described as separate taxonomic species. European groups were described as H. abietinum, $H$. parviporum and H. annosum sensu stricto (Niemelä and Korhonen 1998), whereas North American groups were named $H$. irregulare and $H$. occidentale (Otrosina and Garbelotto 2010).

The mating study by Dai et al. (2002) on Asian " $H$. insulare" collections revealed three intersterile groups in China, which were subsequently described as Heterobasidion linzhiense (Dai et al. 2007), H. orientale and H. ecrustosum (Tokuda et al. 2009). H. australe related to the $H$. insulare species complex was also described from China by Dai and Korhonen (2009). Chen et al. (2014) described two further Heterobasidion species ( $H$. amyloideum and H. tibeticum) from the eastern Himalayas based on phylogenetic evidence. These species are morphologically closely related to the members of the $H$. insulare species complex, but differ in presence of cystidia and amyloid skeletal hyphae in the context. The recently described $H$. amyloideopsis was collected in the western Himalayas (Pakistan) and formed a monophyletic group with the $H$. insulare species complex, sister to H. amyloideum (Zhao et al. 2017).

The main morphological characters which are used for the identification are the resupinate to pileate basidiocarps, the dimitic hyphal system with mostly simple septate generative hyphae, and the asperulate basidiospores showing no reaction in Melzer's reagent. Besides morphology, host preference, geographical distribution, and DNA sequence data have also been used for species identification (Otrosina and Garbelotto 2010; Chen et al. 2015a).

\section{Molecular based identification and diversity}

Heterobasidion has been intensely studied by molecular methods. Sequence data are available for the majority of taxa, and molecular studies were conducted to understand the evolution (Dalman et al. 2010), mating behaviour (Gonthier and Garbelotto 2011), and pathogenicity (Liu et al. 2018a) of Heterobasidion species.

Various marker types were used to resolve the phylogeny of the H. annosum species complex, such as isoenzyme (Karlsson and Stenlid 1991a, b), AFLP (Gonthier and Garbelotto 2011) and SSR (Garbelotto et al. 2013) markers. Sequence analyses were carried out initially on nrITS and intergenic spacer regions (Kasuga and Mitchelson 1993a, b; DeScenzo and Harrington 1994), housekeeping genes (Johanesson and Stenlid 2003), peroxidase (Maijala et al. 2003) and laccase genes (Asiegbu et al. 2004), with which it was possible to distinguish four lineages (three European and one North American) within the complex (Asiegbu et al. 2005). Later, allowing the differentiation of a larger number of taxa, further nuclear genes were applied, such as the calmodulin ( $\mathrm{cam})$, translation elongation factor 1- $\alpha$ (tefl), glyceraldehydes3-phosphate dehydrogenase ( gapdh), heat shock protein $(h s p)$, glutathione-S-transferase $(g s t)$ and transcription factor ( $t$ ) genes (Johanesson and Stenlid 2003; Ota et al. 2006; Dalman et al. 2010), as well as two mitochondrial genes, the mitochondrial ATP synthase subunit 6 (ATP6) and mitochondrial rDNA region (Linzer et al. 2008). Dalman et al. (2010) came to the conclusion, that there are two monophyletic sister clades within the H. annosum species complex, representing the Eurasian and North American species.

The protein coding largest subunit of RNA polymerase II ( $r p b 1)$ and the second subunit of RNA polymerase II ( $r p b 2)$ genes were used by Chen et al. (2014) and were suitable to differentiate Heterobasidion species in the $H$. insulare species complex. The variability of these markers was confirmed by Chen et al. (2015a) and Zhao et al. (2017) who, among other previously mentioned markers, both used the nuclear large ribosomal subunit (nrLSU) and the mitochondrial small subunit (mtSSU) sequences to their studies (Fig. 18).

In this study, we provide a phylogenetic tree (Fig. 19) based on multi-locus phylogenetic analysis of ITS-gapdh-rpb1-rpb2-tef1 sequence data. Sequences of $H$. arbitrarium and $H$. perplexum could not be analysed as they are unavailable in GenBank. Furthermore, no sequences are available for the type of $H$. insulare hence this species was not included in the analysis. The results provide a similar topology to those obtained by Chen et al. $(2015 \mathrm{a}, \mathrm{b})$ and Zhao et al. (2017).

Recommended genetic marker (genus level)—nLSU Recommended genetic markers (species level)—rpb1, rpb2 Accepted number of species -There are 33 epithets in Index Fungorum (2020), however only 15 species are accepted 
Table 11 DNA barcodes for accepted species of Golovinomyces

\begin{tabular}{|c|c|c|c|}
\hline Species & Strain no & ITS & LSU \\
\hline Golovinomyces adenophorae & MUMH < JPN_144 & LC516963 & AB077632 \\
\hline G. ambrosiae & MUMH345 & AB077642 & AB077641 \\
\hline G. arabidis & HMNWAFU-CF2009256 & KR048081 & KR048149 \\
\hline G. artemisiae & MUMH175 & AB077637 & AB077636 \\
\hline G. asperifolii & KUS-F24884 & MH189697 & MH189696 \\
\hline G. asperifoliorum & MUMH769 & AB077684 & AB077684 \\
\hline G. asterum $^{\#}$ & MUMH941 & AB769417 & AB769418 \\
\hline G. biocellatus ${ }^{\#}$ & MUMH4293 & AB307671 & AB307671 \\
\hline G. bolayi ${ }^{\#}$ & OLM 35939* & LC417106 & - \\
\hline G. calceolariae & MUMH 1934 & AB430810 & AB430810 \\
\hline G. chrysanthemi & MUMH853 & AB077654 & AB077653 \\
\hline G. cichoracearum $^{\#}$ & MUMH623 & AB077660 & AB077660 \\
\hline G. circumfusus $^{\#}$ & GLM49501 & MK452630 & MK452703 \\
\hline G. cucubitarum & HMJAU-PM91761 & MK937796 & MK937801 \\
\hline G. cynoglossi ${ }^{\#}$ & VPRI20429 & AB769455 & - \\
\hline G. depressus & MUMH696 & AB077675 & AB077676 \\
\hline G. echinopis & MUMH1363 & AB769414 & - \\
\hline G. euphorbiicola & MUMH3807 & AB769460 & - \\
\hline G. fischeri & MUMH1345 & $\mathrm{AB} 769451$ & AB769452 \\
\hline G. glandulariae & BRIP 70490* & NR_166303 & MN539541 \\
\hline G. hyoscyami & HMNWAFU-CF2013114 & KR048155 & KR048155 \\
\hline G. inulae & MUMH1334 & AB769428 & - \\
\hline G. leuceriae & MUMH2527 & AB246766 & - \\
\hline G. longipes ${ }^{\#}$ & MUMH2489 & AB769440 & - \\
\hline G. macrocarpus & HAL 3153* & NR_154105 & - \\
\hline G. magnicellulatus ${ }^{\#}$ & MUMH441* & AB077647 & AB077646 \\
\hline G. monardae & MUMH936 & AB307668 & AB077691 \\
\hline G. montagnei & MUMH1082 & AB769413 & - \\
\hline G. neosalviae $\#$ & MUMH4294 & AB307673 & - \\
\hline G. ocimi & MUMH<JPN_:1803 & LC306656 & - \\
\hline G. orontii ${ }^{\#}$ & G:00295968 & LC417099 & - \\
\hline G. riedlianus & HMNWAFU-CF2012033 & KR048088 & KR048157 \\
\hline G. reginae & BCRU4645 & AB246759 & - \\
\hline G. salviae & MUMH935 & AB769437 & AB077690 \\
\hline G. sonchicola ${ }^{\#}$ & MUMH683 & AB077673 & AB077672 \\
\hline G. sordidus s $^{\#}$ & MUMHn41 & AB077658 & AB077657 \\
\hline G. spadiceus ${ }^{\#}$ & MUMH<JPN_:3708 & LC306664 & - \\
\hline G. tabaci & BP-1TOB & AF229013 & AB022412 \\
\hline G. valerianae & HMNWAFU-CF2011034 & KR048090 & KR048159 \\
\hline G. verbasci ${ }^{\#}$ & MUMH958 & AB769468 & AB769469 \\
\hline G. vincae & MUMH2480 & AB769444 & - \\
\hline
\end{tabular}

Ex-type/ex-epitype/ex-neotype/ex-lectotype strains are in bold and marked with an asterisk (*). Voucher strains are also in bold. Species confirmed with pathogenicity studies are marked with ${ }^{\#}$
(Table 12). Amongst these, no sequences are available for $H$. arbitrarum and $H$. insulare. Heterobasidion perplexum is not accepted in the genus, pending further studies.

References-Dai and Korhonen (2009) (new sp., China, morphology); Tokuda et al. (2009) (new species, East Asia); Dalman et al. (2010) (Evolution, H. annosum species complex, haplotype network); Otrosina and Garbelotto (2010) (new species, North America, biology); Garbelotto and Gonthier (2013) (biology, epidemiology, control); Chen et al. (2014) (new species, China, phylogeny); Chen et al. (2015a) (biogeography, divergence time estimation, phylogeny); Zhao et al. (2017) (new sp., Pakistan, phylogeny). 


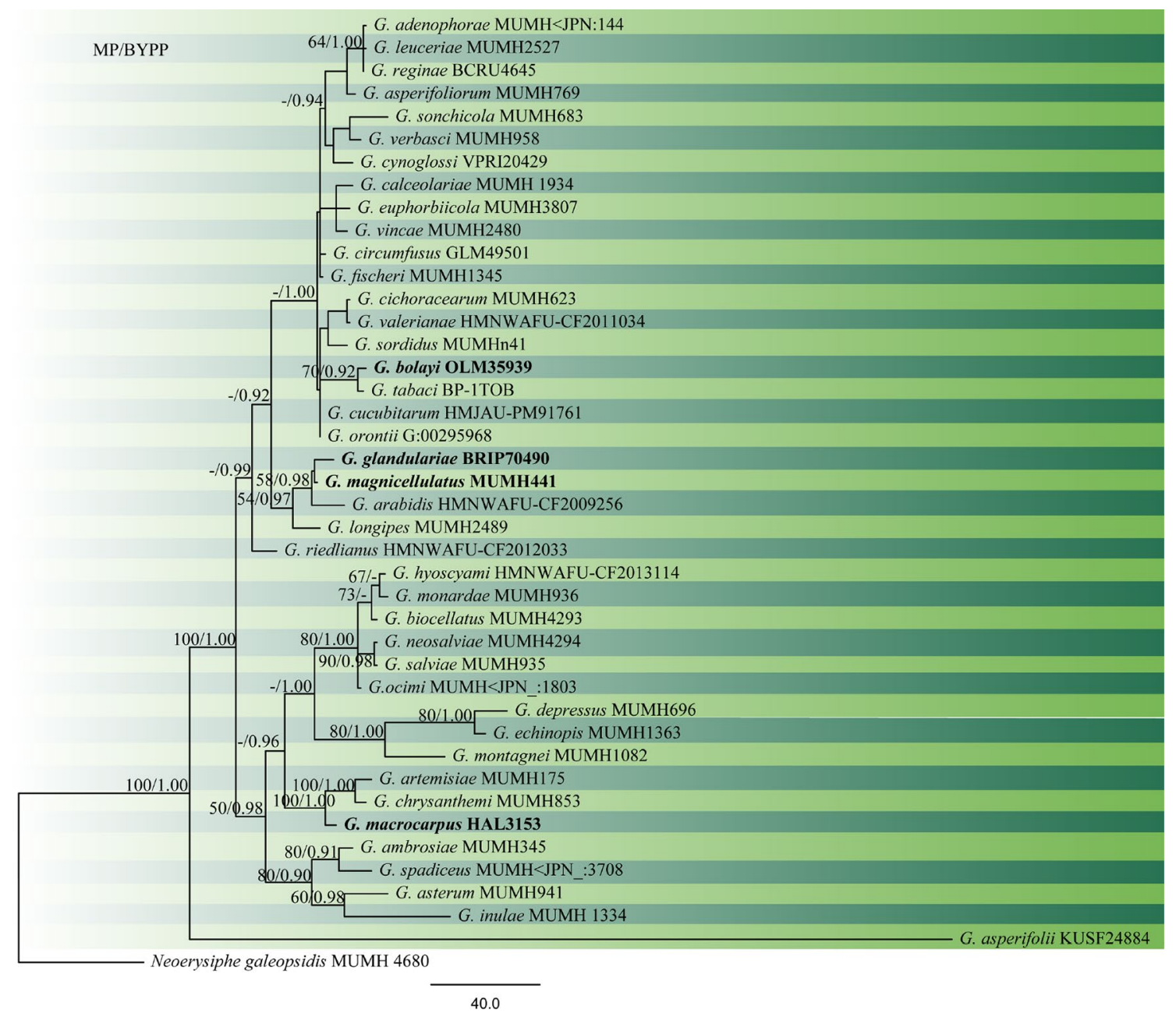

Fig. 17 Phylogram generated from MP analysis based on combined sequences of ITS and LSU sequences of all species of Golovinomyces with molecular data. Related sequences were obtained from GenBank. Fourty-two taxa are included in the analyses, which comprise 1401 characters including gaps, of which 848 characters are constant, 392 characters are parsimony-uninformative and 161 characters parsi-

\section{Meliola Fr., Syst. orb. veg. (Lundae) 1: 111 (1825) Background}

Meliola commonly known as "black mildews" or "dark mildews" is the largest genus of Meliolaceae (Hongsanan et al. 2015; Zeng et al. 2017). Fries (1825) established this genus, with the type species M. nidulans. Species in Meliola are mostly biotrophs or pathogens of living leaves and occasionally petioles, twigs, and branches (Hansford 1961; Hosagoudar 1994, 1996, 2008; Mibey and Hawksworth 1997; Old et al. 2003; Hosagoudar and Riju 2013). The phylogenetic placement of Meliola was established by using sequence data from fruiting bodies and placed in Sordariomycetes (Gregory and John 1999; Pinho et al. 2012, 2014, Hongsanan et al. 2015; Justavino et al. 2015). Meliola has been mony-informative. The parsimony analysis of the data matrix resulted in the maximum of ten equally most parsimonious trees with a length of 927 steps $(\mathrm{CI}=0.740, \mathrm{RI}=0.699, \mathrm{RC}=0.517, \mathrm{HI}=0.260)$ in the second tree. The tree was rooted with Neoerysiphe galeopsidis (MUMH 4680). MP bootstrap support value $\geq 50 \%$ and BYPP $\geq 0.9$ are shown respectively near the nodes. Ex-type strains are in bold

shown to be polyphyletic (Hyde et al. 2020b; Marasinghe et al. 2020; Zeng et al. 2020). There is little sequence data available in GenBank for clarifying relationships between species and establishiing host-specificity (Hongsanan et al. 2015; Zeng et al. 2017).

Classification-Ascomycota, Pezizomycotina, Sordariomycetes, Sordariomycetidae, Meliolales, Meliolaceae

Type species-Meliola nidulans (Schwein.) Cooke

Distribution-commonly found in tropical and subtropical regions (see Zeng et al. 2017)

Disease symptoms -Black mildews, forming black, radiate velvety colonies on the surface of plants.

Hosts - has a wide range of hosts (see Zeng et al. 2017) 
Pathogen biology, disease cycle and epidemiology

For pathogen biology, disease cycle and epidemiology see Hongsanan et al. (2015).

\section{Morphological based identification and diversity}

Species in Meliola are characterized by forming web-like colonies on the host surface, hyphal setae developed from superficial hyphae, with hyphopodia, 2-4-spored, unitunicate asci, and 3-4-septate pigmented ascospores (Pinho et al. 2012, 2014; Hongsanan et al. 2015, 2020; Justavino et al. 2015; Hyde et al. 2020a, b; Fig. 20). Cannon and Kirk (2007) reported that the asexual morph of the genus develops from the hypha, form ampuliform hyphopodia or flaskshaped which are called "phialides" (Hongsanan et al. 2015). Conidiogenous cells formed from vegetative hyphae and small, hyaline, unicellular conidia (Cannon and Kirk 2007; Hongsanan et al. 2015). Currently, Meliola comprises over 1700 species (Zeng et al. 2017), which have mostly been introduced by host association, followed by morphology, and disease distribution (Mibey and Hawksworth 1997). Thus, species identification is almost impossible without a host name. However, the same species can be found in different hosts, but it is not clear if this is widespread (Hongsanan et al. 2015). Therefore, testing of host-specificity in Meliola is needed to establish accurate species determination.

\section{Molecular based identification and diversity}

Sequence data of species in Meliola are from direct sequencing of fruiting bodies and fresh mycelium (Pinho et al. 2012, 2014; Hongsanan et al. 2015; Justavino et al. 2015; Hyde et al. 2016, 2020b). LSU and ITS sequence data placed Meliola in Sordariomycetes (Hongsanan et al. 2015, 2020; Maharachchikumbura et al. 2015, 2016; Hyde et al. 2016, 2020a, b). By adding more sequence data, Meliola was shown to be polyphyletic (Marasinghe et al. 2020; Zeng et al. 2020). A phylogenetic tree for Meliola species is presented in Fig. 21.

Recommended genetic markers (genus level)_LSU, SSU of nrDNA

Recommended genetic marker (species level)-ITS

Accepted number of species-There are 3064 epithets listed in Index Fungorum (2020), however only 25 species have DNA molecular data (Zeng et al. 2017, Table 13).

References - Cannon and Kirk (2007) (morphology); Pinho et al. (2012, 2014), Hongsanan et al. (2015, 2020), Justavino et al. (2015), Zeng et al. (2020) (morphology and phylogeny)

88. Neoerysiphe U. Braun, Schlechtendalia 3: 50 (1999) Background
Neoerysiphe was classified in section Galeopsidis within Erysiphe. Phylogenetic analysis, however, showed Erysiphe to be polyphyletic, and Galeopsidis was raised to generic rank (Takamatsu et al. 1998; Braun 1999; Saenz and Taylor 1999). Therefore, in the current classification Neoerysiphe belongs to the tribe Golovinomyceteae.

Classification-Erysiphaceae, Erysiphales, Leotiomycetidae, Leotiomycetes, Pezizomycotina

Type species-Neoerysiphe galeopsidis (DC.) U. Braun

Distribution-Argentina, Australia, Belarus, Brazil, Bulgaria, Canada, China, Denmark, Finland, France, Germany, Hungary, India, Israel, Italy, Japan, Korea, Netherlands, Norway, Poland, Romania, Russia, Slovakia, Sweden, Switzerland, Turkey, UK, Ukraine and USA (Farr and Rossman 2020).

Disease symptoms-powdery mildew

Hosts-Neoerysiphe species have a wide host distribution infecting more than 300 species from families including Asteraceae, Acanthaceae, Bignoniaceae, Elaeocarpaceae, Lamiaceae, Rubiaceae and Verbenaceae (Amano 1986; Braun 1999; Bahcecioglu et al. 2006). In general, all species have a specific host range confined to one plant family, except $N$. galeopsidis which affects several species in four families (Takamatsu et al. 2008).

\section{Pathogen biology, disease cycle and epidemiology}

Discussed under Erysiphaceae.

\section{Morphological based identification and diversity}

Neoerysiphe is in the tribe Golovinomyceteae with Arthrocladiella and Golovinomyces. These genera share a common asexual morph characterized by catenate conidia without distinct fibrosin bodies (Braun 1999). Neoerysiphe is characterized by lobed appressoria and the striate surface of the conidia (Braun 1981; Cook et al. 1997; Braun and Cook 2012). Braun and Cook (2012) mentioned that 15 species of Neoerysiphe are described on different hosts belonging to 11 plant families. Of these 15 species, 11 sexual morphs and 14 asexual morphs have been identified (except $N$. joerstadii) (Heluta et al. 2010; Braun and Cook 2012). Striatodium is now considered as a synonym of Neoerysiphe and three species viz. N. aloysiae, N. baccharidis and $N$. maquii were transferred to Neoerysiphe, while Striatodium jaborosae was not transferred as its phylogenetic position are unclear (Wijayawardene et al. 2017a).

\section{Molecular based identification and diversity}

The phylogenetic placement of Neoerysiphe within Erysiphaceae has been reported in a few papers (Saenz and 

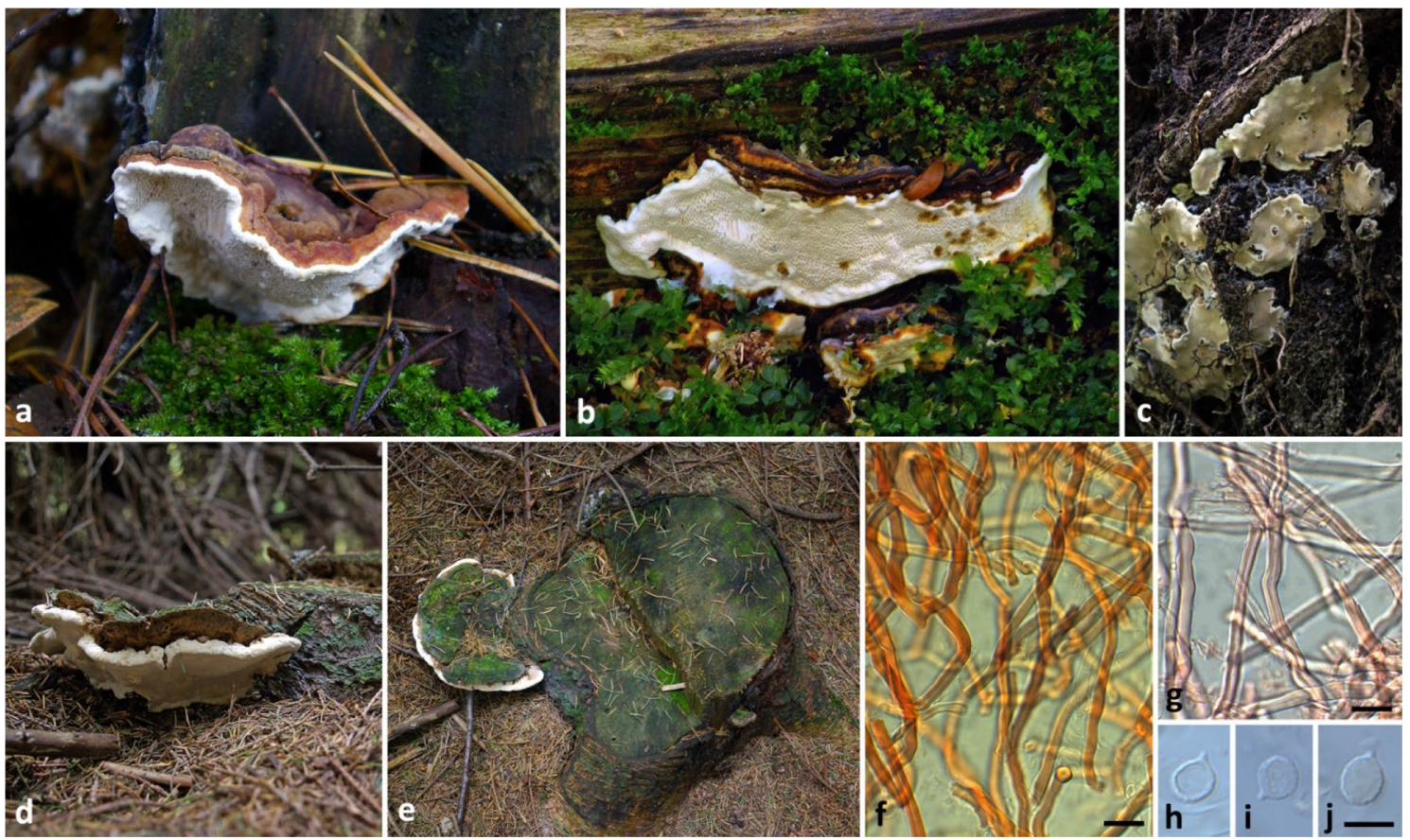

Fig. 18 Members of Heterobasidion annosum species complex. a basidiome on Scots pine, $\mathbf{b}$ basidiome on European silver fir, $\mathbf{c}-\mathbf{e}$ basidiomes on European spruce, $\mathbf{f}$ hyphal structure in the trama, $\mathbf{g}$ hyphal structure in the context, $\mathbf{h}-\mathbf{j}$ basidiospores. Scale bars: $\mathbf{f}, \mathbf{g}=10 \mu \mathrm{m}, \mathbf{h}, \mathbf{j}=5 \mu \mathrm{m}$

Taylor 1999; Mori et al. 2000; Cook et al. 2006). However, these treatments used only limited sequence data for the genus. Takamatsu et al. (2008) conducted the first comprehensive study on this genus using ITS sequence data and the divergent domains D1 and D2 of the 28S rDNA for 30 strains. In their study, the 30 taxa, clustered into three monophyletic groups that were represented by $N$. galeopsidis on Lamiaceae, $N$. galii on Rubiaceae and $N$. cumminsiana from Asteraceae. Takamatsu et al. (2008) used an LSU dataset to estimate the timing of divergence of Neoerysiphe. Neoerysiphe split from other genera ca 35-45 Mya and the three groups of Neoerysiphe diverged between 10 and 15 Mya in the Miocene. Heluta et al. (2010) used 65 ITS sequences in their analyses for identifying Neoerysiphe species infecting Asteraceae and Geranium in Eurasia and introduced three new species, viz. N. hiratae, $N$. joerstadii and $N$. nevoi. Gregorio-Cipriano et al. (2020) introduced a new species $N$. sechii causing powdery mildew on Sechium edule and $S$. mexicanum in Mexico. The authors mentioned that they were unable to recover DNA in pure form from some samples, as fragments of infected leaves were used during the extraction. Therefore, a specific oligonucleotide for Erysiphales at the $5=$ region of ITS was designed: ErysiF (5=AGGATCATTACWGAGYGYGAG-3=) was used along with NLP1 (Limkaisang et al. 2006) to amplify a fragment of approximately $1200 \mathrm{bp}$ (that included the ITS1-5.8S-ITS2 region and a section of approximately 680 nucleotides from
28S). Species used in the phylogenetic analyses done in this study are listed in Table 14 and given in Fig. 22.

Recommended genetic marker (genus level)-ITS and LSU Recommended genetic markers (species level)_ITS

Accepted number of species-There are 16 species epithets in Index Fungorum (2020), for 15 accepted species. However, only 12 species have DNA sequence data (N. chelones, $N$. gnaphalii and $N$. rubiae do not have molecular data) (Table 14).

References-Takamatsu et al. (1998), Braun (1999), Saenz and Taylor (1999) (morphology); Heluta et al. (2010), Braun and Cook (2012), Gregorio-Cipriano et al. (2020) (morphology and phylogeny).

89. Nothophoma Qian Chen \& L. Cai, Stud. Mycol. 82: 212 (2015)

\section{Background}

Nothophoma was introduced by Chen et al. (2015b) by transferring five Phoma species. Species are saprobes and pathogens. In addition, to the phytopathogens, $N$. gossypiicola has been isolated from clinical samples of humans in the respiratory secretion of a patient with pneumonia and a human bronchial wash sample (Valenzuela-Lopez et al. 2018). Chethana et al. (2019) showed that the comparative pathogenicity of Nothophoma species is low when compared to other opportunistic pathogens. Some species grow on other fungi or occur in soil (Boerema et al. 2004; 


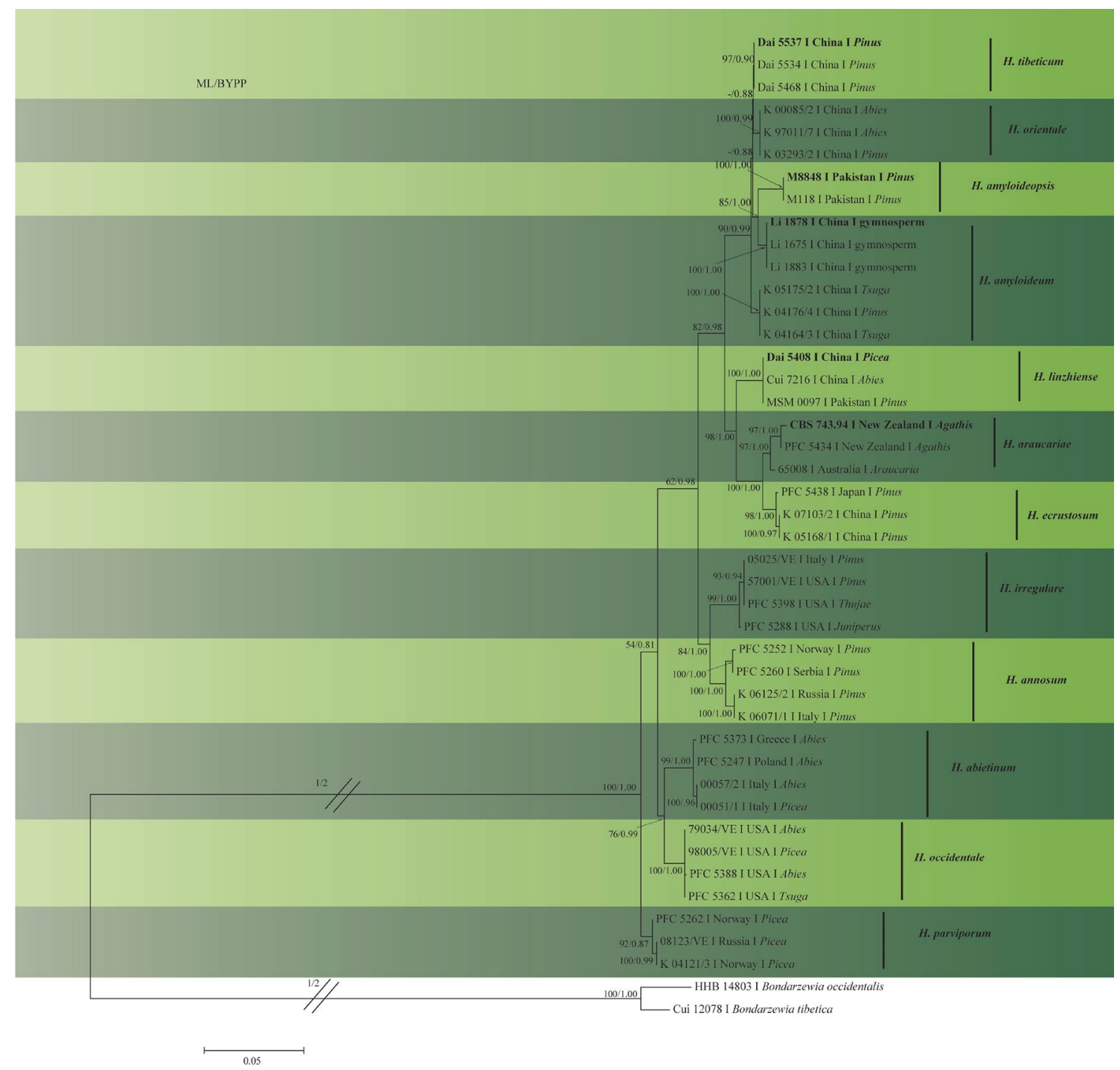

Fig. 19 Phylogram generated from ML analysis based on combined ITS, rpb1, rpb2, gapdh and tef1 sequence data of Heterobasidion species. Related sequences were obtained from GenBank. Fourty-four strains are included in the analyses, which comprised 4314 characters

Aveskamp et al. 2009; 2010; Chen et al. 2015b). Some Nothophoma species might be host-specific to a single plant genus or family (Aveskamp et al. 2010; Chen et al. 2015b). However, there is no study of host-specificity in Didymellaceae. Abdel-Wahab et al. (2017) identified 55 bioactive compounds from an endophyte, $N$. multilocularis. Of these, ten compounds showed strong antimicrobial activity in combination.

Classification-Ascomycota, Pezizomycotina, Dothideomycetes, Pleosporomycetidae, Pleosporales, Didymellaceae Type species-Nothophoma infossa (Ellis \& Everh.) Qian Chen \& L. Cai including gaps. The tree was rooted with Bondarzewia occidentalis (HHB 14803) and B. tibetica (Cui 12078). Tree topology of the ML analysis was similar to the Bayesian analysis. ML bootstrap values ${ }^{>}$ $50 \%$ and BYPP ${ }^{>} 0.80$ are shown respectively near the nodes

Distribution-Argentina, China, Italy, India, Korea, Netherlands, Spain, Tunisia, Ukraine, United States

Disease symptoms-brown spot of fruits, leaf spots, shoot canker, stem cankers

Leaf spot produced by Nothophoma anigozanthi is elliptical to circular and black. Nothophoma pruni and N. quercina develop small, dark red or purple pinpoint lesions (Chethana et al. 2019). Liu et al. (2018b) identified N. quercina infection on ornamental crab-apple. Symptoms on the trunk appear as warts, the periderm around warts can become cracked, and the bark is roughened with a scaly periderm. During dry weather, these cankers expand and coalesce (Liu et al. 2018b; Fig. 23). Nothophoma quercina develops shoot 
Table 12 DNA barcodes for accepted species of Heterobasidion

\begin{tabular}{|c|c|c|c|c|c|c|}
\hline Species & Strain & ITS & $r p b 1$ & $r p b 2$ & gapdh & tefl \\
\hline \multirow[t]{4}{*}{ Heterobasidion abietinum } & $00057 / 2$ & KJ651453 & KJ651632 & KJ651725 & KJ651756 & - \\
\hline & $00051 / 1$ & KJ651450 & KJ651629 & KJ651722 & KJ651753 & - \\
\hline & PFC 5247 & KC492895 & - & - & KP863657 & KC571636 \\
\hline & PFC 5373 & KC492956 & - & - & KP863664 & KC571687 \\
\hline \multirow[t]{2}{*}{ H. amyloideopsis } & MS 8848* & KT598384 & - & KT598388 & - & - \\
\hline & M 118 & KT598385 & - & KT598389 & - & - \\
\hline \multirow[t]{3}{*}{ H. amyloideum } & Li 1878* & KJ651455 & KF033157 & KF006538 & KJ651758 & - \\
\hline & Li 1675 & KJ651454 & KF033155 & KF006534 & KJ651757 & - \\
\hline & Li 1883 & KJ651456 & KF033156 & KF006537 & KJ651759 & - \\
\hline \multirow[t]{4}{*}{ H. annosum } & K 06125/2 & KJ651459 & KF453492 & KF453498 & KJ651762 & - \\
\hline & K 06071/1 & KJ651458 & KF453491 & KF453497 & KJ651761 & - \\
\hline & PFC 5252 & KC492906 & - & - & KP863659 & КС571646 \\
\hline & PFC 5260 & KC492911 & - & - & KP863661 & KC571651 \\
\hline \multirow[t]{3}{*}{ H. araucariae } & 65008 & KJ651462 & KJ651636 & KJ651729 & KJ651766 & - \\
\hline & CBS 743.94* & MH862503 & - & - & - & - \\
\hline & PFC 5434 & KX130098 & - & - & KX130104 & KX130101 \\
\hline \multirow[t]{3}{*}{ H. australe } & K 05175/2 & KJ651467 & KF033137 & KF006506 & KJ651771 & - \\
\hline & K 04167/4 & KJ651465 & KF033135 & KF006502 & KJ651769 & - \\
\hline & K 04164/3 & KJ651464 & KF033134 & KF006500 & KJ651768 & - \\
\hline \multirow[t]{3}{*}{ H. ecrustosum } & K 05168/1 & KJ651468 & KF033142 & KF006513 & KJ651772 & - \\
\hline & K 07103/2 & KJ651471 & KF033145 & KF006517 & KJ651775 & - \\
\hline & PFC 5438 & KX130099 & - & - & KX130105 & KX130102 \\
\hline \multirow[t]{4}{*}{ H. irregulare } & $57001 / \mathrm{VE}$ & KJ651473 & KJ651638 & KJ651731 & KJ651777 & - \\
\hline & 05025/VE & KJ651478 & KJ651643 & KJ651736 & KJ651782 & - \\
\hline & PFC 5398 & KP863586 & - & - & KP863652 & KP863616 \\
\hline & PFC 5288 & KP863575 & - & - & KP863641 & KP863606 \\
\hline \multirow[t]{3}{*}{ H. linzhiense } & Dai 5408* & KJ651484 & KF033154 & KF006533 & KJ651788 & - \\
\hline & Cui 7216 & KJ651480 & KF033148 & KF006524 & KJ651784 & - \\
\hline & MSM 0097 & MH233930 & - & - & - & - \\
\hline \multirow[t]{4}{*}{ H. occidentale } & 79034/VE & KJ651485 & KJ651645 & KJ651738 & KJ651789 & - \\
\hline & 98005/VE & KJ651489 & KJ651649 & KJ651742 & KJ651793 & - \\
\hline & PFC 5362 & KP863584 & - & - & KP863650 & KP863614 \\
\hline & PFC 5388 & KP863585 & - & - & KP863651 & KP863615 \\
\hline \multirow[t]{3}{*}{ H. orientale } & K 97011/7 & KJ651490 & KF033141 & KF006512 & KJ651794 & - \\
\hline & K 03293/2 & KJ651493 & KF033140 & KF006510 & KJ651797 & - \\
\hline & K 00085/2 & KJ651492 & KF033139 & KF006508 & KJ651796 & - \\
\hline \multirow[t]{3}{*}{ H. parviporum } & K 04121/3 & KJ583212 & KF453493 & KF453499 & KJ651800 & - \\
\hline & 08123/VE & KJ651500 & KF453495 & KF453501 & KJ651805 & - \\
\hline & PFC 5262 & KC492957 & - & - & KP863662 & KC571688 \\
\hline \multirow[t]{3}{*}{ H. tibeticum } & Dai 5537* & KJ651507 & KF033153 & KF006531 & KJ651812 & - \\
\hline & Dai 5468 & KJ651505 & KF033151 & KF006527 & KJ651810 & - \\
\hline & Dai 5534 & KJ651506 & KF033152 & KF006529 & KJ651811 & - \\
\hline
\end{tabular}

Ex-type/ex-epitype/ex-neotype/ex-lectotype strains are in bold and marked with an asterisk (*). Voucher strains are also in bold necrosis, stem browning, and wilted leaves on Chaenomeles sinensis (Yun and Oh 2016). In Tunisia, shoot blights caused by $N$. quercina were observed with diffuse cankers with gummosis on buds (Triki et al. 2019).
Hosts - Has a wide range of hosts including Anigozanthos flavidus, Anigozanthus maugleisii, Arachis hypogaea, Chaenomeles sinensis, Gossypium sp., Fraxinu spennsylvanica, Malus micromalus, Microsphaera alphitoides, Olea europaea, Phellodendrona murense, Pistacia vera, Prunu 
Fig. 20 Morphology of Meliola species a Meliola thailandicum on Dimocarpus longan. b Meliola sp. on Citrus reticulata. c Meliola sp. on Citrus maxima. d Colony on the host surface. e Hyphopodia on mycelium. f Section through ascoma. $\mathbf{g}$ Peridium. h Setae. i Young ascus. $\mathbf{j}$ Mature ascus. $\mathbf{k}, \mathbf{l}$ Ascospores. Scale bars: $\mathrm{f}=50$ $\mu \mathrm{m}, \mathrm{g}, \mathrm{i}-\mathrm{l}=30 \mu \mathrm{m}, \mathrm{h}=10 \mu \mathrm{m}$ and $\mathrm{e}=5 \mu \mathrm{m}$
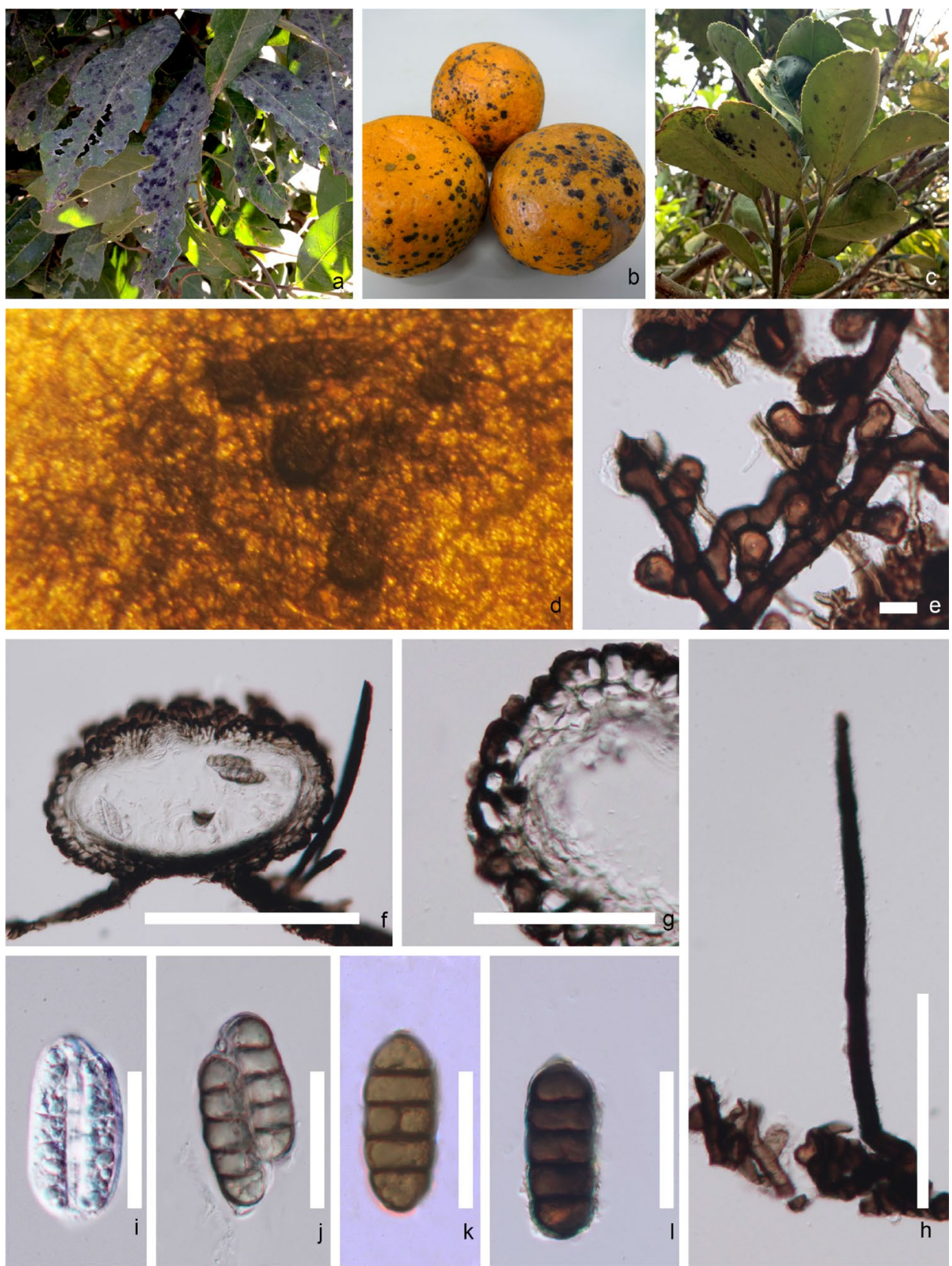

savium, Prunus dulcis, Spiraea salicifolia, Quercus sp. and Ziziphus jujube (Babaahmadi et al. 2018; Chen et al 2015b, 2017; Chethana et al. 2019; Jianyu et al. 2016; Liu et al. 2018b; Moral et al. 2017, 2018; Soleimani et al. 2018; Triki et al. 2019; Valenzuela-Lopez et al. 2018; Yun and Oh 2016; Zhang et al. 2020).

\section{Morphological based identification and diversity}

This genus was introduced by Chen et al. (2015b) based on molecular data to delineate a more natural classification for the Ascochyta-Didymella-Phoma species complex (Chen et al. 2015b; Fig. 23). Species produce elongate, barrel-shaped, olivaceous brown chlamydospores in chains (Chen et al. 2015b). However, there is little morphological variation among species (Valenzuela-Lopez et al. 2018).

\section{Molecular based identification and diversity}

Species identification is based on multi-locus sequence phylogeny. Phylogenetic analyses of combined LSU, ITS, $t u b 2$ and $r p b 2$ sequence data resulted in several new species being added to this genus by Chen et al. (2015b), AbdelWahab et al. (2017), Valenzuela-Lopez et al. (2018), Chethana et al. (2019), Marin-Felix et al. (2019) and Zhang et al. 


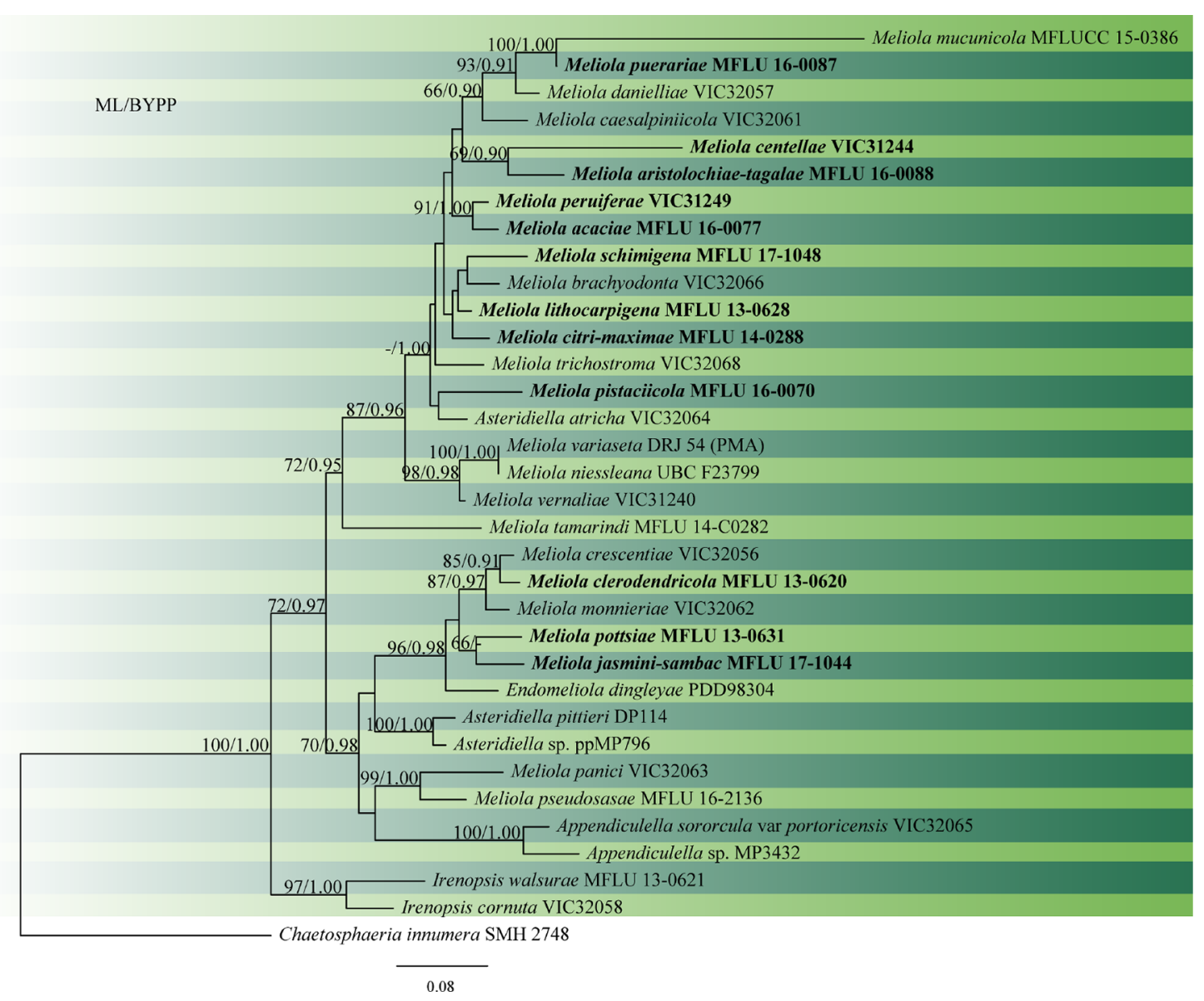

Fig. 21 Phylogram generated from RAxML analysis based on combined ITS and LSU sequence data of Meliola species. Related sequences were obtained from GenBank. Thirty-five strains are included in the analyses, which comprised 1655 characters includ-

(2020). Here we provide an updated phylogenetic tree for this genus (Fig. 24).

\section{Recommended genetic markers (genus level)—LSU, ITS}

Recommended genetic markers (species level)—tub2, rpb2

Since the colony morphology and other morphological features in Didymellaceae often overlap, initial species identification is recommended with LSU and ITS sequence data using all type species in Didymellaceae. Once the genus is identified as Nothophoma, the phylogenetic analysis could be done with LSU, ITS, tub2, and $r p b 2$ sequence data.

Accepted number of species-There are 12 species in Index Fungorum (2020) with DNA sequence data (Table 15).

References-Chen et al. (2015b), Abdel-Wahab et al. (2017), Valenzuela-Lopez et al. (2018), Chethana et al. (2019), Marin-Felix et al. (2019), Zhang et al. (2020) (morphology and phylogeny) ing gaps. The tree was rooted with Chaetosphaeria innumera (SMH 2748). Tree topology of the ML analysis was similar to the Bayesian analysis. ML bootstrap values $\geq 50 \%$ and BYPP $\geq 0.90$ are shown respectively near the nodes

\section{Phellinus Quél., Enchir. fung. (Paris): 172 (1886)} Background

Phellinus was introduced by Quélet (1886) with P. igniarius (三 Boletus igniarius) as its type species (Murrill 1903) and is placed in Hymenochaetaceae (He et al. 2019). Traditionally, most poroid Hymenochaetaceae were placed in Phellinus, which has been characterized by a dimitic hyphal system and perennial habit of the basidiomata (Gilbertson 1979; Larsen and Cobb-Poulle 1990; Ryvarden and Gilbertson 1994; Núñez and Ryvarden 2000). However, phylogenetic studies revealed that the morphologically defined Phellinus sensu lato had polyphyletic origins within the Hymenochaetoid clade, and most species previously classified as Phellinus are now members of various segregate genera (e.g. Wagner and Fischer 2001, 2002; Jeong et al. 2005; Dai 2010; Rajchenberg et al. 2015; Drechsler-Santos et al. 2016). According to the most narrowly defined generic concept, Phellinus sensu stricto is limited to the P. igniarius species complex (Fischer and Binder 2004), which includes species causing a delignifying trunk rot mostly on various 
Table 13 DNA barcodes available for Meliola

\begin{tabular}{|c|c|c|c|}
\hline Species & Culture/specimen number & LSU & ITS \\
\hline & & MN747479 & MN747479 \\
\hline Meliola aristolochiae-tagalae & MFLU 16-0088* & MN747473 & - \\
\hline M. brachyodonta & VIC32066 & КC618644 & - \\
\hline M. caesalpiniicola & VIC32061 & КC618641 & - \\
\hline M. centellae & VIC31244* & NG042650 & NR137799 \\
\hline M. citri-maximae & MFLU 14-0288* & KX458474 & - \\
\hline M. clerodendricola & MFLU 13-0620* & КT021647 & - \\
\hline M. crescentiae & VIC32056 & КC618649 & - \\
\hline M. danielliae & VIC32057 & KC618648 & - \\
\hline M. jasmini-sambac & MFLU 17-1044* & MN747482 & MN747482 \\
\hline M. lithocarpigena & MFLU 13-0628* & MN747474 & MN747474 \\
\hline M. monnieriae & VIC32062 & KC618647 & - \\
\hline M. mucunicola & MFLU 15-0386 & KT157533 & KT157534 \\
\hline M. niessleana & UBC F23799 & КC833049 & - \\
\hline M. panici & VIC32063 & КC618651 & - \\
\hline M. peruiferae & VIC 31249* & NG 060294 & - \\
\hline M. pistaciicola & MFLU 16-0070* & MN747478 & MN747478 \\
\hline M. pottsiae & MFLU 13-0631* & MN747475 & MN747475 \\
\hline M. puerariae & MFLU 16-0087* & MN747472 & - \\
\hline M. pseudosasae & MFLU 16-2136 & KX845434 & - \\
\hline M. schimigena & MFLU 17-1048* & MN747484 & MN747484 \\
\hline M. tamarindi & MFLU 14-C0282 & KP744489 & - \\
\hline M. trichostroma & VIC32068 & KC618643 & - \\
\hline M. variaseta & DRJ 54 (PMA) & EF094840 & - \\
\hline M. vernaliae & VIC 31240 & JX096808 & - \\
\hline
\end{tabular}

Ex-type/ex-epitype/ex-neotype/ex-lectotype strains are in bold and marked with an asterisk $(*)$ deciduous trees in temperate areas (Brazee 2015; Zhou et al. 2016). Based on a wider generic concept, several morphologically similar species described from East Asia, Africa or America are considered as part of Phellinus sensu stricto (Decock et al. 2006; Yombiyeni et al. 2011; Cui and Decock 2013; Bian et al. 2016; Campos-Santana et al. 2016; Vlasák and Vlasák 2017; Salvador-Montoya et al. 2018; Zhu et al. 2018). In this study, we follow the broader concept of classification of Phellinus sensu stricto, pending further studies.

Classification-Agaricomycotina, Basidiomycota, Agaricomycetes, Incertae sedis, Hymenochaetales, Hymenochaetaceae

Type species-Phellinus igniarius (L.) Quél., Enchir. fung. (Paris): 177 (1886)

Distribution-If the wider generic concept of Phellinus were accepted it would be a globally distributed genus, with certain species found in East Asia, Europe, North America (Dai 2010; Cui and Decock 2013; Brazee 2015; Zhou et al. 2016; Vlasák and Vlasák 2017; Zhu et al. 2018), Central- and South America (Decock et al. 2006; Campos-Santana et al.
Table 14 DNA barcodes available for Neoerysiphe

\begin{tabular}{llll}
\hline Species & Strain no & ITS & LSU \\
\hline Neoerysiphe aloysiae & BCRU 04878 & AB329683 & - \\
N. baccharidis & BCRU 01609 & AB329685 & AB329684 \\
N. cumminsiana & VPRI 20387 & GU356539 & - \\
N. galeopsidis & MUMH 4680 & AB498949 & AB022369 \\
$\boldsymbol{N}$. galii & MUMH 4682 & AB498951 & AB103365 \\
$\boldsymbol{N}$. geranii & HMNWAFU- & KR048092 & KR048161 \\
& CF2013083 & & \\
N. hiratae & MUMH 3442 & AB498962 & - \\
$\boldsymbol{N}$. joerstadii & MUMH 4668 & AB498976 & - \\
$\boldsymbol{N}$. kerribeeensis & DAR 33493 & GU356546 & - \\
$\boldsymbol{N}$. maquii & MUMH 2460 & AB329686 & - \\
$\boldsymbol{N}$. nevoi & MUMH 4671 & AB498975 & - \\
\hline
\end{tabular}

Ex-type/ex-epitype/ex-neotype/ex-lectotype strains and voucher strains are in bold 


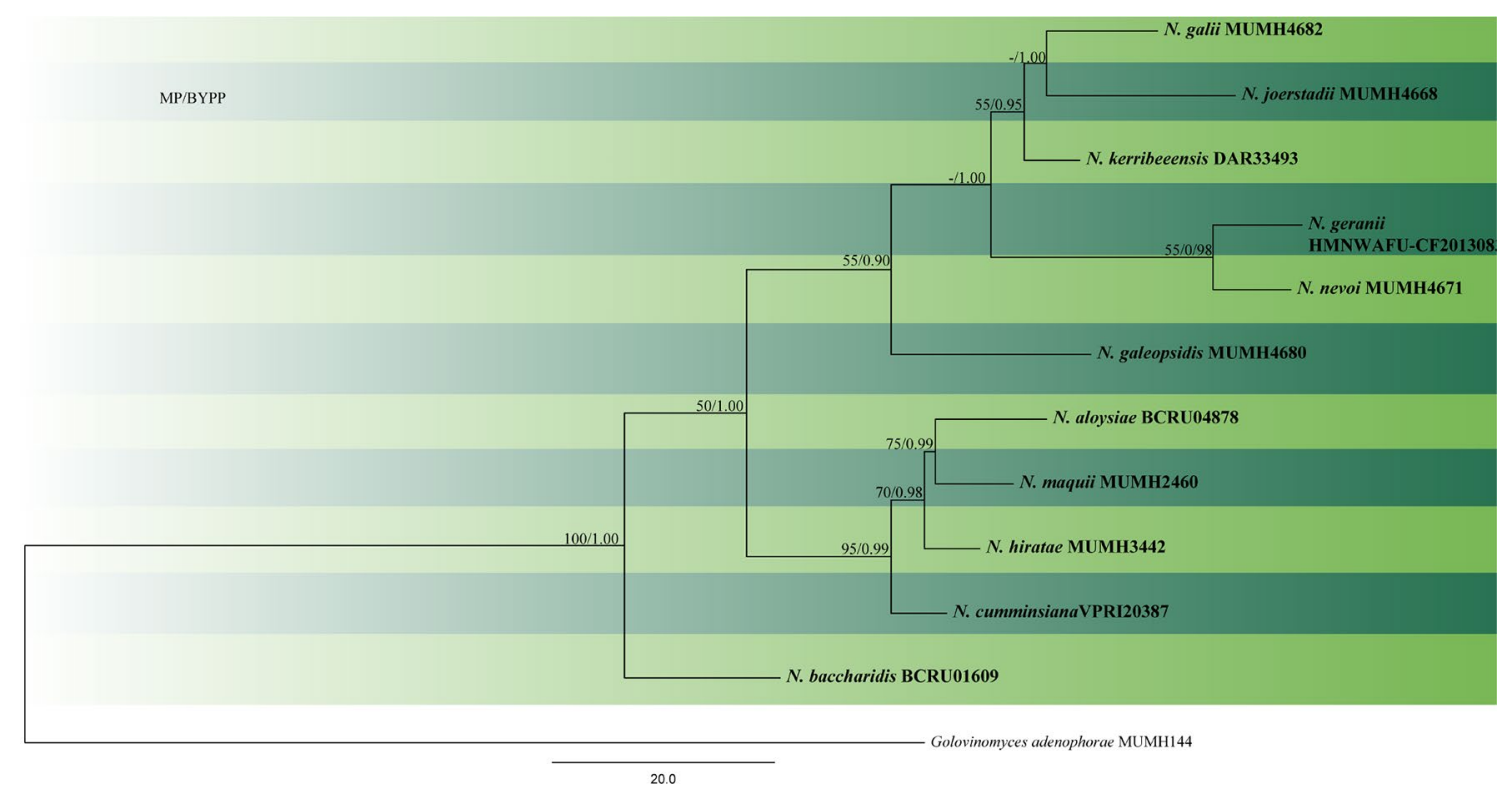

Fig. 22 Phylogram generated from MP analysis based on combined sequences of ITS and LSU sequences of all species of Neoerysiphe with molecular data. Related sequences were obtained from GenBank. 12 taxa are included in the analyses, which comprise 2023 characters including gaps, of which 1790 characters are constant, 167 characters are parsimony-uninformative and 66 characters parsimonyinformative. The parsimony analysis of the data matrix resulted in the

2016; Salvador-Montoya et al. 2018) and Africa (Yombiyeni et al. 2011; Cloete et al. 2016). However, the members of the $P$. igniarius species complex are known only from the Northern Hemisphere (Brazee 2015; Zhou et al. 2016).

Disease symptoms-Members of Phellinus produce white rot, decaying polysaccharides and delignifying the substrata (Niemelä 1974, 1977; Ryvarden and Gilbertson 1994; Wagner and Fischer 2002; Decock et al. 2006; Cui and Decock 2013; Brazee 2015; Cloete et al. 2016, de CamposSantana et al. 2016). The rot could be localized in the trunk as a column of decay (Brazee 2015), in both fallen and in standing dead trunks (Niemelä 1977; Campos-Santana et al. 2016). Branches of living trees (Niemelä 1974; Decock et al. 2006), dead, fallen, corticated branches and logs (Niemelä 1972) and dead stumps (Niemelä 1972; Decock et al. 2006; Campos-Santana et al. 2016) are colonized and decayed. The fungus penetrates the heartwood, causing heartrot (Niemelä 1974; Larsson et al. 2006), sometimes extending into the sapwood (Niemelä 1977; Larsson et al. 2006). Decay characteristics (i.e. colour, fragility and fragmentation) vary between species (Niemelä 1972, 1974, 1977; Yombiyeni et al. 2011; Luna et al. 2012; Campos-Santana et al. 2016). Pathogenic species, such as $P$. tremulae or $P$. resupinatus are usually associated with other basidiomycete species, pathogenic bacteria and basal fungi (Kallio 1972; Cloete et al. maximum of four equally most parsimonious trees with a length of 316 steps $(\mathrm{CI}=0.848, \mathrm{RI}=0.678, \mathrm{RC}=0.575, \mathrm{HI}=0.152)$ in the first tree. Single gene analyses were carried out and compared with each species, to compare the topology of the tree and clade stability. The tree was rooted with Golovinomyces adenophorae (MUMH144). MP bootstrap support value $\geq 50 \%$ and BYPP $\geq 0.9$ are shown respectively near the nodes. Ex-type strains are in bold

2016). Phellinus tremulae is a common and harmful pathogen of aspen (Populus species), penetrating the heartwood along dead branches (Niemelä 1974), but is also capable of spreading through the sapwood (Larsson et al. 2006), forming conks around the decayed tissues (Jones 1998; Fig. 25). Phellinus resupinatus is also a factor of Esca disease, causing white rot and decline of the cordons in vineyards (Cloete et al. 2016), besides other symptoms caused by this disease (Jayawardena et al. 2019a).

Hosts-Most species in the P. igniarius species complex are specialized to a single or few angiosperm genera (Fischer and Binder 1995; Zhou et al. 2016), and only $P$. piceicola has been reported from gymnosperms (Cui and Dai 2012). Species of the P. igniarius species complex have been recorded from various host genera, such as Acer, Alnus, Arctostaphylos, Betula, Carpinus, Fagus, Fraxinus, Laburnum, Picea, Populus, Prunus, Salix, Sorbus and Tilia (Tomšovský et al. 2010; Brazee 2015; Zhou et al. 2016). The members of other Phellinus sensu stricto lineages are known from several additional angiosperm genera, such as Artemisia, Astronium, Caesalpinia, Carya, Castanopsis, Dimorphandra, Minquartia, Morus, Sacaglottis, Schinopsis, Quercus and Vitis (Lombard and Larsen 1985; Decock et al. 2006; Yombiyeni et al. 2011; Cui and Decock 2013; 

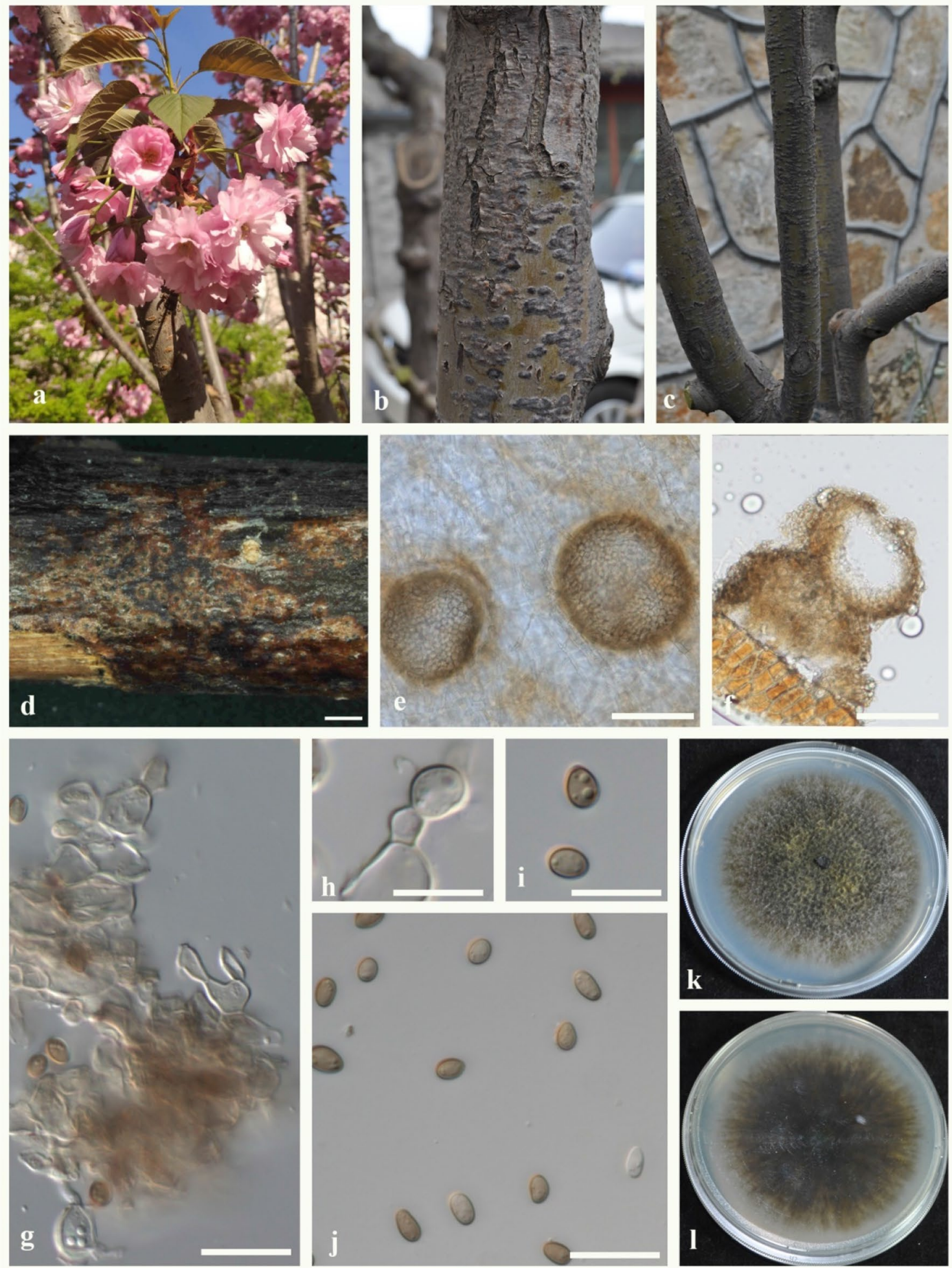

Fig. 23 Nothophoma quercina on Malus micromalus a Malus micromalus (Crab-Apple tree). b Canker on the trunk. c, $\mathbf{d}$ appearance of conidiomata on trunk. e longitudinal section through conidiomata. f cross-section of conidiomata $\mathbf{g}, \mathbf{h}$ conidiogenous cells. $\mathbf{i}, \mathbf{j}$ conidia. $\mathbf{k}$ upper view on PDA. $\mathbf{I}$ reverse view on PDA. Scale bars: $\mathbf{d}=1000 \mu \mathrm{m}$ $\mathbf{e}, \mathbf{f}=50 \mu \mathrm{m} \mathbf{g}-\mathbf{j} 10 \mu \mathrm{m}$ 
Fig. 24 Phylogram generated from maximum likelihood analysis based on combined LSU, ITS, $t u b 2$ and $r p b 2$ sequence data of Nothophoma species. Related sequences were obtained from GenBank. Seventeen strains are included in the combined sequence analyses. Phoma herbarum (CBS 615.75) and Vacuiphoma bulgarica (CBS 357.84) was used as the outgroup taxa. The best scoring RAxML tree with a final likelihood value of -5537.646741 is presented. The matrix had 284 distinct alignment patterns, with $12.23 \%$ of undetermined characters or gaps. Estimated base frequencies were as follows: $\mathrm{A}$ $=0.238395, \mathrm{C}=0.241637, \mathrm{G}=$ $0.276596, \mathrm{~T}=0.243371$; substitution rates $\mathrm{AC}=0.975188$, $\mathrm{AG}=4.004775, \mathrm{AT}=$ $1.500008, \mathrm{CG}=0.519461, \mathrm{CT}$ $=10.843965, \mathrm{GT}=1.000000$; gamma distribution shape parameter $\mathrm{a}=1.764918 \mathrm{ML}$ bootstrap support value $\geq 50 \%$ and BYPP $\geq 0.95$ are shown respectively near the nodes. Extype strains are in bold

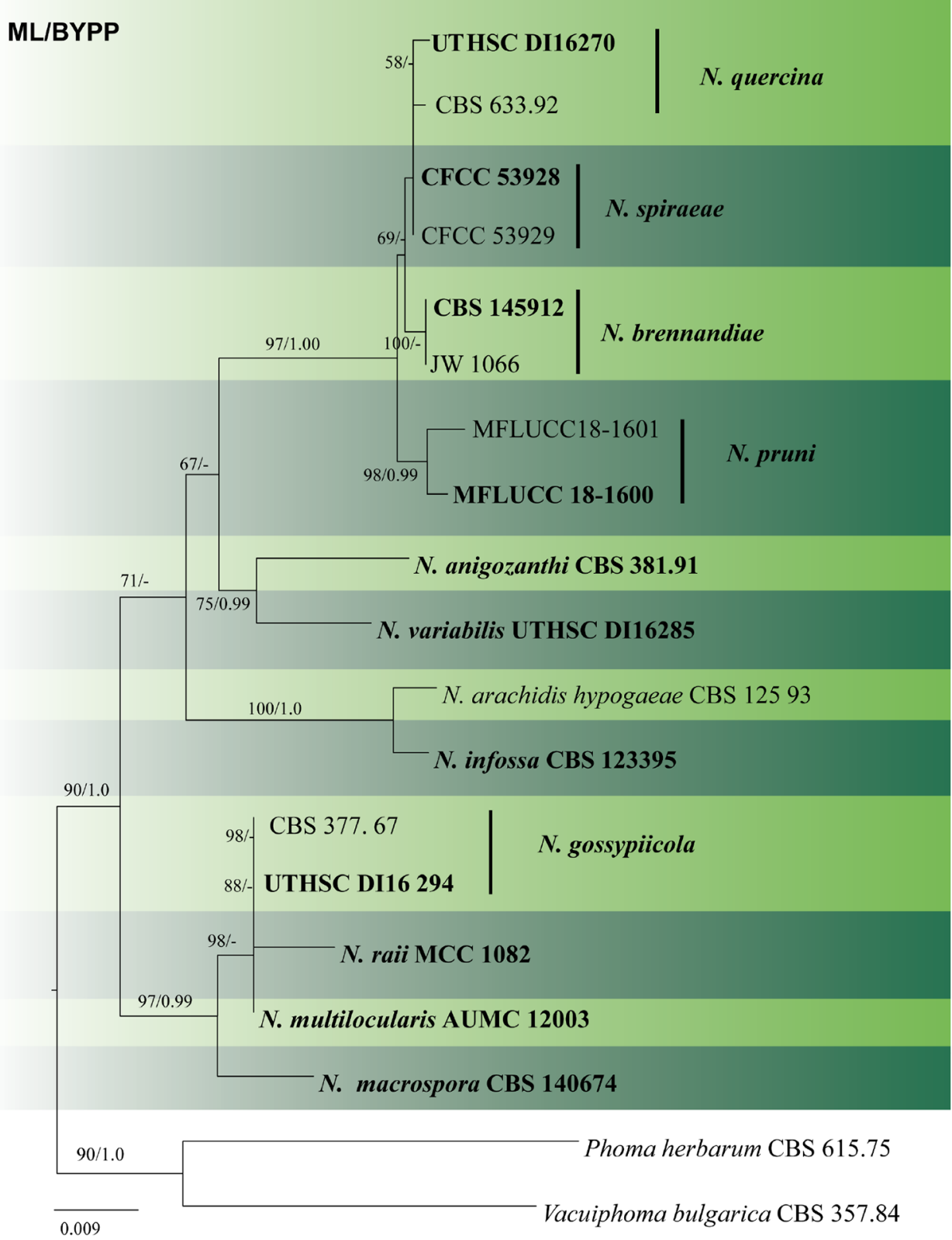

de Campos-Santana et al. 2016; Vlasák and Vlasák 2017; Salvador-Montoya et al. 2018).

\section{Morphological based identification and diversity}

Phellinus in a wider sense is morphologically heterogenous. The main features of the P. igniarius species complex are the crusted pileal surface (except resupinate species), the hymenial setae arising from the subhymenium (except specimens of "P. pseudoigniarius", see Dai and Yang 2008; Zhou et al. 2016), and the colourless, inamyloid, indextrinoid and weakly cyanophilous basidiospores (Wagner and Fischer 2001; Dai 2010; Zhou et al. 2016). In many cases, the species separation in the complex is difficult when solely based on morphological characters (Sell 2008). Host preference is also widely used for delimiting species (Tomšovský et al. 2010).

Similar to members of the P. igniarius species complex, other Phellinus species also have perennial basidiomata, but differ in having distinctive macroscopical features (e.g. size and shape of pores, rimose surface, cracked basidiocarps, absence of pileus crust, see Dai et al. 2008; Bian et al. 2016; Cloete et al. 2016; Vlasák and Vlasák 2017) or microscopic characteristics (e.g. hyphal structure, the shape of setae, basidiospore reaction in chemical solutions). For example, $P$. bicuspidatus is unique in having a monomitic hyphal system with short bicuspid setae (Lombard and Larsen 1985; Cloete et al. 2016). Members of the P. ellipsoideus group are 
Table 15 DNA barcodes available for Nothophoma

\begin{tabular}{|c|c|c|c|c|c|}
\hline Species & Isolate & LSU & ITS & $t u b 2$ & RPB2 \\
\hline Nothophoma anigozanthi & CBS 381.91* & GU238039 & GU237852 & GU237580 & KT389655 \\
\hline N. arachidis-hypogaeae & CBS 125.93 & GU238043 & GU237771 & GU237583 & KT389656 \\
\hline \multirow[t]{2}{*}{ N. brennandiae } & CBS 145912* & MN823430 & MN823579 & MN824753 & MN824604 \\
\hline & JW 1066 & MN823429 & MN823578 & MN824752 & MN824603 \\
\hline \multirow[t]{2}{*}{ N. gossypiicola } & CBS 377.67 & GU238079 & GU237845 & GU237611 & KT389658 \\
\hline & UTHSC:DI16-294 & LN907437 & LT592943 & LT593012 & LT593082 \\
\hline N. infossa & CBS $123395 *$ & GU238089 & FJ427025 & FJ427135 & KT389659 \\
\hline N. macrospora & CBS $140674 *$ & LN880537 & LN880536 & LN880539 & LT593073 \\
\hline N. multilocularis & AUMC-12003* & KY996744 & - & - & - \\
\hline \multirow[t]{2}{*}{ N. pruni } & MFLUCC 18-1600 * & MH827028 & MH827007 & MH853671 & MH853664 \\
\hline & MFLUCC18-1601 & MH827026 & MH827005 & MH853669 & MH853662 \\
\hline \multirow[t]{2}{*}{ N. quercina ${ }^{\#}$} & CBS 633.92 & EU754127 & GU237900 & GU237609 & KT389657 \\
\hline & UTHSC:DI16-270 & LN907413 & LT592929 & LT592998 & LT593067 \\
\hline N. raii & MCC $1082 *$ & - & MF664467 & MF664468 & - \\
\hline \multirow[t]{2}{*}{ N. spiraeae } & CFCC 53928* & MN737828 & MN737833 & MN879295 & MN879292 \\
\hline & CFCC 53929 & MN737829 & MN737834 & MN879296 & MN879293 \\
\hline N. variabilis & UTHSC: DI16-285* & LN907428 & LT592939 & LT593008 & LT593078 \\
\hline
\end{tabular}

Ex-type/ex-epitype/ex-neotype/ex-lectotype strains are in bold and marked with an asterisk (*). Voucher strains are also in bold. Species confirmed with pathogenicity studies are marked with ${ }^{\#}$ well-characterised by their weakly dextrinoid basidiospores and hooked hymenial setae (Zhu et al. 2018).

There are several "Phellinus" species which have been described solely on morphological features. The status of these species should be critically re-evaluated based on molecular evidence. Amongst these, certain species (e.g. $P$. deuteroprunicola, $P$. eugeniae, $P$. formosanus, $P$. livescens, $P$. prunicola, $P$. setulosus, $P$. tenuiculus, $P$. wahlbergii) may belong to Phellinus sensu stricto (Gilbertson 1979; Chang 1995; Chang and Chou 1999, 2000; Robledo et al. 2003; Wang et al. 2011; Rajchenberg et al. 2015; Campos-Santana et al. 2016), but further studies are required to confirm their placements.

\section{Molecular based identification and diversity}

In early molecular studies, the restriction fragment length polymorphism (RFLP) data of enzymatically amplified rDNA was used by Fischer (1995) to study the taxonomy of $P$. igniarius and its closest relatives in Europe. Later, single nuclear genes (ITS, Fischer and Binder 2004), or combined datasets (ITS-tef1, Tomšovský et al. 2010; Zhou et al. 2016) were used to investigate the species boundaries and phylogenetic relationships within the $P$. igniarius species complex. Phylogenetic analyses by Brazee (2015) used ITS, LSU, tefl and $r p b 2$, with isolates representing 13 species-level lineages in the complex. Zhou et al. (2016) distinguished 15 species, five of which are described as new from China and the USA. Based on our multigene analysis (Fig. 26), 16 species can be found in the $P$. igniarius species complex, distributed throughout the Northern Hemisphere. Amongst these, ten species are known from eastern Asia, eight from Europe and seven from North America.

Phellinus caribaeo-quercicola was the first species described from the "P. ellipsoideus group" based on molecular evidence (Decock et al. 2006). The nLSU-based phylogenetic analysis of Decock et al. (2006), have shown that $P$. caribaeo-quercicola grouped close to the $P$. igniarius species complex and some other Phellinus species (viz. $P$. bicuspidatus, $P$. chaquensis and $P$. spiculosus). Later molecular taxonomic studies used combined datasets of various nuclear markers. The combined analyses of nITS, nLSU, tef1 and $r p b 2$ have confirmed the phylogenetic position of $P$. caribaeo-quercicola and five morphologically similar species have been accepted in Phellinus sensu stricto (Yombiyeni et al. 2011; Cui and Decock 2013; Campos-Santana et al. 2016; Zhu et al. 2018). Currently, this later group consists of six species and mostly has tropical or subtropical distributions (Zhu et al. 2018).

\section{Recommended genetic marker (genus level)_LSU Recommended genetic markers (species level)_ITS, tefl, rpb2}

Accepted number of species-There are 479 epithets listed in Index Fungorum (2020. However, most of the species belong to other poroid Hymenochaetaceae genera, such as Fomitiporia, Fomitiporella, Fulvifomes, Fuscoporia, 


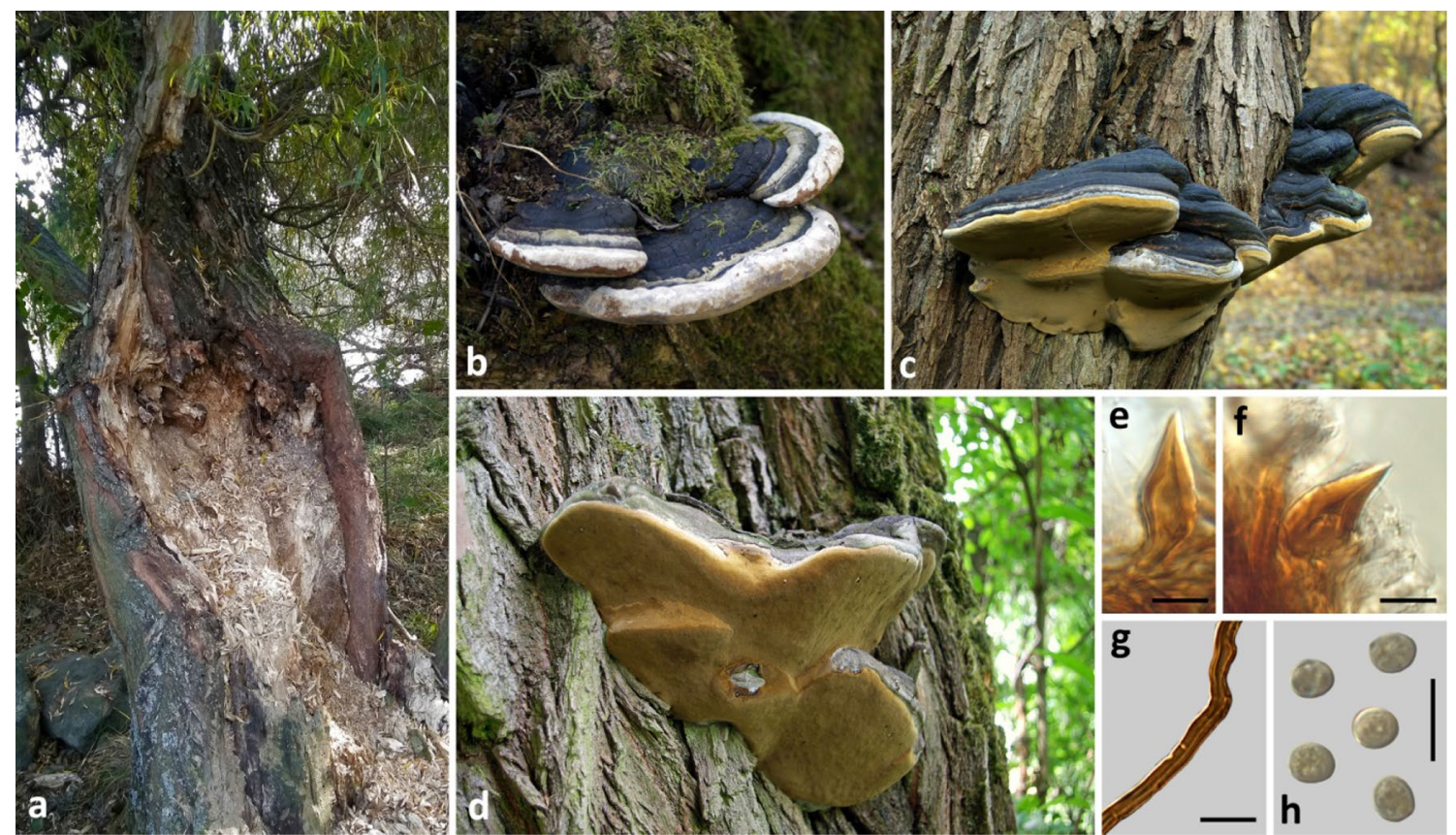

Fig. 25 Phellinus igniarius. a causing white-rot decay on willow $\mathbf{b}-\mathbf{d}$ basidiomes on living willow $\mathbf{e}$, $\mathbf{f}$ hymenial setae $\mathbf{g}$ tramal skeletal hyphae $\mathbf{h}$ basidiospores, Scale bars: $\mathbf{e}-\mathbf{h}=10 \mu \mathrm{m}$

Nothophellinus, Phellinidium, Phellinopsis, Phellinotus, Phellopilus, Phylloporia, Porodaedalea, Sanghuangporus and Tropicoporus (Wagner and Fischer 2001, 2002; Niemalä et al. 2001; Dai 2010; Drechsler-Santos et al. 2016; Rajchenberg et al. 2015; Zhou et al. 2016). Based on molecular data, 30 species are accepted in Phellinus sensu stricto, from among 16 species in the $P$. igniarius species complex (Table 16; Fig. 26).

References-Tomšovský et al. (2010) (phylogeny, P. igniarius species complex, Europe), Brazee (2015) (phylogeny, $P$. igniarius species complex, North America), Zhou et al. (2016) (phylogeny, P. igniarius species complex), Zhu et al. (2018) (phylogeny, P. ellipsoideus group)

91. Pseudoseptoria Speg., Anal. Mus. nac. B. Aires, Ser. 3 13: 388 (1910) [1911]

\section{Background}

Spegazzini (1910) introduced Pseudoseptoria as an asexual genus typified with Pseudoseptoria donacicola. Wijayawardene et al. (2012) placed the genus under Ascomycota, genera incertae sedis. Quaedvlieg et al. (2013) placed the genus in Dothioraceae and this was accepted by Thambugala et al. (2014). With LSU sequence data, Crous et al. (2017) placed Pseudoseptoria to Saccotheciaceae. Wijayawardene et al. (2017a, b, 2018, 2020) accepted this placement. Species of Pseudoseptoria are recorded as pathogens on Poaceae (Quaedvlieg et al. 2013), impairing the photosynthetic process resulting in yield loss.
Classification-Ascomycota, Pezizomycotina, Dothideomycetes, Dothideomycetidae, Dothideales, Saccotheciaceae Type species-Pseudoseptoria donacicola Speg.

Distribution-Australia, Canada, India, Italy, New Zealand, Poland, Russia, UK and USA (Dennis1986; Ginns 1986; French 1989; Pennycook 1989; Merezhko 1991; Cunnington 2003; Mulenko et al. 2008; Kamal 2010; Farr and Rossman 2020).

Disease symptoms - halo spot, leaf blotch and stem speckle

Halo spot: Elliptical, tan to brownish-grey spots $(<10 \mathrm{~mm}$ long) with a dark border surrounded by a prominent yellow halo that can be observed on the leaf blade, sometimes covering the entire leaf blade. In older lesions, small pycnidia may be visible (Slopek and Labun 1992; Carmona et al. 1996; Murray et al. 2013).

Leaf blotch: Brown flecks and frog-eye spots on leaf blades can be observed in early spring, which enlarges to straw-coloured blotches scattered with minute pycnidia. These spots may drop out, leaving holes (Horst 2013).

Stem speckle: The disease occurs in the leaves, sheaths, culms, and head spikes. The lesions are rectangular, ash white, (1-2 mm long) with a brown, thin border. The lesion is delimited by leaf veins and becomes distinct with a clear boundary. The conidia formed on the lesions disperse by wind and rain.

\section{Pathogen biology, disease cycle and epidemiology}

The pathogen is dispersed through spores in rain splash. Infection requires an extended period of wetness. Spore 
germination and infection occur optimally at temperatures between 15 and $25{ }^{\circ} \mathrm{C}$. Spores produced in overwintering crop debris serve as sources of primary inocula (Sinclair and Dhingra1995). Further studies are needed regarding the disease mechanisms and disease cycle.

Hosts - members of Poaceae are susceptible: Alopecurus pratensis, Arrhenatheru melatius, Arundo donax, Bromus species, Dactylis glomerata, Danthonia spicata, Elymus alaskanus, Festu carubra, Hordeum vulgare, Panicum virgatum, Phleum species, Phragmites australis and Poa species (Ginns 1986; Pennycook 1989; Shivas1989; Greuter et al. 1991; Merezhko 1991; Roane and Roane 1996; Gravert and Munkvold 2002; Mulenko et al. 2008; Farr and Rossman 2020)

\section{Morphological based identification and diversity}

The genus is characterized by immersed, branched, septate, pale brown mycelium, pycnidial, solitary or linearly aggregated, immersed, brown, globose, unilocular, thinwalled conidiomata of walls of pale brown cells of textura angularis with distinct, central, circular ostioles. Conidiogenous cells are discrete, determinate or indeterminate, hyaline, smooth, ampulliform with a prominent cylindrical papilla and falcate. Conidia are fusoid, hyaline, aseptate, guttulate, smooth and thin-walled, and acutely rounded at each end (Sutton 1980; Quaedvlieg et al. 2013).

\section{Molecular based identification and diversity}

Quaedvlieg et al. (2013) revised the Septoria and septoria-like genera based on morphology and multi loci analyses and introduced two new species. Phylogenetic analysis conducted by Crous et al. (2017) was based only on LSU sequence data. In our analysis, we used LSU, ITS and $r p b 2$ and obtained the same topology (Fig. 27).

\section{Recommended genetic marker (genus level)_LSU \\ Recommended genetic markers (species level)—LSU, ITS and $r p b 2$}

Accepted number of species-There are eight epithets listed in Index Fungorum (2020). However, only three species have DNA sequence data ( $P$. collariana, $P$. donacis and $P$. obscura) (Table 17).

References-Sutton (1980) (morphology); Quaedvlieg et al. (2013), Crous et al. (2017) (morphology and phylogeny)

92. Stemphylium Wallr., Flora Cryptogamica Germaniae 2: 300 (1833)

\section{Background}

Stemphylium mainly comprises saprobes or weak plant pathogens (Woudenberg et al. 2017). However, some species are primary pathogens causing leaf blight on various crops, resulting in yield and economic losses (Hanse et al. 2015; Brahmanage et al. 2018). The asexual morph is a dematiaceous hyphomycete while the sexual morph was previously defined as Pleospora sensu stricto (Inderbitzin et al. 2009; Woudenberg et al. 2017). Rossman et al. (2015) recommended the use of Stemphylium over Pleospora which has been followed by various authors (Hongsanan et al. 2017, 2020; Wijayawardene et al. 2018, 2020). Stemphylium is one of the most important moulds human allergens in the USA (Gutiérrez-Rodríguez et al. 2011). Brahmanage et al. (2018) discussed the pathogenicity, disease severity, distribution and molecular phylogenetic affinities of pathogenic isolates of Stemphylium.

Stemphylium leaf blight caused by S. versicarum was identified as an emerging disease in New York, USA. Sharma et al. (2020b) provided two genome resources for two $S$. versicarum isolates from leaf blight of onion. Genomic data allows for an understanding of the population biology, fungicide resistance, as well as development of control strategies against the disease. Pathogenesis related 511 secreted proteins were predicted from S. lycopersici by Zeng et al. (2018) which helps in understanding the roles of proteins in host penetration and tissue necrosis. Stemphylium loti secretes Tenuazonic acid, inhibiting the plant plasma membrane H+-ATPase, which results in membrane potential depolarization and eventually necrosis (Bjørk et al. 2019). Su et al. (2019) fine-mapped the tomato grey spot resistance gene $S m$, in a $185 \mathrm{~kb}$ region through a map-based cloning strategy. Leach et al. (2020) identified a relationship between thrips (Thrips tabaci) and S. vesicarium in the development of Stemphylium leaf blight in onion.

Classification-Ascomycota, Pezizomycotina, Dothideomycetes, Pleosporomycetidae, Pleosporales, Pleosporaceae Type species-Stemphylium botryosum Wallr.

Distribution-worldwide

Disease symptoms-Gray spot, Stemphylium leaf blight (Leaf spot, defoliation, curling and bending of the leaf margins and stems)

Initial symptoms of the leaves are small, irregular, brown spots. Generally, the spots gradually lighten and eventually become greyish as they become necrotic and dry. When severe, yellow spots can be seen throughout all leaves of the plant and the heavily infected leaves die (Basallote-Ureba et al. 1999, Crous et al. 2016; Brahmanage et al. 2018).

Hosts-Species are pathogenic on a wide range of hosts including Amaryllidaceae, Asparagaceae, Fabaceae, Malvaceae, Poaceae, Rosaceae and Solanaceae

\section{Pathogen biology, disease cycle and epidemiology}

Species can survive as saprobes on crop residues, soil, plant debris and on many alternative hosts and ascospores become the primary inocula in the following season. Once the disease is established during favourable conditions, conidial production in primary lesions may occur, dispersing 


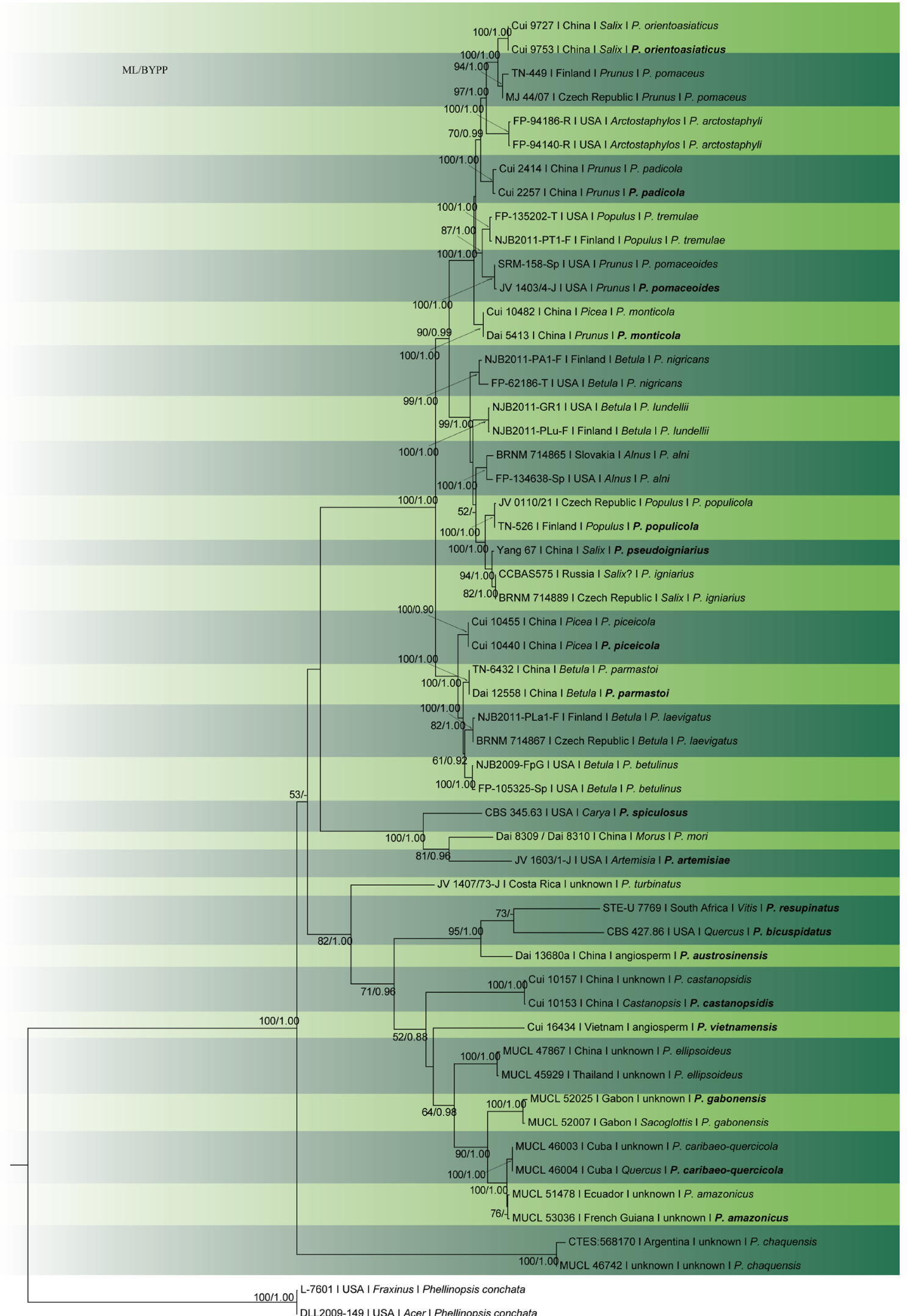

0.05 
4Fig. 26 Phylogram generatedfrom RAxML analysis based on combined ITS, LSU, Tef1- $\alpha$ and $r p b 2$ sequence data of Phellinus species. Related sequences were obtained from GenBank. Fifty-five strains are included in the analyses, which comprised 3170 characters including gaps. The tree was rooted with Phellinopsis conchata (DLL2009-149 and L-7601). Tree topology of the ML analysis was similar to the Bayesian analysis.ML bootstrap values $>50 \%$ and BYPP $>0.80 \%$ are shown respectively near the nodes

spores to healthy plants by wind and rain splashing. Environmental factors such as temperature and moisture are key factors in disease development. Seedlings of plants can transmit the diseases if they become infected in the nursery (Basallote-Ureba et al. 1998, 1999; Boshuizen et al. 2004; Zheng et al. 2010; Blancard 2012). However, to date, diseases and epidemiology such as factors affecting the disease development, interactions with different hosts and genetics of host resistance are poorly studied (Das et al. 2019).

\section{Morphological based identification and diversity}

Species can be distinguished from other hyphomycetes in Pleosporaceae forming phaeodictyospores, based on percurrent proliferation of its conidiophores and apically swollen conidiogenous cells (Köhl et al. 2009). Simmons (1967) established criteria for morphological identification of various Stemphylium species and introduced Pleospora herbarum as the sexual morph of the type species Stemphylium botryosum. However, Simmons (1985) subsequently reclassified and reported Pleospora tarda as the sexual morph of Stemphylium botryosum and Pleospora herbarum as the sexual morph of Stemphylium herbarum (Moslemi et al. 2017). Morphological features, such as size and time of pseudothecial maturation, conidiophores and conidia and ascospore shape and size can be considered as important characteristics in species identification (Câmara et al. 2002; Fig. 28).

Köhl et al. (2009) and Woudenberg et al. (2017) pointed out that the lack of (ex-) type material of species and morphology-based species identifications without molecular evidence make it difficult in determining correct species nomenclature. Therefore, relying on morphological characters alone in identifying species is not recommended.

\section{Molecular based identification and diversity}

ITS (rDNA) and glyceraldehyde-3-phosphate dehydrogenase (gapdh) sequences were used by Câmara et al. (2002) to confirm the monophyly of Stemphylium. In the extensive study of 110 Stemphylium strains from various hosts and DNA sequence data of ITS, gapdh and tefl loci and the intergenic spacer between $v m a A$ and $v p s A$, Inderbitzin et al. (2009) identified 23 representatives derived from type strains, while 40 strains remained unnamed. Woudenberg et al. (2017) revised the genus and accepted 28 species, synonymizing 22 names and proposing two new combinations based on combined analyses of the ITS, gapdh and cmdA gene regions. Marin-Felix et al. (2019) introduced three new species ( $S$. rombundicum, $S$. truncatulae and $S$. waikerieanum), while Brahmanage et al. (2018) introduced $S$. dianthi based on multi loci phylogeny. In this study, we reconstruct the phylogeny based on combined ITS, gapdh and $c m d A$ sequence data (Fig. 29).

Recommended genetic marker (genus level)_-ITS Recommended genetic markers (species level)—cmdA, gapdh

Accepted number of species-There are 207 epithets listed in Index Fungorum, however only $\mathbf{3 2}$ species have DNA sequence data (Table 18).

References-Simmons (1967), Köhl et al. (2009) (morphology); Câmara et al. (2002), Inderbitzin et al. (2009), Moslemi et al. (2017), Woudenberg et al. (2017), Brahmanage et al. (2019), Marin-Felix et al. (2019) (morphology and phylogeny)

93. Thyrostroma Höhn., Sitzungsberichte der Kaiserlichen Akademie der Wissenschaften Math.-naturw. Klasse Abt. I 120: 472 (1911)

\section{Background}

Thyrostroma belongs to Dothidotthiaceae of Pleosporales in Dothideomycetes, Ascomycota (Hongsanan et al. 2020). Thyrostroma was established by Höhnel (Höhnel 1911) and is typified by T. compactum. Thyrostroma had been treated as a synonym of Coryneum, Stegonsporium, Stigmina, and Thyrococcum, Thyrostromella and Wilsonomyces (Höhnel Höhnel 1911; Morgan-Jones 1971; Sutton and Pascoe 1989; Sutton 1997; Index Fungorum 2020). Thyrostroma has been reported as the asexual morph of Dothidotthia based on the production of a hyphomycete state in culture (Ramaley 2005), however, there is no phylogenetic evidence to support this link. With new morphological information and phylogenetic analyses, Thyrostroma and Dothidotthia species were retained in separate genera (Crous et al. 2016; Marin-Felix et al. 2017; Senwanna et al. 2019). Thyrostroma species are pathogens, saprobes or endophytes associated with canker, dieback and leaf spots in terrestrial habitats (Yuan and Old 1990; Marin-Felix et al. 2017; Senwanna et al. 2019). Species of Thyrostroma have been recorded from various plants, however, host-specificity and pathogenic capacity of Thyrostroma has not yet been clarified.

Classification-Ascomycota, Pezizomycota, Dothideomycetes, Pleosporomycetidae, Pleosporales, Dothidotthiaceae 
Table 16 DNA barcodes available for Phellinus

\begin{tabular}{|c|c|c|c|c|c|}
\hline Species & Strain & ITS & LSU & tefl & $r p b 2$ \\
\hline Phellinus alni & FP-134638-Sp & KU139167 & KU139213 & KU139330 & KU139280 \\
\hline P. alni & BRNM 714865 & GQ383730 & - & GQ383840 & - \\
\hline P. amazonicus & MUCL 53036* & KU499940 & KU376305 & KU936772 & - \\
\hline P. amazonicus & MUCL 51478 & KU499929 & KU376294 & KU936769 & - \\
\hline P. arctostaphyli & FP-94186-R & KU139145 & KU139252 & KU139350 & KU139266 \\
\hline P. arctostaphyli & FP-94140-R & KU139143 & KU139250 & KU139348 & KU139264 \\
\hline P. artemisiae & JV 1603/1-J* & KY230518 & KY230518 & - & - \\
\hline P. austrosinensis & Dai 13680a* & - & KP027474 & - & - \\
\hline P. betulinus & NJB2009-FpG & KU139153 & KU139248 & KU139368 & KU139311 \\
\hline P. betulinus & FP-105325-Sp & KU139154 & KU139239 & KU139369 & KU139312 \\
\hline P. bicuspidatus & CBS 427.86* & MH861982 & MH873674 & - & - \\
\hline P. caribaeo-quercicola & MUCL 46004* & HM635698 & DQ127280 & HM635726 & - \\
\hline P. caribaeo-quercicola & MUCL 46003 & HM635697 & DQ127279 & HM635725 & - \\
\hline P. castanopsidis & CUI 10153* & JQ837944 & JQ837956 & KU936783 & - \\
\hline P. castanopsidis & CUI 10157 & JQ837945 & JQ837957 & KU936784 & - \\
\hline P.chaquensis & MUCL 46742 & - & DQ122396 & - & - \\
\hline P.chaquensis & CTES568170 & MG242440 & MG242445 & - & - \\
\hline P. ellipsoideus & MUCL 47867 & KU954545 & KU954540 & KU936786 & - \\
\hline P. ellipsoideus & MUCL 45929 & KU954544 & DQ127283 & KU936785 & - \\
\hline P. gabonensis & MUCL 52025* & HM635708 & HM635690 & HM635731 & - \\
\hline P. gabonensis & MUCL 52007 & HM635718 & HM635685 & HM635729 & - \\
\hline P. igniarius & BRNM 714889 & GQ383709 & - & GQ383791 & - \\
\hline P. igniarius $^{\mathrm{a}}$ & *Yang 67 & JQ828880 & - & KR013111 & - \\
\hline P. igniarius & CCBAS575 & LN714586 & - & - & LN714693 \\
\hline P. laevigatus & NJB2011-PLa1-F & KU139148 & KU139241 & KU139372 & KU139305 \\
\hline P. laevigatus & BRNM 714867 & GQ383778 & - & GQ383856 & - \\
\hline P. lundellii & NJB2011-PLu-F & KU139185 & KU139234 & KU139337 & KU139300 \\
\hline P. lundellii & NJB2011-GR1 & KU139182 & KU139232 & KU139336 & KU139301 \\
\hline P. monticola & Dai 5413* & JQ828889 & - & KR013087 & - \\
\hline P. monticola & Cui 10482 & JQ828888 & - & KR013086 & - \\
\hline P. mori & Dai 8309/Dai 8310 & FJ627259 & HQ328535 & - & - \\
\hline P. nigricans & NJB2011-PA1-F & KU139169 & KU139222 & KU139340 & KU139297 \\
\hline P. nigricans & FP-62186-T & KU139176 & KU139227 & KU139343 & KU139290 \\
\hline P. orientoasiaticus & Cui 9753* & JQ828926 & - & KR013079 & - \\
\hline P. orientoasiaticus & Cui 9727 & JQ828921 & - & KR013076 & - \\
\hline P. padicola & Cui 2257* & JQ828905 & - & KR013073 & - \\
\hline P. padicola & Cui 2414 & JQ828906 & - & - & - \\
\hline P. parmastoi & Dai 12558* & JQ828900 & - & KR013089 & - \\
\hline P. parmastoi & TN-6432 & KU139158 & KU139245 & KU139376 & - \\
\hline P. piceicola & Cui 10440* & JQ828908 & - & - & - \\
\hline P. piceicola & Cui 10455 & JQ828910 & - & KR013085 & - \\
\hline P. pomaceoides & JV 1403/4-J* & KR013069 & - & KR013107 & - \\
\hline P. pomaceoides ${ }^{\mathrm{b}}$ & SRM-158-Sp & KU139140 & KU139210 & KU139353 & KU139267 \\
\hline P. pomaceus & $\mathrm{TN}-449$ & KU139142 & KU139254 & KU139352 & KU139263 \\
\hline P. pomaceus & MJ 44/07 & GQ383783 & - & GQ383858 & - \\
\hline P. populicola & TN-526* & KU139179 & KU139231 & KU139333 & KU139303 \\
\hline P. populicola & JV 0110/21 & KR013062 & - & KR013093 & - \\
\hline P. resupinatus & STE-U 7769* & KM523246 & KM523251 & - & - \\
\hline P. spiculosus & CBS 345.63* & MH858307 & MH869918 & - & - \\
\hline P. tremulae & NJB2011-PT1-F & KU139132 & KU139201 & KU139357 & KU139276 \\
\hline P. tremulae & FP-135202-T & KU139134 & KU139207 & KU139359 & KU139271 \\
\hline P. turbinatus & JV 1407/73-J & KT156687 & - & - & - \\
\hline P. vietnamensis & Cui 16434* & - & MG867716 & MG867722 & MG867719 \\
\hline
\end{tabular}

Ex-type/ex-epitype/ex-neotype/ex-lectotype strains are in bold and marked with an asterisk $(*)$. Voucher strains are also in bold

${ }^{\mathrm{a}}$ as $P$. pseudoigniarius

${ }^{\mathrm{b}}$ as PhellinusNA2 


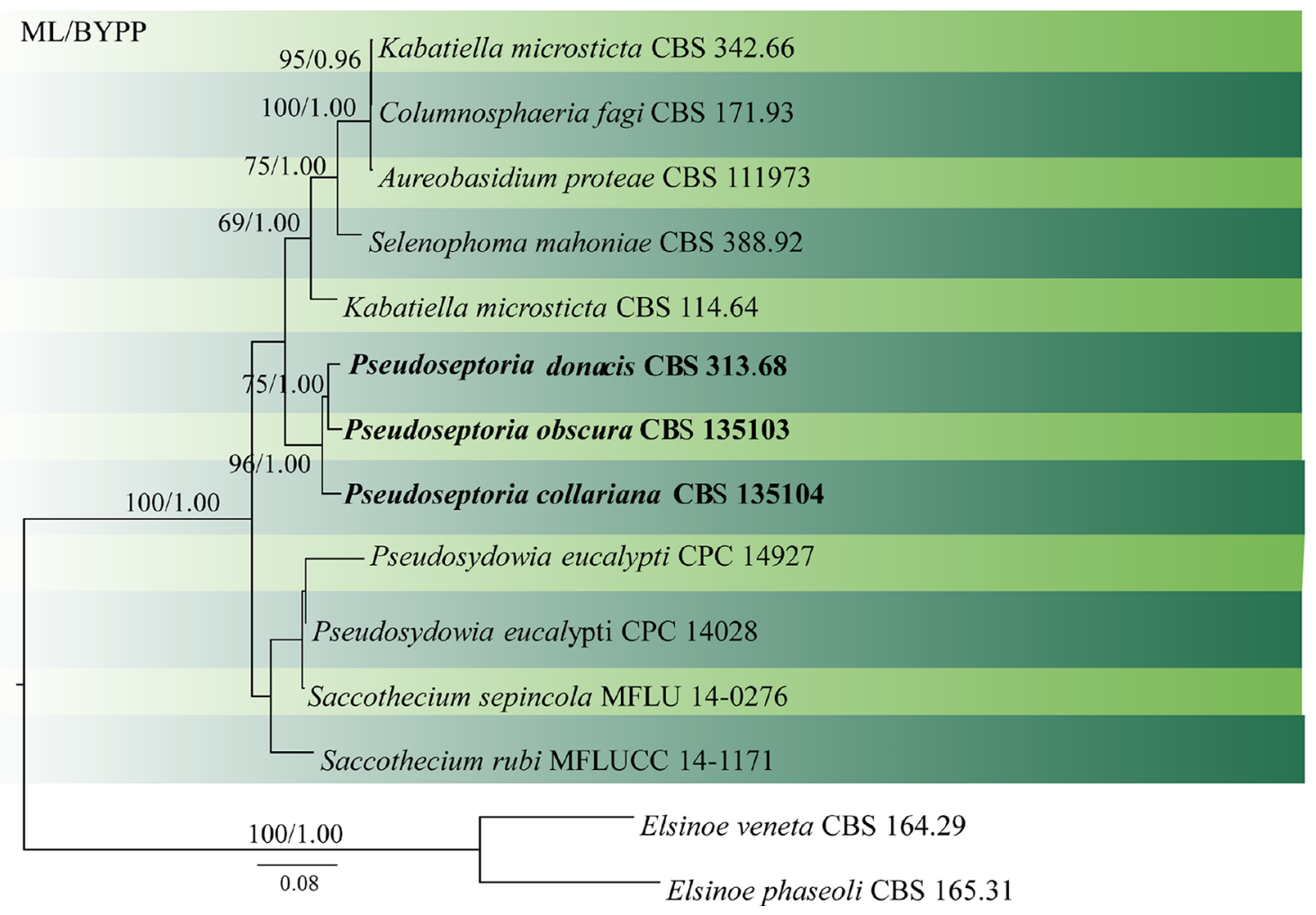

Fig. 27 Phylogenetic tree generated by maximum likelihood analysis of combined LSU, ITS and $r p b 2$ sequence data. Fourteen strains are included in the analyses, which comprised 2207 characters including gaps. The tree was rooted with Elsinoe veneta (CBS 164.29) and Elsinoe phaseoli (CBS165.31). Tree topology of the ML analysis was similar to the BYPP analysis. The best scoring RAxML tree with a final likelihood value of -7330.368152 is presented. The

Table 17 DNA barcodes available for Pseudoseptoria

\begin{tabular}{lllll}
\hline Species & Isolate & LSU & ITS & rpb2 \\
\hline $\begin{array}{c}\text { Pseudosep- } \\
\text { toria col- } \\
\text { lariana }\end{array}$ & CBS 135104* & KF251721 & KF251218 & KF252223 \\
$\begin{array}{c}\text { P. donacis } \\
\text { P. obscura }\end{array}$ & CBS 313.68 & MH870852 & MH859141 & \\
CBS 135103 & KF251722 & KF251219 & KF252224 \\
\hline
\end{tabular}

Ex-type/ex-epitype/ex-neotype/ex-lectotype strains are in bold and marked with an asterisk $(*)$. Voucher strains are also in bold. Species confirmed with pathogenicity studies are marked with \# matrix had 500 distinct alignment patterns, with $29.98 \%$ of undetermined characters or gaps. Estimated base frequencies were as follows: $\mathrm{A}=0.250948, \mathrm{C}=0.235140, \mathrm{G}=0.278289, \mathrm{~T}=0.235623$; substitution rates $\mathrm{AC}=2.242594, \mathrm{AG}=3.171649$, $\mathrm{AT}=1.699638$, $\mathrm{CG}=1.459509, \mathrm{CT}=8.754890, \mathrm{GT}=1.000000$; gamma distribution shape parameter $\alpha=0.601361$ ML bootstrap values $\geq 65 \%$ and BYPP $\geq 0.90$ are shown respectively near the nodes

Type species-Thyrostroma compactum (Sacc.) Höhn Distribution-Australia, Iran, Korea, Russia, USA, Uzbekistan

Disease Symptoms-Thyrostroma canker, dieback and leaf spots (Fig. 30a, b)

Hosts-Pathogens of Acanthophyllum sp., Astragalus sp., Capparis parvifiora, Celtis occidentalis, Cornus officinalis, Echinops sp., Elaeagnus angustifolia, Ephedra equisetina, Eucalyptus mannifera subsp. maculosa, Franseria sp., Halimodendron halodendron, Lycium barbarum, Morus alba, Robinia pseudoacacia, Sambucus caerulea, Styphnolobium 
japonicum, Tilia cordata, Ulmus pumila (Farr and Rossman 2020).

\section{Morphological based identification and diversity}

Thyrostroma species can be differentiated using conidial dimensions and septation in aged conidia and molecular phylogeny (Crous et al. 2016; Marin-Felix et al. 2017; Senwanna et al. 2019; Fig. 30). Senwanna et al. (2019) reported the sexual morph of Thyrostroma in T. ulmicola for the first time. The sexual morph is characterized by pseudothecial, immersed, erumpent or superficial, uniloculate or multiloculate ascostromata, globose to subglobose ascomata, a two-layered peridium, bitunicate, clavate asci, fusiform to ellipsoidal, 1-septate, ascospores.

\section{Molecular based identification and diversity}

In the past, there has been no comprehensive phylogenetic study in Thyrostroma and consequently, its taxonomy was and still is mostly based on morphological characters. Based on LSU sequence data, Thyrostroma clustered in a wellsupported clade within the Dothidotthiaceae (Marin-Felix et al. 2017; Crous et al. 2019). The asexual morph and sexual morph relationship were resolved by Senwanna et al. (2019) by molecular evidence. To achieve correct generic and species identification and taxonomic placement, phylogenetic studies using LSU, SSU, ITS, and tefl were performed (Senwanna et al. 2019). This study reconstructs the phylogeny using a combined LSU, SSU, ITS, and tefl sequence dataset (Fig. 31). The topology is in accordance with Marin-Felix et al. (2017), Senwanna et al. (2019) and Hyde et al. (2020b).

\section{Recommended genetic marker (genus level)_LSU Recommended genetic markers (species level)_ITS, tefl, $r p b 2$ and $t u b 2$}

LSU, ITS and tefl are the common genetic markers used in the identification of Thyrostroma species. Combined LSU, SSU, ITS and tefl genes provide a satisfactory resolution for resolving species. Based on the comparison of ITS and teflgene regions, most species in Thyrostroma are not significantly different from one another, therefore, Senwanna et al. (2019) suggested that $r p b 2, t u b 2$ are reliable genes for distinguishing species within Thyrostroma.

Accepted number of species-There are 27 epithets in Index Fungorum (2020), however only 13 species have DNA sequence data (Table 19).

References - Höhnel (1911), Yuan and Old (1990), Ramaley (2005) (morphology); Marin-Felix et al. (2017), Crous et al. (2016, 2019), Senwanna et al. (2019) (morphology and phylogeny).
94. Wojnowiciella Crous, Hern.-Restr.\& M.J. Wingf., Persoonia 34, 201 (2015)

\section{Background}

Wojnowiciella was introduced by Crous et al. (2015) to include Wojnowiciella eucalypti which exhibited somewhat similar morphological characteristics to Wojnowicia, such as setose pycnidia, with ampulliform, enteroblastic, phialidic conidiogenous cells, but differed with apapillate conidiomata lacking setae and having dark brown conidia.

Classification-Ascomycota, Pezizomycota, Dothideomycetes, Pleosporales, Phaeosphaeriaceae

Type species-Wojnowiciella eucalypti Crous, Hern.-Restr. \& M.J. Wingf

Distribution-Australia (Hernandez-Restrepo et al. 2016), China (Crous et al. 2015, Giraldo et al. 2017), Colombia (Crous et al. 2015, Giraldo et al. 2017), New Zealand (Crous et al. 2019), South Africa and Western Cape (Crous et al. 2016)

\section{Disease symptoms-Leaf spots}

Most species are reported as saprobes with the exception of Wojnowiciella cissampeli, W. eucalypti and W. vibruni which were isolated from leaves and twigs of Cissampelos capensis, Eucalyptus and Viburnum utile respectively (Hernandez-Restrepo et al. 2016). Their pathogenicity or disease symptoms are not indicated clearly and there is a need to establish pathogenicity of these species.

Hosts-Cissampelos capensis, Dactylis sp., Eucalyptus grandis, Rosa sp., Leptocarpus sp., Lonicera sp., Spartium sp. and Viburnum utile (Farr and Rossman 2020).

\section{Morphological based identification and diversity}

Wojnowiciella was introduced to include species that were phylogenetically distinct but morphologically similar to Wojnowicia (Crous et al. 2015). Wojnowiciella is characterized by apapillate conidiomata without setae and dark brown conidia. Some species of Wojnowiciella also produce hyaline microconidia. Karunarathna et al. (2017) first reported the sexual morph of $W$. dactylidis. Phookamsak et al. (2019) transferred Wojnowicia rosicola to Wojnowiciella rosicola based on morphology and phylogenetic analyses.

\section{Molecular based identification and diversity}

Wojnowiciella is a well-supported genus in the family Phaeosphaeriaceae (Phookamsak et al. 2019). A combined multiloci phylogeny of LSU, SSU, tefI and ITS is used in placing species of Wojnowiciella within Phaeosphaeriaceae. To identify species within the genus ITS, LSU, $r p b 2$ and tef1 are used (Marin-Felix et al. 2019; Phookamsak et al. 2019). Here we provide an updated phylogenetic tree for this genus (Fig. 32). 
Fig. 28 Stemphylium sp. a Ascomata on host $\mathbf{b}$ Vertical section through an ascoma $\mathbf{c}$ immature and mature asci $\mathbf{d}$ Pseudoparaphyses e Ascospores f Ascospores in Indian ink. Scale bars: $b=50 \mu \mathrm{m}, \mathrm{c}-\mathrm{f}=$ $10 \mu \mathrm{m}$
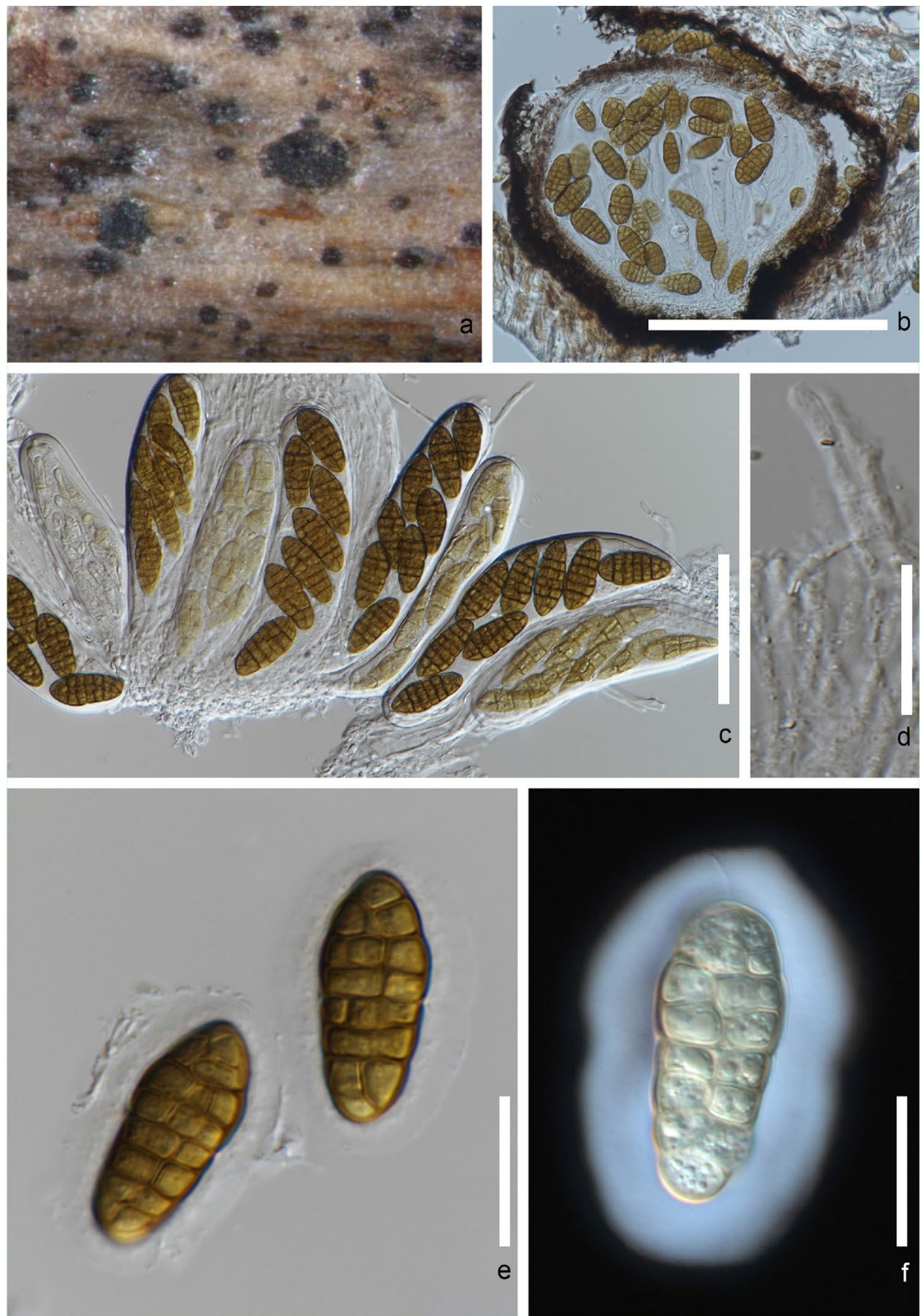

Recommended genetic markers (genus level)—LSU

Recommended genetic markers (species level)_ITS, rpb2, tef1

Accepted number of species-Nine species are accepted with molecular data (Table 20).

References - Crous et al. (2015), Karunarathna et al. (2017), Marin-Felix et al. (2019), Phookamsak et al. (2019) (morphology and phylogeny)

\section{Updated genera}

The following genera are updated due to the addition of many new species during recent years.

95. Cladosporium Link, Mag. Gesell. naturf. Freunde, Berlin 7: 37 (1816) [1815]

Cladosporium Link, Mag. Gesell. naturf. Freunde, Berlin 7: 37 (1816) [1815] 


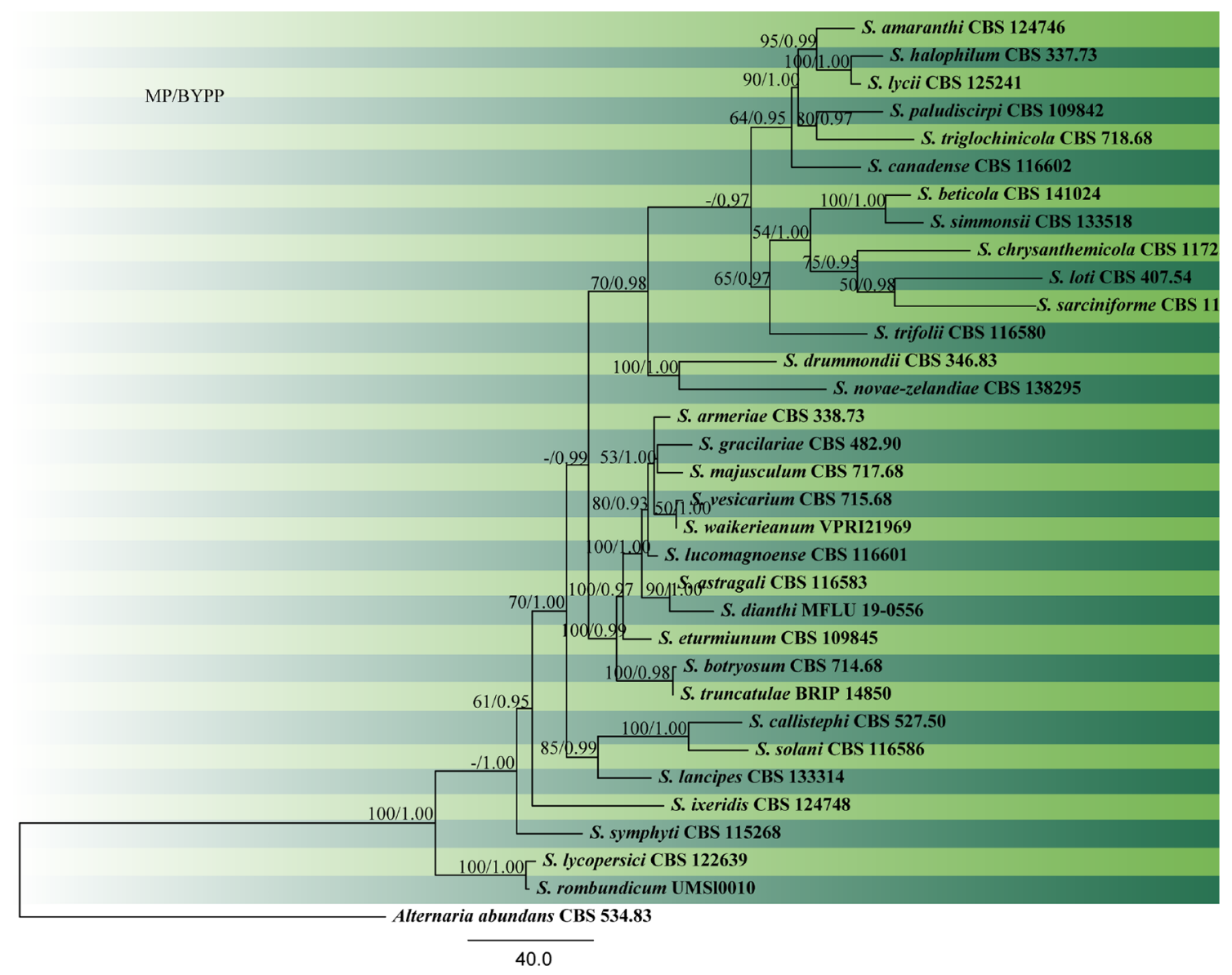

Fig. 29 Phylogram generated from MP analysis based on combined sequences of ITS, gapdh and $\mathrm{cmdA}$ sequences of all species of Stemphylium. Related sequences were obtained from GenBank. Thirty three taxa are included in the analyses, which comprise 1936 characters including gaps, of which 1355 characters are constant, 271 characters are parsimony-uninformative and 310 characters parsimonyinformative. The parsimony analysis of the data matrix resulted in the

\section{Background}

Cladosporium belongs to Cladosporiaceae in the order Capnodiales (Hyde et al. 2013). Established in 1816 with C. herbarum as type species, Cladosporium is one of the largest genera of dematiaceous hyphomycetes. Davidiella was erected by Braun et al. (2003) to accommodate the sexual morph of Cladosporium sensu stricto. Davidiella was therefore recognized as a synonym of Cladosporium as Cladosporium has priority over Davidiella at generic rank, and is also the more commonly used name in literature (Bensch et al. 2012). Therefore, Cladosporiaceae took preference over Davidiellaceae (Bensch et al. 2012). Cladosporium species have a worldwide distribution and can be easily spread in the environment, because of their small conidia. Cladosporium includes many important pathogens causing leaf spots and stem rots of many plant hosts. For maximum of four equally most parsimonious trees with a length of 1112 steps $(\mathrm{CI}=0.660, \mathrm{RI}=0.721, \mathrm{RC}=0.476, \mathrm{HI}=0.340)$ in the first tree. Single gene analyses were carried out and compared with each species, to compare the topology of the tree and clade stability. The tree was rooted with Alternaria abundance (CBS 534.83). MP bootstrap support value $\geq 50 \%$ and BYPP $\geq 0.9$ are shown respectively near the nodes. Ex-type strains are in bold

example, Cladosporium fulvum is the causal agent of tomato leaf mold (van Kan et al. 1991). Cladosporium species have been recorded as endophytes and may have a positive effect, for example, C. sphaerospermum was isolated from the roots of Glycine max which can promote its growth (Hamayun et al. 2009). Some species, such as $C$. herbarum, are also known as common contaminants in clinical laboratories and cause allergic lung disease (de Hoog et al. 2000). Several species were also isolated from human respiratory samples (Sandoval-Denis et al. 2016). Thirteen species are fungicolous (Heuchert et al. 2005; Sun et al. 2019) and have the potential for biological control in agriculture and forestry (Torres et al. 2017).

There have been studies towards understanding the genetic components of Cladosporium. Cladosporium fulvum is an important model species in the plant pathology study. 
Table 18 DNA barcodes available for Stemphylium

\begin{tabular}{|c|c|c|c|c|}
\hline Species name & Isolate/specimen no & ITS & gapdh & $c m d A$ \\
\hline Stemphylium amaranthi & CBS 124746* & KU850505 & KU850652 & KU850793 \\
\hline S. armeriae & CBS 338.73 & KU850511 & KU850658 & KU850799 \\
\hline S. astragali ${ }^{\#}$ & CBS 116583* & KU850512 & KU850659 & KU850800 \\
\hline S. beticola ${ }^{\#}$ & CBS 141024* & KU850520 & KU850667 & KU850808 \\
\hline S. botryosum ${ }^{\#}$ & CBS 714.68* & KC584238 & AF443881 & KU850826 \\
\hline S. callistephi & CBS 527.50* & KU850539 & KU850686 & KU850828 \\
\hline S. canadense & CBS 116602* & KU850641 & KU850782 & KU850932 \\
\hline S. chrysanthemicola ${ }^{\#}$ & CBS 117255* & KU850640 & KU850781 & KU850931 \\
\hline S. dianthi & MFLU 19-0556* & MK500718 & - & MK500734 \\
\hline S. drummondii & CBS 346.83* & GQ395365 & KU850687 & KU850829 \\
\hline S. eturmiunum ${ }^{\#}$ & CBS 109845* & KU850541 & KU850689 & KU850831 \\
\hline S. gracilariae & CBS 482.90* & KU850549 & AF443883 & KU850839 \\
\hline S. halophilum & CBS 337.73* & KU850553 & KU850700 & KU850843 \\
\hline S. ixeridis & CBS 124748* & KU850590 & KU850737 & KU850881 \\
\hline S. lancipes & CBS 133314* & KU850596 & KU850742 & KU850887 \\
\hline S. loti & CBS 407.54* & KU850597 & KU850743 & KU850888 \\
\hline S. lucomagnoense & CBS 116601* & KU850629 & KU850770 & KU850920 \\
\hline S. lycii & CBS 125241* & KU850602 & KU850748 & KU850893 \\
\hline S. lycopersici & CBS 122639* & KU850611 & KU850756 & KU850902 \\
\hline S. majusculum & CBS 717.68* & KU850618 & AF443891 & KU850909 \\
\hline S. novae-zelandiae & CBS 138295* & KU850631 & KU850772 & KU850922 \\
\hline S. paludiscirpi & CBS 109842* & KU850620 & KU850762 & KU850911 \\
\hline S. rombundicum & BRIP 27486* & MK336819 & MK336865 & MK336842 \\
\hline S. sarciniforme & CBS 110049* & KU850591 & KU850738 & KU850882 \\
\hline S. simmonsii ${ }^{\#}$ & CBS 133518* & KU850637 & KU850778 & KU850928 \\
\hline S. solani ${ }^{\#}$ & CBS 116586* & KU850627 & KU850768 & KU850918 \\
\hline S. symphyti & CBS 115268* & KU850643 & KU850784 & KU850934 \\
\hline S. trifolii & CBS 116580* & KU850647 & KU850788 & KU850938 \\
\hline S. triglochinicola & CBS 718.68* & KU850648 & KU850789 & KU850939 \\
\hline S. truncatulae & BRIP 14850* & MK336815 & MK336861 & MK336838 \\
\hline S. vesicarium ${ }^{\#}$ & CBS 715.68* & KU850565 & KU850712 & KU850855 \\
\hline S. waikerieanum & VPRI 21969* & MK336832 & MK336878 & MK336855 \\
\hline
\end{tabular}

Ex-type/ex-epitype/ex-neotype/ex-lectotype strains are in bold and marked with an asterisk (*). Voucher strains are also in bold. Species confirmed with pathogenicity studies are marked with ${ }^{\#}$
Iakovidis et al. (2020) reported classical mapping strategies for loci of tomato that response to sequence-monomorphic effector Ecp5. Convergent evolution could be used for choosing different functional genes according to individual plant breeding needs. Ge et al. (2019) showed that Cladosporium species have the potential to be used in industrial processes. They identified a new glucose oxidase gene $C \operatorname{tgoxB}$ from $C$. tianshanense and suggested this could be a candidate for the aquatic feed and detergent industries. Transcriptome and proteome analyses of $C$. fulvuim showed that 14 out of 59 predicted proteases are expressed during in vitro and in planta, of which nine belong to serine proteases and the rest belong to metallo and aspartic proteases (Jashni et al. 2019). This study also confirmed the presence of six proteases at proteome level during the infection.
Grinn-Gofron et al. (2019) developed and evaluated the models of forecasting possibilities of airborne spore concentrations in 18 sites in six countries across Europe. The study revealed the possibility of reliable prediction of fungal spore levels using gridded meteorological data. They concluded that these forecasting models can be used in the more timely and efficient management of phytopathogenic and of human allergic diseases. An environmentally isolated strain of $C$. sphaerospoermum substantially enhanced plant growth, early flowering and increase in crop yield after exposure in vitro ( $\mathrm{Li}$ et al. 2019). Pan et al. (2020) identified four new hybrid polyketides (Cladosin L-O) from $C$. shaerospermum which showed strong cytotoxicity, antifungal activity and moderate antibacterial activity. 

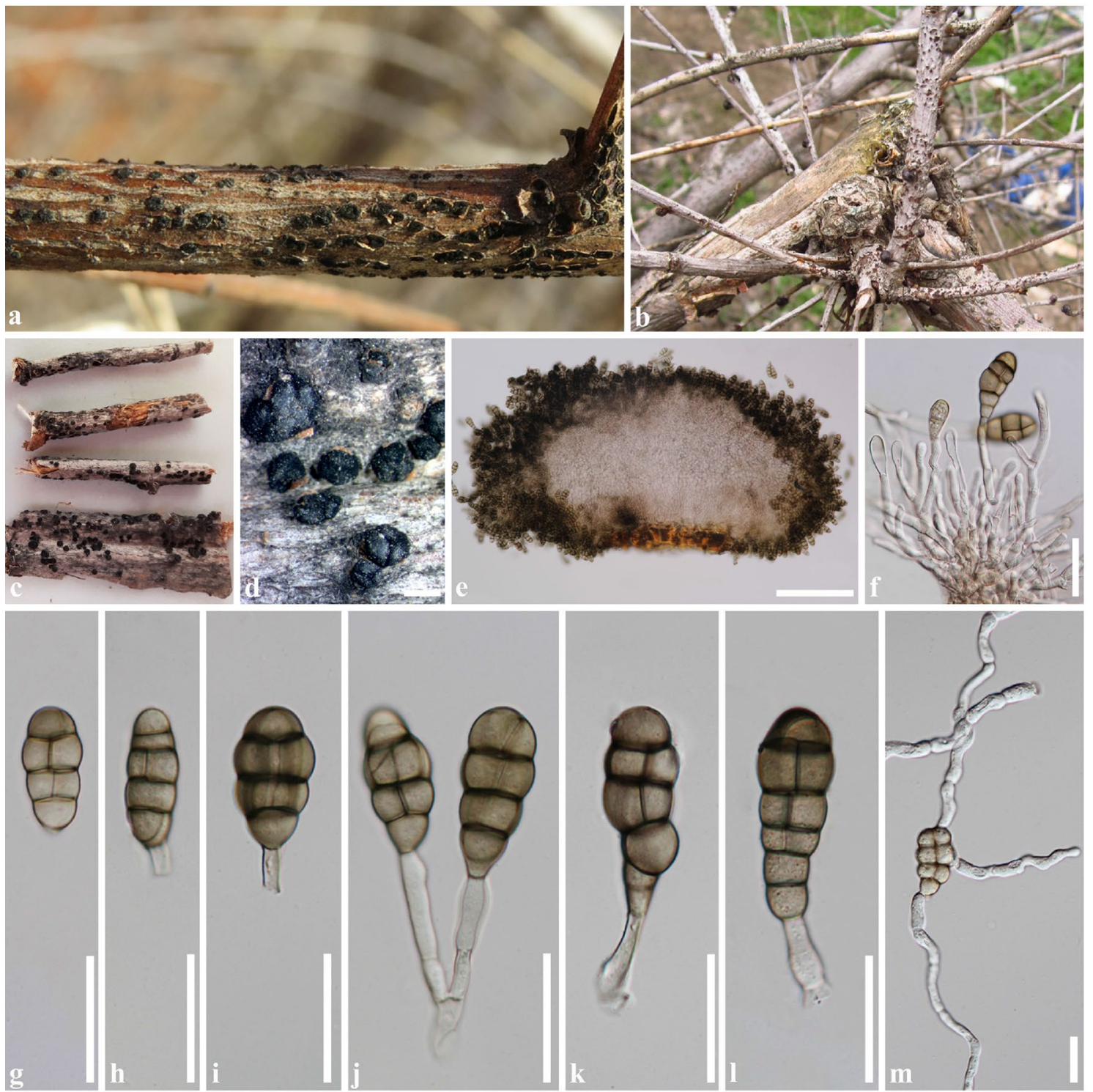

Fig. 30 a, b Symptoms on Ulmus pumila caused by Thyrostroma ulmicola (MFLU 16-1622); c, d Sporodochia on the host surface. e Section of sporodochium. f Conidiogenesis and conidiogenous cells.

g-l Conidia. $\mathbf{m}$ Germinated conidium. Scale bars: $\mathbf{d}=1000 \mu \mathrm{m}, \mathbf{e}=$ $200 \mu \mathrm{m}, \mathrm{f}-\mathrm{m}=30 \mu \mathrm{m}$

Classification: Ascomycota, Pezizomycotina, Dothideomycetes, Pleosporomycetidae, Capnodiales, Cladosporiaceae Type species-Cladosporium herbarum (Pers.) Link Distribution- Worldwide

Disease symptoms-Leaf spots, leaf blight, discolourations, necrosis, or shot-hole symptoms, on stems and fruits, rots Hosts-Cladosporium species occur on a wide range of host plants including Asparagaceae, Asteraceae, Fabaceae, Myrtaceae, Orchidaceae, Poaceae, Solanaceae and Vitaceae (Farr and Rossman 2020). Some species can be hyperparasites of insects and fungi (Heuchert et al. 2005; Islam et al.
2019; Sun et al. 2019; Abdel-Baky 2000). These species can cause allergies in humans such as sneezing, hives and also can cause eye, ear and sinus infections (de Hoog et al. 2000).

\section{Pathogen biology, disease cycle and epidemiology}

Cladosporium survives in the soil or on plant debris and produce spores during humid weather. Fungal spores germinate under high humidity and cool to warm temperatures. Wind, rain and irrigation splash, workers, tools, and insects readily disseminate spores (Jordan et al. 1990; Lan and Scherm 2003; Liu et al. 2019). 


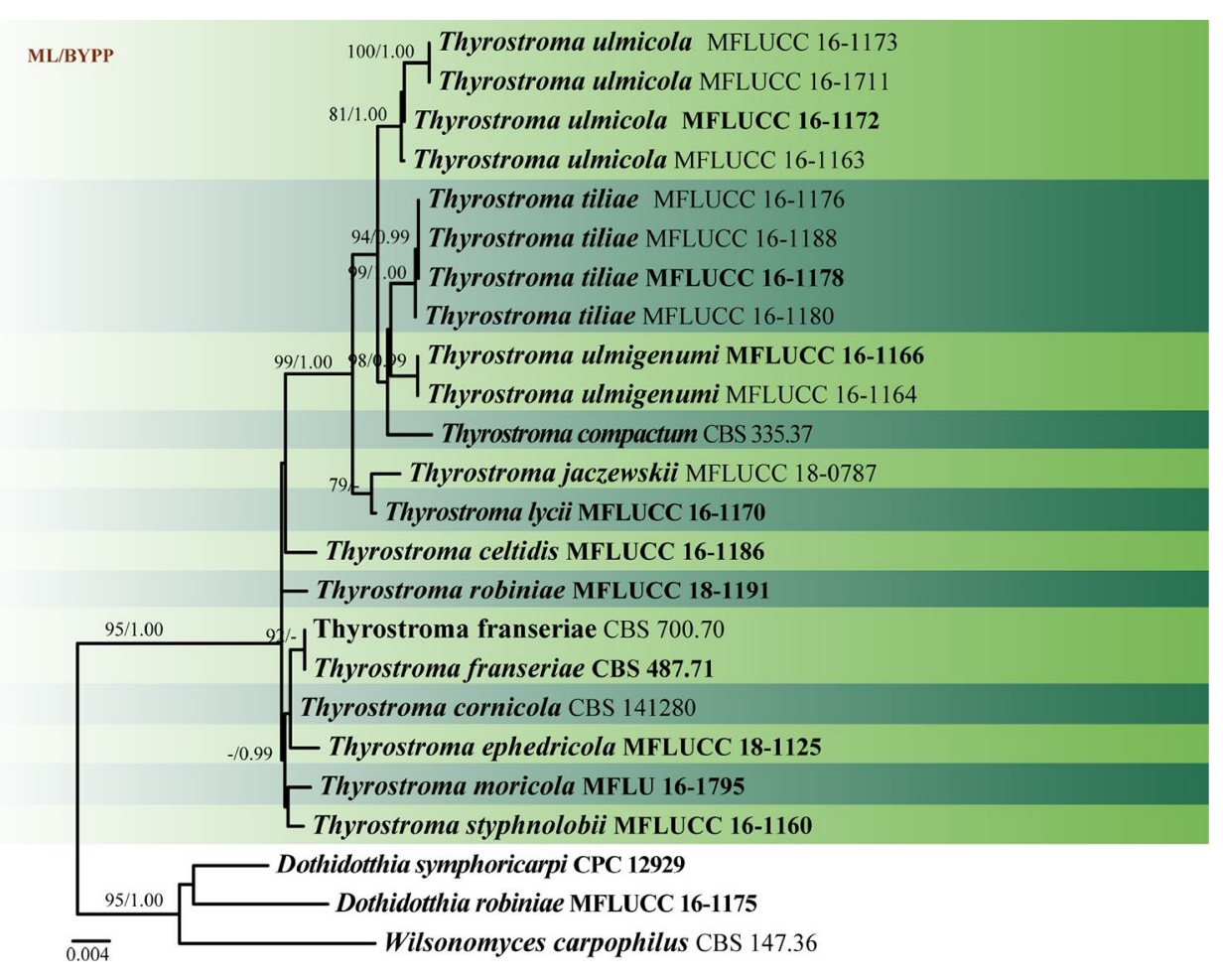

Fig. 31 Phylogenetic tree generated by maximum likelihood analysis of LSU, SSU, ITS and tefl sequence data of Thyrostroma species. Related sequences were obtained from GenBank. The tree was rooted with Dothidotthia robiniae (MFLUCC 16-1175), D. symphoricarpi (CPC 12929) and Wilsonomyces carpophilus CBS 147.36). Tree topology of the ML analysis was similar to the Bayesian analysis. The best scoring RAxML tree with a final likelihood value of - 5556.187049 is presented. The matrix had 170 distinct alignment

\section{Morphological based identification and diversity}

The asexual morph of Cladosporium species is characterized by a unique coronate structure of the conidiogenous loci and conidia, consisting of the central convex dome surrounded by a raised periclinal rim (Bensch et al. 2012; Fig. 33), while ascomata of sexual morphs are identical to those of Mycosphaerella (sect. Tassiana) (Braun et al. 2003). Historically, all types of dematiaceous hyphomycetes with amero- to phragmosporous conidia formed in acropetal chains had been assigned to Cladosporium sensu lato, resulting in the complication to resolve a natural classification of Cladosporium. Various mycologists proposed natural genetic circumscriptions of Cladosporium (David 1997; Braun et al. 2003; Aptroot 2006). David (1997) found the unique structure of conidiogenous loci and conidial hila using scanning electron microscopy. Based on the genetic circumscriptions, some cladosporioid groups, such as Fusicladium being non-coronate (Schubert et al. 2003), have been excluded from Cladosporium s. str. Various Cladosporium species have been re-examined based on the new generic concepts (Schubert and Braun 2004, 2005a, b, 2007; patterns, with $18.30 \%$ of undetermined characters or gaps. Estimated base frequencies were as follows: $\mathrm{A}=0.243922, \mathrm{C}=0.240705, \mathrm{G}$ $=0.270231, \mathrm{~T}=0.245142$; substitution rates $\mathrm{AC}=3.570314, \mathrm{AG}$ $=6.771467$, AT $4.177691, \mathrm{CG}=1.603201, \mathrm{CT}=31.935571, \mathrm{GT}$ $=1.000000 ;$ gamma distribution shape parameter $\alpha=0.602378$. Maximum likelihood bootstrap support values greater than $60 \%$ and Bayesian posterior probabilities $\geq 0.95$ (BYPP) are indicated above the nodes. Ex-type (ex-epitype) and voucher strains are in bold

Schubert 2005; Schubert et al. 2006; Braun and Schubert 2007; Braun et al. 2008). A polyphasic approach revealed three major species complexes within Cladosporium, viz. C. cladosporioides, $C$. herbarum and $C$. sphaerospermum (Schubert et al. 2007; Dugan et al. 2008; Bensch et al. 2010; Bensch et al. 2015). A modern monograph of the genus treated 993 names of Cladosporium sensu lato, of which 169 were recognized in Cladosporium sensu stricto and others remain doubtful (Bensch et al. (2012).

\section{Molecular based identification and diversity}

The first molecular examination of Cladosporium-like hyphomycetes based on ITS and SSU was carried out by Braun et al. (2003), who confirmed the strong heterogeneity. A new genus Davidiella was established to accommodate the sexual morphs of Cladosporium sensu stricto species which were previously assigned in Mycosphaerella. Aptroot (2006) made a better circumscription of Davidiella after he found species of Davidiella have ascospores with irregular cellular inclusions, which are absent in Mycosphaerella. Schoch et al. (2006) studied the phylogenetic relationships 
Table 19 DNA barcodes available for Thyrostroma

\begin{tabular}{|c|c|c|c|c|c|}
\hline Species & Isolate/Voucher no & LSU & SSU & ITS & tefl \\
\hline Thyrostroma compactum & CBS 335.37 & KY905664 & - & KY905670 & KY905681 \\
\hline T. cornicola & CBS 141280* & KX228300 & - & KX228248 & KX228372 \\
\hline T. ephedricola & MFLUCC 18-1125* & MK765854 & MK765853 & MK765855 & - \\
\hline \multirow[t]{2}{*}{ T. franseriae } & CBS 487.71* & KX228301 & - & KX228249 & KY905680 \\
\hline & CBS 700.70 & KX228302 & - & KX228250 & KY905682 \\
\hline T. jaczewskii & MFLUCC 18-0787 & MK765857 & MK765858 & MK765856 & - \\
\hline T. celtidis & MFLUCC 16-1186* & MK751822 & MK751767 & MK751732 & MK908022 \\
\hline T. moricola & MFLU 16-1795* & MK751823 & MK751768 & MK751733 & MK908023 \\
\hline T. lycii & MFLUCC 16-1170* & MK751824 & MK751769 & MK751734 & MK908024 \\
\hline T. robiniae & MFLUCC 18-1191* & MK751825 & MK751770 & MK751735 & MK908025 \\
\hline T. styphnolobii & MFLUCC 16-1160* & MK751826 & MK751771 & MK751736 & MK908026 \\
\hline \multirow[t]{4}{*}{ T. tiliae } & MFLUCC 16-1176 & MK751827 & MK751772 & MK751737 & MK908027 \\
\hline & MFLUCC 16-1178* & MK751828 & MK751773 & MK751738 & MK908028 \\
\hline & MFLUCC 16-1180 & MK751829 & MK751774 & MK751739 & MK908029 \\
\hline & MFLUCC 16-1188 & MK751830 & MK751775 & MK751740 & MK908030 \\
\hline \multirow[t]{4}{*}{ T. ulmicola } & MFLUCC 16-1172* & MK751840 & MK751785 & MK751750 & MK908040 \\
\hline & MFLUCC 16-1173 & MK751841 & MK751786 & MK751751 & MK908041 \\
\hline & MFLUCC 16-1163 & MK751834 & MK751779 & MK751744 & MK908034 \\
\hline & MFLUCC 16-1711 & MK751839 & MK751784 & MK751749 & MK908039 \\
\hline \multirow[t]{2}{*}{ T. ulmigenum } & MFLUCC 16-1166* & MK751846 & MK751791 & MK751756 & MK908046 \\
\hline & MFLUCC 16-1164 & MK751845 & MK751790 & MK751755 & MK908045 \\
\hline
\end{tabular}

Ex-type/ex-epitype/ex-neotype/ex-lectotype strains are in bold and marked with an asterisk (*). Voucher strains are also in bold of 96 taxa of the Dothideomycetes using LSU, SSU, tef1 and rpb2 gene data. Davidiella and its Cladosporium asexual morphs were assigned to the family Cladosporiaceae in the order Capnodiales, together with Mycosphaerellaceae. Crous et al. (2007) delimited Cladosporium from morphologically similar genera using their morphology and DNA phylogeny based on LSU. Several species were transferred to new genera such as Hyalodendriella, Ochrocladosporium, Rachicladosporium, Rhizocladosporium, Toxicocladosporium and Verrucocladosporium. Furthermore, C. castellanii was confirmed as a synonym of Stenella araguata, while the type species of Stenella resided in Teratosphaeriaceae instead of Mycosphaerellaceae. Schubert et al. (2007) performed a comprehensive study of the $C$. herbarum species complex based on both morphology and phylogenetic analysis with five combined genes. Bensch et al. (2010) carried out species and ecological diversity within the $C$. cladosporioides species complex. More than 200 isolates belonging to the C. cladosporioides species complex were examined and analyzed on the basis of ITS, actand tefl gene regions. A comprehensive monograph of Cladosporium sensu lato was provided by Bensch et al. (2012) based on morphology and combined ITS, act and tefl sequence data. In their study, 993 names assigned to Cladosporium sensu lato are treated and 169 names were recognized in Cladosporium sensu stricto. Bensch et al. (2015) introduced the three major species complexes in Cladosporium, i.e. C. cladosporioides, C. herbarum and $C$. sphaerospermum, and 19 new species were described. Razafinarivo et al. (2016) introduced a new species $C$. lebrasiae from milk bread rolls in France, Ma et al. (2017) introduced six new soil-inhabiting Cladosporium species from plateaus in China. Bensch et al. (2018) studied Cladosporium species from indoor environments and introduced 16 new species. Several new Cladosporium species including Cladosporium omanense (Halo et al. 2019), C. passiflorae and C. passifloricola (Rosado et al. 2019) have been introduced more recently. In this study, we reconstruct the phylogeny of Cladosporium based on ITS, tefl and act sequenced data (Table 21; Fig. 34).

Recommended genetic marker (genus level)_ITS and LSU Recommended genetic markers (species level) _ act and tefl (in a few cases $t u b 2$ )

Accepted number of species-There are 844 epithets listed in Index Fungorum (2020), however, 138 species have DNA sequence data.

References-David (1997), Aptroot (2006), Schubert and Braun (2004, 2005a, b, 2007), Schubert (2005), Schubert et al. (2006), Braun and Schubert (2007), Braun et al. (2008) (morphology), Braun et al. (2003), Schoch et al. (2006), Bensch et al. (2010, 2012, 2015), Ma et al. (2017) (morphology and phylogeny) 


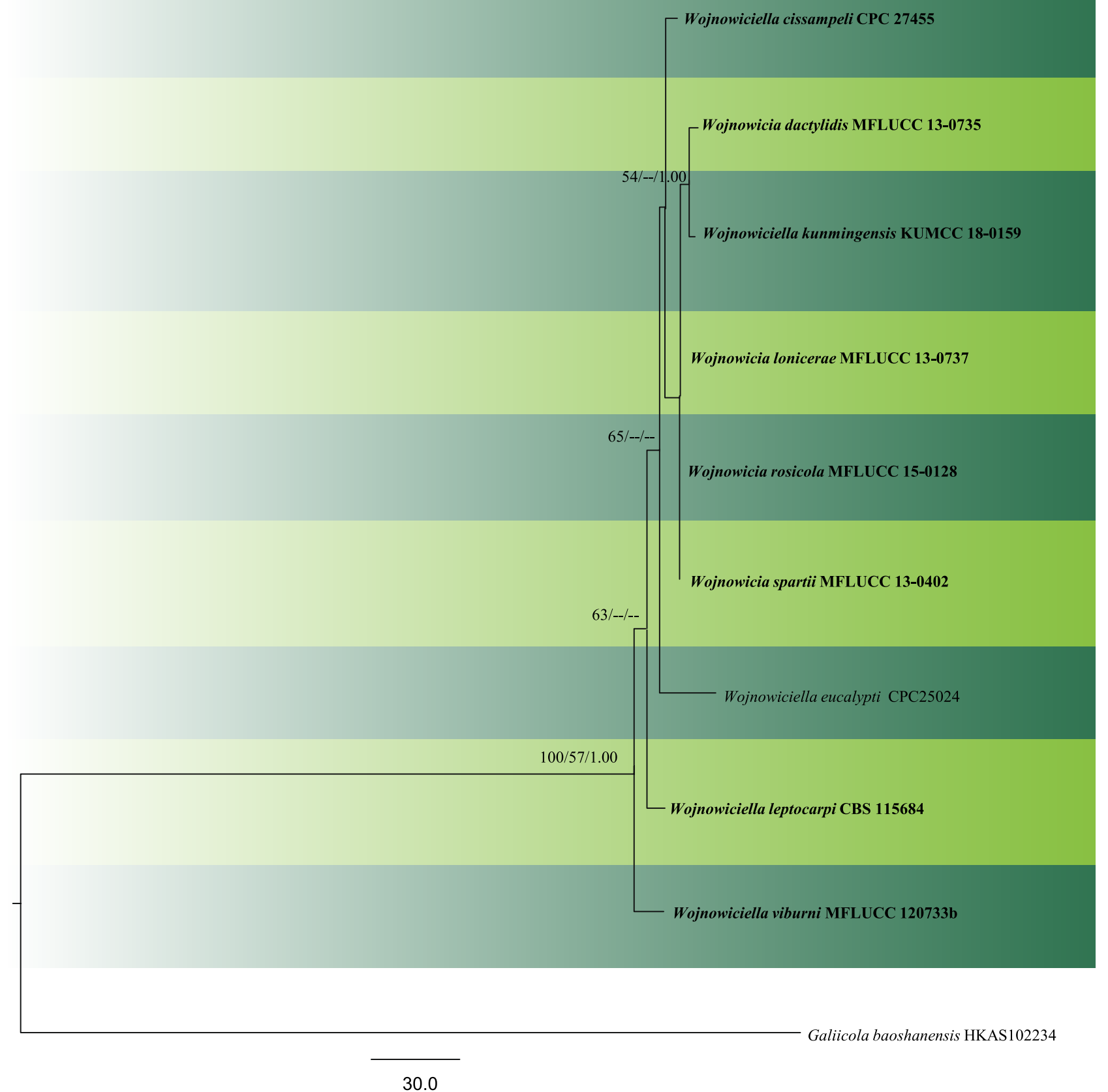

Fig. 32 Phylogram generated from MP analysis based on combined sequences of ITS, LSU and tefl sequences of all the accepted species of Wojnowiciella. Related sequences were obtained from GenBank. Ten taxa are included in the analyses, which comprise 2460 characters including gaps. Single gene analyses were carried out and compared with each species, to compare the topology of the tree and clade stability. The tree was rooted with Galiicola baoshanensis (HKAS102234). The best scoring RAxML tree with a final likeli- hood value of -6772.195394 is presented. The matrix had 261 distinct alignment patterns, with $0.96 \%$ of undetermined characters or gaps. Estimated base frequencies were as follows: $\mathrm{A}=0.230657, \mathrm{C}$ $=0.279364, \mathrm{G}=0.252128, \mathrm{~T}=0.237852$; substitution rates $\mathrm{AC}=$ $1.388608, \mathrm{AG}=2.845402, \mathrm{AT}=2.389715, \mathrm{CG}=0.838197, \mathrm{CT}=$ 7.220493, GT $=1.000000$; gamma distribution shape parameter a $=0.650385$. ML and MP bootstrap support value $\geq 50 \%$ are shown respectively near the nodes. Ex-type strains are in bold 
Table 20 Details of Wojnowiciella, isolates used in the phylogenetic analyses

\begin{tabular}{llllll}
\hline Species & Isolates & ITS & LSU & tef1 & References \\
\hline Wojnowiciella cissampeli & CBS 141297* & KX228272 & KX228323 & LT990616 & Crous et al. (2016) \\
W. dactylidis & MFLUCC 13-0735* & KP744470 & KP684149 & - & Liu et al. (2015) \\
W. eucalypti & CBS 139904* & KR476741 & KR476774 & LT990617 & Crous et al. (2015) \\
W. kunmingensis & KUMCC18-0159* & MK356380 & MK356354 & MK359071 & Phookamsak et al. (2019) \\
W. leptocarpi & CBS 115684* & KX306775 & KX306800 & LT990615 & Hernandez-Restrepo et al. (2016) \\
W. lonicerae & MFLUCC 13-0737* & KP744471 & KP684151 & - & Liu et al. (2015) \\
W. rosicola & MFLUCC 15-0128* & MG828979 & MG829091 & - & Phookamsak et al. (2019) \\
W. spartii & MFLUCC 13-0402* & KU058719 & KU058729 & - & Li et al. (2015) \\
W. viburni & MFLUCC 12-0733* & KC594286 & KC594287 & - & Wijayawardene et al. (2013) \\
\hline
\end{tabular}

Ex-type (or ex-epitype) strains are in bold and marked with an asterisk* and voucher strains are in bold

Fig. 33 Cladosporium cladosporioides. a Conidiomata. b, c, e Macro- and micronematous conidiophores and conidia chains. d. Secondary ramoconidia. f. Conidia. Scale bars: $b$, $\mathrm{c}, \mathrm{e}, \mathrm{f}=50 \mu \mathrm{m}, \mathrm{d}-\mathrm{g}=10 \mu \mathrm{m}$
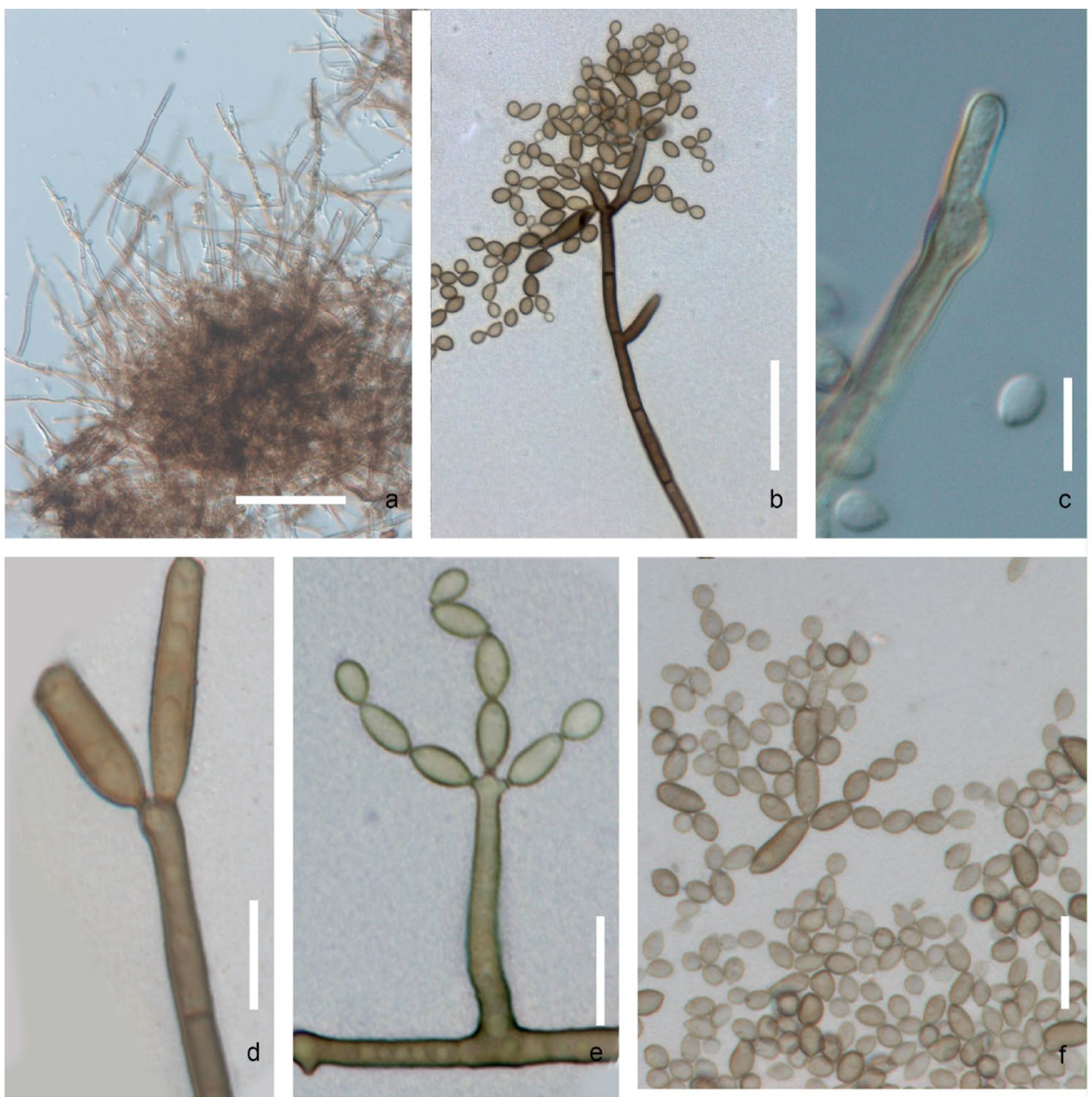

96. Colletotrichum Corda, in Sturm, Deutschl. Fl., 3 Abt. (Pilze Deutschl.) 3(12): 41 (1831)

\section{Background}

Colletotrichum was introduced by Corda (1831), belonging to Glomerellaceae (Glomerellales, Sordariomycetes), and is the sole member of this family (Maharachchikumbura et al. 2015, 2016; Hyde et al. 2020b). Species may occupy different lifestyles, ranging from necrotrophy to hemibiotrophy as well as endophytism (Crouch et al. 2014). Colletotrichum species are important plant pathogens in both tropical and temperate regions on many economically important crops (Hyde et al. 2009a, b, 2014; Cannon et al. 2012; Jayawardena et al. 2016b, c). Based on recognized scientific and economic importance this genus was voted the eighth most important plant pathogenic group in the world (Dean et al. 2012). Colletotrichum species have been identified as endophytes (Manamgoda 
et al. 2013; Tao et al. 2013; Hyde et al. 2014; Jayawardena et al. 2016c) and some are saprobes on dead plant material (Photita et al. 2005; Jayawardena et al. 2016b). A few species have been identified to be pathogenic to humans $(C$. coccodes, C. dematium, C. gloeosporioides (Natarajan et al. 2013)) and on insects (C. fioriniae (Damm et al. 2012b)). Colletotrichum species are cosmopolitan in distribution and show a diverse hosts association (Sharma et al. 2015). A host plant genus can be infected by many Colletotrichum species (Silva et al. 2012; Jayawardena et al. 2016c), and on the contrary, a single species of Colletotrichum can infect many host plants (Damm et al. 2012a, b; Weir et al. 2012).

Correct species identification is important to understand the species diversity, plant pathology and quarantine, concerning human infections, agriculture, bio-control, plant breeding, whole-genome sequencing, developing and maintaining knowledge databases, bioprospecting and understanding the evolutionary history (Jayawardena et al. 2016a). Due to a small number of distinctive morphological characters available for identification, misidentification of these species is frequent. Misapplication and misidentification of species are also due to the misunderstanding of their host-specific nature, ambiguous species boundaries and incorrect sequences (Cannon et al. 2012; Hyde et al. 2014; Jayawardena et al. 2016a). Therefore, having a stable taxonomy for the identification of these species is a significant practical concern (Shenoy et al. 2007). To establish a natural classification system, researchers strongly recommend the use of geographical, ecological, morphological and genetic data (Cai et al. 2009; Sharma and Shenoy 2016).

Species of Colletotrichum are extensively studied as model organisms (Cannon et al. 2012; Hyde et al. 2014). This enables the researchers to understand the pathogen variation, infection mechanism, evolution and population dynamics. Pathogenicity genes of C. graminicola, C. higginsianum and C. orbiculare have been studied (Huser et al. 2009; O'Connell et al. 2012). Asakura et al. (2009) discovered the importance of the pexophagy factor ATG26 for appressorium formation. A total of 28 genome projects that include 25 different Colletotrichum species can be found; 15 of these strains are still at the annotation stage and 13 are now at the 'Fungal Standard Draft' stage (Carbú et al. 2019). These genomes will allow further analysis of species diversity and evolutionary mechanisms and may serve as a foundation for genetic analysis that leads to a greater understanding of interactions between plants and fungal pathogens (Meng et al. 2020). Baroncelli et al. (2016) studied four strains of $C$. acutatum and illustrated the plasticity of Colletotrichum genomes and showed that major changes in host range are associated with relatively recent changes in gene content. A genome of $C$. fructicola from apple in China was compared with its reference genome, which identified a number of strong duplication/loss events at key phylogenetic nodes (Liang et al. 2018). Gan et al. (2019) provided the updated genome for $C$. orbiculare and also provided three draft genomes for $C$. trifolli, C. sidae and $C$. spinosum. Colletotrichum higginsianum has a compartmentalized genome consisting of gene-sparse, transposable elements dense regions with more effector candidate genes and genedense, TE-sparse regions harbouring conserved genes which help the pathogen to generate genomic diversity (Tsushima et al. 2019). Comparative genome analysis indicated that there is a rapid evolution of pathogenicity genes in $C$. tanaceti (Lelwala et al. 2019).

Species of Colletotrichum can be used as biocontrol agents and as biocatalysts (C. dematium, C. gloeosporioides, C. graminicola, C. lindemuthianum, C. orbiculare, C.theobromicola, C. trifoli (Jayawardena et al. 2016b)). Jayawardena et al. (2016b) discussed the importance of secondary metabolites produced by species with relation to pathogenesis, medicines, disease control and toxins.

Classification-Ascomycota, Pezizomycotina Sordariomycetes, Hypocreomycetidae, Glomerellales, Glomerellaceae Type species-Colletotrichum lineola Corda, in Sturm, Deutschl. Fl., 3 Abt. (Pilze Deutschl.) 3(12): 41 (1831)

Distribution-Worldwide

Disease symptoms-Anthracnose disease, red rot, crown and stem rots, ripe rot, seedling blights and brown blotch.

Anthracnose disease symptoms include defined, often sunken necrotic spots on leaves, stems, flowers or fruits and may show a lot of variation depending on the host (35a-e).

Hosts - Pathogens on many host families including, Amaryllidaceae, Amaranthaceae, Anacardiaceae, Annonaceae, Apiaceae, Apocynaceae, Araceae, Araliaceae, Arecaceae, Asparagaceae, Asteraceae, Bignoniaceae, Campanulaceae, Caricaceae, Crassulaceae, Cucurbitaceae, Euphorbiaceae, Fabaceae, Iridaceae, Lamiaceae, Lauraceae, Malvaceae, Melastomataceae, Menispermaceae, Moraceae, Myrtaceae, Oleaceae, Olivaceae, Orchidaceae, Passifloraceae, Pinaceae, Piperaceae, Plumbaginaceae, Poaceae, Podocarpaceae, Polemoniaceae, Proteaceae, Ranunculaceae, Rosaceae, Rubiaceae, Rutaceae, Solanaceae, Theaceae and Vitaceae.

\section{Pathogen biology, disease cycle and epidemiology}

For Colletotrichum biology, disease cycle and epidemiology see Cannon et al. (2012) and De Silva et al. (2017).

\section{Morphological based identification and diversity}

Due to the overlapping morphological characters, species delimitation based on morphology alone is hardly possible (Jayawardena et al. 2016b; Marin-Felix et al. 2017; Fig. $35 f-1)$.

\section{Molecular based identification and diversity}

Cai et al. (2009) proposed the use of a polyphasic approach with multi-loci sequence analyses combined with 
Table 21 DNA barcodes available for Cladosporium

\begin{tabular}{|c|c|c|c|c|}
\hline Species & Isolate & ITS & tefl & act \\
\hline Cladosporium acalyphae & CBS 125982* & HM147994 & HM148235 & HM148481 \\
\hline C. aciculare & CBS 140488* & KT600411 & КT600509 & KT600607 \\
\hline C. aerium & CBS 143356* & MF472897 & MF473324 & MF473747 \\
\hline C. aggregatocicatricatum ${ }^{\#}$ & CBS 140493* & KT600448 & KT600547 & KT600645 \\
\hline C. alboflavescens & CBS 140690* & LN834420 & LN834516 & LN834604 \\
\hline C. allicinum & CBS 121624* & EF679350 & EF679425 & EF679502 \\
\hline C. allii & CBS 101.81 & JN906977 & JN906983 & JN906996 \\
\hline C. angulosum & CBS 140692* & LN834425 & LN834521 & LN834609 \\
\hline C. angustiherbarum & CBS 140479* & KT600378 & KT600475 & KT600574 \\
\hline C. angustisporum & CBS 125983* & HM147995 & HM148236 & HM148482 \\
\hline C. angustiterminale & CBS 140480* & KT600379 & KT600476 & KT600575 \\
\hline C. antarcticum & CBS 690.92* & EF679334 & EF679405 & EF679484 \\
\hline C. anthropophilum & CBS 140685* & LN834437 & LN834533 & LN834621 \\
\hline C. aphidis & CBS 132182* & JN906978 & JN906984 & JN906997 \\
\hline C. arthropodii & CBS 124043* & JN906979 & JN906985 & JN906998 \\
\hline C. asperulatum ${ }^{\#}$ & CBS 126340* & HM147998 & HM148239 & HM148485 \\
\hline C. australiense & CBS 125984* & HM147999 & HM148240 & HM148486 \\
\hline C. austroafricanum & CBS 140481* & KT600381 & KT600478 & KT600577 \\
\hline C. austrohemisphaericum & CBS 140482* & KT600382 & KT600479 & KT600578 \\
\hline C. basiinflatum ${ }^{\#}$ & CBS 822.84* & HM148000 & HM148241 & HM148487 \\
\hline C. chalastosporoides & CBS 125985* & HM148001 & HM148242 & HM148488 \\
\hline C. chasmanthicola & CBS 142612* & KY646221 & KY646227 & KY646224 \\
\hline C. chubutense & CBS 124457* & FJ936158 & FJ936161 & FJ936165 \\
\hline C. cladosporioides ${ }^{\#}$ & CBS 112388* & HM148003 & HM148244 & HM148490 \\
\hline C. colocasiae $^{\#}$ & CBS 386.64* & HM148067 & HM148310 & HM148555 \\
\hline C. colombiae & CBS 274.80B* & FJ936159 & FJ936163 & FJ936166 \\
\hline C. coloradense & CBS $143357 *$ & MF472945 & MF473372 & MF473795 \\
\hline C. crousii & CBS 140686* & LN834431 & LN834527 & LN834615 \\
\hline C. cucumerinum ${ }^{\#}$ & CBS 171.52* & HM148072 & HM148316 & HM148561 \\
\hline C. cycadicola & CBS 137970* & KJ869122 & KJ869236 & KJ869227 \\
\hline C. delicatulum & CBS 126344* & HM148081 & HM148325 & HM148570 \\
\hline C. domesticum & CBS 143358* & MF472955 & MF473382 & MF473805 \\
\hline C. dominicanum & CBS 119415* & DQ780353 & JN906986 & EF101368 \\
\hline C. echinulatum ${ }^{\#}$ & CBS 123191 & JN906980 & JN906987 & JN906999 \\
\hline C. endophyticum & MFLUCC 17-0599* & MG646956 & MG646988 & \\
\hline C. entadae & MFLUCC 17-0919* & MK347728 & & \\
\hline C. europaeum & CBS 134914* & HM148056 & HM148298 & HM148543 \\
\hline C. exasperatum & CBS 125986* & HM148090 & HM148334 & HM148579 \\
\hline C. exile & CBS 125987* & HM148091 & HM148335 & HM148580 \\
\hline C. fildesense & ChFC-554* & JX845290 & MN233633 & MN233632 \\
\hline C. flabelliforme & CBS 126345* & HM148092 & HM148336 & HM148581 \\
\hline C. flavovirens & CBS 140462* & LN834440 & LN834536 & LN834624 \\
\hline C. floccosum $^{\#}$ & CBS 140463* & LN834416 & LN834512 & LN834600 \\
\hline C. funiculosum & CBS 122129* & HM148094 & HM148338 & HM148583 \\
\hline C. fusiforme & CBS 119414* & DQ780388 & JN906988 & EF101372 \\
\hline C. gamsianum & CBS 125989* & HM148095 & HM148339 & HM148584 \\
\hline C. globisporum $^{\#}$ & CBS 812.96* & HM148096 & HM148340 & HM148585 \\
\hline C. grevilleae & CBS 114271* & JF770450 & JF770472 & JF770473 \\
\hline C. halotolerans & CBS 119416* & DQ780364 & JN906989 & EF101397 \\
\hline C. hebeiense ${ }^{\#}$ & JZB390001* & MG516597 & MG516595 & MG516593 \\
\hline C. herbaroides ${ }^{\#}$ & CBS 121626* & EF679357 & EF679432 & EF679509 \\
\hline
\end{tabular}


Table 21 (continued)

\begin{tabular}{|c|c|c|c|c|}
\hline Species & Isolate & ITS & tefl & act \\
\hline C. herbarum & CBS 121621* & EF679363 & EF679440 & EF679516 \\
\hline C. hillianum & CBS 125988* & HM148097 & HM148341 & HM148586 \\
\hline C. inversicolor & CBS 401.80* & HM148101 & HM148345 & HM148590 \\
\hline C. ipereniae & CBS 140483* & KT600394 & KT600491 & KT600589 \\
\hline C. iranicum ${ }^{\#}$ & CBS 126346* & HM148110 & HM148354 & HM148599 \\
\hline C. iridis $^{\#}$ & CBS 138.40* & EF679370 & EF679447 & EF679523 \\
\hline C. kenpeggii & CBS 142613* & KY646222 & KY646228 & KY646225 \\
\hline C. langeronii & CBS 189.54* & DQ780379 & JN906990 & EF101357 \\
\hline C. lebrasiae & CBS 138283* & KJ596568 & KJ596583 & KJ596631 \\
\hline C. licheniphilum & CBS 125990* & HM148111 & HM148355 & HM148600 \\
\hline C. limoniforme $e^{\#}$ & CBS 140484* & KT600397 & KT600494 & KT600592 \\
\hline C. longicatenatum & CBS 140485* & KT600403 & KT600500 & KT600598 \\
\hline C. longissimum & CBS 300.96* & DQ780352 & EU570259 & EF101385 \\
\hline C. lycoperdinum & CBS 126347 & HM148112 & HM148356 & HM148601 \\
\hline C. macrocarpum & CBS 121623* & EF679375 & EF679453 & EF679529 \\
\hline C. magnoliigena & MFLUCC 18-1559* & MK347813 & MK340864 & \\
\hline C. michoacanense & CBS 143588* & LT907958 & LT907945 & LT907961 \\
\hline C. montecillanum & CBS 140486* & KT600406 & KT600504 & KT600602 \\
\hline C. myrtacearum & CBS 126350* & HM148117 & HM148361 & HM148606 \\
\hline C. needhamense & CBS 143359* & MF473142 & MF473570 & MF473991 \\
\hline C. neerlandicum & CBS 143360* & KP701887 & KP701764 & KP702010 \\
\hline C. neolangeronii & CBS 797.97* & MF473143 & & MF473992 \\
\hline C. neopsychrotolerans & CGMCC 3.18031* & KX938383 & KX938400 & KX938366 \\
\hline C. omanense & SQUCC 13165* & MH725789 & MH716047 & MH716046 \\
\hline C. ossifragi & CBS 842.91* & EF679381 & EF679459 & EF679535 \\
\hline C. oxysporum ${ }^{\#}$ & CBS 125991 & HM148118 & HM148362 & HM148607 \\
\hline C. paracladosporioides & CBS 171.54* & HM148120 & HM148364 & HM148609 \\
\hline C. parahalotolerans & CBS 139585* & KP701955 & KP701832 & KP702077 \\
\hline C. paralimoniforme & CGMCC 3.18103* & KX938392 & KX938409 & KX938375 \\
\hline C. parapenidielloides & CBS 140487* & KT600410 & KT600508 & KT600606 \\
\hline C. parasubtilissimum & CBS 143361* & MF473170 & MF473593 & MF474018 \\
\hline C. passiflorae p $^{\#}$ & COAD 2135* & MH682175 & MH724943 & MH729795 \\
\hline C. passifloricola & COAD 2140* & & MH724948 & MH729800 \\
\hline C.penidielloides & CBS 140489* & KT600412 & KT600510 & KT600608 \\
\hline C. perangustum ${ }^{\#}$ & CBS 125996* & HM148121 & HM148365 & HM148610 \\
\hline C.phaenocomae & CBS 128769* & JF499837 & JF499875 & JF499881 \\
\hline C. phlei ${ }^{\#}$ & CBS 358.69* & JN906981 & JN906991 & JN907000 \\
\hline C. phyllactiniicola & CBS 126352* & HM148150 & HM148394 & HM148639 \\
\hline C.phyllophilum & CBS 125992* & HM148154 & HM148398 & HM148643 \\
\hline C.pini-ponderosae & CBS 124456* & FJ936160 & FJ936164 & FJ936167 \\
\hline C. prolongatum & CGMCC 3.18036* & KX938394 & KX938411 & KX938377 \\
\hline C.pseudiridis & CBS 116463* & EF679383 & EF679461 & EF679537 \\
\hline C. pseudochalastosporoides & CBS 140490* & KT600415 & KT600513 & KT600611 \\
\hline C. pseudocladosporioides & CBS 125993* & HM148158 & HM148402 & HM148647 \\
\hline C. psychrotolerans & CBS 119412* & DQ780386 & JN906992 & EF101365 \\
\hline C. pulvericola & CBS 143362* & MF473226 & MF473648 & MF474075 \\
\hline C.puyae & CBS 274.80A* & KT600418 & KT600516 & KT600614 \\
\hline C. ramotenellum & CBS 121628* & EF679384 & EF679462 & EF679538 \\
\hline C. rectoides & CBS 125994* & HM148193 & HM148438 & HM148683 \\
\hline C. rhusicola & CBS 140492* & KT600440 & KT600539 & KT600637 \\
\hline C. ruguloflabelliforme & CBS 140494* & KT600458 & KT600557 & KT600655 \\
\hline
\end{tabular}


Table 21 (continued)

\begin{tabular}{|c|c|c|c|c|}
\hline Species & Isolate & ITS & tefl & act \\
\hline C. rugulovarians & CBS 140495* & KT600459 & KT600558 & KT600656 \\
\hline C. salinae & CBS 119413* & DQ780374 & JN906993 & EF101390 \\
\hline C. scabrellum & CBS 126358* & HM148195 & HM148440 & HM148685 \\
\hline C. silenes & CBS 109082* & EF679354 & EF679429 & EF679506 \\
\hline C. sinense & CBS 143363* & MF473252 & MF473675 & MF474102 \\
\hline C. sinuatum & CGMCC 3.18096* & KX938385 & KX938402 & KX938368 \\
\hline C. sinuosum & CBS 121629* & EF679386 & EF679464 & EF679540 \\
\hline C. sloanii & CBS 143364* & MF473253 & MF473676 & MF474103 \\
\hline C. soldanellae & CBS 132186* & JN906982 & JN906994 & JN907001 \\
\hline C. sphaerospermum ${ }^{\#}$ & CBS 193.54* & DQ780343 & EU570261 & EF101380 \\
\hline C. spinulosum & CBS 119907* & EF679388 & EF679466 & EF679542 \\
\hline C. subcinereum & CBS 140465* & LN834433 & LN834529 & LN834617 \\
\hline C. subinflatum & CBS 121630* & EF679389 & EF679467 & EF679543 \\
\hline C. subtilissimum & CBS 113754* & EF679397 & EF679475 & EF679551 \\
\hline C. subuliforme $e^{\#}$ & CBS 126500* & HM148196 & HM148441 & HM148686 \\
\hline C. succulentum & CBS 140466* & LN834434 & LN834530 & LN834618 \\
\hline C. tenellum ${ }^{\#}$ & CBS 121634* & EF679401 & EF679479 & EF679555 \\
\hline C. tenuissimum ${ }^{\#}$ & CBS 125995* & HM148197 & HM148442 & HM148687 \\
\hline C. tianshanense & CGMCC 3.18033* & KX938381 & & KX938364 \\
\hline C. tuberosum & CBS 140693* & LN834417 & LN834513 & LN834601 \\
\hline C. uredinicola & ATCC 46649 & AY251071 & HM148467 & HM148712 \\
\hline C. uwebraunianum & CBS 143365* & MF473306 & MF473729 & MF474156 \\
\hline C. variabile & CBS 121635* & EF679402 & EF679480 & EF679556 \\
\hline C. varians & CBS 126362* & HM148224 & HM148470 & HM148715 \\
\hline C. velox & CBS 119417* & DQ780361 & JN906995 & EF101388 \\
\hline C. verrucocladosporioides & CBS 126363* & HM148226 & HM148472 & HM148717 \\
\hline C. verruculosum & CGMCC 3.18099* & KX938388 & KX938405 & KX938371 \\
\hline C. versiforme & CBS 140491* & KT600417 & KT600515 & KT600613 \\
\hline C. vicinum & CBS 143366* & MF473311 & MF473734 & MF474161 \\
\hline C. vignae & CBS 121.25 & HM148227 & HM148473 & HM148718 \\
\hline C. welwitschiicola & CBS 142614* & KY646223 & KY646229 & KY646226 \\
\hline C. westerdijkiae & CBS 113746* & HM148061 & HM148303 & HM148548 \\
\hline C. wyomingense & CBS 143367* & MF473315 & MF473738 & MF474165 \\
\hline C. xanthochromaticum & CBS 140691* & LN834415 & LN834511 & LN834599 \\
\hline C. xylophilum & CBS 125997* & HM148230 & HM148476 & HM148721 \\
\hline Toxicocladosporium banksiae & CBS 128215* & HQ599598 & & LT821371 \\
\hline
\end{tabular}

Ex-type/ex-epitype/ex-neotype/ex-lectotype strains are in bold and marked with an asterisk (*). Voucher strains are also in bold. Species confirmed with pathogenicity studies are marked with ${ }^{\#}$

geographical, ecological and morphological data for reliable species delimitation. Application of this polyphasic approach resulted in the delimitation of almost 200 species, most of them belonging to species complexes such as acutatum, boninense and gloeosporioides. There is no universal set of loci to use when identifying Colletotrichum species. Cannon et al. (2012), Damm et al. (2012a, b, 2013, 2014, 2019, Liu et al. 2016) used ITS, gapdh, chs, act, his and tub2 (with some also $g s$ or $\mathrm{cal}$ ) for studying species within the acutatum, boninense, dematium, destructivum, gigasporum, orbiculare, spaethianum and truncatum species complexes, while Weir et al. (2012) additionally applied gs, cal and sod2 within the gloeosporioides species complex. Hyde et al. (2014), Jayawardena et al. (2016b), Marin-Felix et al. (2017) used ITS, gapdh, chs, act and tub2 to differentiate the species. Using five loci for the whole genus gave similar results to 6-7 loci used for the whole genus. In contrast, Crouch et al. (2009b) applied ITS, sod2, apn2 and mat1/apn2, to study the graminicola and caudatum species complexes. Use of ApMat locus to delimit the species within gloeosporioides species complex was emphasized by Silva et al. (2012) and Sharma et al. (2015) as it provides a higher resolution when compared to previously used loci. However, studies by Liu et al. $(2015,2016)$ revealed that using this locus with other 


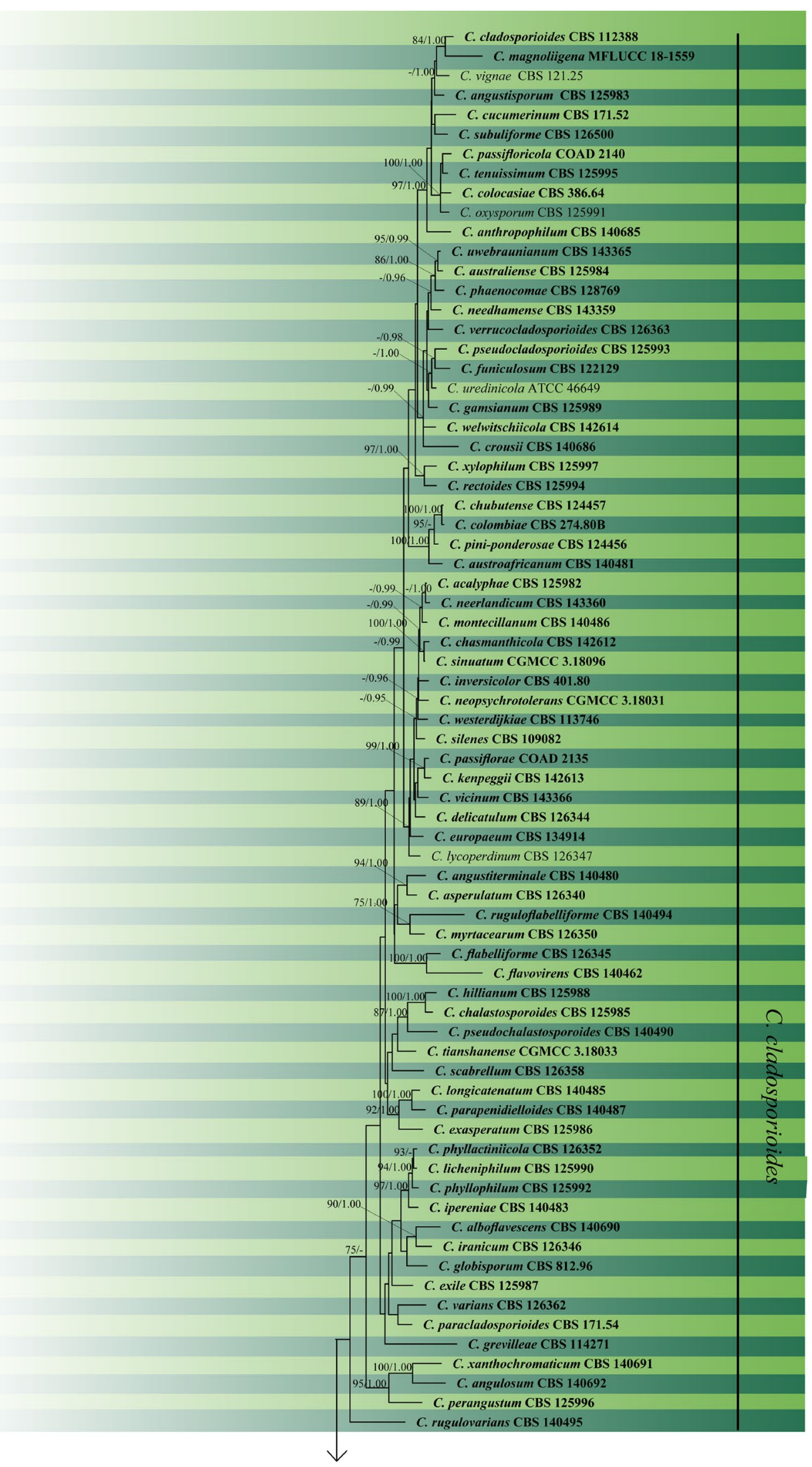

Fig. 34 Phylogram generated from Maximum Likelihood analysis based on ITS, tefl and act sequenced data. Bootstrap support values $\geq 75 \%$ and Bayesian posterior probabilities $\geq 0.95$ are given near the nodes. The ex-type (ex-epitype) and voucher strains are in bold. The tree is rooted with Toxicocladosporium banksiae CBS 128215 


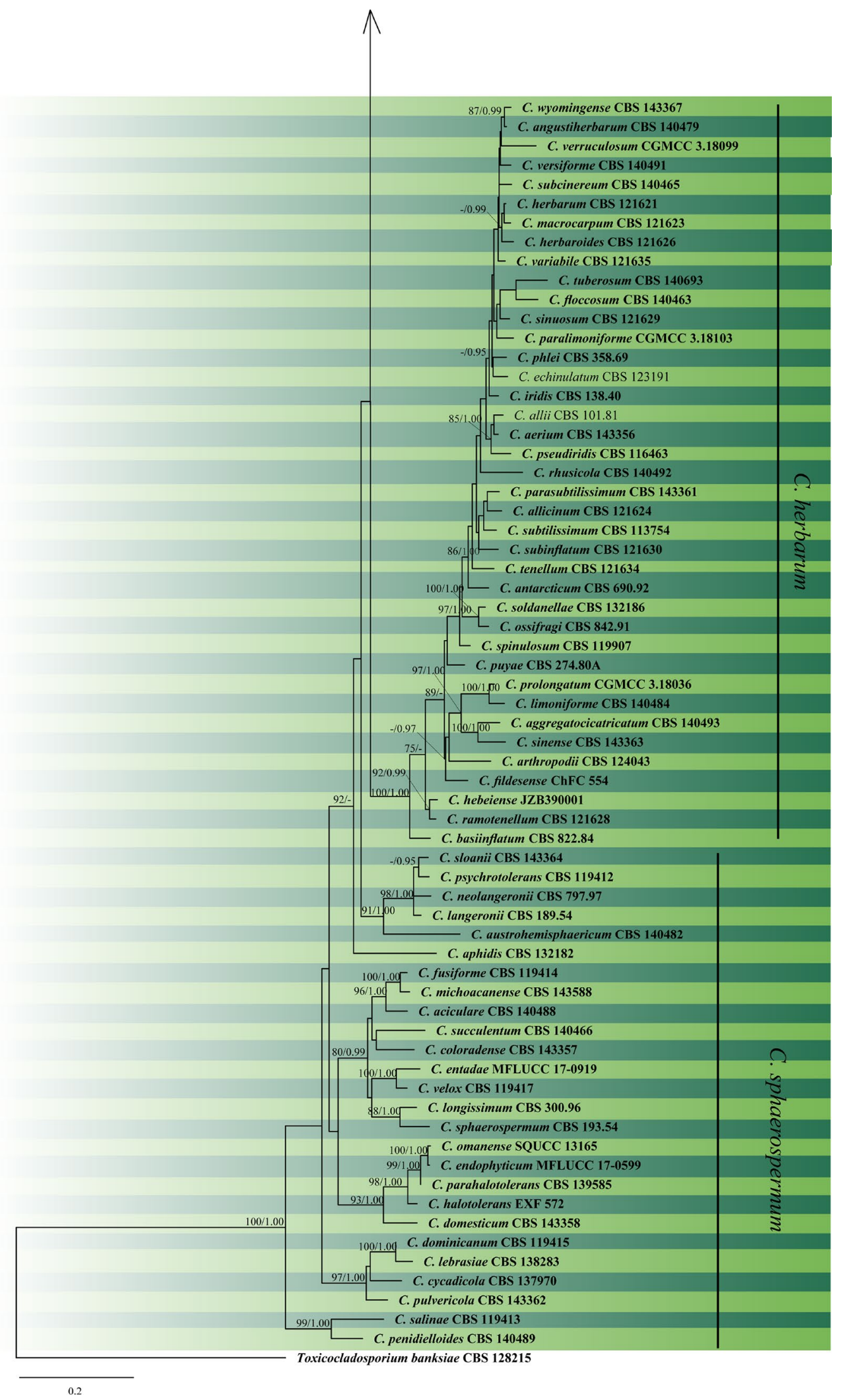

Fig. 34 (continued) 
loci would provide a satisfactory species delimitation within the gloeosporioides species complex. For species delimitation, application of the Genealogical Concordance Phylogenetic Species Recognition (GCPSR) has proven to be a powerful tool (Cai et al. 2009). Coalescent-based species delimitation methods can also be used to infer the dynamic of divergence, evolutionary process and the relationships among species (McCormack et al. 2009, Liu et al. 2016).

Jayawardena et al. (2016b) provided the accepted species for the genus with backbone trees for each species complex and with notes for each accepted species. De Silva et al. (2017) reviewed the lifestyles and how this can be applied to plant biosecurity. Ariyawansa et al. (2015), Yan et al. (2015), Li et al. (2016), De Silva et al. (2017), Hyde et al. (2020a, b), Marin-Felix et al. (2017), Tibpromma et al. (2017, 2018), Samarakoon et al. (2018), Bhunjun et al. (2019) have introduced new species based on morphology, phylogeny and GCPSR evidence. Damm et al. (2019) introduced three new species complexes namely, dracaenophilum, magnum and orchidearum based on morphology and phylogeny. Cabral et al. (2020) based on pathological, morphologi$\mathrm{cal}$, cytogenomic, biochemical and molecular data, assigned the previously known $C$. kahawae subsp. ciggario as a new species, C. ciggario. At present, based on multi-loci phylogeny there are 14 species complexes. With 59 new species having been added since the last treatment (Marin-Felix et al. 2017), here we present an analysis using five loci (Table 21) for all Colletotrichum species (Fig. 36). From the studies conducted on this genus, it is clear that the resolution of species differs depending on both locus and species. Therefore, to select a better genetic marker and the best secondary barcoding gene/genes is still an ongoing process.

\section{Recommended genetic marker (genus level)_ITS}

Recommended genetic markers (species level)—act, apmat, apn2, cal, chs-1, gapdh, gs, his, mat1/apn2, sod2, and tub2. Accepted number of species-There are 903 epithets listed in Index Fungorum (2020), however, 247 species with molecular data are treated as accepted (Table 22).

References-Cai et al. (2009) (polyphasic approach); Hyde et al. (2009a, b) (morphology and accepted species); Cannon et al. (2012) (A review and an updated account of the genus); Crouch et al. (2009a, b, c, 2014), Damm et al. (2009, 2012a, b, 2013, 2014, 2019), Weir et al. (2012) (morphology and phylogeny); Hyde et al. (2014), Jayawardena et al. (2016b), Marin-Felix et al. (2017) (accepted number of species).

\section{Mucor Fresen., Beitr. Mykol. 1: 7 (1850) \\ Background}

Mucor belongs to the order Mucorales, which is among one of the most studied groups of early diverging lineages of fungi. The genus has the largest number of species within the order and half of the sequences submitted to GenBank for Mucorales are of Mucor (Hoffmann et al. 2013; Spatafora et al. 2016; Hyde et al. 2014; Nguyen and Lee 2018).
Mucor belongs to the phylum Mucoromycota, subphylum Mucoromycotina, class Mucoromycetes, order Mucorales and family Mucoraceae (Wijayawardene et al. 2018, 2020). It was described by Fresenius in 1850 and the type species is Mucor mucedo. Recent molecular studies of mucoralean species have indicated that Mucor is polyphyletic (Nguyen et al. 2017). However, even with definite results showing the polyphyly of Mucor, few clear lineages within Mucor are recognized. Some of these lineages share innate characteristics, such as sporangium size and branching of tall sporangiophores and the morphology is still widely used in current taxonomy (Walther et al. 2013). Analysis of internal transcribed spacer (ITS) and large subunit (LSU) rDNA sequence data of several mucoralean species, showed that some Mucor species with curved sporangiophores grouped with species of Backusella and hence was transferred to Backusella (Walther et al. 2013; Nguyen et al. 2017). Mucor species are commonly isolated from soil, dung, insect, and fruits (Benny 2008). Some species are of biotechnological importance such as biofuel, enzyme, terpernoid production and biotransformation while other species cause mucoromycosis in immunosuppressed humans (Nguyen et al. 2017; Steve et al. 2018; Morin-Sardin et al. 2017). Comparative analyses of five Mucor species based on their lifestyles (M. fuscus and M. lanceolatus (used for cheese production), $M$. circinelloides and $M$. racemosus (opportunistic pathogens) and M. endophyticus (an endophyte)) revealed the core transcriptome comprising 5566 orthogroups included genes potentially involved in secondary metabolism. Due to the wide taxonomic range investigated, the five transcriptomes also displayed specificities that can be linked to the different lifestyles, such as differences in the composition of transcripts identified as virulence factors or carbohydrate transporters. Research on this genus has changed its course to identify the link between genetic and biological data, especially in terms of lifestyle and adaptations to a given habitat (Lebreton et al. 2019) (Figs. 37, 38).

Classification-Zygomycota, Mucoromycotina, Mucoromycetes, Mucorales, Mucorineae, Mucoraceae

Type species-Mucor mucedo Fresen.

Distribution-Worldwide

Disease symptoms-Mucor rot and soft rot

Mucor species especially M. fragilis, M. irregularis, M. piriformis and $M$. racemosus often cause postharvest diseases such as Mucor rot and soft rot. The initial symptoms of Mucor rot are similar to plant diseases caused by green mold, blue mold, and sour mold. The infected tissue becomes soft and watery. The lesions turn light to dark brown and as the infection progresses, white or shiny grey sporangiophores form at the lesions. Fungal growth spreads across the whole host and masses of sporangiophores bearing black to pale brown sporangia are observed. Decaying fruits become "juicy" within which are abundant spores of 
the fungus (Li et al. 2014; Saito et al. 2016). Ito et al. (1979) found that three species of fruit flies namely Certitis capitata, Dacus cucurbitae and D. dorsalis, can transmit Mucor rot in guava.

Soft rot caused by Mucor racemosus results in watersoaked appearance followed by a softening of the infected part. When the disease progresses growth of white mycelium and brownish to grey sporangia can be observed. Finally, the infected tissue is broken down and disintegrates in a watery rot (Kwon and Hong 2005; López et al. 2016).
Fig. 36 Phylogram generated from MP analysis based on combined sequences of ITS, gapdh, chs, act and tub2 sequences of all species of Colletotrichum with molecular data. Related sequences were obtained from GenBank. Two hundred and fourty nine taxa are included in the analyses, which comprise 2296 characters including gaps, of which 868 characters are constant, 295 characters are parsimony-uninformative and 1133 characters parsimony-informative. The parsimony analysis of the data matrix resulted in the maximum of ten equally most parsimonious trees with a length of 10088 steps $(\mathrm{CI}=0.283, \mathrm{RI}=0.840, \mathrm{RC}=0.237, \mathrm{HI}=0.717)$ in the third tree. Single gene analyses were carried out and compared with each species, to compare the topology of the tree and clade stability. The tree was rooted with Monilochaetes infuscans (CBS 869.96) and M. populi (CBS 139623). MP bootstrap support value $\geq 50 \%$ and BYPP $\geq 0.9$ are shown respectively near the nodes. Ex-type strains are in bold
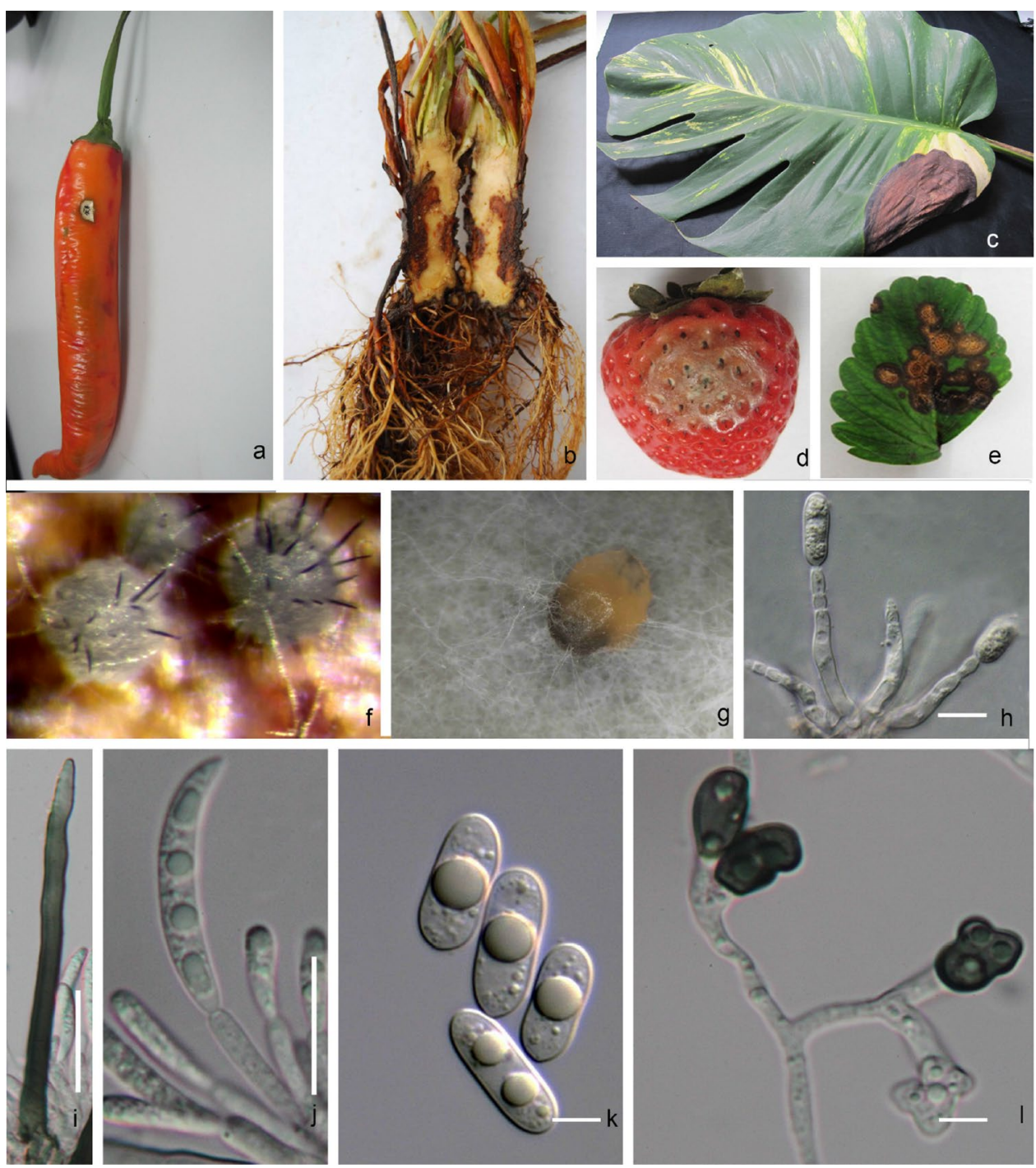

Fig. 35 Colletotrichum sp. a Chilli anthracnose symptoms b Crown rot of strawberry $\mathbf{c}$ Leaf blight of Cannas sp. d, e strawberry anthracnose symptoms $\mathbf{f}, \mathbf{g}$ Conidiomata and spore mass $\mathbf{h}$ Conidiophore i Setae $\mathbf{j}$ Conidiogenous cells and curved conidia $\mathbf{k}$ Conidia of $C$. gloeosporioides I Appressoria. Phylogram generated from RAxML analysis based on combined sequences of ITS and LSU of Mucorand Backusella species. Eighty-one taxa were used for the analysis, which consisted 1256 characters includinggaps. The tree is rooted using Backusella lamprospora (CBS 195.28), and B. grandis (CBS 186.87). Likelihoodof the best scoring ML tree was -16174.718247 . The concatenated matrix contained 657 distinct alignmentpatterns with $22.27 \%$ of undetermined characters or gaps. Estimated base frequencies were as follows; $\mathrm{A}=0.302146, \mathrm{C}=0.168433, \mathrm{G}=0.219872, \mathrm{~T}=0.309549$; substitution rates $\mathrm{AC}=0.776817, \mathrm{AG}=3.154911, \mathrm{AT}=1.674079, \mathrm{CG}=0.632500$, $\mathrm{CT}=4.808262, \mathrm{GT}=1.000000$; gamma distribution shape parameter $\alpha=$ 0.291909.Type species in the dataset are indicated using T. Maximum likelihood RAxML bootstrap support value $\geq 70 \%$ and Bayesian posterior probabilities $\geq 0.70$ are shown near the nodes (ML/BYPP). - indicates bootstrap supportvalues lower than $70 \%$ and $*$ shows unrecovered branching 


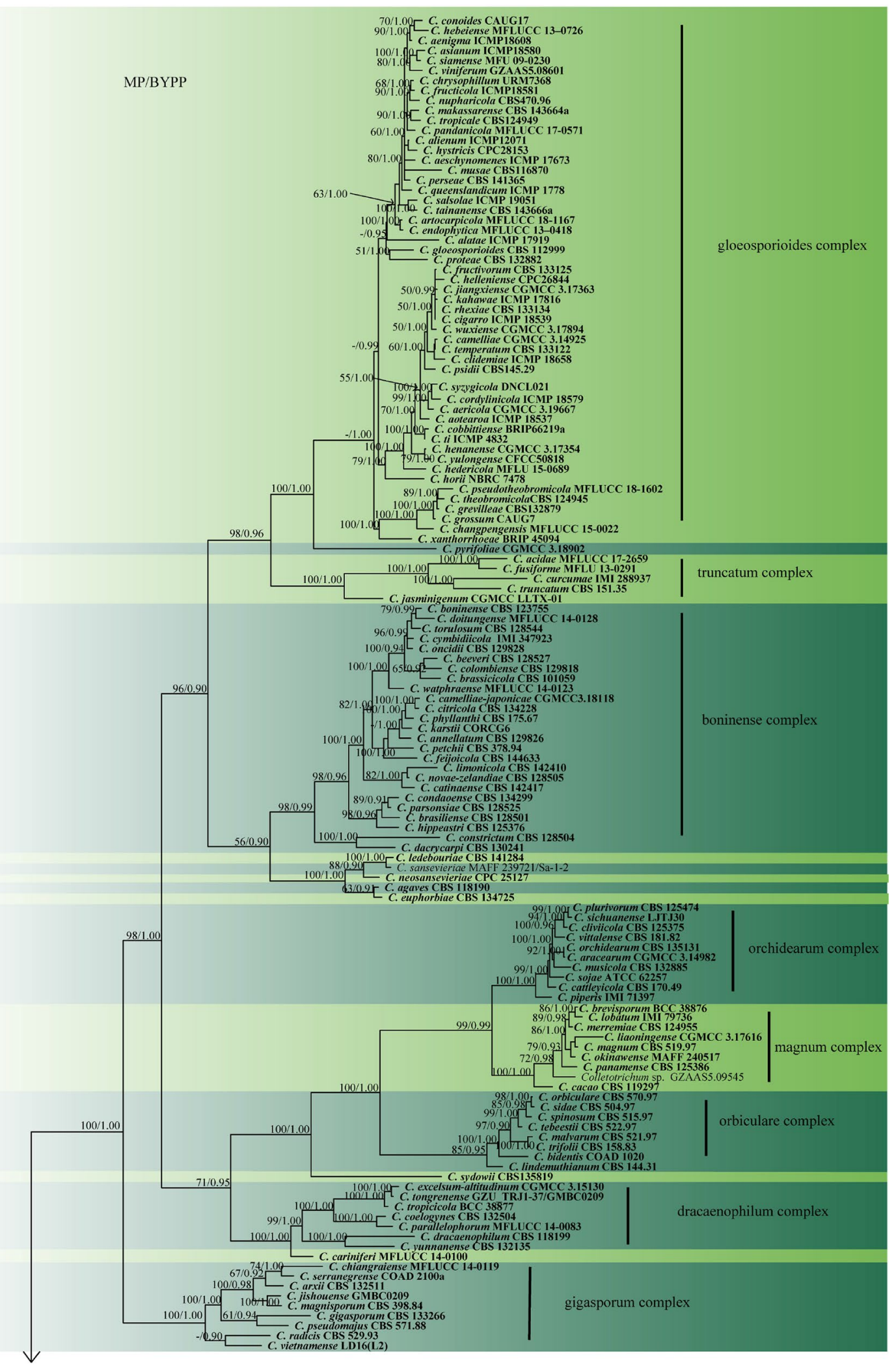




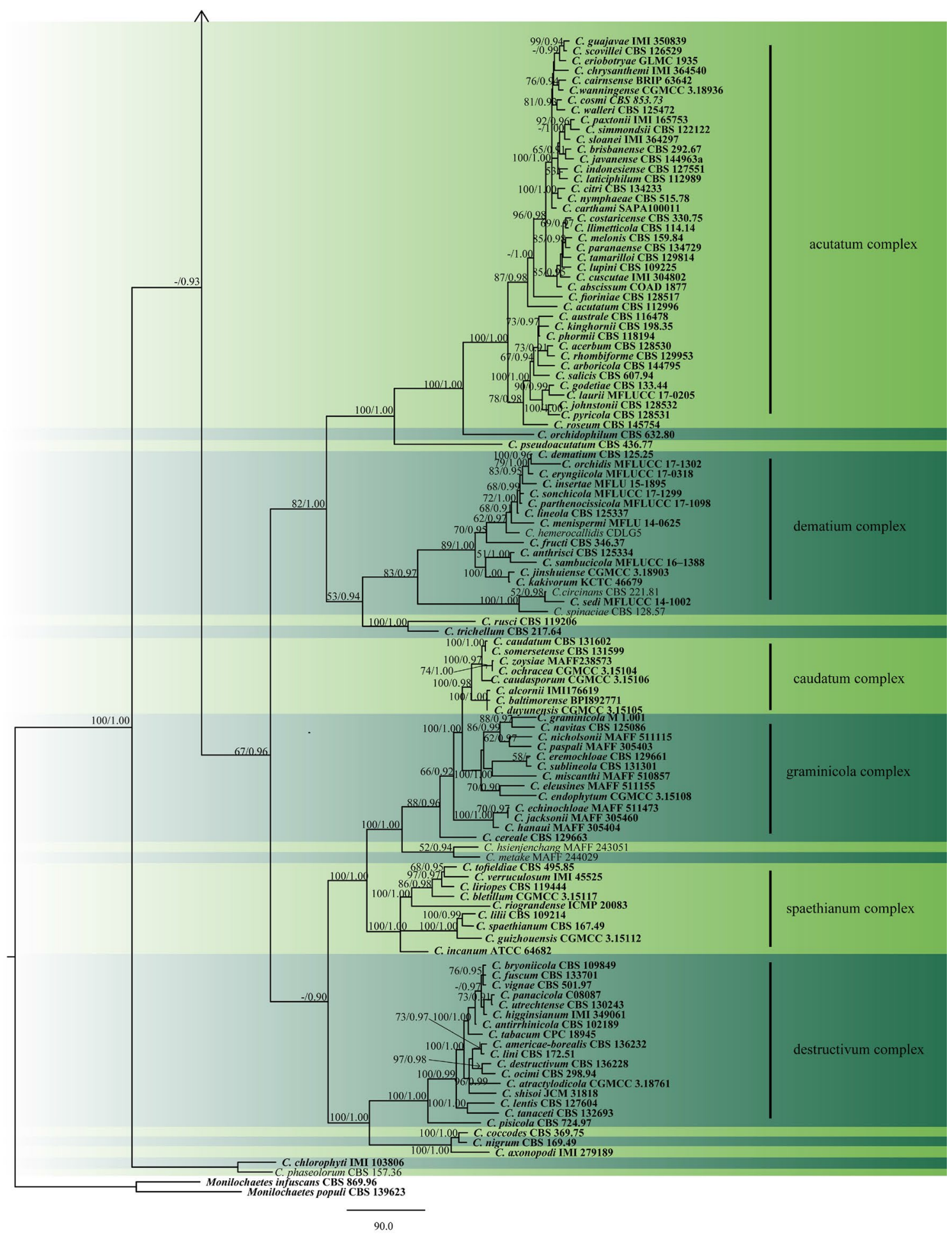

Fig. 36 (continued)

Hosts-Wide host range including, Actinidia deliciosa, Citrus reticulata, Dioscorea species, Fragaria $\times$ ananassa, Mangifera indica, Manihot esculenta, Prunus species, Psidium guajava, Solanum melongena, Solanum lycopersicum and Vitis species (Farr and Rossman 2020).

\section{Pathogen biology, disease cycle and epidemiology}

The pathogen reproduces asexually. Mucor rot often develops by infecting punctured wounds and cracks on the surface of the fruit, stem end or calyx of the host. In the early stages of the infection, the fruit becomes soft and 
Table 22 DNA barcodes available for Colletotrichum, isolates used in the phylogenetic analyses

\begin{tabular}{|c|c|c|c|c|c|c|c|}
\hline Species name & Isolate no & ITS & gapdh & chs-1 & act & $t u b 2$ & Complex \\
\hline Colletotrichum abscissum ${ }^{\#}$ & COAD 1877* & KP843126 & KP843129 & KP843132 & KP843141 & KP843135 & acutatum \\
\hline C. acerbum & CBS 128530* & JQ948459 & JQ948790 & JQ949120 & JQ949780 & JQ950110 & acutatum \\
\hline C. acidae & MFLUCC 17-2659* & MG996505 & МH003691 & MH003694 & MH003697 & MH003700 & truncatum \\
\hline C. acutatum ${ }^{\#}$ & CBS 112996* & JQ005776 & JQ948677 & JQ005797 & JQ005839 & JQ005860 & acutatum \\
\hline C. aenigma ${ }^{\#}$ & ICMP 18608* & JX010244 & JX010044 & JX009774 & JX009443 & JX010389 & gloeosporioides \\
\hline C. aericola ${ }^{\#}$ & CGMCC 3.19667* & MK914635 & MK935455 & MK935541 & MK935374 & MK935498 & gloeosporioides \\
\hline C. aeschynomene $e^{\text {s\# }}$ & ICMP 17673 & JX010176 & JX009930 & JX009799 & JX009483 & JX010392 & gloeosporioides \\
\hline C. agaves & CBS 118190* & DQ286221 & & & & & singleton \\
\hline C. alcornii & IMI176619* & JX076858 & & & & & caudatum \\
\hline C. alatae $^{\#}$ & CBS 304.67* & JX010190 & JX009990 & JX009837 & JX009471 & JX010383 & gloeosporioides \\
\hline C. alienum ${ }^{\#}$ & ICMP 12071* & JX010251 & JX010028 & JX009882 & JX009572 & JX010411 & gloeosporioides \\
\hline C. americae-borealis ${ }^{\#}$ & CBS 136232* & KM105224 & KM105579 & KM105294 & KM105434 & KM105504 & destructivum \\
\hline C. annellatum & CBS 129826* & JQ005222 & JQ005309 & JQ005396 & JQ005570 & JQ005656 & boninense \\
\hline C. anthrisci & CBS 125334* & GU227845 & GU228237 & GU228335 & GU227943 & GU228139 & dematium \\
\hline C. antirrhinicola & CBS 102189* & KM105180 & KM105531 & KM105250 & KM105390 & KM105460 & destructivum \\
\hline C. aotearoa & ICMP 18537* & JX010205 & JX010005 & JX009853 & JX009854 & JX010420 & gloeosporioides \\
\hline C. araceaerum & CGMCC 3.14982* & KX853166 & KX893585 & & KX893577 & KX893581 & singleton \\
\hline C. arboricola ${ }^{\#}$ & CBS 144795* & MH817944 & MH817950 & & MH817956 & MH817962 & acutatum \\
\hline C. artocarpicola & MFLUCC 18-1167* & MN415991 & MN435568 & MN435569 & MN435570 & MN435567 & gloeosporioides \\
\hline C. arxii & CBS 132511* & KF687716 & KF687843 & KF687780 & KF687802 & KF687881 & gigasporum \\
\hline C. asianum ${ }^{\#}$ & ICMP 18580* & JX010196 & JX010053 & JX009867 & JX009584 & JX010406 & gloeosporioides \\
\hline C. atractylodicola & CGMCC 3.18761* & KR149280 & KR259334 & KR259333 & KR132243 & KU058178 & destructivum \\
\hline C. australe & CBS 116478* & JQ948455 & JQ948786 & JQ949116 & JQ949776 & JQ950106 & acutatum \\
\hline C. axonopodi & IMI 279189/279189AA & EU554086 & & & & & singleton \\
\hline C. beeveri & CBS 128527* & JQ005171 & JQ005258 & JQ005345 & JQ005519 & JQ005605 & boninense \\
\hline C. baltimorense & BPI892771* & JX076866 & & & & & caudatum \\
\hline C.bidentis & COAD 1020* & KF178481 & KF178506 & KF178530 & KF178578 & KF178602 & orbiculare \\
\hline C. bletillum & CGMCC 3.15117* & JX625178 & KC843506 & & KC843542 & JX625207 & spaethianum \\
\hline C. boninense $e^{\#}$ & CBS 123755* & JQ005153 & JQ005240 & JQ005327 & JQ005501 & JQ005588 & boninense \\
\hline C. brasiliense & CBS 128501* & JQ005235 & JQ005322 & JQ005409 & JQ005583 & JQ005669 & boninense \\
\hline C. brassicicola & CBS 101059* & JQ005172 & JQ005259 & JQ005346 & JQ005520 & JQ005606 & boninense \\
\hline C. brevisporum ${ }^{\#}$ & BCC 38876* & JN050238 & JN050227 & & JN050216 & JN050244 & magnum \\
\hline C. brisbaniense & CBS 292.67* & JQ948291 & JQ948621 & JQ948952 & JQ949612 & JQ949942 & acutatum \\
\hline C. bryoniicola & CBS 109849* & KM105181 & KM105532 & KM105251 & KM105391 & KM105461 & destructivum \\
\hline C. cacao $^{\#}$ & CBS 119297* & MG600772 & MG600832 & MG600878 & MG600976 & MG601039 & magnum \\
\hline C. cairnsense $e^{\#}$ & BRIP 63642* & KU923672 & KU923704 & KU923710 & KU923716 & KU923688 & acutatum \\
\hline C. camelliae $^{\#}$ & CGMCC3.14925* & KJ955081 & KJ954782 & & KJ954363 & KJ955230 & gloeosporioides \\
\hline C. camelliae-japonicae & CGMCC3.18118* & KX853165 & KX893584 & & KX893576 & KX893580 & boninense \\
\hline C. carthami $^{\#}$ & SAPA100011* & AB696998 & & & & AB696992 & acutatum \\
\hline C. catinaense $^{\#}$ & CBS 142417* & KY856400 & KY856224 & KY856136 & KY855971 & KY856482 & boninense \\
\hline C. cattleyicola & CBS 170.49* & MG600758 & MG600819 & MG600866 & MG600963 & MG601025 & orchidearum \\
\hline C. cariniferi & MFLUCC 14-0100* & MF448521 & & & & MH351274 & singleton \\
\hline C. caudatum & CBS 131602* & JX076860 & & & & & caudatum \\
\hline C. caudasporum & CGMCC 3.15106* & JX625162 & KC843512 & & KC843526 & JX625190 & caudatum \\
\hline C. cereale . $^{\#}$ & CBS 129663* & JQ005774 & & JQ005795 & JQ005837 & JQ005858 & graminicola \\
\hline C. changpingens $e^{\#}$ & MFLUCC 15-0022* & KP683152 & KP852469 & KP852449 & KP683093 & KP852490 & gloeosporioides \\
\hline C. chlorophyti ${ }^{\#}$ & IMI 103806* & GU227894 & GU228286 & GU228384 & GU227992 & GU228188 & singleton \\
\hline C. chiangraiense & MFLUCC 14-0119* & MF448522 & & & MH376383 & MH351275 & gigapsorum \\
\hline C. chrysanthemi ${ }^{\#}$ & IMI 364540* & JQ948273 & JQ948603 & JQ948934 & JQ949594 & JQ949924 & acutatum \\
\hline C. chrysophillum & URM7368* & KX094252 & KX094183 & KX094083 & KX093982 & KX094285 & gloeosporioides \\
\hline
\end{tabular}


Table 22 (continued)

\begin{tabular}{|c|c|c|c|c|c|c|c|}
\hline Species name & Isolate no & ITS & gapdh & $c h s-1$ & act & $t u b 2$ & Complex \\
\hline C. ciggaro $^{\#}$ & ICMP 18539* & JX010230 & JX009966 & JX009800 & JX009523 & JX010434 & gloeosporioides \\
\hline C. circinans & CBS 221.81 & GU227855 & GU228247 & GU228345 & GU227953 & GU228149 & dematium \\
\hline C. citri & CBS 134233* & KC293581 & KC293741 & KY856138 & KY855973 & KC293661 & acutatum \\
\hline C. citricola $^{\#}$ & CBS 134228* & KC293576 & KC293736 & KC293792 & KC293616 & KC293656 & boninense \\
\hline C. clidemiae & ICMP 18658* & JX010265 & JX009989 & JX009877 & JX009537 & JX010438 & gloeosporioides \\
\hline C. cliviicola $^{\#}$ & CBS 125375* & MG600733 & MG600795 & MG600850 & MG600939 & MG601000 & orchidearum \\
\hline C. cobbittiense & BRIP 66219a* & MH087016 & MH094133 & MH094135 & MH094134 & MH094137 & gloeosporioides \\
\hline C. coccodes $^{\#}$ & CBS 369.75* & HM171679 & HM171673 & JQ005796 & HM171667 & JQ005859 & singleton \\
\hline C. coelogynes & CBS 132504* & MG600713 & MG600776 & MG600836 & MG600920 & MG600980 & dracaenophilum \\
\hline C. colombiense & CBS 129818* & JQ005174 & JQ005261 & JQ005348 & JQ005522 & JQ005608 & boninense \\
\hline C. condaoense & CBS 134299* & MH229914 & MH229920 & MH229926 & & MH229923 & boninense \\
\hline C. conoides ${ }^{\#}$ & CAUG17* & KP890168 & KP890162 & KP890156 & KP890144 & KP890174 & gloeosporioides \\
\hline C. constrictum & CBS 128504* & JQ005238 & JQ005325 & JQ005412 & JQ005586 & JQ005672 & boninense \\
\hline C. cordylinicola ${ }^{\#}$ & MFU 09-0551* & JX010226 & JX009975 & JX009864 & HM470234 & JX010440 & gloeosporioides \\
\hline C. cosmi & CBS 853.73* & JQ948274 & JQ948604 & JQ948935 & JQ949595 & JQ949925 & acutatum \\
\hline C. costaricense & CBS 330.75* & JQ948180 & JQ948510 & JQ948841 & JQ949501 & JQ949831 & acutatum \\
\hline C. curcumae $^{\#}$ & IMI 288937* & GU227893 & GU228285 & GU228383 & GU227991 & GU228187 & truncatum \\
\hline C. cuscutae & IMI 304802* & JQ948195 & JQ948525 & JQ948856 & JQ949516 & JQ949846 & acutatum \\
\hline C. cymbidiicola $^{\#}$ & IMI 347923* & JQ005166 & JQ005253 & JQ005340 & JQ005514 & JQ005600 & boninense \\
\hline C. dacrycarpi & CBS 130241* & JQ005236 & JQ005323 & JQ005410 & JQ005584 & JQ005670 & boninense \\
\hline C. dematium ${ }^{\#}$ & CBS 125.25* & GU227819 & GU228211 & GU228309 & GU227917 & GU228113 & dematium \\
\hline C. destructivum ${ }^{\#}$ & CBS 136228* & KM105207 & KM105561 & KM105277 & KM105417 & KM105487 & destructivum \\
\hline C. doitungense & MFLUCC 14-0128* & MF448524 & MH049480 & & MH376385 & MH351277 & boninense \\
\hline C. dracaenophilum ${ }^{\#}$ & CBS 118199* & JX519222 & JX546707 & JX519230 & JX519238 & JX519247 & dracaenophilum \\
\hline C. duyunensis & CGMCC 3.15105* & JX625160 & KC843515 & & KC843530 & JX625187 & caudatum \\
\hline C. echinochloae & MAFF 511473* & AB439811 & & & & & graminicola \\
\hline C. eleusines & MAFF 511155* & JX519218 & & JX519226 & JX519234 & JX519243 & graminicola \\
\hline C. endophytica ${ }^{\#}$ & MFLUCC 13-0418* & KC633854 & KC832854 & & KF306258 & & gloeosporioides \\
\hline C. endophytum & CGMCC $3.15108 *$ & JX625177 & KC843521 & & KC843533 & JX625206 & graminicola \\
\hline C. eremochloae $e^{\#}$ & CBS 129661* & JX519220 & & JX519228 & JX519236 & JX519245 & graminicola \\
\hline C. eriobotryae en $^{\#}$ & GLMC 1935* & MF772487 & MF795423 & MN191653 & MN191648 & MF795428 & acutatum \\
\hline C. eryngiicola & MFLUCC 17-0318* & KY792726 & KY792723 & KY792720 & KY792717 & KY792729 & dematium \\
\hline C. excelsum-altitudinum & CGMCC 3.15130* & HM751815 & KC843502 & & KC843548 & JX625211 & dracaenophilum \\
\hline C. euphorbiae & CBS 134725* & KF777146 & KF777131 & KF777128 & KF777125 & KF777247 & singleton \\
\hline C. falcatum ${ }^{\#}$ & CBS 147945* & JQ005772 & & JQ005793 & JQ005835 & JQ005856 & graminicola \\
\hline C. feijoicola & CBS $144633 *$ & MK876413 & MK876475 & & MK876466 & MK876507 & boninense \\
\hline C. fioriniae f $^{\#}$ & CBS 128517* & JQ948292 & JQ948622 & JQ948953 & JQ949613 & JQ949943 & acutatum \\
\hline C. fructi & CBS 346.37* & GU227844 & GU228236 & GU228334 & GU227942 & GU228138 & dematium \\
\hline C. fructicola ${ }^{\#}$ & ICMP 18581* & JX010165 & JX010033 & JX009866 & FJ907426 & JX010405 & gloeosporioides \\
\hline C. fructivorum $^{\#}$ & CBS 133125* & JX145145 & & & & JX145196 & gloeosporioides \\
\hline C. fuscum $^{\#}$ & CBS 133701* & KM105174 & KM105524 & KM105244 & KM105384 & KM105454 & destructivum \\
\hline C. fusiforme & MFLU 13-0291* & KT290266 & KT290255 & KT290253 & KT290251 & KT290256 & truncatum \\
\hline C. gigasporum ${ }^{\#}$ & CBS 133266* & KF687715 & KF687822 & KF687761 & & KF687866 & gigasporum \\
\hline C. gloeosporioides ${ }^{\#}$ & CBS 112999* & JQ005152 & JQ005239 & JQ005326 & JQ005500 & JQ005587 & gloeosporioides \\
\hline C. godetiae g $^{\#}$ & CBS 133.44* & JQ948402 & JQ948733 & JQ949063 & JQ949723 & JQ950053 & acutatum \\
\hline C. graminicola $^{\#}$ & M 1.001* & JQ005767 & & JQ005788 & JQ005830 & JQ005851 & graminicola \\
\hline C. grevilleae & CBS 132879* & KC297078 & KC297010 & KC296987 & KC296941 & KC297102 & gloeosporioides \\
\hline C. grossum $^{\#}$ & CAUG7* & KP890165 & KP890159 & KP890153 & KP890141 & KP890171 & gloeosporioides \\
\hline C. guajavae & IMI 350839* & JQ948270 & JQ948600 & JQ948931 & JQ949591 & JQ949921 & acutatum \\
\hline C. guizhouensis & CGMCC 3.15112* & JX625158 & KC843507 & & KC843536 & JX625185 & spaethianum \\
\hline
\end{tabular}


Table 22 (continued)

\begin{tabular}{|c|c|c|c|c|c|c|c|}
\hline Species name & Isolate no & ITS & gapdh & $c h s-1$ & act & $t u b 2$ & Complex \\
\hline C. hanaui & MAFF 305404* & JX519217 & & JX519225 & & JX519242 & graminicola \\
\hline C. hebeiense ${ }^{\#}$ & MFLUCC13-0726* & KF156863 & KF377495 & KF289008 & KF377532 & KF288975 & gloeosporioides \\
\hline C. hedericola & MFLU 15-0689* & MN631384 & & MN635794 & MN635795 & & gloeosporioides \\
\hline C. helleniense $e^{\#}$ & CBS 142418* & KY856446 & KY856270 & KY856186 & KY856019 & KY856528 & gloeosporioides \\
\hline C. henanense $e^{\#}$ & CGMCC 3.17354* & KJ955109 & KJ954810 & & KM023257 & KJ955257 & gloeosporioides \\
\hline C. hemerocallidis & CDLG5 & JQ400005 & JQ400012 & Q399998 & JQ399991 & JQ400019 & dematium \\
\hline C. higginsianum ${ }^{\#}$ & IMI 349061* & KM105184 & KM105535 & KM105254 & KM105394 & KM105464 & destructivum \\
\hline C. hippeastri & CBS 125376* & JQ005231 & JQ005318 & JQ005405 & JQ005579 & JQ005665 & boninense \\
\hline C. horii h $^{\#}$ & NBRC 7478* & GQ329690 & GQ329681 & JX009752 & JX009438 & JX010450 & gloeosporioides \\
\hline C. hystricis ${ }^{\#}$ & CBS 142411* & KY856450 & KY856274 & KY856190 & KY856023 & KY856532 & gloeosporioides \\
\hline C. hsienjenchang & MAFF 243051 & AB738855 & & AB738846 & AB738845 & & singleton \\
\hline C. incanum & ATCC 64682* & KC110789 & KC110807 & & KC110825 & KC110816 & spaethianum \\
\hline C. indonesiense & CBS 127551* & JQ948288 & JQ948618 & JQ948949 & JQ949609 & JQ949939 & acutatum \\
\hline C. insertae & MFLU 15-1895* & KX618686 & KX618684 & KX618683 & KX618682 & KX618685 & dematium \\
\hline C. jacksonii & MAFF 305460* & JX519216 & & JX519224 & JX519233 & JX519241 & graminicola \\
\hline C. jasminigenum & CGMCC LLTX-01* & HM131513 & HM131499 & & HM131508 & HM153770 & truncatum \\
\hline C. javanense ${ }^{\#}$ & CBS 144963a* & MH846576 & MH846572 & MH846573 & MH846575 & MH846574 & acutatum \\
\hline C. jiangxiense & CGMCC 3.17363* & KJ955201 & KJ954902 & & KJ954471 & KJ955348 & gloeosporioides \\
\hline C. jinshuiense ${ }^{\#}$ & CGMCC 3.18903* & MG748077 & MG747995 & MG747913 & MG747767 & MG748157 & dematium \\
\hline C. jishouense & GMBC0209* & MH482929 & MH681658 & & MH708135 & MH727473 & gigasporum \\
\hline C. johnstonii & CBS 128532* & JQ948444 & JQ948775 & JQ949105 & JQ949765 & JQ950095 & acutatum \\
\hline C. kahawae & IMI 319418* & JX010231 & JX010012 & JX009813 & JX009452 & JX010444 & gloeosporioides \\
\hline C. kakivorum $^{\#}$ & КСТC 46679* & LC324781 & LC324787 & LC324783 & LC324785 & LC324791 & dematium \\
\hline C. karstiii $^{\#}$ & CORCG6* & HM585409 & HM585391 & HM582023 & HM581995 & HM585428 & boninense \\
\hline C. kinghornii & CBS 198.35* & JQ948454 & JQ948785 & JQ949115 & JQ949775 & JQ950105 & acutatum \\
\hline C. laticiphilum ${ }^{\#}$ & CBS 112989* & JQ948289 & JQ948619 & JQ948950 & JQ949610 & JQ949940 & acutatum \\
\hline C. lauri & MFLUCC 17-0205* & KY514347 & KY514344 & KY514341 & KY514338 & KY514350 & acutatum \\
\hline C. ledebouriae & CBS 141284* & KX228254 & & & KX228357 & & singleton \\
\hline C. lentis ${ }^{\#}$ & CBS 127604* & JQ005766 & KM105597 & JQ005787 & JQ005829 & JQ005850 & destructivum \\
\hline C. liaoningense $e^{\#}$ & CGMCC 3.17616* & KP890104 & KP890135 & KP890127 & KP890097 & KP890111 & magnum \\
\hline C. lilii & CBS 109214/BBA 62147* & GU227810 & GU228202 & GU228300 & GU227908 & GU228104 & spaethianum \\
\hline C. lini & CBS 172.51* & JQ005765 & KM105581 & JQ005786 & JQ005828 & JQ005849 & destructivum \\
\hline C. limetticola & CBS 114.14* & JQ948193 & JQ948523 & JQ948854 & JQ949514 & JQ949844 & acutatum \\
\hline C. limonicola ${ }^{\#}$ & CBS 142410* & KY856472 & KY856296 & KY856213 & KY856045 & KY856554 & boninense \\
\hline C. lindemuthianum ${ }^{\#}$ & CBS 144.31* & JQ005779 & JX546712 & JQ005800 & JQ005842 & JQ005863 & orbiculare \\
\hline C. lineola ${ }^{\#}$ & CBS 125337* & GU227829 & GU228221 & GU228319 & GU227927 & GU228123 & dematium \\
\hline C. liriopes ${ }^{\#}$ & CBS 119444* & GU227804 & GU228196 & GU228294 & GU227902 & GU228098 & spaethianum \\
\hline C. lobatum & IMI 79736* & MG600768 & MG600828 & MG600874 & MG600972 & MG601035 & magnum \\
\hline C. lupini ${ }^{\#}$ & CBS 109225* & JQ948155 & JQ948485 & JQ948816 & JQ949476 & JQ949806 & acutatum \\
\hline C. magnisporum & CBS 398.84* & KF687718 & KF687842 & KF687782 & KF687803 & KF687882 & gigasporum \\
\hline C. makassarense $e^{\#}$ & CBS 143664a* & MH728812 & MH728820 & MH805850 & MH781480 & MH846563 & gloeosporioides \\
\hline C. magnum & CBS 519.97* & MG600769 & MG600829 & MG600875 & MG600973 & MG601036 & magnum \\
\hline C. malvarum & CBS 521.97* & KF178480 & KF178504 & KF178529 & KF178577 & KF178601 & orbiculare \\
\hline C. melonis ${ }^{\#}$ & CBS 159.84* & JQ948194 & JQ948524 & JQ948855 & JQ949515 & JQ949845 & acutatum \\
\hline C. menispermi & MFLU 14-0625* & KU242357 & KU242356 & KU242355 & KU242353 & KU242354 & dematium \\
\hline C. metake & MAFF 244029 & AB738859 & & & & & singleton \\
\hline C. merremiae & CBS 124955* & MG600765 & MG600825 & MG600872 & MG600969 & MG601032 & magnum \\
\hline C. miscanthi & MAFF 510857* & JX519221 & & JX519229 & JX519237 & JX519246 & graminicola \\
\hline C. musae & CBS 116870* & HQ596292 & HQ596299 & JX009896 & HQ596284 & HQ596280 & gloeosporioides \\
\hline C. musicola ${ }^{\#}$ & CBS 132885* & MG600736 & MG600798 & MG600853 & MG600942 & MG601003 & orchidearum \\
\hline
\end{tabular}


Table 22 (continued)

\begin{tabular}{|c|c|c|c|c|c|c|c|}
\hline Species name & Isolate no & ITS & gapdh & chs-1 & $a c t$ & $t u b 2$ & Complex \\
\hline C. navitas & CBS 125086* & JQ005769 & & JQ005790 & JQ005832 & JQ005853 & graminicola \\
\hline C. neosansevieriae & CPC 25127* & KR476747 & KR476791 & & KR476790 & KR476797 & singleton \\
\hline C. nicholsonii & MAFF 511115* & JQ005770 & & JQ005791 & JQ005833 & JQ005854 & graminicola \\
\hline C. nigrum $^{\#}$ & CBS 169.49* & JX546838 & JX546742 & JX546693 & JX546646 & JX546885 & singleton \\
\hline C. novae-zelandiae ${ }^{\#}$ & CBS $128505^{*}$ & JQ005228 & JQ005315 & JQ005402 & JQ005576 & JQ005662 & boninense \\
\hline C. nupharicola ${ }^{\#}$ & CBS 470.96* & JX010187 & JX009972 & JX009835 & JX009437 & JX010398 & gloeosporioides \\
\hline C. nymphaeae ${ }^{\#}$ & CBS 515.78* & JQ948197 & JQ948527 & JQ948858 & JQ949518 & JQ949848 & acutatum \\
\hline C. ocimi & CBS 298.94* & KM105222 & KM105577 & KM105292 & KM105432 & KM105502 & destructivum \\
\hline C. ochracea & CGMCC 3.15104* & JX625156 & KC843513 & & КC843527 & JX625183 & caudatum \\
\hline C. okinawense $\mathrm{e}^{\#}$ & MAFF 240517* & MG600767 & MG600827 & & MG600971 & MG601034 & magnum \\
\hline C. oncidii & CBS 129828* & JQ005169 & JQ005256 & JQ005343 & JQ005517 & JQ005603 & boninense \\
\hline C. orbiculare \# $^{\text {. }}$ & CBS 570.97* & KF178466 & KF178490 & KF178515 & KF178563 & KF178587 & orbiculare \\
\hline C. orchidearum ${ }^{\#}$ & CBS 135131* & MG600738 & MG600800 & MG600855 & MG600944 & MG601005 & orchidearum \\
\hline C. orchidophilum ${ }^{\#}$ & CBS 632.80* & JQ948151 & JQ948481 & JQ948812 & JQ949472 & JQ949802 & singleton \\
\hline C. orchidis & MFLUCC 17-1302* & MK502144 & MK496857 & MK496855 & MK496853 & MK496859 & dematium \\
\hline C. panacicola & $\mathrm{C} 08087 *$ & GU935869 & GU935849 & & GU944758 & GU935889 & destructivum \\
\hline C. pandanicola & MFLUCC 17-0571* & MG646967 & MG646934 & MG646931 & MG646938 & MG646926 & gloeosporioides \\
\hline C. panamense & CBS 125386* & MG600766 & MG600826 & MG600873 & MG600970 & MG601033 & magnum \\
\hline C. paranaense $e^{\#}$ & CBS 134729* & KC204992 & KC205026 & KC205043 & KC205077 & KC205060 & acutatum \\
\hline C. parallelophorum & MFLUCC 14-0083* & MF448525 & MK165695 & & & MH351280 & singleton \\
\hline C. parsonsiae & CBS 128525* & JQ005233 & JQ005320 & JQ005407 & JQ005581 & JQ005667 & boninense \\
\hline C. parthenocissicola & MFLUCC 17-1098* & MK629452 & MK639362 & MK639356 & MK639358 & MK639360 & dematium \\
\hline C. paspali & MAFF 305403* & JX519219 & & JX519227 & JX519235 & JX519244 & graminicola \\
\hline C. paxtonii & IMI 165753* & JQ948285 & JQ948615 & JQ948946 & JQ949606 & JQ949936 & acutatum \\
\hline C. petchii & CBS 378.94* & JQ005223 & JQ005310 & JQ005397 & JQ005571 & JQ005657 & boninense \\
\hline C. persea $e^{\#}$ & CBS 141365* & KX620308 & KX620242 & & KX620145 & KX620341 & gloeosporioides \\
\hline C. phaseolorum ${ }^{\#}$ & CBS 157.36 & GU227896 & GU228288 & GU228386 & GU227994 & GU228190 & dematium \\
\hline C. phormii & CBS 118194* & JQ948446 & JQ948777 & JQ949107 & JQ949767 & JQ950097 & acutatum \\
\hline C. phyllanthi ${ }^{\#}$ & CBS 175.67* & JQ005221 & JQ005308 & JQ005395 & JQ005569 & JQ005655 & boninense \\
\hline C. piperis $^{\#}$ & IMI 71397* & MG600760 & MG600820 & MG600867 & MG600964 & MG601027 & orchidearum \\
\hline C. pisicola & CBS 724.97* & KM105172 & KM105522 & KM105242 & KM105382 & KM105452 & destructivum \\
\hline C. plurivorum ${ }^{\#}$ & CBS 125474* & MG600718 & MG600781 & MG600841 & MG600925 & MG600985 & orchidearum \\
\hline C. pseudoacutatum ${ }^{\#}$ & CBS 436.77* & JQ948480 & JQ948811 & JQ949141 & JQ949801 & JQ950131 & singleton \\
\hline C.pseudomajus & CBS 571.88* & KF687722 & KF687826 & KF687779 & KF687801 & KF687883 & gigasporum \\
\hline C. pseudotheobromicola & MFLUCC 18-1602* & MH817395 & MH853675 & MH853678 & MH853681 & MH853684 & gloeosporioides \\
\hline C. psidii & CBS 145.29* & JX010219 & JX009967 & JX009901 & JX009515 & JX010443 & gloeosporioides \\
\hline C. proteae & CBS 132882* & KC297079 & KC297009 & KC296986 & КC296940 & KC297101 & gloeosporioides \\
\hline C. pyricola & CBS 128531* & JQ948445 & JQ948776 & JQ949106 & JQ949766 & JQ950096 & acutatum \\
\hline C. pyrifoliae p $^{\#}$ & CGMCC 3.18902* & MG748078 & MG747996 & MG747914 & MG747768 & MG748158 & singleton \\
\hline C. queenslandicum ${ }^{\#}$ & ICMP 1778* & JX010276 & JX009934 & JX009899 & JX009447 & JX010414 & gloeosporioides \\
\hline C. radicis & CBS 529.93* & KF687719 & KF687825 & KF687762 & KF687785 & KF687869 & gigasporum \\
\hline C. rhexiae & CBS 133134* & JX145128 & & & & JX145179 & gloeosporioides \\
\hline C. rhombiforme ${ }^{\#}$ & CBS 129953* & JQ948457 & JQ948788 & JQ949118 & JQ949778 & JQ950108 & acutatum \\
\hline C. riograndense & ICMP 20083* & KM655299 & KM655298 & KM655297 & KM655295 & KM655300 & spaethianum \\
\hline C. roseum & CBS 145754 * & MK903611 & MK903603 & & MK903604 & MK903607 & acutatum \\
\hline C. rusci & CBS 119206* & GU227818 & GU228210 & GU228308 & GU227916 & GU228112 & singleton \\
\hline C. salicis ${ }^{\#}$ & CBS 607.94* & JQ948460 & JQ948791 & JQ949121 & JQ949781 & JQ950111 & acutatum \\
\hline C. salsolae ${ }^{\#}$ & ICMP 19051* & JX010242 & JX009916 & JX009863 & JX009562 & JX010403 & gloeosporioides \\
\hline C. sambucicola & MFLUCC 16-1388* & KY098781 & KY098780 & KY098779 & KY098778 & KY098782 & dematium \\
\hline C. sansevieriae ${ }^{\#}$ & MAFF 239721/Sa-1-2 & LC179806 & LC180130 & LC180129 & LC180127 & LC180128 & singleton \\
\hline
\end{tabular}


Table 22 (continued)

\begin{tabular}{|c|c|c|c|c|c|c|c|}
\hline Species name & Isolate no & ITS & gapdh & $c h s-1$ & act & $t u b 2$ & Complex \\
\hline C. scovillei ${ }^{\#}$ & CBS 126529* & JQ948267 & JQ948597 & JQ948928 & JQ949588 & JQ949918 & acutatum \\
\hline C. sedi & MFLUCC14-1002* & KM974758 & KM974755 & KM974754 & KM974756 & KM974757 & dematium \\
\hline C. serranegrense & COAD 2100a* & KY400111 & & KY407894 & KY407892 & KY407896 & gigasporum \\
\hline C. shisoit $^{\#}$ & JCM 31818* & MH660930 & MH660931 & MH660929 & MH660928 & MH660932 & destructivum \\
\hline C. siamense s $^{\#}$ & MFU 090230* & FJ972613 & FJ972575 & JX009865 & FJ907423 & FJ907438 & gloeosporioides \\
\hline C. sidae & CBS 504.97* & KF178472 & KF178497 & KF178521 & KF178569 & KF178593 & orbiculare \\
\hline C. simmondsii ${ }^{\#}$ & CBS 122122* & JQ948276 & JQ948606 & JQ948937 & JQ949597 & JQ949927 & acutatum \\
\hline C. sloanei & IMI 364297* & JQ948287 & JQ948617 & JQ948948 & JQ949608 & JQ949938 & acutatum \\
\hline C. somersetense & CBS 131599* & JX076862 & & & & & caudatum \\
\hline C. sonchicola & MFLUCC 17-1299* & KY962757 & KY962754 & KY962751 & KY962748 & & dematium \\
\hline C. sojae & ATCC 62257* & MG600749 & MG600810 & MG600860 & MG600954 & MG601016 & orchidearum \\
\hline C. spaethianum ${ }^{\#}$ & CBS 167.49* & GU227807 & GU228199 & GU228297 & GU227905 & GU228101 & spaethianum \\
\hline C. spinaciae ${ }^{\#}$ & CBS 128.57 & GU227847 & GU228239 & GU228337 & GU227945 & GU228141 & dematium \\
\hline C. spinosum & CBS 515.97* & KF178474 & KF178498 & KF178523 & KF178571 & KF178595 & orbiculare \\
\hline C. sublineola ${ }^{\#}$ & CBS 131301* & JQ005771 & & JQ005792 & JQ005834 & JQ005855 & graminicola \\
\hline C. sydowii & CBS135819* & KY263783 & KY263785 & KY263787 & KY263791 & KY263793 & singleton \\
\hline C. syzygiicola & MFLUCC 10-0624* & KF242094 & KF242156 & & KF157801 & KF254880 & gloeosporioides \\
\hline C. tabacum & СРC 18945* & KM105204 & KM105557 & KM105274 & KM105414 & KM105484 & destructivum \\
\hline C. tainanense & CBS 143666a* & MH728818 & MH728823 & MH805845 & MH781475 & MH846558 & gloeosporioides \\
\hline C. tanaceti $^{\#}$ & CBS 132693* & JX218228 & JX218243 & JX259268 & JX218238 & JX218233 & destructivum \\
\hline C. tamarilloi ${ }^{\#}$ & CBS 129814* & JQ948184 & JQ948514 & JQ948845 & JQ949505 & JQ949835 & acutatum \\
\hline C. tebeesti & CBS 522.97* & KF178473 & KF178505 & KF178522 & KF178570 & KF178594 & orbiculare \\
\hline C. theobromicola & ICMP 18649* & JX010294 & JX010006 & JX009869 & JX009444 & JX010447 & gloeosporioides \\
\hline C. temperatum & CBS 133122* & JX145159 & & & & JX145211 & gloeosporioides \\
\hline C. $t i^{\#}$ & ICMP 4832* & JX010269 & JX009952 & JX009898 & JX009520 & JX010442 & gloeosporioides \\
\hline C. tofieldiae & CBS 495.85* & GU227801 & GU228193 & GU228291 & GU227899 & GU228095 & spaethianum \\
\hline C. tongrenense & $\begin{array}{c}\text { GZU_TRJ1-37/ } \\
\text { GMBC0209* }\end{array}$ & MH482933 & MH705332 & & MH717074 & MH729805 & dracaenophilum \\
\hline C. torulosum & CBS 128544* & JQ005164 & JQ005251 & JQ005338 & JQ005512 & JQ005598 & boninense \\
\hline C. trichellum & CBS 217.64* & GU227812 & GU228204 & GU228302 & GU227910 & GU228106 & singleton \\
\hline C. trifolii ${ }^{\#}$ & CBS 158.83* & KF178478 & KF178502 & KF178527 & KF178575 & KF178599 & orbiculare \\
\hline C. tropicale & CBS 124949* & JX010264 & JX010007 & JX009870 & JX009489 & JX010407 & gloeosporioides \\
\hline C. tropicicola & ВCC 38877* & JN050240 & JN050229 & & JN050218 & JN050246 & dracaenophilum \\
\hline C. truncatum ${ }^{\#}$ & CBS 151.35* & GU227862 & GU228254 & GU228352 & GU227960 & GU228156 & truncatum \\
\hline C. utrechtense & CBS 130243* & KM105201 & KM105554 & KM105271 & KM105411 & KM105481 & destructivum \\
\hline C. verruculosum & IMI 45525* & GU227806 & GU228198 & GU228296 & GU227904 & GU228100 & spaethianum \\
\hline C. vietnamense & LD16(L2)* & KF687721 & KF687832 & KF687769 & KF687792 & KF687877 & gigasporum \\
\hline C. vignae & CBS 501.97* & KM105183 & KM105534 & KM105253 & KM105393 & KM105463 & destructivum \\
\hline C. viniferum ${ }^{\#}$ & GZAAS5.08601* & JN412804 & JN412798 & & JN412795 & JN412813 & gloeosporioides \\
\hline C. vittalense & CBS 181.82* & MG600734 & MG600796 & MG600851 & MG600940 & MG601001 & orchidearum \\
\hline C. walleri & CBS 125472* & JQ948275 & JQ948605 & JQ948936 & JQ949596 & JQ949926 & acutatum \\
\hline C. wanningense $e^{\#}$ & CGMCC 3.18936* & MG830462 & MG830318 & MG830302 & MG830270 & MG830286 & acutatum \\
\hline C. watphraense & MFLUCC 14-0123* & MF448523 & MH049479 & & MH376384 & MH351276 & boninense \\
\hline C. wuxiense w $^{\#}$ & CGMCC 3.17894* & KU251591 & KU252045 & KU251939 & KU251672 & KU252200 & gloeosporioides \\
\hline C. xanthorrhoeae & BRIP 45094* & JX010261 & JX009927 & JX009823 & JX009478 & JX010448 & gloeosporioides \\
\hline C. yulongense & CFCC 50818* & MH751507 & MK108986 & MH793605 & MH777394 & MK108987 & gloeosporioides \\
\hline C. yunnanense & CBS 132135* & JX546804 & JX546706 & JX519231 & JX519239 & JX519248 & dracaenophilum \\
\hline C. zoysiae & MAFF238573* & JX076871 & & & & & caudatum \\
\hline
\end{tabular}

Ex-type/ex-epitype/ex-neotype/ex-lectotype strains in bold and marked with an asterisk (*).Voucher strains are also in bold. Species confirmed with pathogenicity studies are marked with ${ }^{\#}$ 


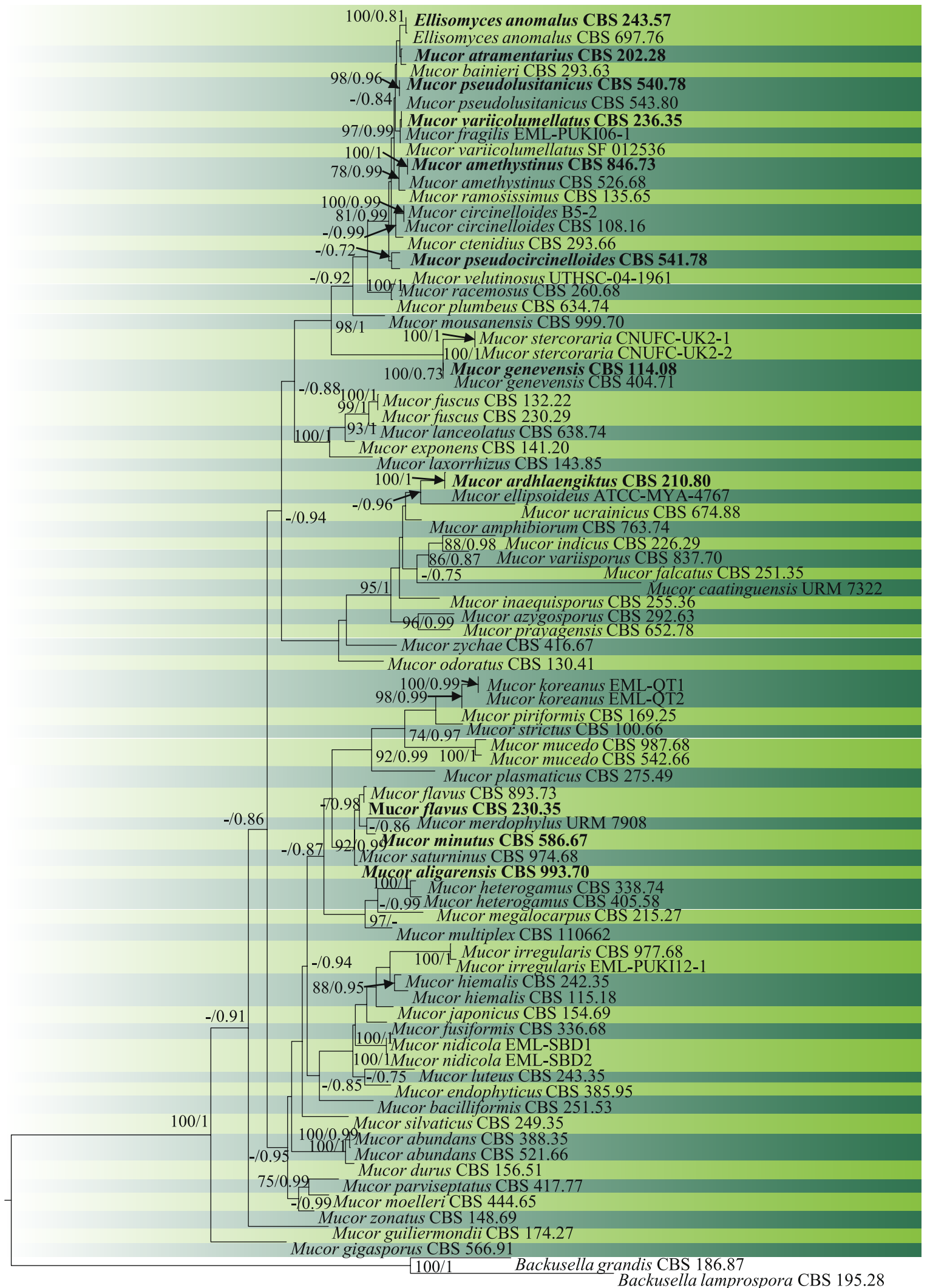


4Fig. 37 Phylogram generated from RAxML analysis based on combined sequences of ITS and LSU of Mucor and Backusella species. Eighty-seven taxa were used for the analysis, which consisted of 1264 characters including gaps. The tree is rooted using Backusella lamprospora (CBS 195.28), and B. grandis (CBS 186.87). Likelihood of the best-scoring ML tree was - 17553.567209. The concatenated matrix contained 716 distinct alignment patterns with $21.98 \%$ of undetermined characters or gaps. Estimated base frequencies were as follows: $\mathrm{A}=0.302082, \mathrm{C}=0.168706, \mathrm{G}=0.219403, \mathrm{~T}=0.309809$; substitution rates $\mathrm{AC}=0.749467, \mathrm{AG}=2.977575, \mathrm{AT}=1.651634$, $\mathrm{CG}=0.631954, \mathrm{CT}=4.647089, \mathrm{GT}=1.000000$; gamma distribution shape parameter $\alpha=0.302610$. The type species are in bold. Scale bar indicates the number of substitutions per site. ML bootstrap support values greater than $70 \%$ are shown near the nodes

appears water-soaked. The lesions formed are quasicircular or irregular, light to dark brown and the sporangiophores protrude through the wounds (Kwon and Hong 2005; Saito et al. 2016; Michailides and Spotts 1990). As the infection advances, the infected part disintegrates into a watery rot and the infection spreads and extends to all extremities of the fruit or even the surface of the container. The infected part is covered with a large mass of mycelium with erect sporangiophores and sporangia (Saito et al. 2016; Michailides and Spotts 1990). When tested, rotten apple and pear by some Mucor species release an alcoholic odour while Mucor rot in peaches and nectarines caused by $M$. piriformis emits a pleasant aromatic odour. At an advanced stage, Mucor rot can be distinguished from other rots caused by Rhizopus or Gilbertella. Differences are observed in the mycelial character, growth, sporangiophores and sporangia. For Mucor rot, erect, white or yellowish sporangiophore with grey to black sporangia is observed which covers the decay lesion densely. However, for Rhizopus rot, the mycelia are interwoven with stolons with dark sporangiophores and black sporangia. The sporangial wall eventually dries and falls apart while in Mucor rot, the sporangia absorb water from the sporangial wall which dissolves (Michailides and Spotts 1990).

\section{Morphology- based identification and diversity}

Mucor is characterized by fast-growing colonies. The sporangiophores are simple or branched without basal rhizoids. However, under some conditions, they form rhizoids. These species normally form globose sporangia, containing the columella and spores. The sporangium is non-apophysate with pigmented and ornamented zygosporangial walls. Arthrospores, chlamydospores, and zygospores may be produced by some species. The zygospores lack appendaged suspenders and broad aseptate or sparsely septate hyphae are commonly found in Mucor species (Nguyen et al. 2016). When spores from sporangia are released, a remaining collarette is observed. The sporangiospores are round or slightly elongated (Larone 1995; Sutton et al. 1998; de Hoog et al. 2000). With 76 accepted species, the genus is the largest and most studied group in Mucorales (Walther et al. 2019).

\section{Molecular identification and diversity}

The present taxonomy of Mucor is mostly based on morphological characters and interfertility tests. The genus was previously diagnosed using biological species recognition and morphological species recognition (Schipper 1973; Hermet et al. 2012). However, identification often fails with only morphology hence phylogenetic species recognition has been used to resolve species (Taylor et al. 2000). The use of multi-gene (ITS, tefl and $a c t$ ) phylogenetic analysis showed that Mucor is not monophyletic (Nguyen et al. 2017). An extensive study by Walther et al. (2013), using about 400 Mucor strains, led to a refinement in the classification of Mucor species. Phylogeny-based on 28S rDNA led to the transfer of some species to different groups and it was shown that some of these groups intermingled with other genera, such as Chaetocladium and Helicostylum, which do not belong to Mucoraceae. The use of five markers (ITS, rpbl, $t s r 1, m c m 7$ and $c f s$ ) phylogeny by Wagner et al. (2019), combined with phenotypic studies, mating tests and the determination of the maximum growth temperatures revealed 16 phylogenetic species of which 14 showed distinct phenotypical traits and were recognized as discrete species.

Recommended genetic markers (genus level)_LSU and SSU

Recommended genetic markers (species level)_ITS and $r p b 1$

Accepted number of species - There are 735 species epithets in Index Fungorum (2020), however only 76 species have DNA sequence data (Table 23) (Walther et al. 2019).

References-Larone (1995), Sutton et al. (1998), de Hoog et al. (2000) (morphology), Nguyen et al. (2016, 2017), Walther et al. (2013, 2019), Wagner et al. (2019) (morphology and phylogeny).

98. Phytophthora de Bary, J. Roy. Agric. Soc. England, ser. 2 12: 240 (1876)

\section{Background}

Phytophthora is classified in the kingdom Straminipila within the diploid, alga-like Oomycetes in the Stramenopile clade of the Kingdom Chromista (Cavalier-Smith 1986; Dick 1995; Yoon et al. 2002; Wijayawardene et al. 2020). Phytophthora consists of about 130 described species with many important plant pathogens. The Oomycota are biologically different from main fungal groups within the Kingdom Fungi (Corliss 1994; Cavalier-Smith 1998). For example, their cell walls are made primarily of cellulose instead of chitin as in most fungi and they cannot synthesize $\beta$-hydroxysterols, which is vital for synthesizing hormones that regulate sexual reproduction (Hyde et al. 2014). Another important difference is that oomycetes are diploid throughout their life cycle. One similarity between Phytophthora species and Eumycotan fungi is that they both produce hyphae. 
Classification-Oomycota, Peronosporales, Peronosporacae Type species-Phytophthora infestans (Mont.) de Bary Distribution-worldwide

Disease symptoms - blight, canker, dieback, root rots and wilt

Species can have a large impact on agriculture (e.g. Phytophthora infestans, potato late blight), arbiculture (e.g. Phytophthora ramorum, sudden oak death) and whole ecosystems (e.g. Phytophthora cinnamomi in Australia). Phytophthora species damage plants by killing the tissues and resulting necrosis can be seen in leaves, stems or roots. Some species can cause multiple symptoms on a single host, or cause different symptoms on different hosts (Jung and Blaschke 1996).

Blight: Initial symptom is the development of a "watersoaked" appearance, which progresses into brown or black irregular-shaped spots or wedge-shaped lesions. These lesions are usually not surrounded by a yellow halo (Babadoost 2004; Pande et al. 2011; Ali et al. 2017).

Canker: A dark discoloured necrotic lesion in the inner bark of a tree can be seen often on the stem or branches. However, generally, cankers are visible once the outer bark is removed. Cankers are often seen with a reddish-brown liquid that oozes through the bark (Davidson et al. 2002; Jung et al. 2018).

Dieback: Death of shoot tips, twigs and branch tips can be observed. The infection progresses towards the main stem accompanied by a loss of foliage (Kuske and Benson 1983; Akilli et al. 2013).

Decline and Death: This is a gradual process that will take place over several years. Plants fail to grow and the canopy becomes thin due to loss of foliage. Then the whole canopy or sections of the canopy may die (Marais 1980; Belisario et al. 2004; González et al. 2020).

Rot: Dark discoloured rotten tissues that are common on roots, but sometimes extend above the soil surface. However, collar rot occurs at the base of the trunk and extends just below the soil line (Jung and Blaschke 1996; Graham et al. 2011; Summerell and Liew 2020).

Wilting: This is the first above-ground symptom of root rot. Foliage becomes flaccid due to lack of water intake (Vettraino et al. 2009; Xiong et al. 2019).

Phytophthora causes disease in important agricultural and ecological plants. Phytophthora infestans was responsible for the Irish potato famine from 1845 to 1852 , causing the death of over 1 million people. Phytophthora ramorum has resulted in the death of millions of coast live oak, tanoak and Japanese larch trees, thus altering the forest ecosystems in California and Oregon, USA (Goheen et al. 2002; Rizzo et al. 2002, 2005).

Hosts-Phytophthora agathidicida (commonly known as kauri dieback), which causes kauri death, is considered as one of the world's most feared fungi (Hyde et al. 2018a). An extensive survey in previously unexplored ecosystems such as natural forests (Rea et al. 2010; Vettraino et al. 2011; Jung et al. 2011, 2017; Reeser et al. 2013), streams (Reeser et al. 2007; Bezuidenhout et al. 2010; Yang et al. 2016; Brazee et al. 2017), riparian ecosystems (Brasier et al. 2003, 2004; Hansen et al. 2012), and irrigation systems (Hong et al. 2010, 2012; Yang et al. 2014a, b) has led an exponential increase in the number of species.

\section{Pathogen biology, disease cycle and epidemiology}

\section{Morphological based identification and diversity}

Species-level classification is based on the morphological characterization of reproductive structures including the sporangium (asexual) and oospore (sexual) as well as the production of chlamydospores (Martin et al. 2012). Characteristics that are important for species classification include the diameter of the oogonium and oospore, thickness of the oospore wall, whether or not the oospore fills the oogonium, ornamentation on the oogonial wall, and mode of attachment of the antheridium (Hyde et al. 2014). Identification and classification of Phytophthora species into morphological groups based on several characteristics was initially based on the key provided by Waterhouse (1963), which was later updated by Stamps et al. (1990).

\section{Molecular based identification and diversity}

Phytophthora has been historically placed in the Pythiales with Pythium and related genera, however recent phylogenetic analysis with the large (LSU) or small (SSU) rDNA sequences or cox2 gene has indicated a closer relationship with downy mildew and white rusts (Albugo.) in the Peronosporales (Beakes and Sekimoto 2009; Thines et al. 2009). Additional multigene analyses are vital to clarify the relationship between the Peronosporales and Pythium. Early efforts focusing on the phylogenetic relationships in Phytophthora used nuclear-encoded rDNA, primarily the ITS region (Crawford et al. 1996; Cooke and Duncan 1997; Förster et al. 2000). The first comprehensive study was based on the phylogenetic study of the ITS region (Cooke et al. 2000). The study by Kroon et al. (2004) was based on analysis using two nuclear $(t e f 1, t u b 2)$ and two mitochondrial (coxl and nadl) genes. Subsequent phylogenetic analysis was based on sequences of seven nuclear genetic markers $(60 \mathrm{~S}$ ribosomal protein L10, tub2, enolase, heat shock protein90, large subunit rDNA, TigA gene fusion and tefl) which divided the species into 10 well-supported clades (Blair et al. 2008). The phylogenetic study by Martin et al. (2014) was based on seven nuclear and four mitochondrial genes (cox2, nad9, rps 10 and $\sec Y$ ). More recently, an extensive study of the genus by Yang et al. (2017) was based on sequences of seven nuclear genetic markers as in Blair et al. (2008).

The number of described species in Phytophthora was approximately 55 in 1999, but since then there has been a significant increase in the number of species nearly doubling the number of described species to 105 (Brasier 2007), and over 128 species (Hyde et al. 2014). Additional species have since been described, for example, $P$. cocois (Weir et al. 2015), P. crassamura (Scanu et al. 2015), P. attenuata, $P$. 
Fig. 38 Disease cycle of Phytophthora infestans (redrawn from Bengtsson 2013)

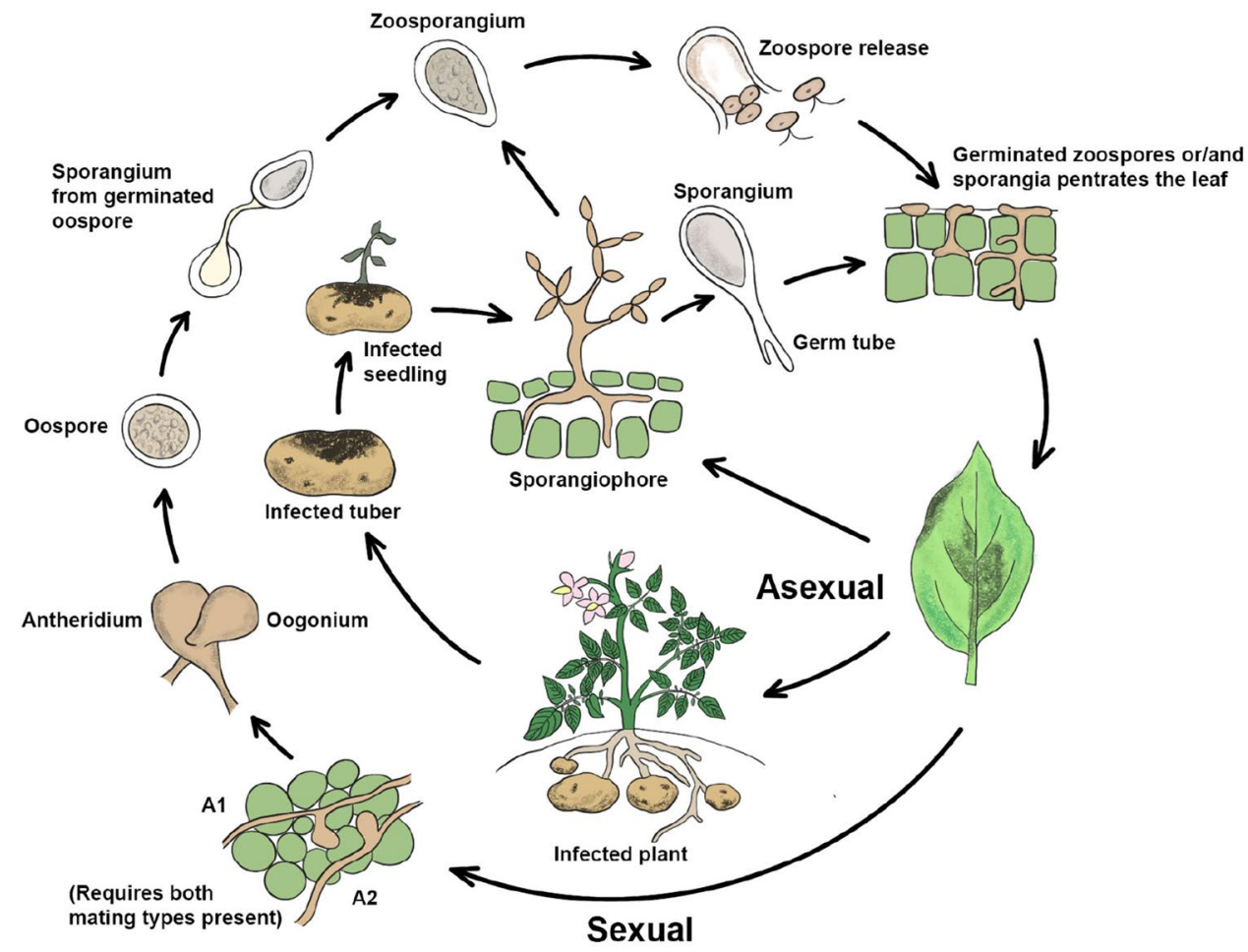

xheterohybrida, P. xincrassata (Jung et al. 2017) bringing the total to over 150 species (Jung et al. 2019). The phylogenetic tree constructed is presented in Fig. 39 and the accepted species are given in Table 24.

\section{Recommended genetic markers (genus level)_LSU, SSU} and $\operatorname{cox} 2$

Recommended genetic markers (species level)—LSU, tub2 and $\operatorname{cox} 2$

Accepted number of species- There are 317 epithets listed in Index Fungorum (2020), however only 162 species have DNA sequence data (Table 24).

References-Waterhouse (1963), Stamps et al. (1990) (morphology); Crawford et al. (1996), Cooke and Duncan (1997), Cooke et al. (2000), Förster et al. (2000), Brasier (2007), Blair et al. (2008) (morphology and phylogeny); Hyde et al. (2014) (phylogeny and accepted species) (Fig. 40).

99. Pythium Pringsh., Jb. wiss. Bot. 1: 304 (1858)

\section{Background}

Pythium is the largest and most comprehensively studied genus in Pythiaceae sensu lato, order Peronosporales sensu lato, class Peronosporomycetes, phylum Oomycota, and kingdom Straminipila (Beakes et al. 2014). Pringsheim (1858) described the genus. However, the initial classification of Pythium has changed many times based on several studies using morphological characteristics (Uzuhashi et al. 2010). Pythium comprises of more than 230 extant species (Hyde et al. 2014), however, identification of species has always been problematic due to limited morphological characters, difficulty in isolating some taxa and lack of molecular data for certain species (Lévesque and de Cock 2004).

Classification-Oomycota, Pythiales, Pythiaceae Type species-Pythium monospermum Pringsh. (Pringsheim 1858)

Distribution-worldwide

Disease symptoms - generally cause rot of fruit, roots and stem including pre- or post-emergence damping-off of seeds and seedlings.

Pythium causes crown and root rot in mature plants, where plants suddenly wilt during warm and sunny weather and when plants have their first heavy fruit load. Often, upper leaves of infected plants wilt in the day and recover overnight. However, plants eventually die (Craft and Nelson 1996; Postma et al. 2000). The first symptoms of Pythium root infections include stunting. In the root system, initial symptoms are brown to dark-brown lesions on root tips and feeder roots. As the disease progresses, symptoms are soft, brown, stubby roots and lack of feeder roots. In larger roots, the outer root tissue or cortex peels away, leaving the string-like vascular bundles underneath (Postma et al. 2000; Moorman et al. 2002; Al-Mahmooli et al. 2015). Pythium rot also occurs in the crown at the stem base. In cucumber, diseased crowns turn orange-brown, often with a soft rot at the base, while in strawberry seedling roots have dark brown, water-soaked rot and rotten crowns (Columbia and English 1988; Ishiguro et al. 2014). Several species of Pythium cause blight of turfgrass, which initially appears as "greasy" water-soaked areas, but later turn brown and grey (Vencelli and Powell 2008). 
Fig. 39 Maximum likelihood of Phytophthora based on the concatenated seven nuclear genetic markers (60S Ribosomal protein L10 (60S), beta-tubulin $(t u b)$, elongation factor 1 alpha $(t e f 1)$, enolase $(E n l)$, heat shock protein 90 ( $h s p 90), 28 \mathrm{~S}$ ribosomal DNA (28S), and tigA gene fusion protein (TigA)). ML bootstrap support values over $60 \%$ are indicated and BYPP $\geq 0.90$ are shown respectively near the nodes. The type species are in bold. Scale bar indicates number of substitutions per site. The tree was rooted with Phytopythiumvexansand Pythium undulatumas as the our group. Likelihood of the best scoring ML tree was - 114471.902046. Estimated base frequencies were as follows: $\mathrm{A}=0.216570$, $\mathrm{C}=0.275568, \mathrm{G}=0.312230$, $\mathrm{T}=0.195632$; substitution rates $\mathrm{AC}=0.414835, \mathrm{AG}=$ $1.176570, \mathrm{AT}=0.600142, \mathrm{CG}$ $=0.970565, \mathrm{CT}=5.227735$, $\mathrm{GT}=1.000000$

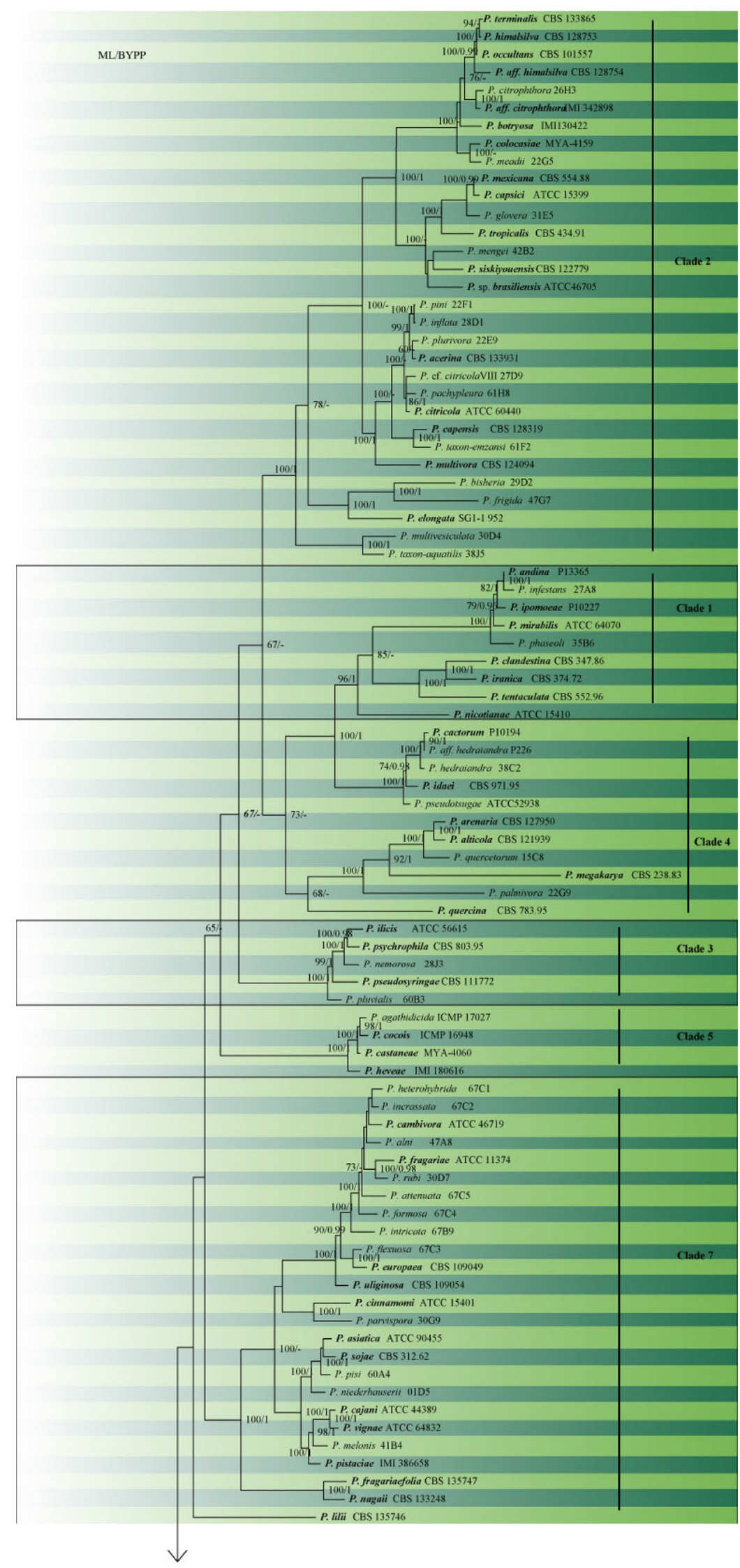


Fig. 39 (continued)

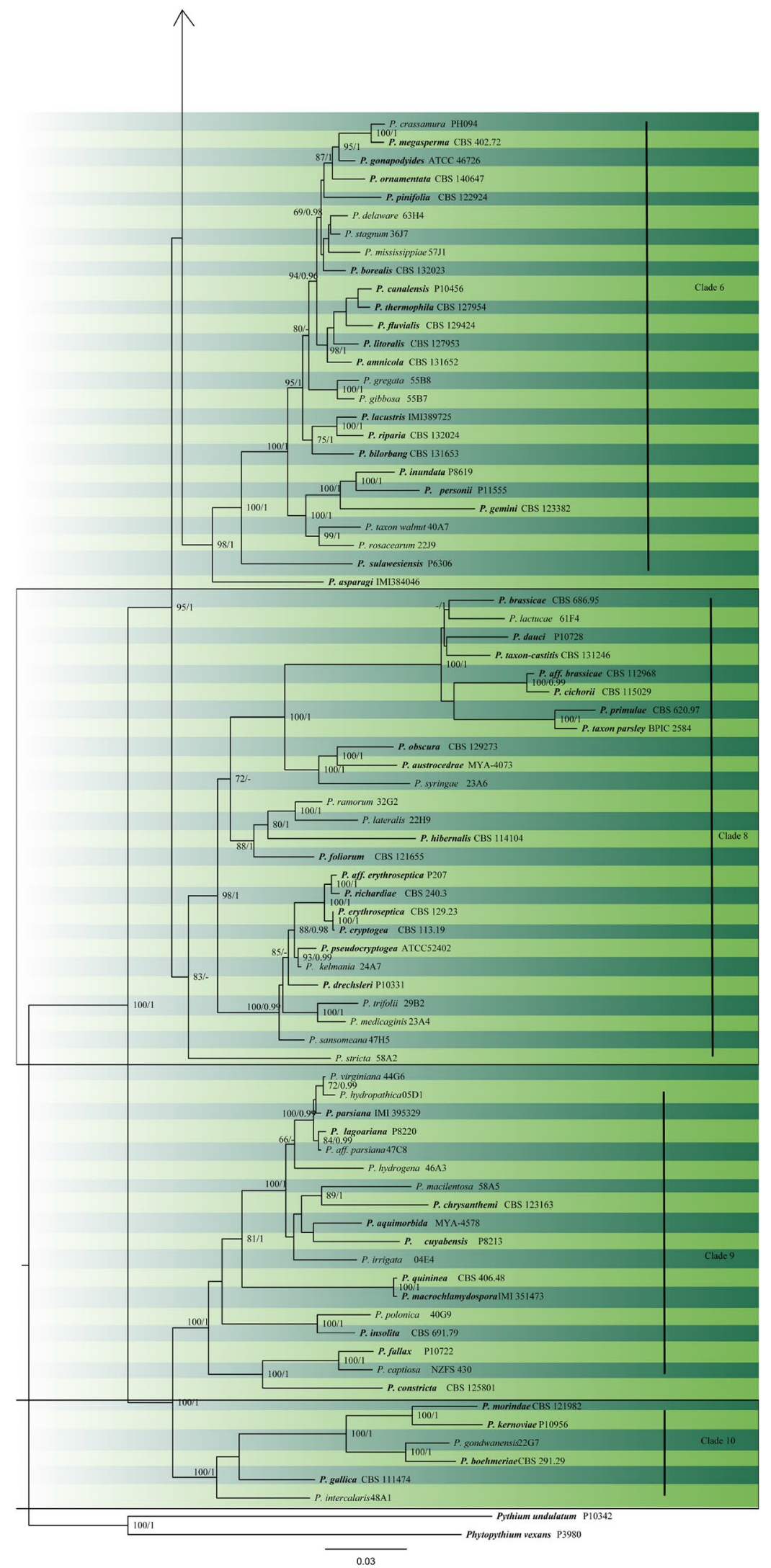


Table 23 DNA barcodes available for Mucor

\begin{tabular}{|c|c|c|c|}
\hline Species & Isolate & ITS & LSU \\
\hline \multirow[t]{2}{*}{ Mucor abundans } & CBS 388.35 & JN206111 & NG_063979 \\
\hline & CBS 521.66 & JN206110 & JN206457 \\
\hline M. aligarensis & CBS 993.70* & & JN206461 \\
\hline M. ambiguus & CBS 126943 & MH864344 & MH875788 \\
\hline M. amphibiorum & CBS 763.74 & NR_103615 & NG_057877 \\
\hline M. ardhlaengiktus & CBS 210.80* & NR_152960 & JN206504 \\
\hline M. atramentarius & CBS 202.28* & MH854979 & JN206418 \\
\hline \multirow[t]{2}{*}{ M. amethystinus } & CBS 846.73* & JN206014 & \\
\hline & CBS 526.68 & JN206015 & JN206426 \\
\hline M. azygosporus & CBS 292.63* & NR_103639 & NG_057928 \\
\hline M. bacilliformis & CBS 251.53* & NR_145285 & NG_057916 \\
\hline M. bainieri & CBS 293.63* & NR_103628 & JN206424 \\
\hline M. caatinguensis & URM 7322 & & NG_060334 \\
\hline \multirow[t]{2}{*}{ M. circinelloides } & B5-2 & KT876701 & \\
\hline & CBS 108.16 & JN205954 & \\
\hline M. ctenidius & CBS 293.66 & MH858796 & JN206417 \\
\hline M. durus & CBS 156.51* & NR_145295 & NG_057918 \\
\hline M. ellipsoideus & ATCC MYA-4767* & NR_111683 & NG_042602 \\
\hline M. endophyticus & CBS 385.95* & NR_111661 & NG_057970 \\
\hline M. exponens & CBS 141.20 & MH854686 & JN206441 \\
\hline M. falcatus & CBS 251.35* & NR_103647 & NG_057931 \\
\hline \multirow[t]{2}{*}{ M. flavus } & CBS 230.35* & JN206061 & JN206464 \\
\hline & CBS 893.73 & & JN206465 \\
\hline M. fragilis & EML-PUKI06-1 & KY047147 & \\
\hline \multirow[t]{2}{*}{ M. fuscus } & CBS 132.22 & JF723619 & \\
\hline & CBS 230.29 & JN206204 & \\
\hline M. fusiformis & CBS 336.68* & NR_111660 & NG_057915 \\
\hline M. gigasporus & CBS 566.91* & NR_103646 & NG_057926 \\
\hline \multirow[t]{2}{*}{ M. genevensis } & CBS 114.08* & HM623318 & \\
\hline & CBS 404.71 & JN206042 & \\
\hline M. guiliermondii & CBS 174.27* & NR_103636 & NG_057923 \\
\hline \multirow[t]{2}{*}{ M. heterogamus } & CBS 338.74 & JN206169 & JN206488 \\
\hline & CBS 405.58 & JN206167 & \\
\hline \multirow[t]{2}{*}{ M. hiemalis } & CBS 242.35 & JN206134 & \\
\hline & CBS 115.18 & JN206127 & \\
\hline M. inaequisporus & CBS 255.36 & JN206177 & NG_057929 \\
\hline M. indicus & CBS 226.29* & NR_077173 & NG_057878 \\
\hline \multirow[t]{2}{*}{ M. irregularis } & CBS 977.68 & JX976259 & \\
\hline & EML-PUKI12-1 & KY047151 & \\
\hline M. japonicus & CBS 154.69 & JN206158 & JN206446 \\
\hline \multirow[t]{2}{*}{ M. koreanus } & $E M L-Q T 1^{*}$ & KT936259 & \\
\hline & EML-QT2 & KT936260 & \\
\hline M. lanceolatus & CBS 638.74 & JN206205 & JN206443 \\
\hline M. laxorrhizus & CBS 143.85* & NR_103642 & NG_057914 \\
\hline M. luteus & CBS 243.35 & JX976254 & \\
\hline M. megalocarpus & CBS 215.27* & NR_145286 & NG_057925 \\
\hline M. merdophylus & URM-7908 & MK775467 & MK775466 \\
\hline M. minutus & CBS 586.67* & JN206048 & JN206463 \\
\hline M. moelleri & CBS 444.65* & MH858663 & NG_057875 \\
\hline M. mousanensis & CBS 999.70* & NR_103629 & NG_057912 \\
\hline
\end{tabular}


Table 23 (continued)

\begin{tabular}{|c|c|c|c|}
\hline Species & Isolate & ITS & LSU \\
\hline \multirow[t]{2}{*}{ M. muсеdo } & CBS 542.66* & JN206086 & JN206480 \\
\hline & CBS 987.68 & JN206089 & JN206480 \\
\hline M. multiplex & CBS 110662* & NR_111662 & NG_057924 \\
\hline \multirow[t]{2}{*}{ M. nidicola } & EML-SBD1 & KY047148 & \\
\hline & EML-SBD2 & KY047149 & \\
\hline M. odoratus & CBS 130.41* & NR_145287 & NG_057927 \\
\hline M. parviseptatus & CBS 417.77 & JN206108 & JN206453 \\
\hline M. piriformis ${ }^{\#}$ & CBS 169.25* & NR_103630 & NG_057874 \\
\hline M. plasmaticus & CBS 275.49 & & JN206483 \\
\hline M. plumbeus & CBS 634.74 & HM999955 & HM849677 \\
\hline M. prayagensis & CBS 652.78 & JN206189 & JN206498 \\
\hline \multirow[t]{2}{*}{ M. pseudolusitanicus } & CBS 540.78* & MF495059 & \\
\hline & CBS 543.80 & MF495060 & \\
\hline M. pseudocircinelloides & CBS 541.78 & JN206013 & JN206431 \\
\hline M. saturninus & CBS 974.68* & NR_103635 & JN206458 \\
\hline \multirow[t]{2}{*}{ M. stercorarius ${ }^{\#}$} & CNUFC-UK2-1* & KX839689 & \\
\hline & CNUFC-UK2-2 & KX839680 & \\
\hline M. strictus & CBS 100.66* & JN206035 & JN206477 \\
\hline M. racemosus & CBS 260.68* & NR_126135 & NG_055727 \\
\hline M. ramosissimus & CBS 135.65* & NR_103627 & NG_056280 \\
\hline M. silvaticus & CBS 249.35 & JN206122 & JN206455 \\
\hline M. ucrainicus & CBS 674.88 & JN206192 & JN206507 \\
\hline M. variisporus & CBS 837.70* & NR_152951 & NG_057972 \\
\hline \multirow[t]{2}{*}{ M. variicolumellatus } & CBS 236.35* & JN205979 & JN206422.1 \\
\hline & SF012536 & MF495054.1 & \\
\hline M. velutinosus & UTHSC-04-1961 & JF299208 & \\
\hline M. zonatus & CBS 148.69* & NR_103638 & NG_057917 \\
\hline M. zychae & CBS 416.67* & NR_103641 & NG_057930 \\
\hline \multirow[t]{2}{*}{ Ellisomyces anomalus } & CBS 243.57* & NR_145284 & NG_067365 \\
\hline & CBS 697.76 & JN205993 & \\
\hline
\end{tabular}

Ex-type/ex-epitype/ex-neotype/ex-lectotype strains are in bold and marked with an asterisk (*). Voucher strains are also in bold. Species confirmed with pathogenicity studies are marked with ${ }^{\#}$

Several Pythium species are capable of causing fruit rot in numerous crops (Martin and Loper 1999). Pythium fruit rot is commonly known as a cottony leak or watery rot and occurs during wet weather or in poorly drained areas of fields (Ho and Abd-Elsalam 2020; Sharma et al. 2020a). Initial symptoms of the fruit rot are brownish, water-soaked lesions that quickly become large, watery, soft and rotten. The rot generally begins on the parts of fruit in contact with the soil. In cucumber, a brown to dark green blister can be seen on fruit before they become watery and rot. Later, white cottony mycelium can be seen on rotten tissues, especially during humid weather. Pythium fruit rot is most severe in poorly-drained fields during wet weather. The disease can render fruit unmarketable (Ho 2009; Sharma et al. 2020a).

Pre-emergence damping-off causes seeds and young seedlings to rot before they emerge from the growing medium in greenhouses, while post-emergence damping-off kills newly emerged seedlings. In the latter, the pathogen causes a watersoaked, soft brown lesion at the stem base, near the soil line, that pinches off the stem causing the seedling to topple over and die (Weiland et al. 2012).

Hosts-Pythium has a wide range of hosts including species of Cucurbitaceae and Poaceae, Ananas comosus, Arachis hypogaea, Brassica sp., Carica papaya, Beta vulgaris, Daucus carota subsp. sativus, Dendrobium sp, Solanum sp. and Zingiber officinale. Some species are pathogens of algae, fungi, other oomycetes, nematodes, insects, animals and humans (Van der Plaäts-Niterink1981; Czeczuga et al. 2005; Kawamura et al. 2005; Hwang et al. 2009; Li et al. 2010; Weiland et al. 2012; Ho 2013; Hyde et al 2014). Several species inhabit different soils in cultivated and uncultivated fields including forest (Uzuhashi et al 2010). Pythium arrhenomanes, $P$. dissotocum, $P$. elongatum, $P$. myriotylum, and $P$. spinosum are important pathogens of rice seedlings (Hendrix 
Table 24 DNA barcodes available for Phytophthora

\begin{tabular}{|c|c|c|c|c|c|c|c|c|}
\hline Species & Strain & $60 \mathrm{~S}$ & tub2 & tef1 & Enl & $H S P 90$ & $28 \mathrm{~S}$ & TigA \\
\hline Phytophthora $\times$ alni & 8 & 251595 & 251596 & 251597 & KX251598 & 251599 & KX251600 & $X 25160$ \\
\hline P. $\times$ heterohybrida & $\mathrm{C} 1$ & $\times 251637$ & X251638 & 251639 & K251640 & 641 & 251642 & 251643 \\
\hline P. $\times$ incrassata & $67 \mathrm{C} 2$ & X251644 & KX251645 & KX251646 & KX251647 & KX251648 & KX251649 & $X 251650$ \\
\hline P. × stagnum ${ }^{\#}$ & $36 \mathrm{~J} 7$ & KX251368 & KX251369 & KX251370 & KX251371 & KX251372 & KX251373 & KX25137 \\
\hline P. acerina $a^{\#}$ & $61 \mathrm{H} 1=\mathrm{CBS} 133931$ & KX250712 & KX250713 & KX250714 & KX250715 & KX250716 & KX250717 & $\mathrm{KX} 25071$ \\
\hline P. aff. brassicae ${ }^{\#}$ & CBS 112968 & EU079880 & EU079881 & EU079882 & EU079883 & EU079884 & EU079885 & EU079886 \\
\hline P. aff. citrophthora ${ }^{\#}$ & IMI 342898 & EU080384 & EU080385 & EU080386 & EU080387 & EU080388 & EU080389 & EU080390 \\
\hline P. aff. erythroseptica & $33 \mathrm{~A} 1=\mathrm{P} 207$ & KX251979 & KX251980 & KX251981 & KX251982 & KX251983 & KX251984 & KX251985 \\
\hline P. aff. hedraiandra ${ }^{\#}$ & $33 \mathrm{~F} 4=\mathrm{P} 226$ & KX250411 & KX250412 & KX250413 & KX250414 & KX250415 & KX250416 & KX250417 \\
\hline P. aff. himalsilva & $61 G 4=C B S 128754$ & KX250621 & KX250622 & KX250623 & KX250624 & KX250625 & KX250626 & KX250627 \\
\hline P. aff. parsiana ${ }^{\#}$ & $47 \mathrm{C} 8$ & KX252397 & KX252398 & KX252399 & KX252400 & KX252401 & KX252402 & N/A \\
\hline P. agathidicida ${ }^{\#}$ & 67D5=ICMP 17027 & KX251076 & KX251077 & KX251078 & KX251079 & KX251080 & KX251081 & KX25108 \\
\hline P. alticola & 47G5=CBS 121939 & KX251006 & KX251007 & KX251008 & KX251009 & KX251010 & KX251011 & KX251012 \\
\hline P. amnicola & BS 131652 & KX251167 & KX251168 & 251169 & 251170 & 251171 & 251172 & 1173 \\
\hline P. andina ${ }^{\#}$ & P13365 & EU080182 & EU080183 & EU080184 & EU080185 & EU080186 & EU080187 & 0188 \\
\hline P. aquimorbida & $40 A 6=$ MYA-4578 & KX252238 & KX252239 & $\mathrm{r} 252240$ & KX252241 & 252242 & 2243 & 2244 \\
\hline$P$. arenaria & $55 C 2=C B S 127950$ & 1013 & 14 & 1015 & KX251016 & 251017 & 251018 & 1019 \\
\hline P. asiatica & 90455 & 51 & 52 & 53 & 654 & 55 & 56 & \\
\hline P. asparagi ${ }^{\#}$ & 33D7 = IMI384046 & KX251466 & KX251467 & KX251468 & KX251469 & KX251470 & KX251471 & KX251472 \\
\hline P. attenuata & $67 \mathrm{C} 5$ & 609 & 610 & 611 & 612 & 613 & 514 & 1615 \\
\hline P. austrocedrae & $41 B 5=$ MYA -4073 & KX252161 & KX252162 & KX252163 & KX252164 & KX252165 & KX252166 & KX252167 \\
\hline P. bilorbang ${ }^{\#}$ & $61 G 8=C B S 131653$ & KX251181 & KX251182 & N/A & KX251183 & KX251184 & KX251185 & KX25118c \\
\hline P. bisheria & 29D2 & KX250873 & KX250874 & KX250875 & KX250876 & KX250877 & KX250878 & KX250879 \\
\hline P. boehmeriae ${ }^{\#}$ & $45 F 9=C B S 291.29$ & EU080161 & EU080162 & EU080163 & EU080164 & EU080165 & EU080166 & EU080167 \\
\hline P. borealis & $60 \mathrm{~B} 2=\mathrm{CBS} 132023$ & KX251187 & KX251188 & KX251189 & KX251190 & KX251191 & KX251192 & KX251193 \\
\hline P. botryosa ${ }^{\#}$ & IMI130422=P6945 & EU079934 & EU079935 & EU079936 & EU079937 & EU079938 & EU079939 & EU079940 \\
\hline P. brassicae \# $^{\#}$ & 29D8=CBS 686.95 & KX251993 & KX251994 & KX251995 & KX251996 & KX251997 & KX251998 & KX25199 \\
\hline P. cactorum $^{\#}$ & $22 \mathrm{E} 6=\mathrm{P} 10194$ & KX250369 & KX250370 & KX250371 & KX250372 & KX250373 & KX250374 & KX25037 \\
\hline P. cajani $^{\#}$ & $45 F 6=A T C C ~ 44389$ & KX251679 & KX251680 & KX251681 & KX251682 & KX251683 & KX251684 & KX25168 \\
\hline P. cambivora $^{\#}$ & 22F6=ATCC 46719 & KX251494 & KX251495 & KX251496 & KX251497 & KX251498 & KX251499 & KX25150 \\
\hline P. capensis & $62 \mathrm{C} 1=\mathrm{CBS} 128319$ & $X 250726$ & KX250727 & $\mathrm{X} 250728$ & KX250729 & $X 250730$ & $\mathrm{X} 250731$ & KX25073 \\
\hline P. capsici $^{\#}$ & 22F4=ATCC 15399 & KX250635 & KX250636 & KX250637 & KX250638 & KX250639 & KX250640 & KX25064 \\
\hline P. captiosa $a^{\#}$ & $46 \mathrm{H} 8=\mathrm{NZFS} 430$ & KX252554 & KX252555 & $\mathrm{X} 252556$ & KX252557 & KX252558 & KX252559 & KX252560 \\
\hline P. castaneae & $22 \mathrm{H6}=\mathrm{MYA}-4060$ & KX251083 & KX251084 & KX251085 & KX251086 & KX251087 & KX251088 & KX251089 \\
\hline P. chrysanthemi ${ }^{\#}$ & $61 F 1=C B S 123163$ & KX252266 & KX252267 & KX252268 & KX252269 & KX252270 & KX252271 & KX252272 \\
\hline P. cichorii & $62 A 8=C B S 115029$ & KX252007 & KX252008 & KX252009 & KX252010 & KX252011 & KX252012 & KX252013 \\
\hline P. cinnamomi $^{\#}$ & 23B2=ATCC 15401 & KX251804 & KX251805 & KX251806 & KX251807 & KX251808 & KX251809 & KX251810 \\
\hline P. citricola & 33H8=ATCC 60440 & KX250747 & KX250748 & KX250749 & KX250750 & KX250751 & KX250752 & KX250753 \\
\hline P. citrophthora ${ }^{\#}$ & $26 \mathrm{H} 3$ & KX250551 & KX250552 & KX250553 & KX250554 & KX250555 & KX250556 & KX250557 \\
\hline P. clandestina & 32G1 $=$ CBS 347.86 & EU079866 & EU079867 & EU079868 & EU079869 & EU079870 & EU079871 & EU079872 \\
\hline P. cocois & 67D6=ICMP 16948 & KX251104 & KX251105 & KX251106 & KX251107 & KX251108 & KX251109 & KX251110 \\
\hline P. colocasiae \# $^{\#}$ & 22F8=MYA-4159 & KX250558 & KX250559 & KX250560 & KX250561 & KX250562 & KX250563 & KX25056 \\
\hline P. constricta & $55 C 3=C B S 125801$ & KX252561 & KX252562 & KX252563 & KX252564 & KX252565 & KX252566 & KX252567 \\
\hline P. crassamura & $66 \mathrm{C} 9=\mathrm{PH} 094$ & KX251194 & KX251195 & KX251196 & KX251197 & KX251198 & KX251199 & KX25120 \\
\hline P. cryptogea $a^{\#}$ & $61 \mathrm{H} 9=\mathrm{CBS} 113.19$ & KX251867 & KX251868 & KX251869 & KX251870 & KX251871 & KX251872 & KX251873 \\
\hline P. dauci & $32 \mathrm{E} 6=\mathrm{P} 10728$ & KX252028 & KX252029 & KX252030 & KX252031 & KX252032 & KX252033 & KX25203 \\
\hline P. drechsleri ${ }^{\#}$ & P10331 & EU079506 & EU079507 & EU079508 & EU079509 & EU079510 & EU079511 & EU079512 \\
\hline P. elongata & 33J3=SG1-1 952 & KX250880 & KX250881 & KX250882 & KX250883 & KX250884 & KX250885 & KX250886 \\
\hline P. erythroseptica & $61 \mathrm{~J} 2=\mathrm{CBS} 129.23$ & KX251895 & KX251896 & KX251897 & KX251898 & KX251899 & KX251900 & KX251901 \\
\hline P. europaea & $62 \mathrm{~A} 2=\mathrm{CBS} 109049$ & KX251522 & KX251523 & KX251524 & KX251525 & KX251526 & KX251527 & KX25152 \\
\hline
\end{tabular}


Table 24 (continued)

\begin{tabular}{|c|c|c|c|c|c|c|c|c|}
\hline Species & Strain & $60 \mathrm{~S}$ & $t u b 2$ & tefl & Enl & HSP9O & $28 \mathrm{~S}$ & TigA \\
\hline fallax & 10722 & X252568 & KX252569 & KX252570 & KX252571 & 2572 & 573 & (1) \\
\hline P. flexиosa & C3 & 1616 & 1617 & 1618 & 251 & 20 & 21 & 162 \\
\hline P. fluvialis & $55 B 6=$ CBS 129424 & KX251208 & KX251209 & KX251210 & KX251211 & KX251212 & KX251213 & KX25121 \\
\hline P. foliorum ${ }^{\#}$ & 49J8=CBS 121655 & KX252112 & KX252113 & KX252114 & KX252115 & KX252116 & KX252117 & X25211 \\
\hline P. formosa & $67 \mathrm{C} 4$ & KX251623 & KX251624 & KX251625 & KX251626 & KX251627 & KX251628 & KX25162 \\
\hline P. fragariae f $^{\#}$ & 22G6=ATCC 11374 & KX251529 & KX251530 & KX251531 & KX251532 & KX251533 & KX251534 & XX25153 \\
\hline P. fragariaefolia & 61H4=CBS 135747 & KX251853 & KX251854 & KX251855 & KX251856 & KX251857 & KX251858 & KX251859 \\
\hline P. frigida ${ }^{\#}$ & $47 \mathrm{G} 7$ & KX250908 & KX250909 & KX250910 & KX250911 & KX250912 & KX250913 & KX250914 \\
\hline P. gallica & 50A1=CBS 111474 & KX252589 & KX252590 & KX252591 & KX252592 & KX252593 & KX252594 & KX252595 \\
\hline P. gemini & 46H1=CBS 123382 & KX251125 & KX251126 & KX251127 & KX251128 & KX251129 & KX251130 & KX251131 \\
\hline P. gibbosa & $55 \mathrm{~B} 7$ & KX251215 & KX251216 & KX251217 & KX251218 & KX251219 & KX251220 & KX251221 \\
\hline P. glovera & $31 \mathrm{E} 5$ & KX250642 & KX250643 & KX250644 & KX250645 & KX250646 & KX250647 & KX25064 \\
\hline P. gonapodyides & $21 \mathrm{~J} 5=\mathrm{ATCC} 46726$ & KX251229 & KX251230 & KX251231 & KX251232 & KX251233 & KX251234 & KX25123 \\
\hline P. gondwanensis & $22 \mathrm{G} 7$ & KX252603 & KX252604 & KX252605 & KX252606 & KX252607 & KX252608 & KX252609 \\
\hline P. gregata $^{\#}$ & $55 \mathrm{~B} 8$ & KX251243 & KX251244 & KX251245 & KX251246 & KX251247 & KX251248 & KX25124 \\
\hline P. hedraiandra ${ }^{\#}$ & $38 \mathrm{C} 2$ & KX250390 & KX250391 & KX250392 & KX250393 & KX250394 & KX250395 & KX250396 \\
\hline P. heveae & $22 J 1=I M I 180616$ & KX251111 & KX251112 & KX251113 & KX251114 & KX251115 & KX251116 & KX251117 \\
\hline P. hibernalis ${ }^{\#}$ & 32F7=CBS 114104 & KX252126 & KX252127 & KX252128 & KX252129 & 252130 & 2131 & 2132 \\
\hline P. himalsilva & $61 G 3=$ CBS 128753 & 250579 & KX25 & 0581 & KX250582 & KX250583 & 250584 & 0585 \\
\hline P. hydrogena & 3 & 30 & 281 & 282 & KX252283 & 284 & 285 & - \\
\hline P. hydropathica & 05D1 & 252294 & KX252295 & 252296 & KX252297 & 252298 & 52299 & $\mathrm{KX} 2$ \\
\hline P. idaei & CBS 971.95 & EU080129 & EU080130 & 131 & 0132 & 33 & 134 & EU0 \\
\hline P. ilicis $^{\#}$ & 23A7 $=$ & KX250936 & KX250937 & KX250938 & KX250939 & KX250940 & KX250941 & KX25094 \\
\hline P. infestans ${ }^{\#}$ & $27 \mathrm{~A} 8$ & KX250474 & KX250475 & KX250476 & KX250477 & KX250478 & KX250479 & KX25048 \\
\hline P. inflata & 28D1 & KX250761 & KX250762 & KX250763 & KX250764 & KX250765 & KX250766 & KX25076 \\
\hline P. insolita $^{\#}$ & 38E $1=\mathrm{CBS}$ & EU080175 & EU080176 & EU080177 & EU080178 & EU080179 & 30180 & EU080181 \\
\hline P. intercalaris & 48A1 & KX252617 & KX252618 & KX252619 & KX252620 & KX252621 & KX252622 & KX252623 \\
\hline P. intricata & $67 \mathrm{~B} 9$ & KX251630 & KX251631 & KX251632 & KX251633 & KX251634 & KX251635 & KX251636 \\
\hline P. inundata & P8619 & EU080202 & EU080203 & EU080204 & EU080205 & EU080206 & EU080207 & EU080208 \\
\hline P. ipomoeae & $31 \mathrm{~B} 6=\mathrm{P} 10227$ & EU080844 & EU080845 & EU080846 & EU080847 & EU080848 & EU080849 & EU080850 \\
\hline P. iranica ${ }^{\#}$ & $61 \mathrm{~J} 4=\mathrm{CBS} 374.72$ & 250439 & 50440 & 250441 & 250442 & 250443 & 50444 & $\mathrm{KX} 2$ \\
\hline P. irrigata & 0 & 8 & 9 & 0 & 252311 & 12 & 2313 & 25251 \\
\hline P. kernoviae & 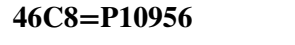 & $\mathrm{I}$ & 2 & 3 & 4 & 5 & U080046 & test \\
\hline P. lactucae & 6 & 42 & 43 & 52044 & 52045 & 46 & 52047 & 20 \\
\hline P. lacustris ${ }^{\#}$ & IMI389725=P10337 & EU080530 & EU080531 & EU080532 & EU080533 & EU080534 & EU080535 & EU08053 \\
\hline P. lateralis ${ }^{\#}$ & $22 \mathrm{H} 9$ & 33 & & 5 & 36 & 37 & & 39 \\
\hline lilii & CBS & 779 & 82 & 788 & 791 & 94 & 97 & 6800 \\
\hline P. litoralis & $55 B 9=$ CBS 127953 & KX251278 & KX251279 & KX251280 & KX251281 & KX251282 & KX251283 & KX251284 \\
\hline P. macilentosa & 58A5 & KX252329 & KX252330 & KX252331 & KX252332 & KX252333 & KX252334 & KX252335 \\
\hline P. macrochlamydospora & G231E9=IMI 351473 & EU080658 & EU080659 & EU080660 & N/A & EU080661 & EU080662 & EU080663 \\
\hline P. meadii & $22 \mathrm{G} 5$ & KX250586 & KX250587 & KX250588 & KX250589 & KX250590 & KX250591 & KX250592 \\
\hline P. medicaginis ${ }^{\#}$ & $23 \mathrm{~A} 4$ & KX251902 & KX251903 & KX251904 & KX251905 & KX251906 & KX251907 & KX25190 \\
\hline P. megakarya & $61 J 5=$ CBS 238.83 & KX251034 & KX251035 & KX251036 & KX251037 & KX251038 & KX251039 & KX25104 \\
\hline P. megasperma $a^{\#}$ & $62 \mathrm{C} 7=\mathrm{CBS} 402.72$ & KX251285 & KX251286 & KX251287 & KX251288 & KX251289 & KX251290 & N/A \\
\hline P. melonis ${ }^{\#}$ & $41 \mathrm{~B} 4$ & KX251700 & KX251701 & KX251702 & KX251703 & KX251704 & KX251705 & KX 25170 \\
\hline P. mengei & $42 \mathrm{~B} 2$ & KX250656 & KX250657 & KX250658 & KX250659 & KX250660 & KX250661 & KX250662 \\
\hline P. mexicana & 45G4=CBS 554.88 & KX250670 & KX250671 & KX250672 & KX250673 & KX250674 & KX250675 & KX250676 \\
\hline P. mirabilis & $30 \mathrm{C} 2=\mathrm{ATCC} 64070$ & KX250488 & KX250489 & KX250490 & KX250491 & KX250492 & KX250493 & KX25049 \\
\hline P. mississippiae & $57 \mathrm{~J} 1$ & KX251291 & KX251292 & KX251293 & KX251294 & KX251295 & KX251296 & KX251297 \\
\hline P. morindae & 62B5 = CBS 121982 & KX252633 & KX252634 & KX252635 & KX252636 & KX252637 & KX252638 & KX2526 \\
\hline
\end{tabular}


Table 24 (continued)

\begin{tabular}{|c|c|c|c|c|c|c|c|c|}
\hline Species & Strain & $60 \mathrm{~S}$ & $t u b 2$ & tefl & Enl & $H S P 90$ & $28 \mathrm{~S}$ & $\operatorname{Tig} A$ \\
\hline P. multivesiculata ${ }^{\#}$ & 30D4 & KX250922 & KX250923 & KX250924 & KX250925 & KX250926 & KX250927 & KX2509 \\
\hline P. multivora & $55 C 5=C B S 124094$ & KX250775 & KX250776 & KX250777 & KX250778 & KX250779 & KX250780 & KX25078 \\
\hline P. nagaii & $61 \mathrm{H5}=\mathrm{CBS} 133248$ & KX251860 & KX251861 & KX251862 & KX251863 & KX251864 & KX251865 & KX251866 \\
\hline P. nemorosa & $28 \mathrm{~J} 3$ & KX250957 & KX250958 & KX250959 & KX250960 & KX250961 & KX250962 & KX25096? \\
\hline P. nicotianae n $^{\#}$ & 22F9=ATCC 15410 & KX250509 & KX250510 & KX250511 & KX250512 & KX250513 & KX250514 & KX250515 \\
\hline P. niederhauserii ${ }^{\#}$ & 01D5 & KX251714 & KX251715 & KX251716 & KX251717 & KX251718 & KX251719 & KX251720 \\
\hline P. obscura & $60 \mathrm{E} 9=\mathrm{CBS} 129273$ & KX252175 & KX252176 & KX252177 & KX252178 & KX252179 & KX252180 & KX25218 \\
\hline P. occultans ${ }^{\#}$ & 65B9=CBS 101557 & KX250600 & KX250601 & KX250602 & KX250603 & KX250604 & KX250605 & KX25060 \\
\hline P. ornamentata & 66D2=CBS 140647 & KX251319 & KX251320 & KX251321 & KX251322 & KX251323 & KX251324 & KX251325 \\
\hline P. pachypleura ${ }^{\#}$ & $61 \mathrm{H} 8$ & KX250796 & KX250797 & KX250798 & KX250799 & KX250800 & KX250801 & KX25080 \\
\hline P. palmivora ${ }^{\#}$ & $22 \mathrm{G} 9$ & KX251055 & KX251056 & KX251057 & KX251058 & KX251059 & KX251060 & KX25106 \\
\hline P. parsiana & 47C3=IMI 395329 & KX252357 & KX252358 & KX252359 & KX252360 & KX252361 & KX252362 & KX252363 \\
\hline P. parvispora ${ }^{\#}$ & 30G9 & KX251818 & KX251819 & KX251820 & KX251821 & KX251822 & KX251823 & KX251824 \\
\hline P. phaseoli & $35 \mathrm{~B} 6$ & 250502 & KX250503 & KX250504 & KX250505 & KX250506 & 50507 & 0508 \\
\hline P. pini ${ }^{\#}$ & $22 \mathrm{~F} 1$ & KX250803 & KX250804 & KX250805 & KX250806 & KX250807 & KX250808 & KX250809 \\
\hline$P$. pinifolia & $47 \mathrm{H}$ & 51333 & 51334 & 251335 & 251336 & 251337 & 51338 & KX251339 \\
\hline P. pisi & $60 \mathrm{~A} 4$ & KX251735 & KX251736 & $\mathrm{KX} 2$ & $\mathrm{KX} 2$ & $\mathrm{KX} 2$ & $\mathrm{KX}$ & KX251741 \\
\hline P. pistacia $e^{\#}$ & $33 D 6=I M I 386658$ & KX251748 & KX251749 & KX251750 & KX251751 & KX251752 & KX251753 & KX251754 \\
\hline P. plurivora ${ }^{\#}$ & $22 \mathrm{E} 9$ & KX250817 & KX250818 & KX250819 & KX250820 & KX250821 & KX250822 & KX250823 \\
\hline P. pluvialis ${ }^{\#}$ & $60 \mathrm{~B} 3$ & KX250971 & KX250972 & KX250973 & KX250974 & KX250975 & KX250976 & KX250977 \\
\hline P. polonica & 40G9 & KX252532 & KX252533 & KX252534 & KX252535 & KX252536 & KX252537 & KX252538 \\
\hline P. primulae p $^{\#}$ & 29E9=CBS 620.97 & KX252063 & KX252064 & KX252065 & KX252066 & KX252067 & KX252068 & KX252069 \\
\hline P. pseudocryptogea & ATCC52402 & EU080626 & EU080627 & EU080628 & EU080629 & EU080630 & EU080631 & N/A \\
\hline P. pseudosyringae & BS 111772 & KX250978 & KX250979 & KX250980 & KX250981 & 250982 & 50983 & KX250984 \\
\hline P. pseudotsugae & $A$ & 6 & 27 & 28 & 29 & 30 & 31 & 0432 \\
\hline P. psychrophila & $=$ CBS 803.95 & 2 & 93 & 94 & 95 & 96 & 97 & 998 \\
\hline P. quercetorum & $15 \mathrm{C} 8$ & $\times 251069$ & KX251070 & KX251071 & KX251072 & & KX251074 & KX251075 \\
\hline P. quercina $a^{\#}$ & 30A4=CBS 783.95 & 252647 & KX252648 & K252649 & KX252650 & 252651 & 252652 & 2653 \\
\hline P. quininea & $45 F 2=C B S 406.48$ & EU080107 & EU080108 & EU080109 & N/A & KX252522 & EU080110 & KX252523 \\
\hline P. ramorum ${ }^{\#}$ & $32 \mathrm{G} 2$ & KX252147 & KX252148 & KX252149 & KX252150 & KX252151 & KX252152 & KX252153 \\
\hline P. richardiae & $45 F 5=$ CBS 240.3 & KX251923 & KX251924 & KX251925 & KX251926 & KX251927 & KX251928 & KX251929 \\
\hline$P$. riparia & 60B1=CBS 132024 & KX251347 & KX251348 & KX251349 & KX251350 & KX251351 & KX251352 & KX251353 \\
\hline P. rosacearum & $22 \mathrm{~J} 9$ & KX251431 & KX251432 & KX251433 & KX251434 & KX251435 & KX251436 & KX251437 \\
\hline P. rubi & $30 \mathrm{D} 7$ & KX251550 & KX251551 & KX251552 & KX251553 & KX251554 & KX251555 & KX251556 \\
\hline P. sansomeana ${ }^{\#}$ & $47 \mathrm{H} 5$ & KX251944 & KX251945 & KX251946 & KX251947 & KX251948 & KX251949 & KX251950 \\
\hline P. siskiyouensis & $41 B 7=C B S 122779$ & KX250677 & KX250678 & KX250679 & KX250680 & KX250681 & KX250682 & KX250683 \\
\hline$P$. sojae $^{\#}$ & 22D8 $=$ CBS 312.62 & KX251762 & KX251763 & KX251764 & KX251765 & KX251766 & KX251767 & KX251768 \\
\hline P. sp. brasiliensis & ATCC46705 $=$ P0630 & EU080419 & EU080420 & EU080421 & EU080422 & EU080423 & EU080424 & EU080425 \\
\hline$P$. sp. canalensis & 10456 & EU079569 & EU079570 & EU079571 & EU079572 & EU079573 & EU079574 & N/A \\
\hline P. sp. citricola VIII & 27D9 & KX250838 & KX250839 & KX250840 & KX250841 & KX250842 & KX250843 & KX25084 \\
\hline P. sp. cuyabensis & P8213 & EU080664 & EU080665 & EU080666 & EU080667 & EU080668 & EU080669 & EU080331 \\
\hline P. sp. delaware & $63 \mathrm{H} 4$ & KX251396 & KX251397 & KX251398 & KX251399 & KX251400 & KX251401 & KX251402 \\
\hline P. sp. kelmania & $24 \mathrm{~A} 7$ & 51986 & KX251987 & KX251988 & KX251989 & KX251990 & KX251991 & KX251992 \\
\hline$P$. sp. lagoariana & $60 \mathrm{~B} 4=P$ & EU080358 & KX252502 & EU080359 & EU080360 & EU080361 & EU080362 & EU080363 \\
\hline P. sp. personii & P11555 & EU080312 & EU080313 & EU080314 & EU080315 & EU080316 & EU080317 & EU080318 \\
\hline P. sp. sulawesiensis & P6306 & EU080345 & N/A & EU080346 & EU080347 & EU080348 & EU080349 & EU080350 \\
\hline P. stricta & $58 \mathrm{~A} 2$ & KX252217 & KX252218 & KX252219 & KX252220 & KX252221 & KX252222 & KX252223 \\
\hline P. syringae ${ }^{\#}$ & $23 \mathrm{~A} 6$ & KX252203 & KX252204 & KX252205 & KX252206 & KX252207 & KX252208 & KX252209 \\
\hline P. taxon parsley & 61G1=BPIC 2584 & KX252105 & KX252106 & KX252107 & KX252108 & KX252109 & KX252110 & KX252111 \\
\hline P. taxon walnut & $40 \mathrm{~A} 7$ & KX251452 & KX251453 & KX251454 & KX251455 & KX251456 & KX251457 & KX251458 \\
\hline
\end{tabular}


Table 24 (continued)

\begin{tabular}{|c|c|c|c|c|c|c|c|c|}
\hline Species & Strain & $60 \mathrm{~S}$ & tub2 & tefl & Enl & HSP90 & $28 \mathrm{~S}$ & TigA \\
\hline P. taxon-aquatilis & $38 \mathrm{~J} 5$ & KX250929 & KX250930 & KX250931 & KX250932 & KX250933 & KX250934 & KX250935 \\
\hline P. taxon-castitis & $61 \mathrm{E} 7=\mathrm{CBS} 131246$ & KX252098 & KX252099 & KX252100 & KX252101 & KX252102 & KX252103 & KX252104 \\
\hline P. taxon-emzansi & $61 \mathrm{~F} 2$ & KX250859 & KX250860 & KX250861 & KX250862 & KX250863 & KX250864 & KX250865 \\
\hline P. tentaculata ${ }^{\#}$ & $29 F 2=$ CBS 552.96 & EU079955 & EU079956 & EU079957 & EU079958 & EU079959 & EU079960 & EU079961 \\
\hline P. terminalis & $65 \mathrm{~B} 8=\mathrm{CBS}$ & 607 & 608 & 609 & 510 & 611 & 612 & 0613 \\
\hline P. thermophila & $55 C 1=C B S 127954$ & KX251354 & KX251355 & KX251356 & KX251357 & KX251358 & KX251359 & KX251360 \\
\hline P. trifolii & 29B2 & KX251951 & KX251952 & $\mathrm{KX}^{2}$ & KX251954 & KX251955 & KX251956 & KX251957 \\
\hline P. tropicalis ${ }^{\#}$ & $35 \mathrm{C} 8=\mathrm{CBS} 434.91$ & KX250698 & KX250699 & KX250700 & KX250701 & KX250702 & KX250703 & KX250704 \\
\hline P. uliginosa & $62 \mathrm{~A} 3=\mathrm{CBS} 109054$ & EU080011 & EU080012 & EU080013 & KX251571 & KX251572 & EU080015 & KX251573 \\
\hline P. vignae ${ }^{\#}$ & 45G9=ATCC 64832 & KX251783 & KX251784 & KX251785 & KX251786 & KX251787 & KX251788 & KX251789 \\
\hline P. virginiana & 44G6 & KX252371 & KX252372 & KX252373 & KX252374 & KX252375 & KX252376 & KX252377 \\
\hline
\end{tabular}

Ex-type/ex-epitype/ex-neotype/ex-lectotype strains and voucher strains are in bold. Species confirmed with pathogenicity studies are marked with $^{\#}$. (VdPN) are strains used by Van der Plaäts-Niterink (1981) for descriptions

Fig. 40 Disease cycle of a Pythium species (redrawn from van West et al. 2003)

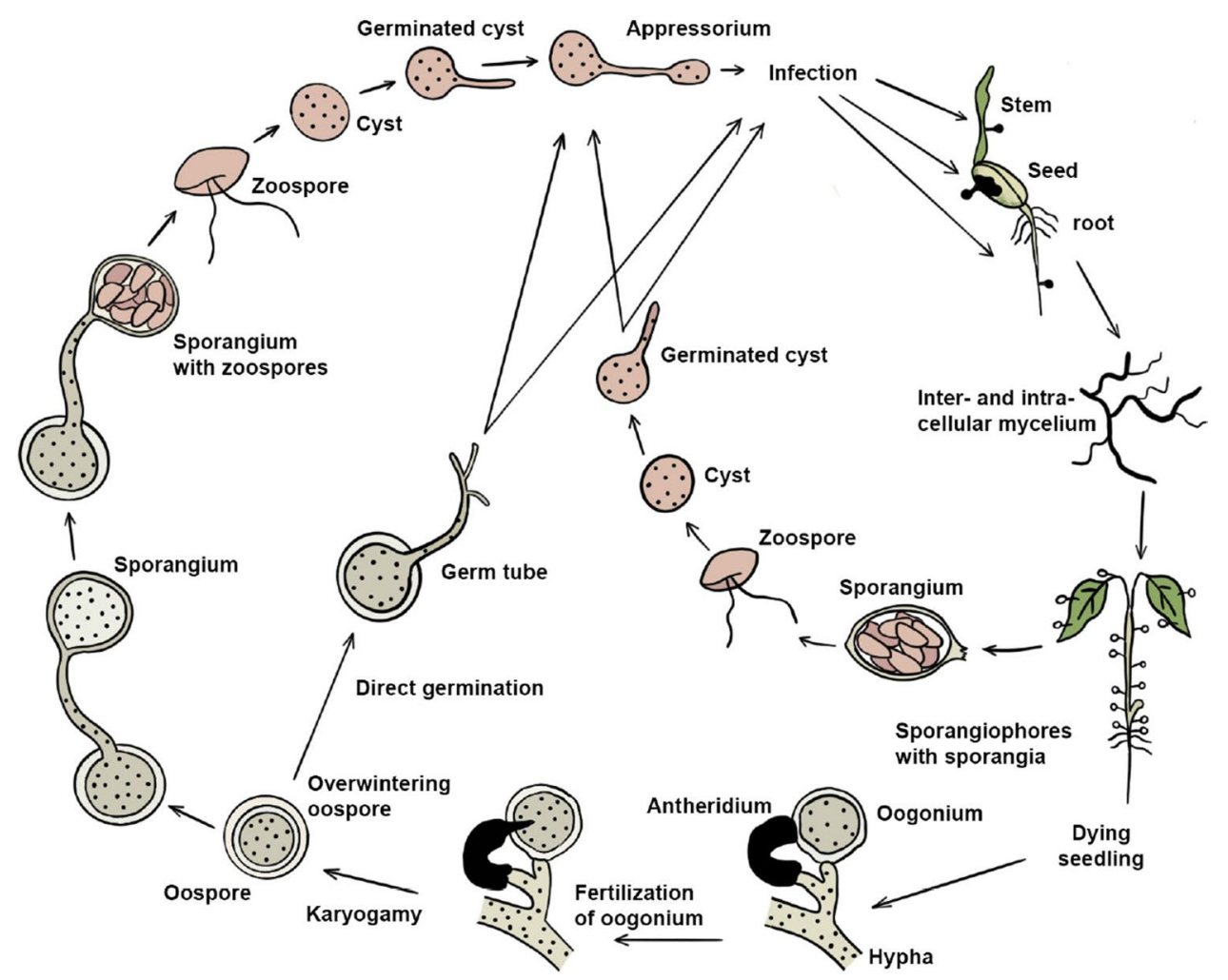

and Campbell 1973; Hsieh 1978; Ventura et al. 1981; Chun and Schneider 1998; Eberle et al. 2007; Kreye et al. 2009; Oliva et al. 2010; Banaay et al. 2012; Van Buyten and Höfte 2013). Pythium insidiosum causes pythiosis in mammals including humans (van der Plaäts-Niterink 1981; de Cock et al. 1987). Some species target below-ground plant parts and some species can cause fruit rot, however, some Pythium species can also benefit plants as endophytes by acting as biocontrol agents (Benhamou et al. 1997) and by stimulating plant growth (Martin and Loper 1999; Mazzola et al. 2002).

\section{Pathogen biology, disease cycle and epidemiology}

Pythium species grow and colonize a plant by producing hyphae which extract nutrients from the host. Once the hyphae from opposite mating types meet, they produce thick-walled oospores which serve as overwintering structures. Upon germination, an oospore may produce more hyphae, or develop a zoosporangium, which produces motile zoospores that swim to and infect plants. Zoosporangia can also germinate and directly infect plants (Ho 2009; van West et al. 2003). 


\section{Morphological based identification and diversity}

Pythium has hyaline hyphae which are coenocytic without cross septa (van der Plaäts-Niterink 1981). Filamentous and globose sporangia are present, and zoospores develop in a vesicle, which is formed at the tip of a discharge tube from a sporangium. After fertilization with paragynous or hypogynous antheridia, oospores are formed in smooth or ornamented oogonia. The oospore can fill the whole organism or can have space between the walls of the oogonia and oospore. The process of zoospore formation within a vesicle is a characteristic feature of the genus, which distinguishes it from morphologically similar genera such as Phytophthora and Halophytophthora. However, the formation of zoospores is similar to Lagenidium, which features endobiotic and holocarpic features not observed in Pythium (Dick 2001). Species delimitation based on morphological characteristics such as shape and size of sporangia and oogonia is difficult as these characteristics are often shared among different species.

\section{Molecular based identification and diversity}

Lévesque and de Cock (2004) separated the genus into 11 clades (A-K) using phylogenies of ITS and 28S. Clade $\mathrm{K}$, which includes $P$. vexans was transferred to a new genus Phytopythium with Phytopythium sindhum as type species (Bala et al. 2010), while the remaining clades can be divided into two groups: species with filamentous sporangia (clades A-D) and species with globose sporangia (clades E-J). Identification of Pythium isolates to species level is recommended based on cox 1 and ITS gene regions. The use of ITS region alone cannot accurately identify all Pythium species. Several species are indistinguishable based on both ITS and coxl sequences. Lévesque and de Cock (2004) provided the first extensive study of Pythium, accepting 116 species. Additional species have recently been described for example P. alternatum (Rahman et al. 2015), P. biforme, P. brachiatum, $P$. junctum, $P$. utonaiense (Uzuhashi et al. 2015), $P$. cedri (Chen et al. 2017), P. heteroogonium, P. longipapillum, P. oryzicollum (Salmaninezhad and Mostowfizadeh-Ghalamfarsa 2019). Currently, there are more than 130 accepted species in the genus (Arafa et al. 2020). The phylogenetic tree constructed is presented in Fig. 41 and the information of species are given in Table 25 .

Recommended genetic markers (generic level within Pythium sensu lato)-18S (small subunit, SSU) and 28S (large subunit, LSU) nuclear rRNA genes

Recommended genetic markers (sub-generic, inter-and intra-specific level) - The internal transcribed spacers (ITS including ITS1, 5.8S rRNA, and ITS2), cytochrome c oxidase subunit $2(\operatorname{cox} 2)$

Accepted number of species-There are 330 epithets listed in Index Fungorum (2020), however only 157 species have DNA sequence data (Table 25).
References - van der Plaäts-Niterink (1981), Dick (2001) (morphology), Lévesque and de Cock (2004), Hyde et al. (2014), Arafa et al. (2020) (phylogeny and accepted species numbers)

100. Rhizopus Ehrenb., Nova Acta Phys.-Med. Acad. Caes. Leop.-Carol. Nat. Cur. 10: 198 (1821)

\section{Background}

Rhizopus is classified in the subphylum Mucoromycotina, class Mucoromycetes, order Mucorales and family Rhizopodaceae (Wijayawardene et al, 2018, 2020). The genus is one of the most diverse and constitutes an important genus within the order Mucorales. Rhizopus species are common post-harvest pathogens of fruits, vegetables, crops and stored foods, while some Rhizopus species are human pathogens. Rhizopus arrhizus and Rhizopus microsporus can cause mucoromycosis in immunocompromised humans (Yildirim et al. 2010; Benedict and Brandt 2016). Morphology-based (size of sporangia and sporangiophores, and rhizoids) and physiology-based (growth temperature) identification and classification grouped the genus in three groups: $R$. microsporus, $R$. stolonifer, and R. arrhizus (syn: R. oryzae) (Schipper 1984). Schipper (1984) and Schipper and Stalpers (1984), provided the first significant monographs of Rhizopus. Fundamental morphological-based identification was provided which is still widely used in current taxonomic classification for Rhizopus (Schipper 1984; Schipper and Stalpers 1984; Hartanti et al. 2015). The inclusion of DNA-based phylogenetic tools has resulted in significant changes in the taxonomic classification (Vebliza et al. 2018). With the implementation of molecular-based identification, Abe et al. (2006, 2010), Zheng et al. (2007b), and Liu et al. (2007) provided significant contributions in the classification of Rhizopus. Briefly, in current taxonomy Rhizopus arrhizus is a synonym of $R$. oryzae, $R$. reflexus to $R$. lyococcus and Amylomyces rouxii is a synonym of Rhizopus arrhizus (Liu et al. 2007; Hyde et al. 2014; Vebliza et al. 2018) (Fig. 42).

Phylogenomic approaches have the potential to provide a clear understanding of the inter-relationships of species (Gryganskyi et al. 2018). In recent revisions, data from wholegenome sequencing have been used (Gryganskyi et al. 2018). Phylogenetic analysis based on a dataset of 192 orthologous protein-coding genes extracted from whole-genome sequencing of representative species provided a robust phylogeny and tree topology for Rhizopus. The phylogenetic analysis resulted in similar tree topology obtained from studies which utilize ITS and pyrG genes or 76 orthologous proteins from the genomes (Liu et al. 2007; Chibucos et al. 2016). In brief, $R$. microsporus is suggested to be a monophyletic sister clade to other Rhizopus clades, $R$. stolonifer was found to be sister to $R$. arrhizus and $R$. delemar and these four species are monophyletic (Gryganskyi et al. 2010, 2018).

A comparative analysis of the mating-type locus across Rhizopus revealed that its structure is flexible even between 
Fig. 41 Maximum likelihood of Pythium species based on the concatenated SSU, ITS, LSU, cox 2 and $t u b 2$ regions. The maximum parsimonious dataset consisted of 528 constant, 71 parsimony-informative and 556 parsimony-uninformative characters. The parsimony analysis of the data matrix resulted in the maximum of ten equally most parsimonious trees with a length of 1637 steps $(\mathrm{CI}=$ $0.200, \mathrm{RI}=0.737, \mathrm{RC}=0.147$, $\mathrm{HI}=0.800$ ). ML and MP bootstrap support values over $60 \%$ and BYPP $\geq 0.90$ are indicated. Type strains are in bold and the 11 clades (A-K) are indicated. Scale bar indicates number of substitutions per site. The tree was rooted with Lagenidium giganteum (CBS 580.84) and Lagenidium sp. (DAOM 242348 and CBS 127283). Likelihood of the best scoring ML tree was - 28453.969593. Estimated base frequencies were as follows: $\mathrm{A}=0.264872, \mathrm{C}$ $=0.163069, \mathrm{G}=0.213432$, $\mathrm{T}=0.358627$; substitution rates $\mathrm{AC}=1.219282, \mathrm{AG}=$ $3.062456, \mathrm{AT}=3.113530, \mathrm{CG}$ $=0.855790, \mathrm{CT}=4.379562$, GT $=1.000000$

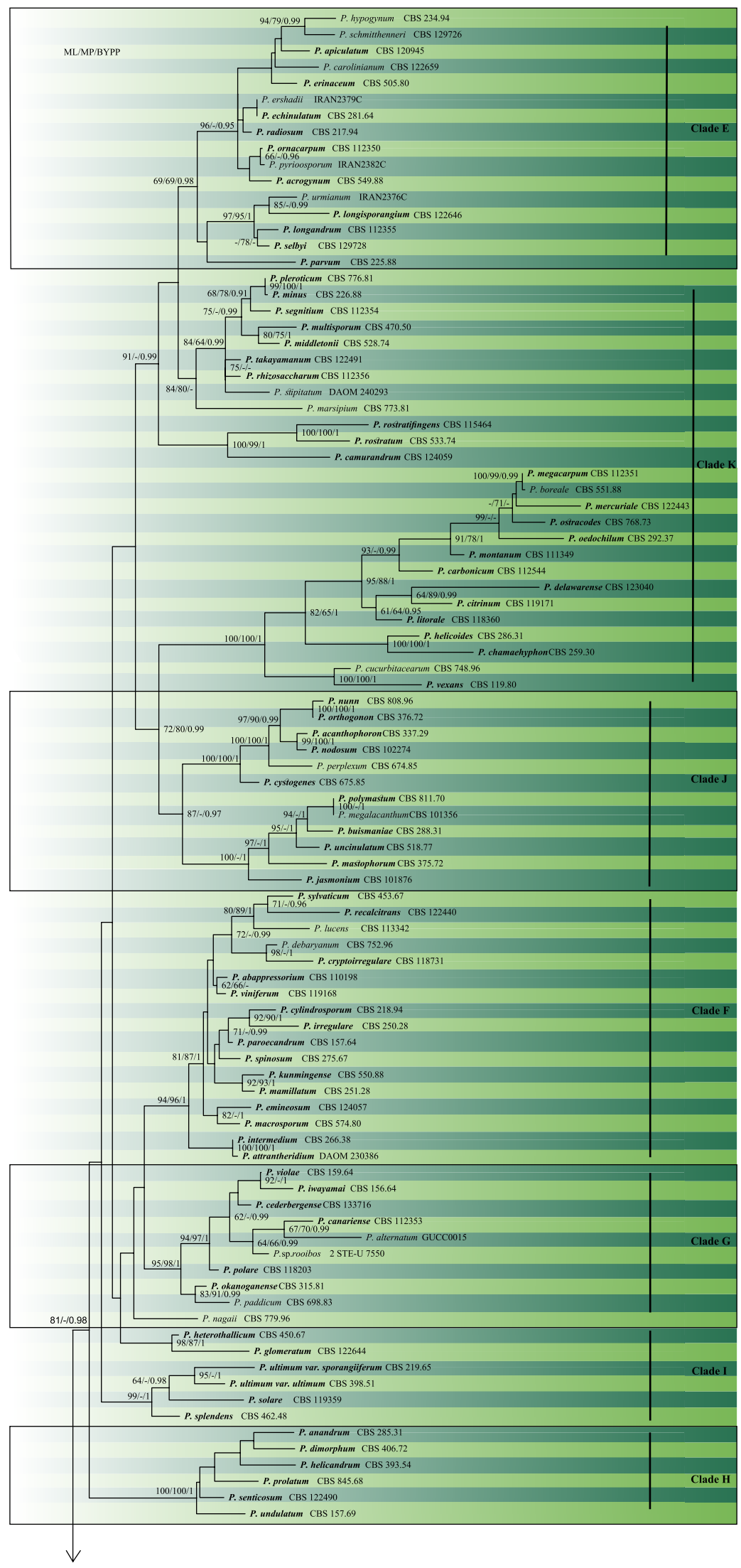


Fig. 41 (continued)

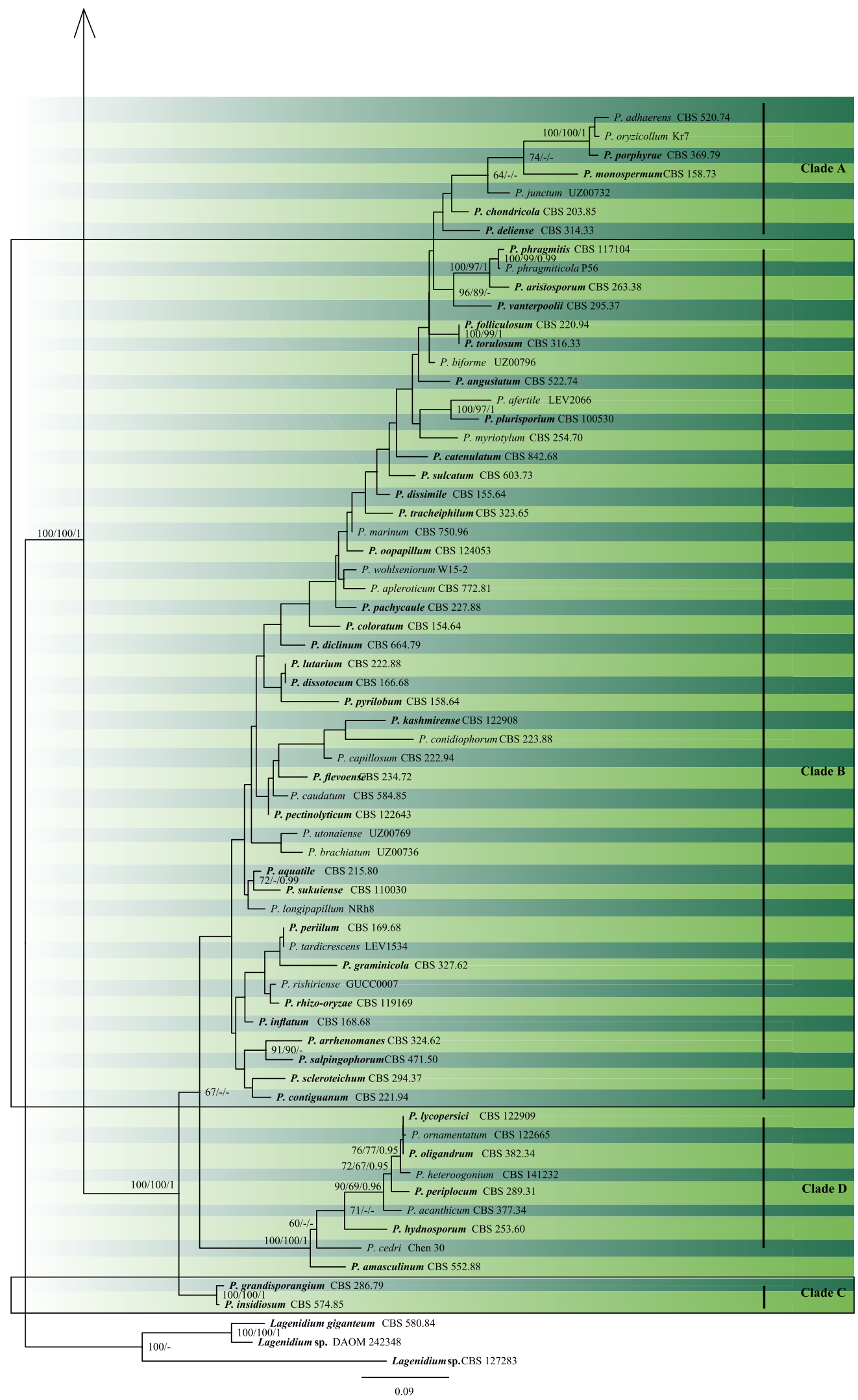


Table 25 DNA barcodes available for Pythium

\begin{tabular}{|c|c|c|c|c|c|c|c|}
\hline Species & Isolate & Host & SSU & ITS & LSU & $\cos 2$ & $t u b 2$ \\
\hline $\begin{array}{l}\text { Pythium abappres- } \\
\text { sorium }^{\#}\end{array}$ & CBS 110198 & Triticum aestivum & HQ643408 & HQ643408 & HQ643408 & KJ595409 & KJ595533 \\
\hline P. acanthicum ${ }^{\#}$ & CBS 377.34 & Solanum tuberosum & AY598617 & AY598617 & AY598617 & KJ595380 & KJ595504 \\
\hline P. acanthophoron ${ }^{\#}$ & CBS 337.29 & Ananas sativus & AY598711 & AY598711 & AY598711 & KJ595376 & KJ595500 \\
\hline P. acrogynum & CBS 549.88 & $\begin{array}{l}\text { Soil (Spinacia } \\
\text { oleracea) }\end{array}$ & N/A & AY598638 & AY598638 & AB362324 & KJ595458 \\
\hline P. adhaerens & CBS 520.74 & Soil & AY598619 & AY598619 & AY598619 & KJ595386 & KJ595510 \\
\hline P. afertile & LEV2066 & Turf grass & N/A & HQ643416 & HQ643416 & KJ595440 & KJ595563 \\
\hline P. alternatum & GUCC0015 & Soil & N/A & AB998876 & N/A & - & N/A \\
\hline P. amasculinum & CBS 552.88 & $\begin{array}{l}\text { Soil (vegetable } \\
\text { garden) }\end{array}$ & AY598671 & AY598671 & AY598671 & KJ595390 & KJ595514 \\
\hline P. anandrum ${ }^{\#}$ & CBS 285.31 & Rheum rhaponticum & AY598650 & AY598650 & AY598650 & AB362328 & KJ595450 \\
\hline P. angustatum ${ }^{\#}$ & $\begin{array}{c}\text { CBS 522.74 } \\
\text { (VdPN) }\end{array}$ & Soil & AY598623 & AY598623 & AY598623 & KJ595387 & KJ595511 \\
\hline P. aphanidermatum ${ }^{\#}$ & CBS 118.80 & Unknown & AY598622 & AY598622 & AY598622 & KJ595344 & KJ595472 \\
\hline P. apiculatum & CBS 120945 & Soil (Vitis sp.) & HQ643443 & HQ643443 & HQ643443 & KJ595422 & KJ595547 \\
\hline P. apleroticum & CBS 772.81 & Nymphyoidespeltata & AY598631 & AY598631 & AY598631 & KJ595400 & KJ595524 \\
\hline P. aquatile a $^{\#}$ & CBS 215.80 & Soil & AY598632 & AY598632 & AY598632 & KJ595355 & KJ595481 \\
\hline P. aristosporum & CBS 263.38 & Triticum aestivum & AY598627 & AY598627 & AY598627 & AB507410 & DQ071297 \\
\hline P. arrhenomanes ${ }^{\#}$ & $\begin{array}{c}\text { CBS } 324.62 \\
(V d P N)\end{array}$ & Zea mays & AKXY02050628 & AY598628 & AY598628 & AKXY02053172 & KJ595451 \\
\hline P. attrantheridium ${ }^{\#}$ & DAOM 230386 & Prunus serotina & HQ643476 & HQ643476 & HQ643476 & AB512889 & AB512822 \\
\hline P. biforme & UZ00796 & Aquatic & N/A & KJ995584 & KJ995601 & N/A & N/A \\
\hline P. boreale & CBS 551.88 & Soil & AY598662 & AY598662 & AY598662 & EF408876 & EF408882 \\
\hline P. brachiatum & UZ00736 & Aquatic & N/A & KJ995581 & KJ995603 & N/A & N/A \\
\hline P. buismaniae & CBS 288.31 & Linumusitatissimum & AY598659 & AY598659 & AY598659 & KJ595368 & KJ595493 \\
\hline P. camurandrum & CBS 124059 & Hordeum vulgare & GQ244426 & GQ244426 & GQ244426 & KJ595433 & KJ595558 \\
\hline P. canariense & CBS 112353 & Soil & HQ643482 & HQ643482 & HQ665069 & JX397983 & JX397969 \\
\hline P. capillosum & CBS 222.94 & Soil & AY598635 & AY598635 & AY598635 & KJ595360 & KJ595485 \\
\hline P. carbonicum $^{\#}$ & CBS 112544 & Soil (spoil heap) & HQ643373 & HQ643373 & HQ643373 & AB690678 & KJ595464 \\
\hline P. carolinianum $^{\#}$ & CBS 122659 & Soil & N/A & HQ643484 & HQ665111 & KJ595427 & KJ595551 \\
\hline P. catenulatum $^{\#}$ & $\begin{array}{c}\text { CBS 842.68 } \\
(\text { VdPN })\end{array}$ & Turf grass & AY598675 & AY598675 & AY598675 & KJ595404 & KJ595528 \\
\hline P. caudatum & CBS 584.85 & Xiphinemarivesi & HQ643136 & HQ643136 & HQ665277 & AF290309 & KJ595459 \\
\hline P. cederbergense $e^{\#}$ & CBS 133716 & Aspalathuslinearis & N/A & JQ412768 & KJ716864 & JQ412805 & JQ412781 \\
\hline P. cedri ${ }^{\#}$ & Chen 30 & roots of Cedrus & N/A & KX423751 & N/A & N/A & N/A \\
\hline P. chamaehyphon & CBS 259.30 & Carica papaya & AY598666 & AY598666 & AY598666 & AB257280 & KJ595448 \\
\hline P. chondricola ${ }^{\#}$ & CBS 203.85 & Chondruscrispus & $\mathrm{N} / \mathrm{A}$ & AY598620 & AY598620 & KJ595354 & KJ595480 \\
\hline P. citrinum & CBS 119171 & Soil (Vitis sp.) & HQ643375 & HQ643375 & HQ643375 & AB690679 & KJ595465 \\
\hline P. coloratum $^{\#}$ & CBS 154.64 & Soil (tree nursery) & AY598633 & AY598633 & AY598633 & KJ595346 & KJ595474 \\
\hline P. conidiophorum ${ }^{\#}$ & CBS 223.88 & Soil & AY598629 & AY598629 & AY598629 & KJ595361 & KJ595486 \\
\hline P. contiguanum & CBS 221.94 & Soil (salt marsh) & HQ643514 & HQ643514 & HQ665162 & KJ595358 & KJ595483 \\
\hline P. cryptoirregulare $^{\#}$ & CBS 118731 & $\begin{array}{l}\text { Euphorbia pulcher- } \\
\quad \text { rima }\end{array}$ & HQ643515 & HQ643515 & HQ643515 & GU071763 & GU071888 \\
\hline P. cucurbitacearum $^{\#}$ & CBS 748.96 & Unknown & AY598667 & AY598667 & AY598667 & AB690680 & KJ595460 \\
\hline P. cylindrosporum ${ }^{\#}$ & CBS 218.94 & Soil & AY598643 & AY598643 & AY598643 & GU071762 & GU071877 \\
\hline P. cystogenes ${ }^{\#}$ & CBS 675.85 & Viciafaba & HQ643518 & HQ643518 & HQ643518 & KJ595396 & KJ595520 \\
\hline P. debaryanum ${ }^{\#}$ & CBS 752.96 & Tulipa sp. & AY598704 & AY598704 & AY598704 & KJ595399 & KJ595523 \\
\hline P. delawarense & CBS 123040 & Glycine max & KF853241 & EU339312 & KF853240 & KJ595430 & KJ595555 \\
\hline P. deliense $\mathrm{e}^{\#}$ & CBS 314.33 & Nicotiana tabacum & AY598674 & AY598674 & AY598674 & KJ595372 & KJ595497 \\
\hline P. diclinum ${ }^{\#}$ & CBS 664.79 & Beta vulgaris & N/A & AY598690 & HQ665282 & KJ595394 & KJ595518 \\
\hline
\end{tabular}


Table 25 (continued)

\begin{tabular}{|c|c|c|c|c|c|c|c|}
\hline Species & Isolate & Host & SSU & ITS & LSU & $\cos 2$ & tub2 \\
\hline P. dimorphum ${ }^{\#}$ & CBS 406.72 & Pinus taeda & AY598651 & AY598651 & AY598651 & AB362331 & KJ595454 \\
\hline P. dissimile & CBS 155.64 & Pinus radiata & AY598681 & AY598681 & AY598681 & KJ595347 & KJ595475 \\
\hline P. dissotocum ${ }^{\#}$ & $\begin{array}{c}\text { CBS 166.68 } \\
\text { (VdPN) }\end{array}$ & Triticum aestivum & AY598634 & AY598634 & AY598634 & KJ595351 & KJ595479 \\
\hline P. echinulatum ${ }^{\#}$ & $\begin{array}{c}\text { CBS 281.64 } \\
(\text { VdPN) }\end{array}$ & Soil (forest nursery) & AY598639 & AY598639 & AY598639 & AB362327 & KJ595449 \\
\hline P. emineosum & CBS 124057 & Juniperus communis & N/A & GQ244427 & GQ244427 & KJ595432 & KJ595557 \\
\hline P. erinaceum & CBS 505.80 & Soil & N/A & AY598694 & HQ665243 & AB362326 & KJ595456 \\
\hline P. ershadii & IRAN2379C & Soil & N/A & KT894054 & N/A & - & N/A \\
\hline P. flevoense & CBS 234.72 & Soil & AY598691 & AY598691 & AY598691 & KJ595363 & KJ595488 \\
\hline P. folliculosum ${ }^{\#}$ & CBS 220.94 & Soil & AY598676 & AY598676 & HQ665160 & N/A & N/A \\
\hline P. glomeratum ${ }^{\#}$ & CBS 122644 & Soil & N/A & HQ643542 & HQ665097 & KJ595424 & KJ595548 \\
\hline P. graminicola g $^{\#}$ & CBS 327.62 & $\begin{array}{l}\text { Saccharum offici- } \\
\text { narum }\end{array}$ & AY598625 & AY598625 & AY598625 & AF196593 & KJ595452 \\
\hline $\begin{array}{l}\text { P. grandisporan- } \\
\text { gium }^{\#}\end{array}$ & CBS 286.79 & $\begin{array}{l}\text { Decaying leaf (Zos- } \\
\text { tera marina) }\end{array}$ & AY598692 & AY598692 & AY598692 & KJ595367 & KJ595492 \\
\hline P. helicandrum & CBS 393.54 & Rumex acetosella & AY598653 & AY598653 & AY598653 & AB362329 & KJ595453 \\
\hline P. helicoides ${ }^{\#}$ & CBS 286.31 & Phaseolus vulgaris & AY598665 & AY598665 & AY598665 & DQ071377 & AB511994 \\
\hline P. heteroogonium & 079-1 - CBS 141232 & Soil & N/A & KX228103 & N/A & KX228131 & KX228117 \\
\hline P. heterothallicum ${ }^{\#}$ & CBS 450.67 & Soil (Sambucus) & AY598654 & AY598654 & AY598654 & AB512919 & AB512850 \\
\hline P. hydnosporum ${ }^{\#}$ & $\begin{array}{c}\text { CBS 253.60 } \\
(\text { VdPN) }\end{array}$ & Unknown & AY598672 & AY598672 & AY598672 & KJ595364 & KJ595489 \\
\hline P. hypogynum ${ }^{\#}$ & CBS 234.94 & Soil & AY598693 & HQ643565 & HQ665171 & AB362325 & KJ595447 \\
\hline P. inflatum ${ }^{\#}$ & $\begin{array}{l}\text { CBS 168.68 } \\
\text { (VdPN) }\end{array}$ & $\begin{array}{l}\text { Saccharum offici- } \\
\text { narum }\end{array}$ & AY598626 & AY598626 & AY598626 & KJ595352 & N/A \\
\hline P. insidiosum $^{\#}$ & CBS 574.85 & Equus ferus & AF289981 & AY598637 & AY598637 & KJ595391 & KJ595515 \\
\hline P. intermedium ${ }^{\#}$ & $\begin{array}{c}\text { CBS 266.38 } \\
(\text { VdPN) }\end{array}$ & Agrostis stolonifera & AY598647 & AY598647 & AY598647 & AB507410 & AB512836 \\
\hline P. irregular & CBS 250.28 & Phaseolus vulgaris & AY598702 & AY598702 & AY598702 & GU071760 & GU071886 \\
\hline P. iwayamai & $\begin{array}{c}\text { CBS 156.64 } \\
(\text { VdPN) }\end{array}$ & Soil (Pinus sp.) & AY598648 & AY598648 & AY598648 & JX397979 & JX397965 \\
\hline P. jasmonium & CBS 101876 & Arabidopsis thaliana & HQ643778 & HQ643778 & HQ643778 & KJ595406 & KJ595530 \\
\hline P. junctum & UZ00732 & Aquatic & N/A & KJ995576 & KJ995605 & N/A & N/A \\
\hline P. kashmirense $^{\#}$ & CBS 122908 & Soil & HQ643671 & HQ643671 & HQ643671 & KJ595429 & KJ595553 \\
\hline P. kunmingense $\mathrm{e}^{\#}$ & CBS 550.88 & Soil (Viciafaba) & AY598700 & AY598700 & HQ665259 & KJ595389 & KJ595513 \\
\hline P. litorale \# $^{\#}$ & CBS 118360 & $\begin{array}{l}\text { Soil (Phragmites } \\
\text { australis) }\end{array}$ & HQ643386 & HQ643386 & HQ643386 & KJ595418 & KJ595543 \\
\hline P. longandrum ${ }^{\#}$ & CBS 112355 & Soil & HQ643679 & HQ643679 & HQ665071 & KJ595413 & KJ595538 \\
\hline P. longipapillum & $\mathrm{NRh} 8 *$ & Soil & N/A & KX228105 & N/A & KX228130 & KX228114 \\
\hline P. longisporangium & CBS 122646 & Soil (Vitis sp.) & N/A & HQ643680 & HQ665099 & KJ595426 & KJ595550 \\
\hline P. lucens ${ }^{\#}$ & CBS 113342 & Triticum & HQ643681 & HQ643681 & HQ643681 & KJ595415 & KJ595540 \\
\hline P. lutarium ${ }^{\#}$ & CBS 222.88 & Soil & HQ643682 & HQ643682 & HQ665163 & KJ595359 & KJ595484 \\
\hline P. lycopersici & CBS 122909 & $\begin{array}{l}\text { Soil (Lycopersicum } \\
\text { esculentum) }\end{array}$ & N/A & HQ643683 & HQ665119 & KJ595343 & KJ595554 \\
\hline P. macrosporum ${ }^{\#}$ & CBS 574.80 & Flower bulb & AY598646 & AY598646 & AY598646 & AB512916 & AB512842 \\
\hline P. mamillatum ${ }^{\#}$ & $\begin{array}{c}\text { CBS 251.28 } \\
(\text { VdPN) }\end{array}$ & Beta vulgaris & AY598703 & AY598703 & HQ665173 & AB362325 & AB512844 \\
\hline P. marinum $^{\#}$ & CBS 750.96 & Soil & N/A & AY598689 & AY598689 & KJ595398 & KJ595522 \\
\hline P. marsipium ${ }^{\#}$ & CBS 773.81 & Nymphyoides peltata & N/A & AY598699 & HQ665297 & KJ595401 & KJ595525 \\
\hline P. mastophorum ${ }^{\#}$ & $\begin{array}{c}\text { CBS } 375.72 \\
(\text { VdPN })\end{array}$ & Apiumgraveolens & AY598661 & AY598661 & AY598661 & KJ595378 & KJ595502 \\
\hline P. megacarpum & CBS 112351 & Soil (Vitis sp.) & HQ643388 & HQ643388 & HQ643388 & AB690665 & KJ595536 \\
\hline
\end{tabular}


Table 25 (continued)

\begin{tabular}{|c|c|c|c|c|c|c|c|}
\hline Species & Isolate & Host & SSU & ITS & LSU & $\cos 2$ & $t u b 2$ \\
\hline P. megalacanthum ${ }^{\#}$ & CBS 101356 & Chrysanthemum & N/A & HQ643693 & KJ716865 & KJ595435 & N/A \\
\hline P. mercurial $^{\#}$ & CBS 122443 & $\begin{array}{l}\text { Macadamia integ- } \\
\text { rifolia }\end{array}$ & KF853243 & DQ916363 & KF853236 & AB690666 & KJ595466 \\
\hline P. middletonii ${ }^{\#}$ & CBS 528.74(VdPN) & Soil & N/A & AY598640 & AY598640 & AB362318 & KJ595457 \\
\hline P. minus ${ }^{\#}$ & CBS 226.88 & Soil & HQ643696 & HQ643696 & HQ665168 & AB362320 & KJ595446 \\
\hline P. monospermum & $\begin{array}{c}\text { CBS } 158.73 \\
\text { (VdPN) }\end{array}$ & Soil & HQ643697 & HQ643697 & HQ643697 & KJ595350 & KJ595478 \\
\hline P. montanum & CBS 111349 & Soil (Picea abies) & HQ643389 & HQ643389 & HQ643389 & KJ595410 & KJ595534 \\
\hline P. multisporum & CBS 470.50 & Soil & AY598641 & AY598641 & AY598641 & AB362319 & KJ595455 \\
\hline P. nagaii $^{\#}$ & CBS 779.96 & Soil & AY598705 & AY598705 & AY598705 & KJ595402 & KJ595526 \\
\hline P. nodosum ${ }^{\#}$ & CBS 102274 & Soil & N/A & HQ643709 & HQ665055 & KJ595407 & KJ595531 \\
\hline P. nunn $^{\#}$ & CBS 808.96 & Soil & AY598709 & AY598709 & AY598709 & AF196609 & DQ071325 \\
\hline P. oedochilum ${ }^{\#}$ & CBS 292.37 & Unknown & AY598664 & AY598664 & AY598664 & AB108011 & EF408883 \\
\hline P. okanoganense $e^{\#}$ & CBS 315.81 & Triticum aestivum & AY598649 & AY598649 & AY598649 & KJ595373 & KJ595498 \\
\hline P. oligandrum ${ }^{\#}$ & $\begin{array}{l}\text { CBS } 382.34 \\
(\text { VdPN })\end{array}$ & Viola sp. & AY598618 & AY598618 & AY598618 & KJ595381 & KJ595505 \\
\hline P. oopapillum ${ }^{\#}$ & CBS 124053 & Cucumis sativus & N/A & FJ655174 & FJ655174 & KJ595431 & KJ595556 \\
\hline P. ornacarpum & CBS 112350 & Soil & HQ643721 & HQ643721 & HQ643721 & KJ595411 & KJ595535 \\
\hline P. ornamentatum & CBS 122665 & Soil & N/A & HQ643722 & HQ665117 & KJ595428 & KJ595552 \\
\hline P. orthogonon & CBS 376.72 & Zea mays & AY598710 & AY598710 & HQ665221 & KJ595379 & KJ595503 \\
\hline P. oryzicollum ${ }^{\#}$ & $\mathrm{Kr} 7$ & Soil & N/A & KX228072 & N/A & KX228125 & KX228108 \\
\hline P. ostracodes & $\begin{array}{l}\text { CBS } 768.73 \\
\text { (VdPN) }\end{array}$ & Soil & AY598663 & AY598663 & AY598663 & AB690668 & EF408880 \\
\hline P. pachycaule & CBS 227.88 & Soil & AY598687 & AY598687 & HQ665169 & KJ595362 & KJ595487 \\
\hline P. paddicum ${ }^{\#}$ & CBS 698.83 & $\begin{array}{l}\text { Triticum and Hor- } \\
\text { deum }\end{array}$ & AY598707 & AY598707 & AY598707 & JX397982 & JX397968 \\
\hline P. paroecandrum ${ }^{\#}$ & $\begin{array}{l}\text { CBS 157.64 } \\
\text { (VdPN) }\end{array}$ & Soil & AY598644 & AY598644 & AY598644 & DQ071391 & DQ071332 \\
\hline P. parvum & CBS 225.88 & Soil & AY598697 & AY598697 & AY598697 & AB362322 & KJ595445 \\
\hline P. pectinolyticum & CBS 122643 & Soil & HQ643739 & HQ643739 & HQ643739 & N/A & KJ595469 \\
\hline P. periilum ${ }^{\#}$ & $\begin{array}{c}\text { CBS 169.68 } \\
\text { (VdPN) }\end{array}$ & Soil & AY598683 & AY598683 & HQ665141 & N/A & KJ595444 \\
\hline P. periplocum ${ }^{\#}$ & CBS 289.31 & Citrullus vulgaris & AY598670 & AY598670 & AY598670 & KJ595369 & KJ595494 \\
\hline P. perplexum ${ }^{\#}$ & CBS 674.85 & Viciafaba & AY598658 & AY598658 & AY598658 & KJ595395 & KJ595519 \\
\hline P. phragmitis ${ }^{\#}$ & CBS 117104 & $\begin{array}{l}\text { Soil (Phragmites } \\
\text { australis) }\end{array}$ & HQ643746 & HQ643746 & HQ665081 & AJ890351 & EU152854 \\
\hline P. pleroticum & CBS 776.81 & Nymphyoides peltata & AY598642 & AY598642 & AY598642 & AB362321 & KJ595461 \\
\hline P. plurisporium ${ }^{\#}$ & CBS 100530 & Agrostis & AY598684 & AY598684 & AY598684 & KJ595405 & KJ595529 \\
\hline P. polare $e^{\#}$ & CBS 118203 & Sanionia uncinata & KJ716858 & AB299390 & KJ716859 & KJ595417 & KJ595542 \\
\hline P. polymastum ${ }^{\#}$ & $\begin{array}{l}\text { CBS } 811.70 \\
\text { (VdPN) }\end{array}$ & Lactuca sativa & AY598660 & AY598660 & AY598660 & KJ595403 & KJ595527 \\
\hline P. porphyrae ${ }^{\#}$ & $\begin{array}{l}\text { CBS 369.79 } \\
\text { (VdPN) }\end{array}$ & Porphyrayezoensis & AY598673 & AY598673 & AY598673 & KJ595377 & KJ595501 \\
\hline P. phragmiticola & P56 & Soil & N/A & KC145165 & N/A & KC145166 & KC145167 \\
\hline P. prolatum ${ }^{\#}$ & CBS 845.68 & Rhododendron sp. & AY598652 & AY598652 & AY598652 & AB362330 & KJ595462 \\
\hline P. pyrioosporum & IRAN2382C & Soil & N/A & KT894052 & N/A & - & N/A \\
\hline P. pyrilobum ${ }^{\#}$ & CBS 158.64 & Pinus radiata & AY598636 & AY598636 & AY598636 & KJ595349 & KJ595477 \\
\hline$P$. radiosum & CBS 217.94 & Soil & N/A & AY598695 & HQ665156 & KJ595356 & N/A \\
\hline P. recalcitrans ${ }^{\#}$ & CBS 122440 & Soil (Vitis vinifera) & N/A & DQ357833 & KJ716861 & KJ595423 & EF195143 \\
\hline P. rishiriense & GUCC0007 & Aquatic & N/A & AB998878 & N/A & - & N/A \\
\hline P. rhizo-oryzae ${ }^{\#}$ & CBS 119169 & Soil & HQ643757 & HQ643757 & HQ643757 & KJ595420 & KJ595545 \\
\hline
\end{tabular}


Table 25 (continued)

\begin{tabular}{|c|c|c|c|c|c|c|c|}
\hline Species & Isolate & Host & SSU & ITS & LSU & $\cos 2$ & $t u b 2$ \\
\hline P. rhizosaccharum & CBS 112356 & $\begin{array}{l}\text { Soil (Saccharum } \\
\text { officinarum) }\end{array}$ & N/A & HQ643760 & HQ665072 & AB362323 & KJ595463 \\
\hline P. rostratifingens ${ }^{\#}$ & CBS 115464 & Soil (Malus sp.) & HQ643761 & HQ643761 & HQ643761 & KJ595416 & KJ595541 \\
\hline P. rostratum ${ }^{\#}$ & CBS 533.74 & Soil & AY598696 & AY598696 & AY598696 & KJ595388 & KJ595512 \\
\hline P. salpingophorum ${ }^{\#}$ & $\begin{array}{l}\text { CBS 471.50 } \\
\text { (VdPN) }\end{array}$ & $\begin{array}{l}\text { Lupinus angusti- } \\
\text { folius }\end{array}$ & AY598630 & AY598630 & AY598630 & KJ595384 & KJ595508 \\
\hline P. schmitthenneri ${ }^{\#}$ & CBS 129726 & Glycine $\max$ & N/A & JF836869 & KJ716862 & JF895530 & KJ595470 \\
\hline P. scleroteichum ${ }^{\#}$ & CBS 294.37 & Ipomoea batatas & AY598680 & AY598680 & AY598680 & KJ595370 & KJ595495 \\
\hline P. segnitium & CBS 112354 & Soil & HQ643772 & HQ643772 & HQ643772 & KJ595412 & KJ595537 \\
\hline P. selbyi ${ }^{\#}$ & CBS 129728 & Zea mays & N/A & JF836871 & KJ716863 & JF895532 & KJ595471 \\
\hline P. senticosum ${ }^{\#}$ & CBS 122490 & Soil (forest) & HQ643773 & HQ643773 & HQ643773 & AB362317 & KJ595467 \\
\hline P. solare & CBS 119359 & Phaseolus vulgaris & N/A & EF688275 & KJ716860 & KJ595421 & KJ595546 \\
\hline P. spinosum ${ }^{\#}$ & $\begin{array}{c}\text { CBS } 275.67 \\
(\text { VdPN) }\end{array}$ & Compost & AY598701 & AY598701 & AY598701 & KJ595366 & KJ595491 \\
\hline P. splendens ${ }^{\#}$ & $\begin{array}{c}\text { CBS } 462.48 \\
(\mathrm{VdPN})\end{array}$ & Unknown & AY598655 & AY598655 & AY598655 & AB512921 & AB512852 \\
\hline P. stipitatum & DAOM 240293 & Soil & N/A & KJ716866 & KJ716866 & KJ595437 & KJ595560 \\
\hline P. sukuiense & CBS 110030 & Soil & N/A & HQ643836 & HQ665059 & KJ595408 & KJ595532 \\
\hline P. sulcatum ${ }^{\#}$ & CBS 603.73 & Daucus carota & AY598682 & AY598682 & HQ665281 & KJ595393 & KJ595517 \\
\hline P. sylvaticum ${ }^{\#}$ & CBS 453.67 & Soil & AY598645 & AY598645 & AY598645 & KJ595383 & KJ595507 \\
\hline P. takayamanum & CBS 122491 & Soil & HQ643854 & HQ643854 & HQ643854 & AB362315 & KJ595468 \\
\hline P. tardicrescens ${ }^{\#}$ & LEV1534 & Turfgrass & N/A & HQ643855 & HQ643855 & KJ595439 & KJ595562 \\
\hline P. torulosum & $\begin{array}{c}\text { CBS } 316.33 \\
\text { (VdPN) }\end{array}$ & Grass & AY598624 & AY598624 & AY598624 & KJ595374 & KJ595499 \\
\hline P. tracheiphilum & CBS 323.65 & Lactuca sativa & N/A & AY598677 & HQ665207 & KJ595375 & N/A \\
\hline $\begin{array}{l}\text { P. ultimum var. } \\
\text { sporangiiferum }^{\#}\end{array}$ & CBS 219.65 & Chenopodium album & AKYB02045405 & AY598656 & AY598656 & KJ595357 & KJ595482 \\
\hline $\begin{array}{l}\text { P. ultimum var. } \\
\text { ultimum }^{\#}\end{array}$ & CBS 398.51 & Lepidium sativum & AY598657 & AY598657 & AY598657 & KJ595382 & KJ595506 \\
\hline P. uncinulatum ${ }^{\#}$ & CBS 518.77 & Lactuca sativa & AY598712 & AY598712 & AY598712 & KJ595385 & KJ595509 \\
\hline P. undulatum ${ }^{\#}$ & $\begin{array}{c}\text { CBS } 157.69 \\
\text { (VdPN) }\end{array}$ & Soil (Pinus sp.) & AY598708 & AY598708 & AY598708 & KJ595348 & KJ595476 \\
\hline P. urmianum & IRAN2376C & Soil & N/A & KT894049 & N/A & - & N/A \\
\hline P. utonaiense & UZ00769 & Aquatic & N/A & KJ995587 & KJ995600 & N/A & N/A \\
\hline P. vanterpoolii ${ }^{\#}$ & CBS 295.37 & Triticum aestivum & AY598685 & AY598685 & AY598685 & KJ595371 & KJ595496 \\
\hline P. vexans ${ }^{\#}$ & CBS 119.80(VdPN) & Soil & HQ643400 & HQ643400 & HQ643400 & GU133518 & EF426556 \\
\hline$P$. viniferum ${ }^{\#}$ & CBS 119168 & Soil (Vitis sp.) & HQ643956 & HQ643956 & HQ643956 & KJ595419 & KJ595544 \\
\hline P. violae ${ }^{\#}$ & $\begin{array}{c}\text { CBS 159.64 } \\
(\text { VdPN) }\end{array}$ & Soil & AY598706 & AY598706 & AY598706 & JX397980 & JX397966 \\
\hline P. wohlseniorum & W15-2 & Aquatic & N/A & MH277978 & MH289800 & MH289798 & MH289799 \\
\hline Pythiumsp. rooibos 2 & STE-U 7550 & Aspalathus linearis & N/A & JQ412777 & N/A & JQ412813 & JQ412789 \\
\hline
\end{tabular}

Ex-type/ex-epitype/ex-neotype/ex-lectotype strains and voucher strains are in bold. Species confirmed with pathogenicity studies are marked with \#. (VdPN) are strains used by Van der Plaäts-Niterink (1981) for descriptions

different species in the same genus, but shows similarities between Rhizopus and other mucoralean taxa. Variation of the genome size was also noted to be approximately three-fold within a species which are induced by changes in transposable element copy numbers and genome duplications (Gryganskyi et al. 2018). Bruni et al. (2019) successfully adapted the CRISPR-Cas 9 technique for inducing $p y r F$ gene-specific mutations in two strains of $R$. delemar, the causative agent of mucoromycosis. This new tool is suggested to be useful in investigating the pathogenesis mechanisms of $R$. delemar and also generating specific mutants of Mucorales fungi.

Classification-Mucoromycota, Mucoromycotina, Mucoromycetes, Mucorales, Rhizopodaceae 
Fig. 42 Phylogenetic tree generated by maximum likelihood analysis of combined ITS- LSUSSU sequence data of Rhizopus, Backusella and Mucor species. Twenty-six taxa containing 2600 characters including gaps were used in the phylogenetic analysis. The tree was rooted using Backusella circina (CBS 128.70) and Mucor indicus (CBS 226.29). The best scoring RAxML tree with a final likelihood value of -11138.113172 is presented. The matrix contained 761 distinct alignment patterns, with $41.20 \%$ of undetermined characters or gaps. Estimated base frequencies were as follows: $\mathrm{A}=0.293528$, $\mathrm{C}=0.180262, \mathrm{G}=0.236482$, $\mathrm{T}=0.289728$; substitution rates $\mathrm{AC}=0.787730, \mathrm{AG}=$ $2.127667, \mathrm{AT}=1.579251, \mathrm{CG}$ $=0.715792, \mathrm{CT}=3.683423$, $\mathrm{GT}=1.000000$; gamma distribution shape parameter $\alpha=$ 0.181944 .ML bootstrap support values greater than $70 \%$ are shown near the nodes. The type species are in bold. Scale bar indicates the number of substitutions per site

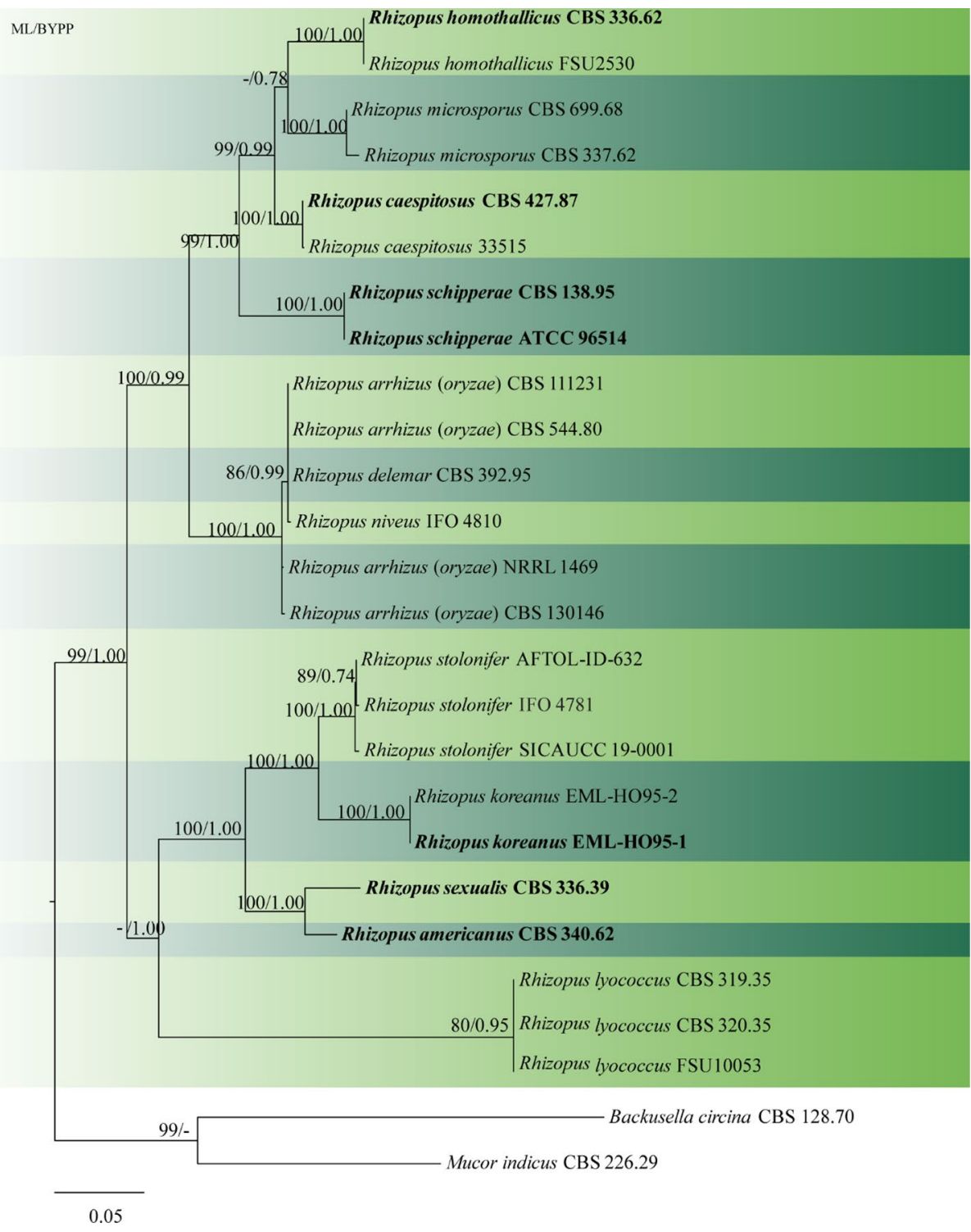

Type species—Rhizopus stolonifera (Ehrenb.) Vuill. 1902 Distribution-worldwide

Disease symptoms-Rhizopus blight, Rhizopus head rot and Rhizopus soft rot

Rhizopus blight: Rhizopus blight can affect flowers, leaves, and stems. When infected, the plant shows symptoms such as soft and mushy brown rot. The rot produces white mycelia with black sporangia and the abundant mycelia projects a 'bearded' appearance. Spores of the fungus can be spread by water and air. The mode of infection is similar to bacterial soft rot in which enzymes secreted by the fungus causes cell deterioration of the host tissue. The fungi require high temperatures, high humidity and weakened host tissues or wounds (Hartley 1992).

Rhizopus head rot on sunflowers: Rhizopus head rot may be caused by several Rhizopus species such as Rhizopus arrhizus, $R$. microsporus and $R$. stolonifer (Markell et al. 2015). Historically, Rhizopus head rot was deemed as a minor disease. However, recent surveys have shown their severity. Initial signs of Rhizopus head rot are dark spots of different sizes on different types of wounds on the plant. Soft watery rot appears on the infected fruit which often turns dark brown and extends to the back of the flower head, sepals and peduncles as the disease progresses. The infected sunflower receptacle disintegrates and becomes soft and pulpy. Infection by Rhizopus causes the head to shrivel and dry. Morphological characteristics are mycelial strands bearing sporangiophore and sporangia which are seen as the disease advances (Markell et al. 2015; Zhou et al. 2018). These whiskers are tufts of hyphae containing numerous sporangia and generally appear around lenticels or breaks in the periderm. Sometimes hyphae may not be visible on the outside of the root but can be viewed by pulling apart the infected tissue, giving it a stringy appearance (Clark et al. 2013). 
Table 26 DNA barcodes available for Rhizopus

\begin{tabular}{|c|c|c|c|c|}
\hline Species name & Isolate no & SSU & ITS & LSU \\
\hline Rhizopus americanus & CBS 340.62* & NG_062623 & HM999967 & NG_057873 \\
\hline \multirow[t]{3}{*}{ R. arrhizus } & CBS 111231 & & JN206338 & \\
\hline & CBS 544.80 & & JN206337 & \\
\hline & NRRL 1469 & & DQ641279 & \\
\hline \multirow[t]{2}{*}{ R. caespitosus } & CBS 427.87* & NG_062622 & NR_137056 & NG_057871 \\
\hline & 33515 & & AF115730 & DQ466604 \\
\hline R. delemar & CBS 392.95 & & MH862535 & MH874170 \\
\hline \multirow[t]{2}{*}{ R. homothallicus } & CBS336.62* & NG_062624 & HМ999968 & NG_057870 \\
\hline & FSU2530 & KJ408537 & KJ408567 & KJ408554 \\
\hline \multirow[t]{2}{*}{ R. koreanus } & EML-HO95-1* & KU058194 & KU058202 & KU058196 \\
\hline & EML-HO95-2 & KU058195 & KU058203 & KU058197 \\
\hline \multirow[t]{3}{*}{ R. lyococcus } & strain FSU10053 & KJ408545 & & KJ408562 \\
\hline & CBS 319.35 & & AB100449 & \\
\hline & CBS 320.35 & & JN206373 & JN206534 \\
\hline \multirow[t]{2}{*}{ R. microsporus ${ }^{\#}$} & CBS 699.68* & & HМ999970 & \\
\hline & CBS 337.62 & AB250177 & JN206362 & MH869765 \\
\hline R. niveus ${ }^{\#}$ & IFO 4810 & & DQ641284 & \\
\hline \multirow[t]{2}{*}{ R. oryzae } & CBS 112.07* & NG_062621 & NR_103595 & NG_056282 \\
\hline & CBS 130146 & & MH865585 & MH877020 \\
\hline \multirow[t]{2}{*}{ R. schipperae } & CBS 138.95 & & NR077174 & HM849672 \\
\hline & ATCC 96514* & NG_064824 & DQ641323 & NG_059417 \\
\hline R. sexualis ${ }^{\#}$ & CBS 336.39* & NG_063011 & AB113017 & MH867536 \\
\hline \multirow[t]{2}{*}{ R. stolonifer ${ }^{\#}$} & CBS 389.95 & & DQ641318 & \\
\hline & SICAUCC 19-0001 & MN148534 & MN267051 & MN148530 \\
\hline
\end{tabular}

Ex-type/ex-epitype/ex-neotype/ex-lectotype strains are in bold and marked with an asterisk $(*)$. Voucher strains are also in bold. Species confirmed with pathogenicity studies are marked with ${ }^{\#}$
Rhizopus soft rot: Common causative agents of Rhizopus soft rot are Rhizopus stolonifer and Rhizopus oryzae. The disease is considered as one of the most common and destructive postharvest diseases in many plants such as sweet potato (Ipomoea batatas), potato (Solanum tuberosum) and tomato (Solanum lycopersicum). The most frequent mode of infection is wounds and injuries present on the plants. Studies have also shown that the type of wounding and storage time have a significant impact on the susceptibility of infection by Rhizopus species (Scruggs and Quesada-Ocampo 2016). Earliest symptoms of infections are soft water-soaked lesions. The disease spreads across the wounded area and progresses to the extremities of the substrate. Hyphae soon develop on the rotten tissues and produce grey sporangiophores which subsequently bear sporangia (Khokhar et al. 2019). Whiskers are characteristics features of Rhizopus soft rot and have been reported in the case of soft rot on sweet potatoes (Clark et al. 2013; Scruggs and Quesada-Ocampo 2016) (Table 26).

Hosts-Wide range of hosts including species of Allium, Ananas, Brassica, Cucumis, Cucurbita, Fragaria, Lycopersicon, Phaseolus, Pisum and Solanum (Farr and Rossman 2020)

\section{Pathogen biology, disease cycle and epidemiology}

The pathogen reproduces asexually. Spores of Rhizopus species are commonly found in the air and can survive easily on crop debris, fruits, vegetables, and even on tools and equipment. Factors such as the Rhizopus species, type of fruit, stage of maturity of the plant and fruit or the storage will have a slight difference in the disease cycle. Rhizopus stolonifer, as well as the other species causing post-harvest diseases such as Rhizopus soft rot, require wound injuries, cracks or any mechanical damage for entry (Hartley 1992; Bautista-Baños et al. 2014; Scruggs and Quesada-Ocampo 2016). Infection and colonization are highly dependent on the enzymes produced by the fungi. To establish within the host, Rhizopus species produce numerous enzymes, including amylase, pectinase, and cellulase that can damage cell walls and permit host colonization (Ogundero 1988; Tang et al. 2012). This results in the softening of the host tissue; one of the symptoms of the disease (Nelson 2009; Kwon et al, 2012; Bautista-Baños et al. 2014; Feliziani and Romanazzi 2016). During initial stages of infection, Rhizopus rot appears as water-soaked areas and in the case of Rhizopus stolonifer, the rot also exudes clear leachate. In the case of Rhizopus soft rot caused by $R$. oryzae in banana, 
the symptoms and disease cycle are similar to $R$. stolonifer (Kwon et al. 2012). In Okinawan sweet potatoes, the disease causes a soft and moist appearance and a stringy flesh during the initial stages and as the disease progresses, the tissue of the sweet potato turns brownish and eventually black (Nelson 2009). In the case of $R$. stolonifer, the fungal mycelia quickly spread across the infection site. The sporangia formed are normally black and the whole plant is covered by fungal mycelia (Bautista-Baños et al. 2014). The enzymes exuded from the pathogen generally liquefy the internal tissues, for an example in sweet potato parenchyma of the root becomes liquefied, leaving the periderm and outer fibres of the root intact (Scruggs and Quesada-Ocampo 2016). The disease becomes more severe in warm, humid environments (Zoffoli and Latorre 2011). Avoidance of Rhizopus species is difficult due to their ubiquitous nature; therefore, sanitation and storing produce under unfavourable disease conditions is the key to control this pathogen.

\section{Morphology- based identification and diversity}

Rhizopus is normally distinguished by rhizoids, stolons and single or branched sporangiophores (Vebliza et al. 2018). Identification of species takes into account the growth temperature, size of sporangiophore and sporangium and the branching of rhizoids (Abe et al. 2007). The white mycelia consist of coenocytic hyphae which bear the sporangiophore with normally black sporangia. These taxa are fast-growing and form rhizoids at the base of sporangiophores. The sporangium contains a columella and spores (Bullerman 2003). During the sexual stage, there is the formation of zygospores and chlamydospores can also be seen during the growth of the fungi (Bullerman 2003; Abe et al. 2007).

\section{Molecular identification and diversity}

Traditionally, Rhizopus species were classified using morphological characters such as the shape and size of the structures (chlamydospores, rhizoids, sporangiophores and columellae) and physiological features such as optimal growth conditions. Current classification and taxonomic grouping follow that of Schipper (Schipper 1984). Schipper classified Rhizopus into three groups namely $R$. microsporus, $R$. stolonifer and $R$. arrhizus based on the physiological factors and morphology (Abe et al. 2010; Gryganskyi et al. 2018). Later, studies such as Abe et al. (2006), Liu et al. (2007), Zheng et al. (2007a, b), Abe et al. (2010) implemented molecular phylogeny using DNA sequence data in the classification of these fungi. With novel approaches used, the classification proposed by Schipper was found to agree with some recent studies while others divided the genus into ten species and seven varieties or eight species. Zheng et al. (2007b) used zygospore formation, and molecular systematic morphological characters, mating compatibility, physiology and molecular systematic to accept the division of the genus in ten species and seven varieties. Abe et al. (2010) also used the rDNA ITS gene region together with actin-1 and tefl, to reorganize the proposed taxonomy into eight species instead of ten species. One important data provided by this study was the problematic rDNA ITS region of $R$. americanus. It was discovered that $R$. sexualis var. americanus has three rDNA ITS gene regions which are distinct from each other. However, Liu et al. (2007) were not able to obtain all three rDNA ITS gene region instead they were able to amplify only one ITS region which was similar to that of Rhizopus oryzae. So, this led to the conclusion that $R$. americanus was phylogenetically different from $R$. sexualis.

Genetic markers (species and genus level)-ITS and rpb1 Genetic markers (higher-level phylogeny)-SSU, LSU and act

Accepted number of species-There are 152 species epithets in Index Fungorum (2020), however only 12 species have DNA sequence data (Table 25).

References-Bullerman (2003), Abe et al. (2007) (morphology); Abe et al. (2010), Gryganskyi et al. (2018), Vebliza et al. (2018) (morphology and phylogeny)

\section{Discussion}

This is the fourth in the One Stop Shop series focusing on providing a stable platform for the taxonomy of plant pathogenic fungi and fungus-like organisms. These series aim to provide updated backbone trees and information regarding plant pathogens in one place for ease of access. Databases play an important role in aggregating the scattered data into an easily accessible form and many of the pathogenic genera were annotated in the UNITE database (Nilsson et al. 2014). However, this database mainly focused on ITS region rather than the protein-coding gene regions. There are very few databases dedicated to identity the plant pathogens and related fungi-like organisms. We have been trying to provide a stable and updated taxonomy for 97 genera and three families since 2014, which are listed in Table 1. All this information is available in http://www.onestopshopfungi.org.

Acknowledgements Dr Yong Wang thanks National Natural Science Foundation of China (No. 31972222, 31560489), Program of Introducing Talents of Discipline to Universities of China (111 Program, D20023), Talent project of Guizhou Science and Technology Cooperation Platform ([2017]5788-5 and [2019]5641) and Guizhou Science, Technology Department International Cooperation Basic project ([2018]5806), Guizhou University cultivation project [2017]5788-33. Kevin D. Hyde would like to thank "the future of specialist fungi in a changing climate: baseline data for generalist and specialist fungi associated with ants, Rhododendron species and Dracaena species" 
(Grant No. DBG6080013), Thailand Research Fund (TRF) Grant no RDG6130001 "Impact of climate change on fungal diversity and biogeography in the Greater Mekong Subregion". Work of Viktor Papp was supported by the Ministry for Innovation and Technology within the framework of the Higher Education Institutional Excellence Program (NKFIH-1159-6/2019) in the scope of plant breeding and plant protection research of Szent István University. Sinang Honsanan would like to thank the National Natural Science Foundation of China for supporting the Project no. 31950410548. Our thanks are due to the Research and Researchers for Industries Grant (PHD57I0015) for financial support to Boontiya Chuankid. Napalai Chaiwan would like to thank the Royal Golden Jubilee PhD Program under Thailand Research Fund (RGJ) The scholarship no. PHD60K0147. Mingkwan Doilom thanks the 5th batch of Postdoctoral Orientation Training Personnel in Yunnan Province (Grant no.: Y934283261) and the 64th batch of China Postdoctoral Science Foundation (Grant no.: Y913082271).

Open Access This article is licensed under a Creative Commons Attribution 4.0 International License, which permits use, sharing, adaptation, distribution and reproduction in any medium or format, as long as you give appropriate credit to the original author(s) and the source, provide a link to the Creative Commons licence, and indicate if changes were made. The images or other third party material in this article are included in the article's Creative Commons licence, unless indicated otherwise in a credit line to the material. If material is not included in the article's Creative Commons licence and your intended use is not permitted by statutory regulation or exceeds the permitted use, you will need to obtain permission directly from the copyright holder. To view a copy of this licence, visit http://creativecommons.org/licenses/by/4.0/.

\section{References}

Abdel-Baky NF (2000) Cladosporium spp. an entomopathogenic fungus for controlling whiteflies and aphids in Egypt. Pak J Biol Sci 3:1662-1667

Abdel-Wahab MA, Bahkali AH, El-Gorban AM, Hodhod MS (2017) Natural products of Nothophoma multilocularis sp. nov. an endophyte of the medicinal plant Rhazya stricta. Mycosphere 8:1185-1200

Abdollahzadeh J, Goltapeh EM, Javadi A, Shams-Bakhsh M, Zare R, Phillips AJL (2009) Barriopsis iraniana and Phaeobotryon cupressi: two new species of the Botryosphaeriaceae from trees in Iran. Persoonia 23:1

Abe A, Oda Y, Asano K, Sone T (2006) The molecular phylogeny of the genus Rhizopus based on rDNA sequences. Biosci Biotechnol Biochem 70:2387-2393

Abe A, Oda Y, Asano K, Sone T (2007) Rhizopus delemar is the proper name for Rhizopus oryzae fumaric-malic acid producers. Mycologia 99:714-722

Abe A, Asano K, Sone T (2010) A molecular phylogeny-based taxonomy of the genus Rhizopus. Biosci Biotechnol Biochem 74:1325-1331

Adaskaveg JE (1993) Wood decay, lingnicolous fungi, and decline of peach trees in South Carolina. Plant Dis 77:707-711

Adaskaveg JE, Blanchette RA, Gilbertson RL (1991) Decay of date palm wood by white-rot and brown-rot fungi. Can J Bot 69:615-629

Agrios GN (2005) Plant pathology, 5th edn. Academic Press, New York

Agudelo-Valencia D, Uribe-Echeverry PT, Betancur-Pérez JF (2020) De novo assembly and annotation of the Ganoderma australe genome. Genomics 112:930-933

Agustí-Brisach C, Armengol J (2013) Black-foot disease of grapevine: an update on taxonomy, epidemiology and management strategies. Phytopathol Mediter 52:245-261
Ahmadi P, Muharam FM, Ahmad K, Mansor S, Abu Seman I (2017) Early detection of Ganoderma basal stem rot of oil palms using artificial neural network spectral analysis. Plant Dis 101:1009-1016

Akilli S, Ulubaş Serçe Ç, Katırcıŏglu YZ, Maden S (2013) Phytophthora dieback on narrow leaved ash in the Black Sea region of Turkey. For Pathol 43:252-256

Albu S, Schneider RW, Price PP, Doyle VP (2016) Cercospora cf. flagellaris and Cercospora cf. sigesbeckiae are associated with Cercospora leaf blight and purple seed stain on soybean in North America. Phytopathology 106:1376-1385

Albu S, Sharma S, Bluhm BH, Price PP, Schneider RW, Doyle VP (2017) Draft genome sequence of Cercospora cf. sigesbeckiae, a causal agent of Cercospora leaf blight on soybean. Genome Announc 5:e00708-e00717

Ali N, Ramdass AC, Latchoo RK, Rampersad SN (2017) First report of Phytophthora capsici associated with Phytophthora blight of papaya in Trinidad. Plant Dis 101:1827

Al-Mahmooli IH, Al-Fahdi AR, Al-Sadi AM, Deadman ML (2015) First report of root rot and crown necrosis caused by Pythium aphanidermatum on Phaseolus vulgaris in Oman. Plant Dis 99:419

Almeida ÁMR, Piuga FF, Marin SRR, Binneck E, Sartori F, Costamilan LM, Teixeira MRO, Lopes M (2005) Pathogenicity, molecular characterization, and cercosporin content of Brazilian isolates of Cercospora kikuchii. Fitopatol Bras 30:594-602

Amano K (1986) Host range and geographical distribution of the powdery mildew fungi. Japan Scientific Societies, Tokyo, p 741

Amsalem L, Freeman S, Rav-David D, Nitzani Y, Sztejnberg A, Pertot I, Elad Y (2006) Effect of climatic factors on powdery mildew caused by Sphaerotheca macularis f. sp. fragariae on strawberry. Eur J Plant Pathol 114:283-292

Anderson JB, Stasovski E (1992) Molecular phylogeny of northern hemisphere species of Armillaria. Mycologia 84(4):505-516

Anderson JB, Ullrich RC (1979) Biological species of Armillaria mellea in North America. Mycologia 71(2):402-414

Aptroot A (2006) Mycosphaerella and its anamorphs: 2. Conspectus of Mycosphaerella. CBS Biodiver Ser 5:1-231

Arafa RA, Kamel SM, Abd-Elsalam KA (2020) The genus Pythium: genomics and breeding for resistance. In: Rai M, Abd-Elsalam KA, Ingle AP (eds) Pythium: diagnosis, diseases and management. CRC Press, Boca Raton

Arantes, Dias LP, Costa JH, Saraiva KD, Morais JK, Sousa DO, Soares AA, Vasconcelos IM, Oliveira JT (2020) Gene expression during development and overexpression after Cercospora kikuchii and salicylic acid challenging indicate defensive roles of the soybean toxin. Plant Cell Rep Mar 2:1-4

Ariyawansa HA, Hyde KD, Jayasiri SC, Buyck B, Chethana KWT, Dai DQ, Dai YC, Daranagama DA, Jayawardena RS, Lucking R, Ghobad-Nejhad M, Niskanen T, Thambugala KM, Voigt K, Zhao RL, Li GJ, Doilom M, Boonmee S, Yang ZL, Cai Q, Cui YY, Bahkali AH, Chen J, Cui BK, Chen JJ, Dayarathne MC, Dissanayake AJ, Ekanayaka AH, Hashimoto A, Hongsanan S, Jones EBG, Larsson E, Li WJ, Li QR, Liu JK (2015) Fungal diversity notes 111-252-taxonomic and phylogenetic contributions to fungal taxa. Fungal Divers 75:27-274

Asakura M, Ninomiya S, Sugimoto M, Oku M, Yamashita SI, Okuno T, Sakai Y, Takano Y (2009) Atg26-mediated pexophagy is required for host invasion by the plant pathogenic fungus Colletotrichum orbiculare. Plant Cell 21:1291-1304

Asiegbu FO, Abu S, Stenlid J, Johansson M (2004) Sequence polymorphism and molecular characterisation of laccase genes of theconifer pathogen Heterobasidion annosum. Mycol Res 108:136-148 
Asiegbu FO, Adomas A, Stenlid JAN (2005) Conifer root and butt rot caused by Heterobasidion annosum (Fr.) Bref. s.l. Mol Plant Pathol 6:395-409

Athow KL, Probst AH, Kurtzman CP, Laviolette FA (1962) A newly identified physiological race of Cercospora sojina on soybean. Phytopathology 52:712-714

Atkinson GF (1908) Observations on Polyporus lucidus Leys and some of its allies from Europe and North America. Bot Gaz 46:321-338

Aveskamp MM, Verkley GJM, de Gruyter J, Murace MA, Perelló A, Woudenberg HC, Groenewald JZ, Crous PW (2009) DNA phylogeny reveals polyphyly of Phoma section Peyronellaea and multiple taxonomic novelties. Mycologia 101:363-382

Aveskamp MM, de Gruyter H, Woudenberg J, Verkley G, Crous PW (2010) Highlights of the Didymellaceae: a polyphasic approach to characterise Phoma and related pleosporalean genera. Stud Mycol 65:1-60

Ayres MP, Lombardero MJ (2000) Assessing the consequences of global change for forest disturbance from herbivores and pathogens. Sci Total Environ 262:263-286

Babaahmadi G, Mehrabi-Koushki M, Hayati J (2018) Allophomahayatii sp. nov., an undescribed pathogenic fungus causing dieback of Lantana camara in Iran. Mycol Progr 17:365-379

Babadoost M (2004) Phytophthora blight: a serious threat to cucurbit industries. Urbana 51:61801

Bahcecioglu Z, Braun U, Kabaktepe S (2006) Neoerysiphe rubiae a new powdery mildew species on Rubia cf. tinctoria from Turkey. Nova Hedwigia 83:489-492

Bakhshi M, Arzanlou M, Babai-Ahari A, Groenewald JZ, Braun U, Crous PW (2015) Application of the consolidated species concept to Cercospora spp. from Iran. Persoonia 34:65

Bakhshi M, Arzanlou M, Babai-Ahari A, Groenewald JZ, Crous PW (2018) Novel primers improve species delimitation in Cercospora. IMA Fungus 9:299

Bala K, Robideau GP, Levesque CA, de Cock AWAM, Abad G, Lodhi AM, Shahzad S, Ghaffar A, Coffey MD (2010) Phytopythium Abad, de Cock, Bala, Robideau, Lodhi \& Levesque, gen. nov. and Phytopythium sindhum Lodhi, Shahzad \& Levesque, sp. nov. Persoonia 24:136-137

Banaay CGB, Cuevas VC, Vera Cruz CM (2012) Trichoderma ghanense promotes plant growth and controls diseases caused by Pythium arrhenomanes in seedling of aerobic rice variety Apo. Philipp Agric Sci 95:175-184

Bandara AY, Weerasooriya DK, Bradley CA, Allen TW, Esker PD (2020) Dissecting the economic impact of soybean diseases in the United States over two decades. PLoS ONE 15:e0231141

Baroncelli R, Amby DB, Zapparata A, Sarrocco S, Vannacci G, Le Floch G, Harrison RJ, Holub E, Sukno SA, Sreenivasaprasad S, Thon MR (2016) Gene family expansions and contractions are associated with host range in plant pathogens of the genus Colletotrichum. BMC Genomics 17:555

Barr ME (1989) The genus Dothidotthia (Botryosphaeriaceae) in North America. Mycotaxon 34:517-526

Basallote-Ureba MJ, Prados-Ligero AM, Melero-Vara JM (1998) Effectiveness of tebuconazole and procymidone in the control of Stemphylium leaf spots in garlic. Crop Prot 17(6):491-495

Basallote-Ureba MJ, Prados-Ligero AM, Melero-Vara JM (1999) Aetiology of leaf spot of garlic and onion caused by Stemphylium vesicarium in Spain. Plant Pathol 48(1):139-145

Baumgartner K, Rizzo DM (2002) Spread of Armillaria root disease in a California vineyard. Am J Enol Viticult 53:197-203

Bautista-Baños S, Bosquez-Molina E, Barrera-Necha LL (2014) Rhizopus stolonifer (soft rot). Posthar Decay 1-44.

Beakes G, Sekimoto S (2009) The evolutionary phylogeny of Oomycetes-insights gained from studies of holocarpic parasites of algae and invertebrates. In: Lamour K, Kamoun S (eds)
Oomycete genetics and genomics: diversity, interactions, and research tools. Wiley, New York, pp 1-24

Beakes GW, Honda D, Thines M (2014) Systematics of the Straminipila: Labyrinthulomycota, Hyphochytriomycota and Oomycota. In: McLaughlin J, Spathaphora JW (eds) Mycota VIIA (systematics and evolution), 2nd edn. Springer, New York

Belisario A, Maccaroni M, Vettraino AM, Vannini A, Valier A (2004) Phytophthora species associated with decline and death of English walnut in Italy and France. V Interna Walnut Sympos 705:401-407

Benedict K, Brandt M (2016) Fungal disease outbreaks and natural disasters. Environ Mycol Pub Health 213-219.

Bengtsson T (2013) Boosting potato defense against late blight. Ph.D. thesis, Swedish University of Agricultural Science.

Benhamou N, Rey P, Chérif M, Hockenhull J, Tirilly Y (1997) Treatment with the mycoparasite Pythium oligandrum triggers induction of defense-related reactions in tomato roots when challenged with Fusarium oxysporum f. sp. radicis-lycopersici. Phytopathology $87: 108-122$

Benny GL (2008) Methods used by Dr. R. K. Benjamin, and other mycologists, to isolate zygomycetes. Aliso 26:37-61

Bensch K, Groenewald JZ, Dijksterhuis J, Starink-Willemse M, Andersen B, Summerell BA, Shin HD, Dugan FM, Schroers HJ, Braun U, Crous PW (2010) Species and ecological diversity within the Cladosporium cladosporioides complex (Davidiellaceae, Capnodiales). Stud Mycol 67:1-94

Bensch K, Braun U, Groenewald JZ, Crous PW (2012) The genus Cladosporium. Stud Mycol 72:1-401

Bensch K, Groenewald JZ, Braun U, Dijksterhuis J, de Jesús YáñezMorales M, Crous PW (2015) Common but different: the expanding realm of Cladosporium. Stud Mycol 82:23-74

Bensch K, Groenewald JZ, Meijer M, Dijksterhuis J, Jurjević Ž, Andersen B, Houbraken J, Crous PW, Samson RA (2018) Cladosporium species in indoor environments. Stud Mycol 89:177-301

Bérubé J, Dessureault M (1989) Morphological studies of the Armillaria mellea complex: two new species, A. gemina and A. calvescens. Mycologia 81(2):216-225

Bezuidenhout CM, Denman S, Kirk SA, Botha WJ, Mostert L, McLeod A (2010) Phytophthora taxa associated with cultivated Agathosma, with emphasis on the $P$. citricola complex and $P$. capensis sp. nov. Persoonia 25:32-49

Bhunjun CS, Jayawardena RS, Wei DP, Huanraluek N, Abeywickrama PD, Jeewon R, Monkai J, Hyde KD (2019) Multigene phylogenetic characterisation of Colletotrichum artocarpicola sp nov from Artocarpus heterophyllus in northern Thailand. Phytotaxa 418(3):273-286

Bian LS, Yuan Y, Wu F, Si J (2016) Two new species of Hymenochaetaceae (Basidiomycota) from China. Nova Hedwigia 102(1-2):211-222

Bjørk PK, Rasmussen SA, Gjetting SK, Havshøi NW, Petersen TI, Ipsen JØ, Larsen TO, Fuglsang AT (2019) Tenuazonic acid from Stemphylium loti inhibits the plant plasma membrane $\mathrm{H}+-$ ATPase by a mechanism involving the C-terminal regulatory domain. New Phytol 226:770-784

Blair JE, Coffey MD, Park SY, Geiser DM, Kang S (2008) A multilocus phylogeny for Phytophthora utilizing markers derived from complete genome sequences. Fungal Genet Biol 45(3):266-277

Blancard D (2012) Tomato diseases: identification, biology and control: a colour handbook. CRC Press, Boca Raton

Boerema GH, de Gruyter J, Noordeloos ME, Hamers MEC (2004) Phoma identification manual. Differentiation of specific and infra-specific taxa in culture. CABI Publishing, Wallingford

Boesewinkel HJ (1980) The morphology of the imperfect states of powdery mildews (Erysiphaceae). Bot Rev 46:167-224 
Boesewinkel HJ (1982) Cylindrocladiella, a new genus to accommodate Cylindrocladium parvum and other small-spored species of Cylindrocladium. Can J Bot 60:2288-2294

Boshuizen A, de Jong PF, Heijne B (2004). Modelling Stemphylium vesicarium on pear: an hourly-based infection model. In: VII International symposium on modelling in fruit research and orchard management, pp 205-209.

Brahmanage RS, Hyde KD, Li XH, Jayawardena RS, McKenzie EHC, Yan JY (2018) Are pathogenic isolates of Stemphylium host specific and cosmopolitan? Plant Pathol Quarant 8:153-164

Brasier CM (2007) Phytophthora biodiversity: how many Phytopthora species are there? In: Goheen EM, Frankel SJ (eds) USDA,Forest Service. Pacific Southwest Research Station, Albany, pp 101-115

Brasier CM, Cooke DEL, Duncan JM, Hansen EM (2003) Multiple new phenotypic taxa from trees and riparian ecosystems in Phytophthora gonapodyides-P. megasperma ITS Clade 6 , which tend to be high-temperature tolerant and either inbreeding or sterile. Mycol Res 107:277-290

Brasier CM, Kirk SA, Delcan J, Cooke DEL, Thomas J, In't Veld WAM (2004) Phytophthora alni sp. nov. and its variants: designation of emerging heteroploid hybrid pathogens spreading on Alnus trees. Mycol Res 108:1172-1184

Braun U (1978) Beitrag zur systematik und nomenklatur der Erysiphales. Feddes Repert 88:655-665

Braun U (1981) Taxonomic studios in the genus Erysiphe I. generic delimitation and position in the system of the Erysiphaceae. Nova Hedwigia 34:679-719

Braun U (1987) A monograph of the Erysiphales (powdery mildews). Nova Hedwigi 89:1-700

Braun U (1999) Some critical notes on the classification and the generic concept of the Erysiphaeeae. Schlechtendalia 3:48-54

Braun U, Cook RTA (2012) Taxonomic manual of the Erysiphales (powdery mildews). CBS biodiversity series no.11, Utrecht

Braun U, Schubert K (2007) Taxonomic revision of the genus Cladosporium s. lat. 7. descriptions of new species, a new combination and further new data. Schlechtendalia 16:61-76

Braun U, Takamatsu S (2000) Phylogeny of Erysiphe, Microsphaera, Uncinula (Erysipheae) and Cystotheca, Podosphaera, Sphaerotheca (Cystotheceae) inferred from rDNA ITS sequences. Schlechtendalia 4:1-33

Braun U, Cook RTA, Inman AJ, Shin HD (2002) The taxonomy of the powdery mildew fungi. In: Belanger R, Dik AJ, Bushnell WR (eds) Powdery mildews: a comprehensive treatise. APS Press, St Paul, pp 13-54

Braun U, Crous PW, Dugan F, Groenewald JE, de Hoog GS (2003) Phylogeny and taxonomy of Cladosporium-like hyphomycetes, including Davidiella gen. nov., the teleomorph of Cladosporium s. str. Mycol Prog 2(1):3-18

Braun U, Crous PW, Schubert K (2008) Taxonomic revision of the genus Cladosporium s. lat. 8. Re-introduction of Graphiopsis (= Dichocladosporium) with further reassessments of cladosporioid hyphomycetes. Mycotaxon 103:207-216

Braun U, Nakashima C, Crous PW (2013) Cercosporoid fungi (Mycosphaerellaceae) 1. Species on othe fungi, Pteridophyta and Gymnospermae. IMA Fungus 4:265-345

Braun U, Crous PW, Nakashima C (2014) Cercosporoid fungi (Mycosphaerellaceae) 2. species on monocots (Acoraceae to Xyridaceae, excluding Poaceae). IMA fungus 5:203-390

Braun U, Crous PW, Nakashima C (2015a) Cercosporoid fungi (Mycosphaerellaceae) 3. Species on monocots (Poaceae, true grasses). IMA Fungus 6:25-98

Braun U, Crous PW, Nakashima C (2015b) Cercosporoid fungi (Mycosphaerellaceae) 4. Species on dicots (Acanthaceae to Amaranthaceae). IMA Fungus 6:373
Braun U, Crous PW, Nakashima C (2016) Cercosporoid fungi (Mycosphaerellaceae) 5. Species on dicots (Anacardiaceae to Annonaceae). IMA Fungus 7:161-216

Braun U, Bradshaw M, Zhao TT, Cho SE, Shin HD (2018) Taxonomy of the Golovinomyces cynoglossi complex (Erysiphales, Ascomycota) disentangled by phylogenetic analyses and reassessments of morphological traits. Mycobiology 46:192-204

Braun U, Shin HD, Takamatsu S, Meeboon J, Kiss L, Lebeda A, Kitner M, Götz M (2019) Phylogeny and taxonomy of Golovinomyces orontii revisited. Mycol Prog 18:335-357

Brazee NJ (2015) Phylogenetic relationships among species of Phellinus sensu stricto, cause of white trunk rot of hardwoods, from northern North America. Forests 6:4191-4211

Brazee NJ, Yang X, Hong C (2017) Phytophthora caryae sp. nov., a new species recovered from streams and rivers in the eastern United States. Plant Pathol 66:805-817

Brefeld O (1888) Basidiomyceten III. Autobasidiomyceten. Untersuchungen Aus Dem Gesammtgebiete Der Mykologie. Heft 10: Ascomyceten II. Münster 8:1-184

Bremer K (1994) Asteraceae cladistics \& classification. Timber Press, Portland

Brielmaier-Liebetanz U, Wagner S, Werres S (2013) First report of dieback on Euonymus fortunei caused by Cylindrocladiella parva in Germany. Plant Dis 97:1120

Brundza K (1934) Beiträge zur kenntnis der Erysiphaceen. Litauens ZU Akad Metras 2:107-197

Bruni GO, Zhong K, Lee SC, Wang P (2019) CRISPR-Cas9 induces point mutation in the mucormycosis fungus Rhizopus delemar. Fungal Gen Biol 124:1-7

Buchanan PK (1988) A new species of Heterobasidion (Polyporaceae) from Australia. Mycotaxon 32:325-337

Buchanan PK, Ryvarden L (1988) Type studies in the Polyporaceae-18. Species described by G.H. Cunningham. Mycotaxon $31: 1-38$

Bullerman LB (2003) SPOILAGEl Fungi in food-an overview. Encyclopedia of food sciences and nutrition, pp 5511-5522.

Burdsall HH, Volk TJ (1993) The state of taxonomy of the genus Armillaria. McIlvainea 11:4-12

Burgess TI, Tan YP, Garnas J, Edwards J, Scarlett KA, Shuttleworth LA, Daniel R, Dann EK, Parkinson LE, Dinh Q, Shivas RG, Jami F (2019) Current status of the Botryosphaeriaceae in Australia. Australasian Plant Pathol 48:35-44

Bushnell WR, Allen PJ (1962) Induction of disease symptoms in barley by powdery mildew. Plant Physiol 37:50

Cabarroi-Hernández M, Villalobos-Arámbula AR, Torres-Torres MG, Decock C, Guzmán-Dávalos L (2019) The Ganoderma weberianum-resinaceum lineage: multilocus phylogenetic analysis and morphology confirm G. mexicanum and G. parvulum in the Neotropics. MycoKeys 59:95-131

Cabral A, Azinheira HG, Talhinhas P, Batista D, Ramos AP, Silva MDC, Oliveira H, Várzea V (2020) Pathological, morphological, cytogenomic, biochemical and molecular data support the distinction between Colletotrichum cigarro comb. et. stat. nov. and Colletotrichum kahawae. Plants 9(4):502

Cai G, Schneider RW, Padgett GB (2009) Assessment of lineages of Cercospora kikuchii in Louisiana for aggressiveness and screening soybean cultivars for resistance to Cercospora leaf blight. Plant Dis 93:868-874

Câmara MP, O'Neill NR, van Berkum P (2002) Phylogeny of Stemphylium spp. based on ITS and glyceraldehyde-3-phosphate dehydrogenase gene sequences. Mycologia 94(4):660-672

Campos-Santana M, Amalfi M, Castillo G, Decock C (2016) Multilocus, DNA-based phylogenetic analyses reveal three new species lineages in the Phellinus gabonensis-P. caribaeo-quercicola species complex, including P. amazonicus sp. nov. Mycologia 108:939-953 
Cannon PF, Kirk PM (2007) Fungal families of the world, illustrate. CABI, Wallingford, $\mathrm{p} 456$

Cannon PF, Damm U, Johnston PR, Weir BS (2012) Colletotrichum current status and future directions. Stud Mycol 73:181-213

Cao Y, Wu SH, Dai YC (2012) Species clarification of the prize medicinal Ganoderma mushroom 'Lingzhi', Fungal Divers 56:49-62

Capretti P, Korhonen K, Mugnai L, Romagnoli C (1990) An intersterility group of Heterobasidion annosum specialized to Abies alba. For Pathol 20:231-240

Carbú M, Moraga J, Cantoral JM, Collado IG, Garrido C (2019) Recent approaches on the genomic analysis of the phytopathogenic fungus Colletotrichum spp. Phytochem Rev 1-13.

Carmona M, Barreto D, Fortugno C (1996) Occurrence of halo spot in barley caused by Pseudoseptoria donacis in Argentina. EPPO Bull 26:437-439

Castello JD, Shaw CG, Furniss MM (1976) Isolation of Cryptoporus volvatus and Fomes pinicola from Dendroctonus pseudotsugae. Phytopathology 66:1431-1434

Cavalier-Smith TA (1986) The kingdom Chromista: origin and systematics. In: Round FE, Chapman DJ (eds) Progress in phycological research. Biopress, Bristol, pp 309-317

Cavalier-Smith TA (1998) A revised six-kingdom system of life. Biol Camb Philos Soc 73:203-266

Chang TT (1995) Decline of nine tree species associated with brown root rot caused by Phellinus noxius in Taiwan. Plant Dis 79(9):962-965

Chang TT, Chou WN (1999) Two new species of Phellinus from Taiwan. Mycol Res 103:50-52

Chang TT, Chou WN (2000) Three new species of Hymenochaetaceae from Taiwan. Mycologia 92:801-804

Chase TE (1989) Genetics and population structure of Heterobasidion annosum with special reference to western North America. In: Otrosina WJ, Scharpf RF (eds) Proceedings of the symposium on research and management of Annosus Root Disease (Heterobasidion annosum) in western North America. Pacific Southwest Forest and Range Experiment Station, Monterey, pp 19-25.

Chen JJ, Korhonen K, Li W, Dai YC (2014) Two new species of the Heterobasidion insulare complex based on morphology and molecular data. Mycoscience 55:289-298

Chen JJ, Cui BK, Zhou LW, Korhonen K, Dai YC (2015a) Phylogeny, divergence time estimation, and biogeography of the genus Heterobasidion (Basidiomycota, Russulales). Fungal Divers 71:185-200

Chen Q, Jiang JR, Zhang GZ, Cai L, Crous PW (2015b) Resolving the Phoma enigma. Stud Mycol 82:137-217

Chen JJ, Li Lu, Ye WW, Wang YC, Zheng XB (2017) Pythium cedri sp. nov. (Pythiaceae, Pythiales) from southern China based on morphological and molecular characters. Phytotaxa 309:135-142

Chethana KWT, Jayawardene RS, Zhang W, Zhou YY, Liu M, Hyde KD, Li XH, Wang J, Zhang KC, Yan JY (2019) Molecular characterization and pathogenicity of fungal taxa associated with cherry leaf spot disease. Mycosphere 10:490-530

Chibucos M, Soliman S, Gebremariam T, Lee H, Daugherty S, Orvis J, Shetty A, Crabtree J, Hazen T, Etienne K, Kumari P, O'Connor T, Rasko D, Filler S, Fraser C, Lockhart S, Skory C, Ibrahim A, Bruno V (2016) An integrated genomic and transcriptomic survey of mucormycosis-causing fungi. Nat Commun 7:1-11

Chillali M, Idder-Ighili H, Guillaumin JJ, Mohammed C, Escarmant BL, Botton B (1998) Variation in the ITS and IGS regions of ribosomal DNA among the biological species of European Armillaria. Mycol Res 102:533-540

Cho SE, Takamatsu S, Meeboon J, Shin HD (2014) Erysiphe magnoliicola, a new powdery mildew on Magnolia. Mycotaxon 129:153-161
Chun SC, Schneider RW (1998) Sites of infection by Pythium species in rice seedlings and effects of plant age and water depth on disease development. Phytopathology 88:1255-1261

Chupp C (1954) A monograph of the fungus genus Cercospora. Ithaca, New York

Clark CA, Ferrin DM, Smith TP, Holmes GJ (2013) Compendium of sweet potato diseases, pests and disorders. APS Press, Second Minnesota

Cloete M, Fischer M, Du Plessis IL, Mostert L, Halleen F (2016) A new species of Phellinus sensu stricto associated with esca on grapevine in South Africa. Mycol Prog 15(3):25

Coetzee MPA, Wingfield BD, Coutinho TA, Wingfield MJ (2000a) Identification of the causal agent of Armillaria root rot of Pinus species in South Africa. Mycologia 92(4):777-785

Coetzee MPA, Wingfield BD, Harrington TC, Dalevi D, Coutinho TA, Wingfield MJ (2000b) Geographical diversity of Armillaria mellea ss based on phylogenetic analysis. Mycologia 92:105-113

Coetzee MPA, Wingfield BD, Bloomer P, Ridley G, Kile G, Wingfield M (2001a) Phylogenetic relationships of Australian and New Zealand Armillaria species. Mycologia 93:887-896

Coetzee MPA, Wingfield BD, Harrington TC, Steimel J, Coutinho TA, Wingfield MJ (2001b) The root rot fungus Armillaria mellea introduced into South Africa by early Dutch settlers. Mole Ecol 10(2):387-396

Coetzee MPA, Marincowitz S, Muthelo VG, Wingfield MJ (2015) Ganoderma species, including new taxa associated with root rot of the iconic Jacaranda mimosifolia in Pretoria, South Africa. IMA Fungus 6:249-256

Coetzee MPA, Wingfield BD, Wingfield MJ (2018) Armillaria root-rot pathogens: species boundaries and global distribution. Pathogens 7:83

Coleman LC (1927) Structure of spore wall in Ganoderma. Botani Gazet 83(1):48-60

Columbia IB, English L (1988) Pythium spp. associated with crown rot of cucumbers. Plant Dis 683

Cook RTA, Inman AJ, Billings C (1997) Identification and classification of powdery mildew anamorphs using light and scanning electron microscopy and host range data. Mycol Res 101:975-1002

Cook RTA, Henricot B, Beales P (2006) First report of Neoerysiphe galeopsidis on Acanthus spinosus in the UK. Plant Pathol 55(4):575

Cooke DEL, Duncan JM (1997) Phylogenetic analysis of Phytophthora species based on ITS1 and ITS2 sequences of the ribosomal RNA gene repeat. Mycol Res 101:667-677

Cooke DEL, Drenth A, Duncan JM, Wagels G, Brasier CM (2000) A molecular phylogeny of Phytophthora and related oomycetes. Fungal Genet Biol 30(1):17-32

Corda ACI (1831) Die pilze deutschlands. In: Sturm J (ed) Deutschlands flora in Abbildungen nach der Natur mit Beschreibungen Sturm, Nürnberg vol. 3, Abt 12, pp 33-64.

Corliss JO (1994) An interim utilitarian (user-friendly) hierarchical classification and characterization of the protists. Acta Protozool 33:1-51

Corner EJH (1947) Variation in the size and shape of spores, basidia and cystidia in Basidiomycetes. New Phytol 46:195-228

Corner EJH (1989) The genera Albatrellus, Boletopsis, Coriolopsis (dimitic), Cristelloporia, Diacanthodes, Elmerina, Fomitopsis (dimitic), Gloeoporus, Grifola, Hapalopilus, Heterobasidion, Hydnopolyporus, Ischnoderma, Loweporus, Parmastomyces, Perenniporia, Pyrofomes, Stecchericium, Trechispora, Truncospora and Tyromyces. Beih Nova Hedwigia 96:1-218

Craft CM, Nelson EB (1996) Microbial properties of composts that suppress damping-off and root rot of creeping bent grass caused by Pythium graminicola. Appl Environ Microbiol 62:1550-1557 
Crawford AR, Bassam BJ, Drenth A, Maclean DJ, Irwin JAG (1996) Evolutionary relationships among Phytophthora species deduced from rDNA sequence analysis. Mycol Res 100:437-443

Crouch JA, Beirn LA, Cortese LM, Bonos SA, Clarke BB (2009a) Anthracnose disease of switchgrass caused by the novel fungal species Colletotrichum navitas. Mycol Res 113:1411-1421

Crouch JA, Clarke BB, White JF Jr, Hillman BI (2009b) Systematic analysis of the falcate-spored graminicolous Colletotrichum and a description of six new species from warm-season grasses. Mycologia 101:717-732

Crouch JA, Tredway LP, Clarke BB, Hillman BI (2009c) Phylogenetic and population genetic divergence correspond with habitat for the pathogen Colletotrichum cereale and allied taxa across diverse grass communities. Mole Ecol 18:123-135

Crouch JA, O'Connell R, Gan P, Buiate E, Torres MF, Beirn L, Shirasu K, Vaillancourt L (2014) The genomics of Colletotrichum. Genomics of plant-associated fungi: monocot pathogens. Springer, Berlin, pp 69-102

Crous PW, Braun U (2003) Mycosphaerella and its anamorphs: 1. Names published in Cercospora and Passalora. CBS Biodiversity Series 1. National History Book Service, Utrecht

Crous PW, Wingfield MJ (1993) A re-evaluation of Cylindrocladiella, and a comparison with morphologically similar genera. Mycol Res 97:433-448

Crous PW, Wingfield MJ, Lennox CL (1994) A comparison of generic concepts in Calonectria and Nectria with anamorphs in Cylindrocladium and Cylindrocladiella. S Afr J Sci 90:485-488

Crous PW, Braun U, Schubert K, Groenewald JZ (2007) Delimiting Cladosporium from morphologically similar genera. Stud Mycol 58:33-56

Crous PW, Wingfield MJ, Guarro J, Hernández-Restrepo M, Sutton DA, Acharya K, Barber PA, Boekhout T, Dimitrov RA, Dueñas M, Dutta AK, Gené J, Gouliamova DE, Groenewald M, Lombard L, Morozova OV, Sarkar J, Smith MTh, Stchigel AM, Wiederhold NP, Alexandrova AV, Antelmi I, Armengol J, Barnes I, Cano-Lira JF, Castañeda-Ruiz RF, Contu M, PrR Courtecuisse, da Silveira AL, Decock CA, Ade Goes, Edathodu J, Ercole E, Firmino AC, Fourie A, Fournier J, Furtado EL, Geering ADW, Gershenzon J, Giraldo A, Gramaje D, Hammerbacher A, He XL, Haryadi D, Khemmuk W, Kovalenko AE, Krawczynski R, Laich F, Lechat C, Lopes UP, Madrid H, Malysheva EF, Marin-Felix Y, Martín MP, Mostert L, Nigro F, Pereira OL, Picillo B, Pinho DB, Popov ES, Rodas-Peláez CA, Rooney-Latham S, SandovalDenis M, Shivas RG, Silva V, Stoilova-Disheva MM, Telleria MT, Ullah C, Unsicker UB, van der Merwe NA, Vizzini A, Wagner HG, Wong PTW, Wood AR, Groenewald JZ (2015) Fungal planet description sheets: 320-370. Persoonia 34:167-266

Crous PW, Wingfield MJ, Richardson DM, Le Roux JJ, Strasberg D, Edwards J, Roets F, Hubka V, Taylor PWJ, Heykoop M, Martín MP, Moreno G, Sutton DA, Wiederhold NP, Barnes CW, Carlavilla JR, Gené J, Giraldo A, Guarnaccia V, Guarro J, Hernández-Restrepo M, Kolařík M, Manjón JL, Pascoe IG, Popov ES, Sandoval-Denis M, Woudenberg JHC, Acharya K, Alexandrova AV, Alvarado P, Barbosa RN, Baseia IG, Blanchette RA, Boekhout T, Burgess TI, Cano-Lira JF, Čmoková A, Dimitrov RA, Dyakov MYu, Dueñas M, Dutta AK, EsteveRaventós F, Fedosova AG, Fournier J, Gamboa P, Gouliamova DE, Grebenc T, Groenewald M, Hanse B, Hardy GESTJ, Held BW, Jurjević Z, Kaewgrajang T, Latha KPD, Lombard L, Luangsa-ard JJ, Lysková P, Mallátová N, Manimohan P, Miller AN, Mirabolfathy M, Morozova OV, Obodai M, Oliveira NYT, Ordóñez ME, Otto EC, Paloi S, Peterson SW, Phosri C, Roux J, Salazar WA, Sánchez A, Sarria GA, Shin HD, Silva BDB, Silva GA, Smith MTH, SouzaMotta CM, Stchigel AM, Stoilova-Disheva MM, Sulzbacher MA, Telleria MT, Toapanta C, Traba JM, Valenzuela-Lopez
N, Watling R, Groenewald JZ (2016) Fungal planet description sheets: 400-468. Persoonia 36:316-458

Crous PW, Wingfield MJ, Burgess TI, Hardy GESTJ, Barber PA, Alvarado P, Barnes CW, Buchanan PK, Heykoop M, Moreno G (2017) Fungal planet description sheets: 558-624. Persoonia $38: 240-384$

Crous PW, Schumache RK, Akulov A, Thangavel R, HernándezRestrepo M, Carnegie AJ, Cheewangkoon R, Wingfeld MJ, Summerel BA, Quaedvlieg W, Coutnho TA, Roux J, Wood AR, Giraldo A, Groenewald JZ (2019) New and interesting fungi. 2. Fungal Syst Evol 3:57-134

Cruickshank MG, Morrison DJ, Lalumière A (2011) Site, plot, and individual tree yield reduction of interior gouglas-fir associated with non-lethal infection by Armillaria root disease in southern British Columbia. For Ecol Manag 261:297-307

Cui BK, Dai YC (2012) Wood-decaying fungi in eastern Himalayas 3. Polypores from Laojunshan Mountains, Yunnan province. Mycosystema 31:486-492

Cui BK, Decock C (2013) Phellinus castanopsidis sp. nov. (Hymenochaetaceae) from southern China, with preliminary phylogeny based on rDNA sequences. Mycol Prog 12:341-351

Cunnington J (2003) Pathogenic fungi on introduced plants in Victoria. A host list and literature guide for their identification. Department of Primary Industries, Research Victoria, p 57

Czeczuga B, Mazalska B, Godlewska A, Muszynska E (2005) Aquatic fungi growing on dead fragments of submerged plants. Limnologica 35:283-297

Dai YC (2010) Hymenochaetaceae (Basidiomycota) in China. Fung Divers 45:131-343

Dai YC (2012) Polypore diversity in China with an annotated checklist of Chinese polypores. Mycoscience 53:49-80

Dai YC, Korhonen K (2009) Heterobasidion australe, a new polypore derived from the Heterobasidion insulare complex. Mycoscience 50:353-356

Dai YC, Niemelä T (1995) Changbai wood-rotting fungi 4. Some species described by A.S. Bondartsev and L.V. Lyubarsky from the Russian Far East. Ann Bot Fenn 32:211-226

Dai YC, Yang ZL (2008) A revised checklist of medicinal fungi in China. Mycosystema 27:801-824

Dai YC, Vainio EJ, Hantula J, Niemelä T, Korhonen K (2002) Sexuality and intersterility within the Heterobasidion insulare complex. Mycol Res 106:1435-1448

Dai YC, Yuan HS, Wei YL, Korhonen K (2006) New records of Heterobasidion parviporum in China. For Pathol 36:287-293

Dai YC, Yu CJ, Wang HC (2007) Polypores from eastern Xizang (Tibet), western China. Ann Bot Fenn 44:135-145

Dai YC, Cui BK, Tao WQ (2008) Phellinus mori sp. nov. (Basidiomycota, Hymenochaetales) from China. Mycotaxon 105:53-58

Dalman K, Olson A, Stenlid J (2010) Evolutionary history of the conifer root rot fungus Heterobasidion annosumsensulato. Mol Ecol 19:4979-4993

Damm U, Woudenberg JHC, Cannon PF, Crous PW (2009) Colletotrichum species with curved conidia from herbaceous hosts. Fungal Divers 39:45-87

Damm U, Cannon PF, Woudenberg JHC, Crous PW (2012a) The Colletotrichum acutatum species complex. Stud Mycol 73:37-113

Damm U, Cannon PF, Woudenberg JHC, Johnston PR, Weir BS, Tan YP, Shivas RG, Crous PW (2012b) The Colletotrichum boninense species complex. Stud Mycol 73:1-36

Damm U, Cannon PF, Liu F, Barreto RW, Guatimosim E, Crous PW (2013) The Colletotrichum orbiculare species complex: important pathogens of field and weeds. Fungal Divers 61:29-59

Damm U, O'Connell RJ, Groenewald JZ, Crous PW (2014) The Colletotrichum destructivum species complex-hemibiotrophic pathogens of forage and field crops. Stud Mycol 79:49-84 
Damm U, Sato T, Alizadeh A, Groenewald JZ, Crous PW (2019) The Colletotrichum dracaenophilum, C. ámagnum and C. áorchidearum species complexes. Stud Mycol 92:1-46

Darriba D, Taboada GL, Doallo R, Posada D (2012) jModelTest 2: more models, new heuristics and parallel computing. Nat Methods 9:772

Das A, Dutta S, Jash S, Barman AR, Das R, Kumar S, Gupta S (2019) Current knowledge on pathogenicity and management of Stemphylium botryosum in Lentils (Lens culinaris ssp. culinaris Medik). Pathogens 8:225

Daub ME, Herrero S, Chung KR (2005) Photoactivated perylenequinone toxins in fungal pathogenesis of plants. FEMS Microbiol Lett 252:197-206

David JC (1997) A contribution to the systematics of Cladosporium. Revision of the fungi previously referred to Heterosporium. Mycol Pap 172:1-157

Davidson JM, Rizzo DM, Garbelotto M, Tjosvold S, Slaughter GW (2002) Phytophthora ramorum and sudden oak death in California: II. Transmission and survival. In: Standiford RB (ed) Proceedings of the fifth symposium on Oak Woodlands: oaks in California's challenging landscape. Gen. Tech. Rep. PSWGTR-184, Pacific Southwest Research Station, Forest Service, US Department of Agriculture, Albany, vol 184, pp 741-749.

Davis AR, Bruton BD, Pair SD, Thomas CE (2001) Powdery mildew: an emerging disease of watermelon in the United States. Cucurbit Genet Coop Rpt 24:42-48

de Cock AWAM, Mendoza L, Padhye A, Ajello L, Kaufman L (1987) Pythium insidiosum sp. nov., the etiologic agent of pythiosis. J Clin Microbiol 25:344

de Hoog GS, Guarro J, Gené J, Figueras MJ (2000) Atlas of clinical fungi, 2nd edn. Centraalbureau voor Schimmelcultures (CBS), Utrecht

de Oliveira TS, Dallagnol LJ, de Araujo Filho JV, de Castro Moretti FR, Camargo LEA (2015) First report of powdery mildew caused by Erysiphe platani on Platanus $\times$ acerifolia in Rio Grande do Sul, Brazil. Plant Dis 99:157

De Silva DD, Rapior S, Fons F, Bahkali AH, Hyde KD (2012a) Medicinal mushrooms in support ivecancer therapies: an approach to anti-cancer effects and putative mechanisms of action. Fungal Divers 55:1-35

De Silva DD, Rapior S, Hyde KD, Bahkali AH (2012b) Medicinal mushrooms in prevention and control of diabetes mellitus. Fungal Divers 56:1-29

De Silva DD, Rapior S, Sudarman E, Stadler M, Xu J, Alias SA, Hyde KD (2013) Bioactive metabolites from macrofungi: ethnopharmacology, biological activities and chemistry. Fungal Divers 62:1-40

De Silva DD, Crous PW, Ades PK, Hyde KD, Taylor PW (2017) Life styles of Colletotrichum species and implications for plant biosecurity. Fungal Biol Rev 31(3):155-168

Dean R, van Kan JAL, Pretorius ZA, Hammond-Kosack KE, Di Pietro A, Spanu PD, Rudd JJ, Dickman M, Kahmann R, Ellis J, Foster GD (2012) The top 10 fungal pathogens in molecular plant pathology. Mol Plant Pathol 13:414-430

Decock C, Figueroa SH, Robledo G, Castillo G (2006) Phellinus caribaeo-quercicolus sp. nov., parasitic on Quercus cubana: taxonomy and preliminary phylogenetic relationships. Mycologia 98:265-274

Dennis RWG (1986) Fungi of the hebrides. Royal Botanic Gardens, Kew, p 383

DeScenzo RA, Harrington TC (1994) Use of (CAT)5 as a fingerprinting probe for fungi. Phytopathology 84:534-540

Dettman JR, Jacobson DJ, Taylor JW (2003) A multilocus genealogical approach to phylogenetic species recognition in the model eukaryote Neurospora. Evolution 57:2703-2720
Dick MW (1995) Sexual reproduction in the Peronosporomycetes (chromistan fungi). Can J Bot 73(S1):712-724

Dick MW (2001) Straminipilous fungi: systematics of the Peronosporomycetes including accounts of the marine straminipilous protists, the Plasmodiophorids and similar organisms. Kluwer Academic Publishers, Dordrecht

Dissanayake AJ, Phillips AJL, Li XH, Hyde KD (2016) Botryosphaeriaceae: current status of genera and species. Mycosphere 7:1001-1073

Doilom MW, Shuttleworth LA, Roux J, Chukeatirote E, Hyde KD (2014) Barriopsis tectonae sp. nov. a new species of Botryosphaeriaceae from Tectona grandis (teak) in Thailand. Phytotaxa 176:81-91

Donk MA (1960) The generic names proposed for Polyporaceae. Persoonia 1:173-302

Douanla-Meli C, Langer E (2009) Ganoderma carocalcareus sp. nov., with crumbly-friable context parasite to saprobe on Anthocleista nobilis and its phylogenetic relationship in G. resinaceum group. Mycol Prog 8:145-155

Drechsler-Santos ER, Robledo G, Lima-Junior NC, Malosso E, Reck MA, Gibertoni TB, Cavalcanti MAQ, Rajchenberg M (2016) Phellinotus, a new neotropical genus in the Hymenochaetaceae (Basidiomycota, Hymenochaetales). Phytotaxa 261:218-239

Dugan FM, Braun U, Groenewald JZ, Crous PW (2008) Morphological plasticity in Cladosporium sphaerospermum. Persoonia 21:9

Eberle MA, Rothroch CS, Cartwright RD (2007) Pythium species associates with rice stand establishment problems in Arkansas. AAES Res Ser 560:57-63

Ekandjo LK, Chimwamurombe PM (2012) Traditional medicinal uses and natural hosts of the genus Ganoderma in North-Eastern parts of Namibia. J Pure Appl Microbiol 6:1139-1146

Ellis MB (1971) Dematiaceous hyphomycetes. Commonwealth Mycological Institute, Kew

Ellis MB (1976) More dematiaceous hyphomycetes. Commonwealth Mycological Institute, Kew

Fabro G, Di Rienzo JA, Voigt CA, Savchenko T, Dehesh K, Somerville S, Alvarez ME (2008) Genome-wide expression profiling Arabidopsis at the stage of Golovinomyces cichoracearum haustorium formation. Plant Physiol 146:1421-1439

Farinas C, Gluck-Thaler E, Slot JC, Hand FP (2019) Whole-genome sequence of the phlox powdery mildew pathogen Golovinomyces magnicellulatus strain FPH2017-1. Microbiol Resour Announc 8(36):e00852-19

Farr DF, Rossman AY (2020) Fungal databases, systematic mycology and microbiology laboratory, ARS, USDA. http://nt.ars-grin.gov/ fungaldatabases/

Feliziani E, Romanazzi G (2016) Postharvest decay of strawberry fruit: etiology, epidemiology, and disease management. J Berry Res 6:47-63

Ferraris T (1910) Flora italica cryptogama, part I fungi. Rocca San Casciano, Florence, Italy, pp 591-916

Filip GM, Goheen DJ (1984) Root diseases cause severe mortality in White and Grand Fir Stands of the Pacific Northwest. For Sci 30:138-142

Fischer M (1995) Phellinus igniarius and its closest relatives in Europe. Mycol Res 99(6):735-744

Fischer M, Binder M (1995) Phellinus species on Betula. Mating tests, RFLP analysis of enzymatically amplified rDNA, and relations to Phellinus alni. Karstenia 35:67-84

Fischer M, Binder M (2004) Species recognition, geographic distribution and host-pathogen relationships: a case study in a group of lignicolous basidiomycetes. Phellinus s. 1. Mycologia 96:799-811

Floudas D, Binder M, Riley R, Barry K, Blanchette RA, Henrissat B, Martínez AT, Otillar R, Spatafora JW, Yadav JS, Aerts A, Benoit I, Boyd A, Carlson A, Copeland A, Coutinho PM, de Vries RP, 
Ferreira P, Findley K, Foster B, Gaskell J, Glotzer D, Górecki P, Heitman J, Hesse C, Hori C, Igarashi K, Jurgens JA, Kallen N, Kersten P, Kohler A, Kües U, Kumar TK, Kuo A, LaButti K, Larrondo LF, Lindquist E, Ling A, Lombard V, Lucas S, Lundell T, Martin R, McLaughlin DJ, Morgenstern I, Morin E, Murat C, Nagy LG, Nolan M, Ohm RA, Patyshakuliyeva A, Rokas A, Ruiz-Dueñas FJ, Sabat G, Salamov A, Samejima M, Schmutz J, Slot JC, St John F, Stenlid J, Sun H, Sun S, Syed K, Tsang A, Wiebenga A, Young D, Pisabarro A, Eastwood DC, Martin F, Cullen D, Grigoriev IV, Hibbett DS (2012) The paleozoic origin of enzymatic lignin decomposition reconstructed from 31 fungal genomes. Science 336:1715-1719

Foex E (1913) Recherches sur Oidiopsis taurica (Lév.). Arn Bull Soc Mycol Fr 29:577-588

Förster H, Cummings MP, Coffey MD (2000) Phylogenetic relationships of Phytophthora species based on ribosomal ITS I DNA sequence analysis with emphasis on Waterhouse groups $\mathrm{V}$ and VI. Mycol Res 104:1055-1061

French AM (1989) California plant disease host index. California Department of Food and Agriculture, Division of Plant Industry, Sacramento, p 394

Fries E (1825) Systema orbis. Vegetabilis 2:1-373

Gan P, Tsushima A, Narusaka M, Narusaka Y, Takano Y, Kubo Y, Shirasu K (2019) Genome sequence resources for four phytopathogenic fungi from the Colletotrichum orbiculare species complex. Mol Plant Microbe Interact 32:1088-1090

Garbelotto M (2004) Root and butt rot diseases. In: Burley J, Evans J, Youngquist JA (eds) Encyclopedia of forest sciences, vol 2. Elsevier, Oxford, pp 750-758

Garbelotto M, Gonthier P (2013) Biology, epidemiology, and control of Heterobasidion species worldwide. Annu Rev Phytopathol 51:39-59

Garbelotto M, Guglielmo F, Mascheretti S, Croucher PJ, Gonthier P (2013) Population genetic analyses provide insights on the introduction pathway and spread patterns of the North American forest pathogen Heterobasidion irregulare in Italy. Mol Ecol 22:4855-4869

Garbelotto M, Friedman M, Bedell W, Henkel T (2017) First report of Heterobasidion occidentale on Sequoia sempervirens in Northern California. Plant Dis 101:2152

Ge J, Yin Y, Jiang X, Liu W, Yao B, Luo H (2019) Gene cloning and characterization of a novel glucose oxidase from Cladosporium tianshanense SL19. J Agric Sci Technol 21:49-57

Geisler LG (2013) Purple seed stain and Cercospora blight. Plant pathology fact sheet. University of Nebraska-Lincoln. http://pdc. unl.edu/agriculturecrops/soybean/purple-seed-stain. Accessed March 2020.

Gilbertson RL (1979) The genus Phellinus (Aphyllophorales: Hymenochaetaceae) in Western North America. Mycotaxon 9:51-89

Gilbertson RL (1980) Wood-rotting fungi of North America. Mycologia 72:1-49

Gilbertson RL, Ryvarden L (1986) North American polypores. vol. I. Abortiporus-Lindtneria. Oslo, Norway: Fungi flora A/S 387.

Ginns JH (1986) Compendium of plant disease and decay fungi in Canada 1960-1980. Can Gov Publ Centre 1813:416

Giraldo A, Crous PW, Schumacher RK, Cheewangkoon R, GhobadNejhad M, Langer E (2017) The genera of fungi-G3: Aleurocustis, Blastacervulus, Clypeophysalospora, Licrostroma, Neohendersonia and Spumatoria. Mycol Progr 16:325-348

Glawe DA (2008) The powdery mildews: a review of the world's most familiar (yet poorly known) plant pathogens. Ann Rev Phytopathol 46.

Glen M, Bougher NL, Francis AA, Nigg SQ, Lee SS, Irianto R, Barry KM, Beadle CL, Mohammed CL (2009) Ganoderma and Amauroderma species associated with root-rot disease of Acacia mangium plantation trees in Indonesia and Malaysia. Australas Plant Pathol 38:345-356

Goheen DJ, Hansen EM (1993) Effects of pathogens and bark beetles on forests. In: Schowalter TD, Filip GM (eds) Beetle-pathogen interactions in conifer forests. Academic Press, San Diego, pp $175-196$

Goheen DJ, Otrosina WJ (1998) Characteristics and consequences of root diseases in forests of western North America. In: Frankel SJ (ed) User's guide to the western root disease model, version 3.0. Gen Tech Rep PSW-GTR 165. U.S. Department of Agriculture, Forest Service, Pacific Southwest Station, Albany, pp 3-8.

Goheen EM, Hansen EM, Kanaskie A, Mcwilliams MG, Osterbauer N, Sutton W (2002) Sudden oak death caused by Phytophthora ramorum in Oregon. Plant Dis 86:441

Gonthier P, Garbelotto M (2011) Amplified fragment length polymorphism and sequence analyses reveal massive gene introgression from the European fungal pathogen Heterobasidion annosum intoits introduced congener $H$. irregulare. Mol Ecol 20:2756-2770

González M, Romero MÁ, García LV, Gómez-Aparicio L, Serrano MS (2020) Unravelling the role of drought as predisposing factor for Quercus suber decline caused by Phytophthora cinnamomi. Europ J Plant Pathol 1-7

Gottlieb AM, Wright JE (1999a) Taxonomy of Ganoderma from southern South America: subgenus Ganoderma. Mycol Res 103:661-673

Gottlieb AM, Wright JE (1999b) Taxonomy of Ganoderma from southern South America: subgenus Elfvingia. Mycol Res 103:1289-1298

Gottlieb AM, Saidman BO, Wright JE (1995) Characterization of six isoenzymatic systems in Argentine representatives of two groups of Ganoderma. In: Buchanan PK, Hseu RS, Moncalyo JM (eds) Proceedings of Contributed Symposium, 59A, B 5th International Mycological Congress, pp 25-29.

Gottlieb AM, Saidman BO, Wright JE (1998) Isozymes of Ganoderma species from southern South America. Mycol Res 102:415-426

Graham J, Hackett CA, Smith K, Woodhead M, MacKenzie K, Tierney I, Cooke D, Bayer M, Jennings N (2011) Towards an understanding of the nature of resistance to Phytophthora root rot in red raspberry. Theoret Appl Genet 123:585-601

Gravert CE, Munkvold GP (2002) Fungi and diseases associated with cultivated switchgrass in Iowa. J Iowa Acad Sci 109:30-34

Gregorio-Cipriano R, González D, Félix-Gastélum R, Chacón S (2020) Neoerysiphe sechii (Ascomycota: Erysiphales): a new species of powdery mildew found on Sechium edule and Sechium mexicanum (Cucurbitaceae) in Mexico. Botany 185-195.

Gregory SS, John WT (1999) Phylogenetic relationships of Meliola and Meliolina inferred from nuclear small subunit rRNA sequences. Mycol Res 103:1049-1056

Greuter W, Poelt J, Raimondo FM (1991) A checklist of Sicillian fungi. Bocconea 2:222

Grinn-Gofroń A, Nowosad J, Bosiacka B, Camacho I, Pashley C, Belmonte J, De Linares C, Ianovici N, Manzano JMM, Sadyś M, Skjøth C (2019) Airborne Alternaria and Cladosporium fungal spores in Europe: forecasting possibilities and relationships with meteorological parameters. Sci Total Environ 653:938-946

Groenewald M, Groenewald JZ, Crous PW (2005) Distinct species exist within the Cercospora apii morphotype. Phytopathology 95:951-959

Groenewald M, Groenewald JZ, Harrington TC, Abeln EC, Crous PW (2006) Mating type gene analysis in apparently asexual Cercospora species is suggestive of cryptic sex. Fungal Genet Biol 43:813-825

Groenewald M, Groenewald JZ, Crous PW (2010) Mating type genes in Cercospora beticola and allied species. In: Lartey RT, Weiland JJ, Panella L, Crous PW, Windels CE (eds) Cercospora leaf 
spot of sugar beet and related species. APS Press, Minnesota, pp 39-53

Groenewald JZ, Nakashima C, Nishikawa J, Shin HD, Park JH, Jama AN, Groenewald M, Braun U, Crous PW (2013) Species concepts in Cercospora: spotting the weeds among the roses. Stud Mycol 75:115-170

Gryganskyi A, Lee S, Litvintseva A, Smith M, Bonito G, Porter T, Anishchenko I, Heitman J, Vilgalys R (2010) Structure, function, and phylogeny of the mating locus in the Rhizopus oryzaecomplex. PLoS ONE 5:15273

Gryganskyi AP, Golan J, Dolatabadi S, Mondo S, Robb S, Idnurm A, Muszewska A, Steczkiewicz K, Masonjones S, Liao H, Gajdeczka M, Anike F, Vuek A, Anishchenko I, Voigt K, de Hoog G, Smith M, Heitman J, Vilgalys R, Stajich J (2018) Phylogenetic and phylogenomic definition of Rhizopus species. Genes Genomes Genet 8:2007-2018

Gu X, Ding J, Liu W, Yang X, Yao L, Gao X, Zhang M, Yang S, Wen J (2020) Comparative genomics and association analysis identifies virulence genes of Cercospora sojina in soybean. BMC Genom 21:1-7

Guatimosim E, Schwartsburd PB, Barreto RW, Crous PW (2016) Novel fungi from an ancient niche: cercosporoid and related sexual morphs on ferns. Persoonia 37:106

Guillaumin JJ, Legrand P (2013) Armillaria root rots. Infectious forest diseases, pp 159-177.

Guo T, Wang HC, Xue WQ, Zhao J, Yang ZL (2016) Phylogenetic analyses of Armillaria reveal at least 15 phylogenetic lineages in China, seven of which are associated with cultivated Gastrodia elata. PLoS ONE 11:e0154794

Gutiérrez-Rodríguez A, Postigo I, Guisantes JA, Suñén E, Martínez J (2011) Identification of allergenshomologous to Alt a 1 from Stemphylium botryosum and Ulocladium botrytis. Medical mycol 49(8):892-896

Haight JE, Laursen GA, Glaeser JA, Taylor DL (2016) Phylogeny of Fomitopsis pinicola: a species complex. Mycologia 108:925-938

Haight JE, Nakasone KK, Laursen GA, Redhead SA, Taylor DL, Glaeser JA (2019) Fomitopsis mounceae and F. schrenkii-two new species from North America in the F. pinicola complex. Mycologia 111:339-357

Hall TA (1999) BioEdit: a user-friendly biological sequence alignment editor and analysis program for Windows 95/98/NT. Nucleic Acids Symp Ser 41:95-98

Halo BA, Maharachchikumbura SSN, Al-Yahyai RA, Al-Sadi AM (2019) Cladosporium omanense, a new endophytic species from Zygophyllum coccineum in Oman. Phytotaxa 388:145-154

Hamayun M, Khan SA, Ahmad N, Tang DS, Kang SM, Na CI, Sohn EY, Hwang YH, Shin DH, Lee BH, Kim JG, Lee IJ (2009) Cladosporium sphaerospermum as a new plant growth-promoting endophyte from the roots of Glycine max (L.) Merr. World J Microbiol Biotechnol 25:627-632

Han ML, Chen YY, Shen LL, Song J, Vlasák J, Dai YC, Cui BK (2016) Taxonomy and phylogeny of the brown-rot fungi: Fomitopsis and its related genera. Fungal Divers 80:343-373

Hanse B, Raaijmakers EEM, Schoone AHL, Van Oorschot PMS (2015) Stemphylium sp., the cause of yellow leaf spot disease in sugar beet (Beta vulgaris L.) in the Netherlands. Eur J Plant Pathol 142(2):319-330

Hansen EM, Reeser PW, Sutton W (2012) Phytophthora borealis and Phytophthora riparia, new species in Phytophthora ITS Clade 6. Mycologia 104:1133-1142

Hansford CG (1961) The Meliolaceae a monograph. Sydowia Beih 2:1-806

Hapuarachchi KK, Wen TC, Jeewon R, Wu XL, Kang JC, Hyde KD (2016a) Mycosphere essays 7: Ganoderma lucidum-are the beneficial anti-cancer properties substantiated? Mycosphere $7: 305-332$
Hapuarachchi KK, Wen TC, Jeewon R, Wu XL, Kang JC (2016b) Mycosphere essays 15: Ganoderma lucidum - are the beneficial medical properties substantiated? Mycosphere 7:687-715

Hapuarachchi KK, Cheng CR, Wen TC, Jeewon R, Kakumyan P (2017) Mycosphere essays 20: therapeutic potential of Ganoderma species: insights into its use as traditional medicine. Mycosphere 8:1653-1694

Hapuarachchi KK, Elkhateeb WA, Karunarathna SC, Phengsintham P, Cheng CR, Bandara AR, Kakumyan P, Hyde KD, Daba GM, Wen TC (2018a) Current status of global Ganoderma cultivation, products, industry and market. Mycosphere 9:1025-1052

Hapuarachchi KK, Karunarathna SC, Raspé O, De Silva KHWL, Thawthong A, Wu XL, Kakumyan P, Hyde KD, Wen TC (2018b) High diversity of Ganoderma and Amauroderma (Ganodermataceae, Polyporales) in Hainan Island, China. Mycosphere 9:931-982

Hapuarachchi KK, Karunarathna SC, McKenzie EHC, Wu XL, Kakumyan P, Hyde KD, Wen TC (2019a) High phenotypic plasticity of Ganoderma sinense (Ganodermataceae, Polyporales) in China. Asian J Mycol 2:1-47

Hapuarachchi KK, Karunarathna SC, Phengsintham P, Yang HD, Kakumyan P, Hyde KD, Wen TC (2019b) Ganodermataceae (Polyporales): diversity in Greater Mekong Subregion countries (China, Laos, Myanmar, Thailand and Vietnam). Mycosphere 10:221-309

Harrington TC, Wingfield BD (1995) A PCR-based identification method for species of Armillaria. Mycologia 87:280-288

Hartanti A, Rahayu G, Hidayat I (2015) Rhizopus species from fresh tempeh collected from several regions in Indonesia. Hayati J Biosci 22:136-142

Hartley D (1992) Poinsettias. In: Larson R (ed) Introduction to floriculture, 2nd edn. Academic Press, San Diego, pp 305-331

Hattori T (2001) Type studies of the polypores described by E. J. H. Corner from Asia and West Pacific areas III. Species described in Trichaptum, Albatrellus, Boletopsis, Diacanthodes, Elmerina, Fomitopsis and Gloeoporus. Mycoscience 42:423-431

Hattori T (2003) Type studies of the polypores described by E.J.H. Corner from Asia and West Pacific areas. VI. Species described in Tyromyces (3), Cristelloporia, Grifola, Hapalopilus, Heterobasidion, Ischnoderma, Loweporus, and Stecchericium. Mycoscience 44:453-463

He MQ, Zhao RL, Hyde KD, Begerow D, Kemler M, Yurkov A, McKenzie EHC, Raspé O, Kakishima M, Sánchez-Ramírez S, Vellinga EC, Halling R, Papp V, Zmitrovich IV, Buyck B, Ertz D, Wijayawardene NN, Cui BK, Schoutteten N, Liu XZ, Li TH, Yao YJ, Zhu XY, Liu AQ, Li GJ, Zhang MZ, Ling ZL, Cao B, Antonín V, Boekhout T, da Silva BDB, Crop ED, Decock C, Dima B, Dutta AK, Fell JW, Geml J, Ghobad-Nejhad M, Giachini AJ, Gibertoni TB, Gorjón SP, Haelewaters D, He SH, Hodkinson BP, Horak E, Hoshino T, Justo A, Lim YW, Menolli N Jr, Mešić A, Moncalvo JM, Mueller GM, Nagy LG, Nilsson RH, Noordeloos M, Nuytinck J, Orihara T, Ratchadawan C, Rajchenberg M, Silva-Filho AGS, Sulzbacher MA, Tkalčec Z, Valenzuela R, Verbeken A, Vizzini A, Wartchow F, Wei TZ, Weiß M, Zhao CL, Kirk PM (2019) Notes, outline and divergence times of Basidiomycota. Fungal Divers 99:105-367

Heffer V, Johnson KB, Powelson ML, Shishkoff N (2006) Identification of powdery mildew fungi anno 2006. Plant Health Instruct. https ://doi.org/10.1094/PHI-I-2006-0706-01

Heluta VP (1988a) Filogeneticheskie vzaimosvyazi mezhdu rodami erizifalnykh gribov i nekotorye voprosy sistematiki poryadka Erysiphales. Biol Z Arm 41:351-358

Heluta VP (1988b) Novi taksonomichni kombinatsyyi v rodini Erysiphaceae. Ukrainsk Bot Zhurn 45:62-63

Heluta V, Takamatsu S, Harada M, Voytyuk S (2010) Molecular phylogeny and taxonomy of Eurasian Neoerysiphe species infecting Asteraceae and Geranium. Persoonia 24:81 
Hendrichs M, Bauer R, Oberwinkler F (2003) The Cryptobasidiaceae of tropical Central and South America. Sydowia 55:33-64

Hendrix FF, Campbell WA (1973) Pythiums as plant pathogens. Annu Rev Phytopathol 11:77-98

Hennicke F, Cheikh-Ali Z, Liebisch T, Maciá-Vicente JG, Bode HB, Piepenbring M (2016) Distinguishing commercially grown Ganoderma lucidum from Ganoderma lingzhi from Europe and East Asia on the basis of morphology, molecular phylogeny, and triterpenic acid profiles. Phytochemistry 127:29-37

Hepting GH (1971) Diseases of forest and shade trees of the United States. US Department of Agriculture, Agricultural Handbook, vol 386, pp 1-658.

Herink J (1973) Taxonomie václavky obecné-Armillaria mellea (Vahl. ex Fr.) Kumm. In: Hasek J (ed) Sympozium o václavce obecné. Lesnicka fakulta VSZ, Brno, pp 21-48

Hermet A, Méheust D, Mounier J, Barbier G, Jany J (2012) Molecular systematics in the genus Mucor with special regards to species encountered in cheese. Fungal Biol 116:692-705

Hernandez-Restrepo M, Schumacher RK, Wingfield MJ, Ahmad I, Cai L, Duong TA, Edwards J, Gene J, Groenewald JZ, Jabeen S, Khalid AN, Lombard L, Madrid H, Marin-Felix Y, Marincowitz S, Miller AN, Rajeshkumar KC, Rashid A, Sarwar S, Stchigel AM, Taylor PWJ, Zhou N, Crous PW (2016) Fungal Systematics and Evolution: FUSE 2. Sydowia 68:193-230

Hershman D (2009) Cercospora leaf blight in Kentucky. Plant pathology fact sheet PPFS-AG-S-20. University of Kentucky Cooperative Extension Service, Lexington, KY. https://mra.asm.org/conte nt/5/36/e00708-17.short.

Hertert HD, Miller DL, Partridge AD (1975) Interactions of bark beetles (Coleoptera: Scolytidae) and root rot pathogens in northern Idaho. Can Entomol 107:899-904

Heuchert B, Braun U, Schubert K (2005) Morpho taxonomic revision of fungicolous Cladosporium species (hyphomycetes). Schlechtendalia 13:1-78

Hintikka V (1973) A note on the polarity of Armillariella mellea. Karstenia 13:32-39

Hirata T, Cunnington JH, Paksiri U, Limkaisang S, Shishkoff N, Grigaliunaite B, Sato Y, Takamatsu S (2000) Evolutionary analysis of subsection Magnicellulatae of Podosphaera section Sphaerotheca (Erysiphales) based on the rDNA ITS sequences with special reference to host plants. Can J Bot 78:1521-1530

Hirose S, Tanda S, Levente KISS, Grigaliunaite B, Havrylenko M, Takamatsu S (2005) Molecular phylogeny and evolution of the maple powdery mildew (Sawadaea, Erysiphaceae) inferred from nuclear rDNA sequences. Mycol Res 109:912-922

Ho HH (2009) The genus Pythium in Taiwan, China (1) - a synoptic review. Front Biol 4:15-28

Ho HH, Abd-Elsalam KA (2020) Pathogenic and Beneficial Pythium Species in China: An Updated Review. Pythium: Diagnosis, Diseases and Management, p.1883

Hoffmann K, Pawłowska J, Walther G, Wrzosek M, de Hoog GS, Benny GL, Kirk PM, Voigt K (2013) The family structure of the Mucorales: a synoptic revision based on comprehensive multigene genealogies. Persoonia 30:57-76

Höhnel FXR von (1911) Fragmente zur mykologie. XIII Mitteilung (Nr. 642 bis 718). Sitzungsberichte der Kaiserlichen Akademie der Wissenschaften in Wien Mathematisch-Naturwissenschaftliche Classe, Abt. 1 120:379-484.

Hong SG, Jung HS (2004) Phylogenetic analysis of Ganoderma based on nearly complete mitochondrial small-subunit ribosomal DNA sequences. Mycologia 96:742-755

Hong KK, Geon SS, Hong GK (2001) Comparison of characteristics of Ganoderma lucidum according to geographical origins: consideration of morphological characteristics. Micobiology 29:80-84
Hong CX, Gallegly ME, Richardson PA, Kong P, Moorman GW, LeaCox JD, Ross DS (2010) Phytophthora hydropathica, a new pathogen identified from irrigation water, Rhododendron catawbiense and Kalmia latifolia. Plant Pathol 59:913-921

Hong CX, Richardson PA, Hao W, Ghimire SR, Kong P, Moorman GW, Lea-Cox JD, Ross DS (2012) Phytophthora aquimorbida sp. nov. and Phytophthora taxon 'aquatilis' recovered from irrigation reservoirs and a stream in Virginia, USA. Mycologia 104:1097-1108

Hong CY, Lee SY, Ryu SH, Kim M (2017) Whole-genome de novo sequencing of wood rot fungus Fomitopsis palustris (ATCC62978) with both a cellulolytic and ligninolytic enzyme system. J Biotechnol 251:156-159

Hongsanan S, Tian Q, Peršoh D, Zeng XY, Hyde KD, Chomnunti P, Boonmee S, Bahkali AH, Wen TC (2015) Meliolales. Fungal Divers 74:91-141

Hongsanan S, Maharachchikumbura SSN, Hyde KD, Samarakoon MC, Jeewon R, Zhao Q, Al-Sadi AM, Bahkali AH (2017) An updated phylogeny of Sordariomycetes based on phylogenetic and molecular clock evidence. Fung Divers 84:25-41

Hongsanan S, Hyde KD, Phookamsak R, Wanasinghe DN, McKenzie EHC, Sarma VV, Boonmee S, Lücking R, Pem D, Bhat JD, Liu N, Tennakoon DS, Karunarathna A, Jiang SH, Jones EBG, Phillips AJL, Manawasinghe I, Tibpromma S, Jayasiri SC, Sandamali D, Jayawardena RS, Wijayawardene NN, Ekanayaka AH, Jeewon R, Lu YZ, Dissanayake AJ, Luo ZL, Tian Q, Phukhamsakda C, Thambugala KM, Dai DQ, Chethana TKW, Ertz D, Doilom M, Liu JK, Pérez-Ortega S, Suija A, Senwanna C, Wijesinghe SN, Konta S, Niranjan M, Zhang SN, Ariyawansa HA, Jiang HB, Zhang JF, de Silva NI, Thiyagaraja V, Zhang H, Bezerra JDP, Miranda-Gonzáles R, Aptroot A, Kashiwadani H, Harishchandra D, Aluthmuhandiram JVS, Abeywickrama PD, Bao DF, Devadatha B, Wu HX, Moon KH, Gueidan C, Schumm F, Bundhun D, Mapook A, Monkai J, Chomnunti P, Samarakoon MC, Suetrong S, Chaiwan N, Dayarathne MC, Jing Y, Rathnayaka AR, Bhunjun CS, Xu JC, Zheng JS, Liu G, Feng Y, Xie N (2020) Refined families of Dothideomycetes: Dothideomycetidae and Pleosporomycetidae. Fungal Divers (in press)

Horst RK (2013) Westcott's plant disease handbook. Springer, New York

Hosagoudar VB (1994) Meliolales of India. J Econ Taxon Bot 18:253-265

Hosagoudar VB (1996) Meliolales of India. Botanical Survey of India, Calcutta, p 363

Hosagoudar VB (2008) Meliolales of India, vol II. Botanical Survey of India, Calcutta, p 390

Hosagoudar VB, Riju MC (2013) Foliicolous fungi of silent valley national park, Kerala, India. J Threatened Taxa 5:3701-3788

Hseu RS, Wang HH, Wang HF, Moncalvo JM (1996) Differentiation and grouping of isolates of the Ganoderma lucidum complex by random amplified polymorphic DNA-PCR compared. J Appl Environ Microbiol 62:1354-1363

Hsieh HJ (1978) An annotated list of Pythium in Taiwan. Bot Bull Acad Sin 19:199-205

Huser A, Takahara H, Schmalenbach W, O’Connell R (2009) Discovery of pathogenicity genes in the crucifer anthracnose fungus Colletotrichum higginsianum, using random insertional mutagenesis. Mol Plant Microbe Interact 22(2):143-156

Hwang EK, Park CS, Kakinuma M (2009) Physicochemical responses of Pythium porphyrae (Oomycota), the causative organism of red rot disease in Porphyra to acidification. Aquac Res 40:1777-1784

Hyde KD, Cai L, Cannon PF, Crouch JA, Crous PW, Damm U, Goodwin PH, Chen H, Johnston PR, Jones EBG, Liu ZY, McKenzie EHC, Moriwaki J, Noireung P, Pennycook SR, Pfenning LH, Prihastuti H, Sato T, Shivas RG, Tan YP, Taylor PWJ, Weir BS, 
Yang YL, Zhang JZ (2009a) Colletotrichum—names in current use. Fungal Divers 39:147-182

Hyde KD, Cai L, McKenzie EHC, Yang YL, Zhang JZ, Prihastuti H (2009b) Colletotrichum: a catalogue of confusion. Fungal Divers 39(1):1-17

Hyde KD, Jones EBG, Liu JK, Ariyawansa HA, Boehm E, Boonmee S, Braun U, Chomnunti P, Crous PW, Dai DQ, Diederich P, Dissanayake A, Doilom M, Doveri F, Hongsanan S, Jayawardena R, Lawrey JD, Li YM, Liu YX, Lücking R, Monkai J, Muggia L, Nelsen MP, Pang KL, Phookamsak R, Senanayake IC, Shearer CA, Suetrong S, Tanaka K, Thambugala KM, Wijayawardene NN, Wikee S, Wu HX, Zhang Y, Aguirre-Hudson B, Alias SA, Aptroot A, Bahkali AH, Bezerra JL, Bhat DJ, Camporesi E, ChukeatiroteE Gueidan C, Hawksworth DL, Hirayama K, De Hoog S, Kang JC, Knudsen K, Li WJ, Li XH, Liu ZY, Mapook A, McKenzie EHC, Miller AN, Mortimer PE, Phillips AJL, Raja HA, Scheuer C, Schumm F, Taylor JE, Tian Q, Tibpromma S, Wanasinghe DN, Wang Y, Xu JC, Yacharoen S, Yan JY, Zhang M (2013) Families of dothideomycetes. Fungal Divers 63:1-313

Hyde KD, Nilsson RH, Alias SA, Ariyawansa HA, Blair JE, Cai L, de Cock AWAM, Dissanayake AJ, Glockling SL, Goonasekara ID, Gorczak M, Hahn M, Jayawardena RS, van Kan JAL, Laurence MH, Lévesque CA, Li XH, Liu JK, Maharachchikumbura SSN, Manamgoda DS, Martin FN, McKenzie EHC, McTaggart AR, Mortimer PE, Nair PVR, Pawłowska J, Rintoul TL, Shivas RG, Spies CFJ, Summerell BA, Taylor PWJ, Terhem RB, Udayanga D, Vaghefi N, Walther G, Wilk M, Wrzosek M, Xu JC, Yan JY, Zhou N (2014) One stop shop: backbones trees for important phytopathogenic genera: I. Fungal Divers 67:21-125

Hyde KD, Hongsanan S, Jeewon R, Bhat DJ, McKenzie EHC, Jones EBG, Phookamsak R, Ariyawansa HA, Boonmee S, Zhao Q, Abdel-Aziz FA, Abdel-Wahab MA, Banmai S, Chomnunti P, Cui BK, Daranagama DA, Das K, Dayarathne MC, de Silva NL, Dissanayake AJ, Doilom M, Ekanayaka AH, Gibertoni TB, GóesNeto A, Huang SK, Jayasiri SC, Jayawardena RS, Konta S, Lee HB, Li WJ, Lin CG, Liu JK, Lu YZ, Luo ZL, Manawasinghe IS, Manimohan P, Mapook A, Niskanen T, Norphanphoun C, Papizadeh M, Perera RH, Phukhamsakda C, Richter C, de Santiago ALCMA, Drechsler-Santos ER, Senanayake IC, Tanaka K, Tennakoon TMDS, Thambugala KM, Tian Q, Tibpromma S, Thongbai B, Vizzini A, Wanasinghe DN, Wijayawardene NN, Wu H, Yang J, Zeng XY, Zhang H, Zhang JF, Bulgakov TS, Camporesi E, Bahkali AH, Amoozegar AM, Araujo-Neta LS, Ammirati JF, Baghela A, Bhatt RP, Bojantchev S, Buyck B, da Silva GA, de Lima CLF, de Oliveira RJV, de Souza CAF, Dai YC, Dima B, Duong TT, Ercole E, Mafalda-Freire F, Ghosh A, Hashimoto A, Kamolhan S, Kang JC, Karunarathna SC, Kirk PM, Kytövuori I, Lantieri A, Liimatainen K, Liu ZY, Liu XZ, Lücking R, Medardi G, Mortimer PE, Nguyen TTT, Promputtha I, Raj KNA, Reck MA, Lumyong S, Shahzadeh-Fazeli SA, Stadler M, Soudi MR, Su HY, Takahashi T, Tangthirasunun N, Uniyal P, Wang Y, Wen TC, Xu JC, Zhang ZK, Zhao YC, Zhou JZ, Zhu L (2016) Fungal diversity notes 367-491: taxonomic and phylogenetic contributions to fungal taxa. Fungal Divers 80:1-270

Hyde KD, Al-Hatmi AM, Andersen B, Boekhout T, Buzina W, Dawson TL, Eastwood DC, Jones EG, de Hoog S, Kang Y, Longcore JE (2018a) The world's ten most feared fungi. Fungal Divers 85:1-34

Hyde KD, Norphanphoun C, Chen J, Dissanayake AJ, Doilom M, Hongsanan S, Jayawardena RS, Jeewon R, Perera RH, Thongbai B, Wanasinghe DN, Wisitrassameewong K, Tibpromma S, Stadler M (2018b) Thailand's amazing diversity: up to $96 \%$ of fungi in northern Thailand may be novel. Fungal Divers 93:215-239
Hyde KD, Xu JC, Rapior S, Jeewon R, Lumyong S, Niego AGT, Abeywickrama PD, Aluthmuhandiram JVS, Brahamanage RS, Brooks S, Chaiyasen A, Chethana KWT, Chomnunti P, Chepkirui C, Chuankid B, de Silva NI, Doilom M, Faulds C, Gentekaki E, Gopalan V, Kakumyan P, Harishchandra D, Hemachandran H, Hongsanan S, Karunarathna A, Karunarathna SC, Khan S, Kumla J, Jayawardena RS, Liu JK, Liu N, Luangharn T, Macabeo APG, Marasinghe DS, Meeks D, Mortimer PE, Mueller P, Nadir S, Nataraja KN, Nontachaiyapoom S, O'Brien M, Penkhrue W, Phukhamsakda C, Ramanan US, Rathnayaka AR, Sadaba RB, Sandargo B, Samarakoon BC, Tennakoon DS, Siva R, Sriprom W, Suryanarayanan TS, Sujarit K, Suwannarach N, Suwunwong T, Thongbai B, Thongklang N, Wei DP, Wijesinghe SN, Winiski J, Yan J, Yasanthika E, Stadler M (2019) The amazing potential of fungi: 50 ways we can exploit fungi industrially. Fungal Divers 97:1-136

Hyde KD, de Silva N, Jeewon R, Bhat DJ, Phookamsak R, Doilom M, Boonmee S, Jayawardena RS, Maharachchikumbura SSN, Senanayake IC, Manawasinghe IS, Liu NG, Abeywickrama PD, Chaiwan N, Karunarathna A, Pem D, Lin CG, Sysouphanthong P, Luo ZL, Wei DP, Wanasinghe DN, Norphanphoun C, Tennakoon DS, Samarakoon MC, Jayasiri SC, Jiang HB, Zeng XY, Li JF, Wijesinghe SN, Devadatha B, Goonasekara ID, Brahmanage RS, Yang EF, Aluthmuhandiram JVS, Dayarathne MC, Marasinghe DS, Li WJ, Dissanayake LS, Dong W, Huanraluek N, Lumyong S, Liu JK, Karunarathna SC, Jones EBG, Al-Sadi AM, Xu JC, Harishchandra D, Sarma VV (2020a) AJOM new records and collections of fungi: 1-100. Asian J Mycol 3:22-294

Hyde KD, Norphanphoun C, Maharachchikumbura SSN, Bao DF, Bhat DJ, Boonmee S, Bundhun D, Calabon MS, Chaiwan N, Chen YJ, Chethana KWT, Dai DQ, Dayarathne MC, Devadatha B, Dissanayake AJ, Dissanayake LS, Doilom M, Dong W, Fan XL, Goonasekara ID, Hongsanan S, Huang SK, Jayawardena RS, Jeewon R, Jones EBG, Karunarathna A, Konta S, Kumar V, Lin CG, Liu JK, Liu N, Lu YZ, Luangsa-ard J, Lumyong S, Luo ZL, Marasinghe DS, McKenzie EHC, Niego AGT, Niranjan M, Perera RH, Phukhamsakda C, Rathnayaka AR, Samarakoon MC, Samarakoon SMBC, Sarma VV, Senanayake IC, Shang QJ, Stadler M, Tibpromma S, Wanasinghe DN, Wei DP, Wijayawardene NN, Xiao YP, Xiang MM, Yang J, Zeng XY, Zhang SN (2020b) Refined families of Sordariomycetes. Mycosphere 11:305-1059

Iakovidis M, Soumpourou E, Anderson E, Etherington G, Yourstone S, Thomas C (2020) Genes encoding recognition of the Cladosporium fulvum effector protein Ecp5 are encoded at several loci in the tomato genome. G3: Genes, Genomes, Genetics.

Inderbitzin P, Mehta YR, Berbee ML (2009) Pleospora species with Stemphylium anamorphs: a four-locus phylogeny resolves new lineages yet does not distinguish among species in the Pleospora herbarum clade. Mycologia 101(3):329-339

Index Fungorum (2020) Index Fungorum. http://www.indexfungorum. org/Names/Names.asp. Accessed March 2020.

Inuma T, Khodaparast SA, Takamatsu S (2007) Multilocus phylogenetic analyses within Blumeria graminis, a powdery mildew fungus of cereals. Mol Phylogenet Evol 44:741-751

Ishiguro Y, Otsubo K, Watanabe H, Suzuki M, Nakayama K, Fukuda T, Fujinaga M, Suga H, Kageyama K (2014) Root and crown rot of strawberry caused by Pythium helicoides and its distribution in strawberry production areas of Japan. J Gen Plant Pathol 80:423-429

Islam T, Gupta DR, Surovy MZ, Mahmud NU, Mazlan N, Islam T (2019) Identification and application of a fungal biocontrol agent Cladosporium cladosporioides against Bemisia tabaci. Biotechnol Biotechnol Equip 33:1698-1705

Ito S (1935) Notae mycologicae Asiae orientalis II. Transactions of Sapporo Natural History Society 14:87-96 
Ito S (1936) Mycological flora of Japan. vol 2, no 1.Yokendo, Tokyo, pp 1-146.

Ito PJ, Kunimoto R, Ko WH (1979) Transmission of Mucor rot of guava fruits by three species of fruit flies. J Trop Agric 56:49-52

Jacobsen RM, Kauserud H, Sverdrup-Thygeson A, Bjorbækmo MM, Birkemoe T (2017) Wood-inhabiting insects can function as targeted vectors for decomposer fungi. Fungal Ecol 29:76-84

Jaczewski A (1927) Karmannyj opredelitel' gribov 2. Mucnistorosjanye Griby, Leningrad

Jahnke KD, Bahnweg G, Worrall J (1987) Species delimitation in the Armillaria mellea complex by analysis of nuclear and mitochondrial DNAs. Transe Brit Mycol Soc 88:572-575

Jargalmaa S, Eimes JA, Park MS, Park JY, Oh SY, Lim YW (2017) Taxonomic evaluation of selected Ganoderma species and database sequence validation. Peer J 5:e3596

Jashni MK, van der Burgt A, Battaglia E, Mehrabi R, Collemare J, de Wit PJ (2019) Transcriptome and proteome analyses of proteases in biotroph fungal pathogen Cladosporium fulvum. J Plant Pathol $1-10$.

Jayawardena RS, Huang J, Jin B, Yan JY, Li XH, Hyde KD, Bahkali AH, Yin S, Zhang GZ (2016a) An updated account of Colletotrichum species associated with strawberry anthracnose in China based on molecular data. Mycosphere 7:1147-1163

Jayawardena RS, Hyde KD, Damm U, Cai L, Liu M, Li XH, Zhang W, Zhao WS, Yan JY (2016b) Notes on currently accepted species of Colletotrichum. Mycosphere 7:1192-1260

Jayawardena RS, Hyde KD, Jeewon R, Li XH, Liu M, Yan JY (2016c) Mycosphere essay 6: why is it important to correctly name Colletotrichum species? Mycosphere 7:1076-1092

Jayawardena RS, Hyde KD, Jeewon R, Ghobad-Nejhad M, Wanasinghe DN, Liu N, Phillips AJL, Oliveira-Filho JRC, da Silva GA, Gibertoni TB, Abeywikrama P, Carris LM, Chethana KWT, Dissanayake AJ, Hongsanan S, Jayasiri SC, McTaggart AR, Perera RH, Phutthacharoen K, Savchenko KG, Shivas RG, Thongklang N, Dong W, Wei DP, Wijayawardena NN, Kang JC (2019a) One stop shop II: taxonomic update with molecular phylogeny for important phytopathogenic genera: 26-50. Fungal Divers 94:41-129

Jayawardena RS, Hyde KD, McKenzie EHC, Jeewon R, Phillips AJL, Perera RH, de Silva NI, Maharachchikumburua SSN, Samarakoon MC, Ekanayake AH, Tennakoon DS, Dissanayake AJ, Norphanphoun C, Lin C, Manawasinghe IS, Tian Q, Brahmanage R, Chomnunti P, Hongsanan S, Jayasiri SC, Halleen F, Bhunjun CS, Karunarathna A, Wang Y (2019b) One stop shop III: taxonomic update with molecular phylogeny for important phytopathogenic genera: 51-75. Fungal Divers 97:1-84

Jeong WJ, Lim YW, Lee JS, Jung HS (2005) Phylogeny of Phellinus and related genera inferred from combined data of ITS and mitochondrial SSU rDNA sequences. J Microbiol Biotechnol 15(5): 1028

Jiang M, Kirschner R (2016) Unraveling two East Asian species of Clinoconidium (Cryptobasidiaceae). Mycoscience 57:440-447

Jianyu B, Xiaoming W, Yanjiang S, Canxing D (2016) Occurrence and identification of Nothophoma quercina causing brown spot of jujube in China. Can J plant Pathol 38:527-532

Johanesson H, Stenlid J (2003) Molecular markers reveal genetic isolation and phylogeography of the $\mathrm{S}$ and $\mathrm{F}$ intersterility groups of the wood decay fungus Heterobasidion annosum. Mol Phylogen Evol 29:94-101

Jones AC (1998) Estimating white trunk rot in aspen stands. North J Appl For 15:33-36

Jordan MM, Burchill RT, Maude RB (1990) Epidemiology of Cladosporium allii and Cladosporium allii-cepae, leaf blotch pathogens of leek and onion. II. Infection of host plants. Ann Appl Biol 117:327-336
Jung T, Blaschke H (1996) Phytophthora root rot in declining forest trees. Phyton-horn 36:95-102

Jung T, Stukely MJC, Hardy GESJ, White D, Paap T, Dunstan WA, Burgess TI (2011) Multiple new Phytophthora species from ITS clade 6 associated with natural ecosystems in Australia: evolutionary and ecological implications. Persoonia 26:13-39

Jung T, Jung MH, Scanu B, Seress D, Kovács GM, Maia C, PérezSierra A, Chang TT, Chandelier A, Heungens K, van Poucke K, Abad-Campos P, Léon M, Cacciola SO, Bakonyi J (2017) Six new Phytophthora species from ITS Clade 7a including two sexually functional heterothallic hybrid species detected in natural ecosystems in Taiwan. Persoonia 38:100-135

Jung T, Pérez-Sierra A, Durán A, Jung MH, Balci Y, Scanu B (2018) Canker and decline diseases caused by soil-and airborne Phytophthora species in forests and woodlands. Persoonia 40:182

Jung T, La Spada F, Pane A, Aloi F, Evoli M, Horta Jung M, Scanu B, Faedda R, Rizza C, Puglisi I, di San Magnano, Lio G (2019) Diversity and distribution of Phytophthora species in protected natural areas in Sicily. Forests 10:259

Justavino DR, Kirschner R, Piepenbring M (2015) New species and new records of Meliolaceae from Panama. Fungal Divers 70:73-84

Kakishima M (1982) A taxonomic study on the Ustilaginales in Japan. Mem Inst Agric For Univ Tsukuba 1:1-124

Kakishima M, Ji JX, Nagao H, Wang Q, Denchev CM (2017a) Clinoconidium globosum, nom. nov. (Cryptobasidiaceae) producing galls on fruits of Cinnamomum daphnoides in Japan. Phytotaxa 299:267-272

Kakishima M, Nagao H, Ji JX, Sun Y, Denchev CN (2017b) Clinoconidium onumae comb. nov. (Cryptobasidiaceae), producing galls on shoot buds of Cinnamomum tenuifolium in Japan. Phytotaxa 313:175-184

Kallio T (1972) Decay in a ten-year old stand of hybrid aspen. Silva Fenn 6:1-13

Kamal (2010) Cercosporoid fungi of India. Bishen Singh Mahendra Pal Singh, Dehra Dun, p 351

Kandan A, Bhaskaran R, Samiyappan R (2010) Ganoderma-a basal stem rot disease of coconut palm in south Asia and Asia pacific regions. Arch Phytopathol Plant Protect 43:1445-1449

Kärhä K, Koivusalo V, Palander T, Ronkanen M (2018) Treatment of Piceaabies and Pinussylvestris stumps with urea and Phlebiopsis gigantea for control of Heterobasidion. Forests 9:139

Karlsson JO, Stenlid J (1991a) Pectic isozyme profiles of intersterility groups in Heterobasidion annosum. Mycol Res 95:531-536

Karlsson JO, Stenlid J (1991b) Pectic isozyme profiles of intersterility groups in Heterobasidion annosum. Mycol Res 95:531-536

Karsten P (1881) Symbolae AD mycologiam fennicam. Meddn Soc Fauna Flora Fenn 6:7-14

Karsten P (1889) Symbolae and mycologicam XXXIX. Soc Fauna Flora Fenn Meddel 16:84-106

Karunarathna A, Papizadeh M, Senanayake IC, Jeewon R, Phookamsak R, Goonasekara ID, Wanasinghe DN, Wijayawardene NN, Amoozegar MA, Shahzadeh Fazeli SA, Camporessi E (2017) Novel fungal species of Phaeosphaeriaceae with an asexual/ sexual morph connection. Mycosphere 8:1818-1834

Kasuga T, Mitchelson K (1993a) Determination of the DNA sequence of the 5.8S ribosomal gene of Heterobasidion annosum and Heterobasidion araucariae. Nucleic Acids Res 21:1320

Kasuga T, Mitchelson K (1993b) Determination of the DNA sequence of the $5.8 \mathrm{~S}$ ribosomal gene of Heterobasidion annosum and Heterobasidion araucariae. Nucleic Acids Res 21:1320

Katoh K, Toh H (2008) Recent developments in the MAFFT multiple sequence alignment program. Brief Bioinform 9:286-298

Kawamura Y, Yokoo K, Tojo M, Hishiike M (2005) Distribution of Pythium porphyrae, the causal agent of red rot disease of Porphyrae spp., in the Ariake Sea, Japan. Plant Dis 89:1041-1047 
Khodaparast SA, Takamatsu S, Hedjaroude GA (2001) Phylogenetic structure of the genus Leveillula (Erysiphales: Erysiphaceae) inferred from the nucleotide sequences of the rDNA ITS region with special reference to the $L$. taurica species complex. Mycol Res 105:909-918

Khokhar I, Mukhtar I, Wang J, Jia Y, Yan Y (2019) A report of Rhizopus oryzae causing postharvest soft rot of apple fruit in China. Australas Plant Dis Notes 14:7

Kile GA, McDonald GI, Byler JW (1991) Ecology and disease in natural forests. In: Shaw CG, Kile GA (eds) Armillaria Root Disease. Forest Service, United States Department of Agriculture, Washington, pp 102-121

Kim MS, Klopfenstein N, Hanna J, McDonald G (2006) Characterization of North American Armillaria species: genetic relationships determined by ribosomal DNA sequences and AFLP markers. For Pathol 36:145-164

Kinge TR, Mih AM (2014) Ganoderma lobenense (basidiomycetes), a new species from oil palm (Elaeis guineensis) in Cameroon. $\mathbf{J}$ Plant Sci 2(5):242-245

Kliejunas JT, Geils BW, Glaeser JM, Goheen EM, Hennon P, Kim MS, Kope H, Stone J, Sturrock R, Frankel SJ (2009) Review of literature on climate change and forest diseases of western North America. Gen. Tech. Rep. PSW-GTR-225. US Department of Agriculture, Forest Service, Pacific Southwest Research Station, Albany, vol 54, p 225.

Klopfenstein NB (2009) Approaches to predicting potential impacts of climate change on forest disease: an example with Armillaria root disease. US Department of Agriculture, Forest Service, Rocky Mountain Research Station

Klopfenstein N, Lundquist J, Hanna J, Kim MS, McDonald G (2009) First report of Armillaria sinapina, a cause of armillaria root disease, associated with a variety of forest tree hosts on sites with diverse climates in Alaska. Plant Dis 93:111-111

Köhl J, Groenenboom-de Haas B, Goossen-van de Geijn H, Speksnijder A, Kastelein P, de Hoog S, van den Ende BG (2009) Pathogenicity of Stemphylium vesicarium from different hosts causing brown spot in pear. Eur J Plant Pathol 124(1):151

Kolb TE, Fettig CJ, Ayres MP, Bentz BJ, Hicke JA, Mathiasen R, Stewart JE, Weed AS (2016) Observed and anticipated impacts of drought on forest insects and diseases in the United States. For Ecol Manag 380:321-334

Konta S, Phillips AJL, Bahkali AH, Jones EBG, Eungwanichayapant DP, Hyde KD, Boonmee S (2016) Botryosphaeriaceae from palms in Thailand-Barriopsis archontophoenicis sp nov, from Archontophoenix alexandrae. Mycosphere 7:921-932

Korhonen K (1978a) Infertility and clonal size in the Armillariella mellea complex. Karstenia 18:31-42

Korhonen K (1978b) Intersterility groups of Heterobasidion annosum. Commun Insti Fore Fenn 94:1-25

Korhonen K, Stenlid J (1998) Biology of Heterobasidion annosum. In: Woodward S, Stenlid J, Karjalainen R, Hüttermann A (eds) Heterobasidion annosum: biology, ecology, impact and control. CAB International, Wallingford, pp 43-70

Korhonen K, Delatour C, Greig BJW, Schönar S (1998) Silvicultural control. In: Woodward S, Stenlid J, Karjalainen R, Hüttermann A (eds) Heterobasidion annosum: biology, ecology, impact and control. CAB International, Wallingford, pp 283-313

Kreye C, Bouman B, Castañeda AR, Lampayan RM, Faronilo JE, Lactaoen AT, Fernandez L (2009) Possible causes of yield failure in tropical aerobic rice. Field Crops Res 111:197-206

Kroon LPNM, Bakker FT, Van Den Bosch GBM, Bonants PJM, Flier WG (2004) Phylogenetic analysis of Phytophthora species based on mitochondrial and nuclear DNA sequences. Fungal Genet Biol 41(8):766-782

Kubiak K, Żółciak A, Damszel M, Lech P, Sierota Z (2017) Armillaria pathogenesis under climate changes. Forests 8:100
Kües U, Nelson DR, Liu C, Yu GJ, Zhang J, Li J, Wang XC, Sun H (2015) Genome analysis of medicinal Ganoderma spp. with plant-pathogenic and saprotrophic life-styles. Phytochemistry 114:18-37

Kuske CR, Benson DM (1983) Survival and splash dispersal of Phytophthora parasitica, causing dieback of Rhododendron. Phytopathology 73:1188-1191

Kwon JH, Hong SB (2005) Soft rot of tomato caused by Mucor racemosus in Korea. Mycobiology 33:240-242

Kwon J, Ryu J, Chi T, Shen S, Choi O (2012) Soft Rot of Rhizopus oryzae as a postharvest pathogen of banana fruit in Korea. Mycobiology 40:214-216

La Porta N, Capretti P, Thomsen IM, Kasanen R, Hietala AM, Von Weissenberg K (2008) Forest pathogens with higher damage potential due to climate change in Europe. Can J Plant Pathol 30:177-195

Lan Z, Scherm H (2003) Moisture sources in relation to conidial dissemination and infection by Cladosporium carpophilum within peach canopies. Phytopathology 93:1581-1586

Larone DH (1995) Medically important fungi-a guide to identification, 3rd edn. ASM Press, Washington

Larsen MJ, Cobb-Poulle LA (1990) The genus Phellinus (Hymenochaetaceae): a survey of the world taxa. Fungi flora, Oslo, p 206

Larsson KH, Parmasto E, Fischer M, Langer E, Nakasone KK, Redhead SA (2006) Hymenochaetales: a molecular phylogeny for the hymenochaetoid clade. Mycologia 98:926-936

Leach A, Hay F, Harding R, Damann KC, Nault B (2020) Relationship between onion thrips (Thrips tabaci) and Stemphylium vesicarium in the development of Stemphylium leaf blight in onion. Ann Appl Biol 176:55-64

Lebreton A, Meslet-Cladière L, Morin-Sardin S, Coton E, Jany JL, Barbier G, Corre E (2019) Comparative analysis of five Mucor species transcriptomes. Genomics 111:1306-1314

Lelwala RV, Korhonen PK, Young ND, Scott JB, Ades PK, Gasser RB, Taylor PW (2019) Comparative genome analysis indicates rapid evolution of pathogenicity genes in Colletotrichum tanaceti. Bio Rxiv 536516.

Lévesque CA, de Cock AWAM (2004) Molecular phylogeny and taxonomy of the genus Pythium. Mycol Res 108:1363-1383

Li W, Zhang T, Tang X, Wang B (2010) Oomycetes and fungi: important parasites on marine algae. Acta Oceanol Sin 29:74-81

Li HJ, Han ML, Cui BK (2013) Two new Fomitopsis species from southern China based on morphological and molecular characters. Mycol Prog 12:709-718

Li J, Gaskins VL, Yan HJ, Luo YG, Jurick WM II (2014) First report of Mucor rot on stored 'Gala' apple fruit caused by Mucor piriformis in Pennsylvania. Plant Dis 98:1157-1157

Li GJ, Hyde KD, Zhao RL, Hongsanan S, Abdel-Aziz FA, AbdelWahab MA, Alvarado P, Alves-Silva G, Ammirati JF, Ariyawansa HA, Baghela A, Bahkali AH, Beug M, Bhat DJ, Bojantchev D, Boonpratuang T, Bulgakov TS, Camporesi E, Boro MC, Ceska O, Chakraborty D, Chen JJ, Chethana KWT, Chomnunti P, Consiglio G, Cui BK, Dai DQ, Dai YC, Daranagama DA, Das K, Dayarathne MC, De Crop E, De Oliveira RJV, de Souza CAF, de Souza JI, Dentinger BTM, Dissanayake AJ, Doilom M, Drechsler-Santos ER, Ghobad-Nejhad M, Gilmore SP, GóesNeto A, Gorczak M, Haitjema CH, Hapuarachchi KK, Hashimoto A, He MQ, Henske JK, Hirayama K, Iribarren MJ, Jayasiri SC, Jayawardena RS, Jeon SJ, Jerônimo GH, Jesus AL, Jones EBG, Kang JC, Karunarathna SC, Kirk PM, Konta S, Kuhnert E, Lagner E, Lee HS, Lee HB, Li WJ, Li XH, Liimatainen K, Lima DX, Lin CG, Liu JK, Liu XZ, Liu ZY, Luangsa-ard JJ, Lücking R, Lumbsch HT, Lumyong S, Leaño EM, Marano AV, Matsumura M, McKenzie EHC, Mongkolsamrit S, Mortimer PE, Nguyen TTT, Niskanen T, Norphanphoun C, O'Malley MA, Parnmen S, Pawlowska J, Perera RH, Phookamsak R, Phukhamsakda C, 
Pires-Zottarelli CLA, Raspé O, Reck MA, Rocha SCO, de Santiago ALCMA, Senanayake IC, Setti L, Shang QJ, Singh SK, Sir EB, Solomon KV, Song J, Sriktikulchai P, Stadler M, Suetrong S, Takahashi H, Takahashi T, Tanaka K, Tang LP, Thambugala KM, Thanakitpipattana D, Theodorou MK, Thongbai B, Thummarukcharoen T, Tian Q, Tibpromma S, Verbeken A, Vizzini A, Vlasák J, Voigt K, Wanasinghe DN, Wang Y, Weerakoon G, Wen HA, Wen TC, Wijayawardena NN, Wongkanoun S, Wrzosek M, Xiao YP, Xu JC, Yan JY, Yang J, Yang SD, Hu Y, Zhang JF, Zhao J, Zhou LW, Peršoh D, Phillips AJL, Maharachchikumbura SSN (2016) Fungal diversity notes 253-366: taxonomic and phylogenetic contributions to fungal taxa. Fungal Divers 78:1-237

Li LF, Liu HB, Zhang QW, Li ZP, Wong TL, Fung HY, Zhang JX, Bai SP, Lu AP, Han QB (2018) Comprehensive comparison of polysaccharides from Ganoderma lucidum and G. sinense: chemical, antitumor, immunomodulating and gut-microbiota modulatory properties. Sci Rep 8:1-12

Li ZT, Janisiewicz WJ, Liu Z, Callahan AM, Evans BE, Jurick WM, Dardick C (2019) Exposure in vitro to an environmentally isolated strain TC09 of Cladosporium sphaerospermum triggers plant growth promotion, early flowering, and fruit yield increase. Front plant Sci 9:1959

Liang X, Wang B, Dong Q, Li L, Rollins JA, Zhang R, Sun G (2018) Pathogenic adaptations of Colletotrichum fungi revealed by genome wide gene family evolutionary analyses. PLoS ONE 13:e0196303

Liberato JR (2007) Taxonomic notes on two powdery mildews: Phyllactinia chorisiae and Ovulariopsis wissadulae (Erysiphaceae: Phyllactinieae). Mycotaxon 101:29-34

Liberato JR, Barreto RW, Niinomi S, Takamatsu S (2006) Queirozia turbinata (Phyllactinieae, Erysiphaceae): a powdery mildew with a dematiaceous anamorph. Mycol Res 110:567-574

Lim YW, Kim JJ, Lu M, Breuil C (2005) Determining fungal diversity on Dendroctonus ponderosae and Ips pini affecting lodgepole pine using cultural and molecular methods. Fungal Divers 19:79-94

Limkaisang S, Cunnington JH, Wui LK, Salleh B, Sato Y, Divarangkoon R, Fangfuk W, To-anun C, Takamatsu S (2006) Molecular phylogenetic analyses reveal a close relationship between powdery mildew fungi on some tropical trees and Erysiphe alphitoides, an oak powdery mildew. Mycoscience 47:327-335

Lin B, Kelly H (2018) Frogeye leaf spot of soybean. The Plant Health Instructor.

Linnaeus C (1753) Species plantarum. Tomus I. Impensis Laurentii Salvii, Holmiae.

Linzer RE, Otrosina WJ, Gonthier P, Bruhn J, Laflamme G, Bussières G, Garbelotto M (2008) Inferences on the phylogeography of the fungal pathogen Heterobasidion annosum, including evidence of interspecific horizontal genetic transfer and of human-mediated, long range dispersal. Mol Phylogene Evol 46:844-862

Liu XY, Huang H, Zheng RY (2007) Molecular phylogenetic relationships within Rhizopus based on combined analyses of ITS rDNA and pyrG gene sequences. Sydowia 59:235-253

Liu JK, Phookamsak R, Doilom M, Wiki S, Mei LY, Ariyawansa HA, Boonmee S, Chomnunti P, Dai DQ, Bhat DJ, Romero AI, Xhuang WY, Monkai J, Jones EBG, Chukeatirote E, KoKo TW, Zhoa YC, Wang Y, Hyde KD (2012) Towards a natural classification of Botryosphaeriales. Fungal Divers 57:149-210

Liu F, Weir BS, Damm U, Crous PW, Wang Y, Liu B, Wang M, Zhang M, Cai L (2015) Unravelling Colletotrichum species associated with Camellia: employing ApMat and GS loci to resolve species in the C. gloeosporioides complex. Persoonia 35:63-86

Liu F, Wang M, Damm U, Crous PW, Cai L (2016) Species boundaries in plant pathogenic fungi: a Colletotrichum case study. BMC Evol Biol 16:81
Liu JJ, Shamoun SF, Leal I, Kowbel R, Sumampong G, Zamany A (2018a) Characterization of Heterobasidion occidentale transcriptomes reveals candidate genes and DNA polymorphisms for virulence variations. Microb Biotechnol 11:537-550

Liu M, Zhang W, Manawasighe IS, Zhou Y, Xing QK, Li XH, Yan JY, Wang S (2018b) First report of Nothophoma quercina causing trunk canker on crabapple (Malus micromalus) in China. Plant Dis 102:1462

Liu YL, Yin XG, Lu JN, Li Y, Zhou YH (2019) First report of castor leaf spot caused by Cladosporium tenuissimum in Zhanjiang, China. Plant Dis 103:375

Liyanage KK, Khan S, Brooks S, Mortimer PE, Karunarathna SC, Xu J, Hyde KD (2017) Taxonomic revision and phylogenetic analyses of rubber powdery mildew fungi. Microb Pathogen 105:185-195

Lockman IB, Kearns HS (2016) Forest root diseases across the United States. Gen. Tech. Rep. RMRS-GTR-342. US Department of Agriculture, Forest Service, Rocky Mountain Research Station, Ogden, vol 55, p 342.

Lombard FF, Larsen MJ (1985) Phellinus bicuspidatus (Hymenochaetales, Hymenochaetaceae), a new species associated with a white sap rot of oak in Louisiana. Mycologia 77:55-61

Lombard L, Shivas RG, To-Anun C, Crous PW (2012) Phylogeny and taxonomy of the genus Cylindrocladiella. Mycol Prog 11:835-868

Lombard L, van der Merwe NA, Groenewald JZ, Crous PW (2015) Generic concepts in Nectriaceae. Stud Mycol 80:189-245

Lombard L, Cheewangkoon R, Crous PW (2017) New Cylindrocladiella spp. from Thailand soils. Mycosphere 8:1088-1104

López SN, Sangorrín MP, Pildain MB (2016) Fruit rot of sweet cherries and raspberries caused by Penicillium crustosum and Mucor piriformis in South Patagonia, Argentina. Can J Plant Pathol 38:511-516

Luangharn T, Karunarathna SC, Mortimer PE, Hyde KD, Xu J (2019) Additions to the knowledge of Ganoderma in Thailand: Ganoderma casuarinicola, a new record; and Ganoderma thailandicum sp. nov. MycoKeys 59:47-65

Luna ML, Murace MA, Robledo GL, Saparrat MCN (2012) Characterization of Schinopsis haenkeana wood decayed by Phellinus chaquensis (Basidiomycota, Hymenochaetales). IAWA J 33:91-104

Ma R, Chen Q, Fan Y, Wang Q, Chen S, Liu X, Yao B (2017) Six new soil-inhabiting Cladosporium species from plateaus in China. Mycologia 109(2):244-260

Maharachchikumbura SSN, Hyde KD, Jones EBG, McKenzie EHC, Huang SK, Abdel-Wahab MA, Daranagama DA, Dayarathne M, D'souza MJ, Goonasekara ID, Hongsanan S, Jayawardena RS, Kirk PM, Konta S, Liu JK, Liu ZY, Norphanphoun C, Pang KL, Perera RH, Senanayake IC, Shang Q, Shenoy BD, Xiao YP, Bahkali AH, Kang JC, Somrothipol S, Suetrong S, Wen TC, Xu JC (2015) Towards a natural classification and backbone tree for Sordariomycetes. Fungal Divers 72:199-301

Maharachchikumbura SSN, Hyde KD, Jones EBG, McKenzie EHC, Bhat DJ, Dayarathne MC, Huang SK, Norphanphoun C, Senanayake IC, Perera RH, Shang QJ, Xiao YP, D’souza MJ, Hongsanan S, Jayawardena RS, Daranagama DA, Konta S, Goonasekara ID, Zhuang WY, Jeewon R, Phillips AJL, Abdel-Wahab MA, AlSadi AM, Bahkali AH, Boonmee S, Boonyuen N, Cheewangkoon R, Dissanayake AJ, Kang JC, Li QR, Liu JK, Liu XZ, Liu ZY, Luangsa-ard JJ, Pang KL, Phookamsak R, Promputtha I, Suetrong S, Stadler M, Wen TC, Wijayawardene NN (2016) Families of Sordariomycetes. Fungal Divers 79:1-317

Maijala P, Harrington TC, Raudaskoski M (2003) A peroxidasegene family and gene trees in Heterobasidion and related genera. Mycologia 95:209-221 
Manamgoda DS, Udayanga D, Cai L, Chukeatirote E, Hyde KD (2013) Endophytic Colletotrichum from tropical grasses with a new species $C$. endophytica. Fungal Divers 61:107-115

Maphosa L, Wingfield BD, Coetzee MPA, Mwenje E, Wingfield MJ (2006) Phylogenetic relationships among Armillaria species inferred from partial elongation factor 1-alpha DNA sequence data. Australas Plant Pathol 35:513-520

Marais PG (1980) Fungi associated with decline and death of nursery grapevines in the Western Cape. Phytophylactica 12:9-14

Marasinghe DS, Boonme S, Hyde KD, Hongsanan S (2020) Morphomolecular analysis reveals Appendiculella viticis sp. nov. (Appendiculella, Meliolaceae). Phytotaxa (in press).

Marin-Felix Y, Groenewald JZ, Cai L, Chen Q, Marincowitz S, Barnes I, Bensch K, Braun U, Camporesi E, Damm U, De Beer ZW (2017) Genera of phytopathogenic fungi: GOPHY 1. Stud Mycol 86:99-216

Marin-Felix Y, Hernández-Restrepo M, Wingfield MJ, Akulov A, Carnegie AJ, Cheewangkoon R, Gramaje D, Groenewald JZ, Guarnaccia V, Halleen F, Lombard L, Luangsa-ard J, Marincowitz S, Moslemi A, Mostert L, Quaedvlieg W, Schumacher RK, Spies CFJ, Thangavel R, Taylor PWJ, Wilson AM, Wingfield BD, Wood AR, Crous PW (2019) Genera of phytopathogenic fungi: GOPHY 2. Stud Mycol 92:47-133

Markell SG, Harveson RM, Block CC, Gulya TJ (2015) Sunflower Diseases. Sunflower 93-128.

Markovic M, Rajkovic S, Miric M, Mitic D, Milovanovic J, TabakovicTosic M (2011) Colonization of the substrate of wood-decaying fungi Fomitopsis pinicola (Sw.:Fr.) P. Karst. isolated from beech and fir under controlled temperature and $\mathrm{pH}$ conditions. Fresenius Environ Bull 20:583-589

Martin FN, Loper JE (1999) Soilborne plant diseases caused by Pythium spp.: ecology, epidemiology, and prospects for biological control. CRC Crit Rev Plant Sci 18:111-181

Martin FN, Abad G, Balci Y, Ivors K (2012) Identification and detection of Phytophthora: reviewing our progress, identifying our needs. Plant Dis 96:1080-1103

Martin FN, Blair JE, Coffey MD (2014) A combined mitochondrial and nuclear multilocus phylogeny of the genus Phytophthora. Fungal Genet Biol 66:19-32

Matsuda S, Takamatsu S (2003) Evolution of host-parasite relationship of Golovinomyces (Ascomycota: Erysiphaceae) inferred from nuclear rDNA sequences. Mol Phylogen Evol 27:314-327

Mazzola M, Andrews PK, Reganold JP, Lévesque CA (2002) Frequency, virulence, and metalaxyl sensitivity of Pythium spp. isolated from apple roots under conventional and organic production systems. Plant Dis 86:669-675

McCormack JE, Huang H, Knowles LL (2009) Maximum likelihood estimates of species trees: how accuracy of phylogenetic inference depends upon the divergence history and sampling design. Syst Biol 58:501-508

McKernan KJ, Helbert Y, Kane LT, Ebling H, Zhang L, Liu B, Eaton Z, McLaughlin S, Kingan S, Baybayan P, Concepcion G (2020) Sequence and annotation of 42 cannabis genomes reveals extensive copy number variation in cannabinoid synthesis and pathogen resistance genes. BioRxiv. https://doi. org/10.1101/2020.01.03.894428

Meeboon J, Takamatsu S (2013a) Erysiphe havrylenkoana and E. prunastri var. japonica: a new species and a new variety of Erysiphe sect. Uncinula (Erysiphaceae, Ascomycota). Mycol Prog $12: 277-282$

Meeboon J, Takamatsu S (2013b) Erysiphe paracarpinicola: a new species of Erysiphe sect. Uncinula on Carpinus cordata (Betulaceae). Mycoscience 54(3):210-216

Meeboon J, Hidayat I, Takamatsu S (2013) Setoidium castanopsidis, a new species of anamorphic Cystotheca (Ascomycota, Erysiphales) from Indonesia. Mycoscience 54:274-278
Meng Y, Ren Y, Wang W, Gleason ML, Sun G, Zhang R (2020) A genome sequence resource for the geographically widespread anthracnose pathogen Colletotrichum asianum. Plant Dis (in press).

Merezhko TA (1991) Loculoacomycetes and celomycetes species new and rare for the Ukr. SSR mycobiota. Ukrayins'k Bot Zhurn 48:65-67

Mian MAR, Missaoui AM, Walker DR, Phillips DV, Boerma HR (2008) Frogeye leaf spot of soybean: a review and proposed race designations for isolates of Cercospora sojina Hara. Crop Sci 48:14-24

Mibey RK, Hawksworth DL (1997) Meliolaceae and Asterinaceae of the Shimba Hills. Kenya Mycol Pap 174:1-108

Michailides TJ, Spotts RA (1990) Postharvest diseases of pome and stone fruits caused by Mucor piriformis in the Pacific Northwest and California. Plant Dis 74(8):537-543

Miller OK Jr, Johnson JL, Burdsall HH, Flynn T (1994) Species delimitation in North American species of Armillaria as measured by DNA reassociation. Mycol Res 98:1005-1011

Miller MA, Pfeiffer W, Schwartz T (2010) Creating the CIPRES Science Gateway for inference of large phylogenetic trees. Proceedings of the Gateway Computing Environments Workshop (GCE). San Diego Supercomput. Center, New Orleans, pp 1-8.

Misra AK (2001) Powdery mildew-a serious disease of mango. J Appl Hort 3:63-68

Moncalvo JM, Ryvarden L (1997) A nomenclature study of the Ganodermataceae Donk. Synops Fungorum 11:1-114

Moncalvo JM, Wang HF, Hseu RS (1995) Gene phylogeny of the Ganoderma lucidum complexbased on ribosomal DNA sequences. Comparison with traditional taxonomic characters. Mycoll Res 99:1489-1499

Monkai JM, Hyde KD, Xu JC, Mortimer PE (2017) Diversity and ecology of soil fungal communities in rubber plantation. Fungal Biol Rev 31:1-11

Moorman GW, Kang S, Geiser DM, Kim SH (2002) Identification and characterization of Pythium species associated with greenhouse floral crops in Pennsylvania. Plant Dis 86:1227-1231

Moral J, Agusti-Brisach C, Perez-Rodriguez M, Xavier C, Raya MC, Rhouma A, Trapero A (2017) Identification of fungal species associated with branch dieback of olive and resistance of table cultivars to Neofusicoccum mediterraneum and Botryosphaeria dothidea. Plant Dis 101:306-316

Moral J, Lichtemberg PSF, Papagelis A, Sherman J, Michailides TJ (2018) Didymella glomerata causing leaf blight on pistachio. Eur J Plant Pathol 151:1095-1099

Morgan-Jones G (1971) Sciniatosporium Kalchbr., and its synonyms Marcosia Syd., Stigmina Sacc, Thyrostroma Höhnel, and Thyrostromella Syd., non Höhnel. Can J Bot 49(6):993-1009

Mori Y, Sato Y, Takamatsu S (2000) Evolutionary analysis of the powdery mildew fungi using nucleotide sequences of the nuclear ribosomal DNA. Mycologia 92(1):74-93

Morin-Sardin S, Nodet P, Coton E, Jany JL (2017) Mucor: a Janusfaced fungal genus with human health impact and industrial applications. Fungal Biol Rev 31:12-32

Moslemi A, Ades PK, Groom T, Nicolas ME, Taylor PW (2017) Alternaria infectoria and Stemphylium herbarum, two new pathogens of pyrethrum (Tanacetum cinerariifolium) in Australia. Austral Plant Pathol 46(1):91-101

Mounce I (1929) Studies in forest pathology. II. The biologyof Fomes pinicola (Fr.) Cooke. Bull Dep Agric Dom Can 111:1-56

Mueller GM, Schmit JP, Leacock PR, Buyck B, Cifuentes J, Desjardin DE, Halling RE, Hjorstam K, Iturriaga T, Larsson KH, Lodge DJ, May TW, Minter D, Rajchenberg M, Redhead SA, Ryvarden L, Trappe JM, Watling R, Wu QX (2007) Global diversity and distribution of macro fungi. Biodivers Conserv 16:37-48 
Mulenko W, Majewski T, Ruszkiewicz-Michalska M (2008) A preliminary checklist of Micromycetes in Poland. W Szafer Inst Bot Pol Acad Sci 9:752

Murray TD, Parry DW, Cattlin ND (2013) Diseases of small grain cereal crops: a colour handbook. CRC Press, Boca Raton

Murrill WA (1902) The Polyporaceae of North America. I. The genus Ganoderma. J Torrey Bot Soc 29:599-608

Murrill WA (1903) A historical review of the genera of the Polyporaceae. J Mycol 9:87-102

Muthelo V (2009) Molecular characterization of Ganoderma species. M. Sc, Thesis. Faculty of Natural and Agricultural Science, Department of Microbiology. University of Pretoria, South Africa, $\mathrm{p} 121$

Mwenje E, Wingfield BD, Coetzee MPA, Nemato H, Wingfield MJ (2006) Armillaria species on tea in Kenya identified using isozyme and DNA sequence comparisons. Plant Pathol 55:343-350

Natarajan SV, Rekha NS, Sharda RD, Mahalingam N (2013) Colletotrichum keratitis: a rare but definite clinical entity. J Clin Diagn Res 7(7):1430

Nayak AK, Bandamaravuri KB (2019) Detection of Golovinomyces orontii using species-specific primers and high-resolution melting analysis. Trop Plant Pathol 44:343-351

Nelson S (2009). Rhizopus soft rot of sweet potato. Department of Plant and Environmental Protection Sciences College of Tropical Agriculture and Human Resources, University of Hawaiii at Manoa (Cooperative Extension Servive). http://www.ctahr.hawai i.edu/freepubs. Accessed 24 Oct 2019.

Nguyen TT, Lee HB (2018) Isolation and characterization of three zygomycetous fungi in Korea: Backusella circina, Circinella muscae, and Mucor ramosissimus. Mycobiology 46:317-327

Nguyen TT, Duong T, Lee H (2016) Characterization of two new records of Mucoralean species isolated from gut of soldier fly larva in Korea. Mycobiology 44:310-313

Nguyen TT, Jung HY, Lee YS, Voigt K, Lee HB (2017) Phylogenetic status of two undescribed zygomycete species from Korea: Actinomucor elegans and Mucor minutus. Mycobiology 45:344-352

Niemalä T, Wagner T, Fischer M, Dai YC (2001) Phellopilus gen. nov. and its affinities within Phellinus s. lato and Inonotus s. lato (Basidiomycetes). Ann Bot Fenn 38:51-62

Niemelä T (1972) On Fennoscandian polypores. II. Phellinus laevigatus (Fr.) Bourd. \& Galz. and P. lundellii Niemelä, n.sp. Ann Bot Fenn 9:41-59

Niemelä T (1974) On Fennoscandian polypores. III. Phellinus tremulae (Bond.) Bond. \& Borisov. Ann Bot Fenn 11:202-215

Niemelä T (1977) On Fennoscandian polypores. 5. Phellinus pomaceus. Karstenia 17:77-86

Niemelä T, Korhonen K (1998) Taxonomy of the genus Heterobasidion. In: Woodward S, Stenlid J, Karjalainen R, Hüttermann A (eds) Heterobasidion annosum: biology, ecology, impact and control. CAB International, Wallingford, pp 27-41

Nilsson RH, Hyde KD, Pawłowska J, Ryberg M, Tedersoo L, Aas AB, Alias SA, Alves A, Anderson CL, Antonelli A, Arnold AE, Bahnmann B, Bahram M, Bengtsson-Palme J, Berlin A, Branco S, Chomnunti P, Dissanayake A, Drenkhan R, Friberg H, Frøslev TG, Halwachs B, HartmannM, Henricot B, Jayawardena R, Jumpponen A, Kauserud H, Koskela S, Kulik T, Liimatainen K, Lindahl BD, Lindner D, Liu J-K, Maharachchikumbura S, Manamgoda D, Martinsson S, Neves MA, Niskanen T, Nylinder S, Pereira OL, Pinho DB, Porter TM, Queloz V, Riit T, SánchezGarcía M, Sousa FD, Stefańczyk E, Tadych M, Takamatsu S, Tian Q, Udayanga D, Unterseher M, Wang Z, Wikee S, Yan J, Larsson E, Larsson K-H, Kõljalg U, Abarenkov K (2014) Improving ITS sequence data for identification of plant pathogenic fungi. Fungal Divers 67:11-19
Nirwan B, Choudhary S, Sharma K, Singh S (2016) In vitro studies on management of root rot disease caused by Ganoderma lucidum in Prosopis cineraria. Curr Life Sci 2:118-126

Núñez M, Ryvarden L (2000) East Asian polypores 1. Ganodermataceae and Hymenochaetaceae. Syn Fung 13:1-168

Núñez M, Ryvarden L (2001) East Asian polypores 2. Syn Fung 14:165-522

Nylander JAA (2004) MrModeltest 2.0. Program distributed by the author. Evolutionary Biology Centre. Uppsala University, Uppsala

Oberti R, Marchi M, Tirelli P, Calcante A, Iriti M, Borghese AN (2014) Automatic detection of powdery mildew on grapevine leaves by image analysis: optimal view-angle range to increase the sensitivity. Comput Electron Agric 104:1-8

O'Connell RJ, Thon MR, Hacquard S, Amyotte SG, Kleemann J, Torres MF, Damm U, Buiate EA, Epstein L, Alkan N, Altmüller J, Alvarado-Balderrama L, Bauser CA, Becker C, Birren BW, Chen Z, Choi J, Crouch JA, Duvick JP, Farman MA, Gan P, Heiman D, Henrissat B, Howard RJ, Kabbage M, Koch C, Kracher B, Kubo Y, Law AD, Lebrun MH, Lee YH, Miyara I, Moore N, Neumann U, Nordström K, Panaccione DG, Panstruga R, Place M, Proctor RH, Prusky D, Rech G, Reinhardt R, Rollins JA, Rounsley S, Schardl CL, Schwartz DC, Shenoy N, Shirasu K, Sikhakolli UR, Stüber K, Sukno SA, Sweigard JA, Takano Y, Takahara H, Trail F, van der Does HC, Voll LM, Will I, Young S, Zeng Q, Zhang J, Zhou S, Dickman MB, Schulze-Lefert P, Loren Ver, van Themaat E, Ma LJ, Vaillancourt LJ (2012) Life-style transitions in plant pathogenic Colletotrichum fungi deciphered by genome and transcriptome analyses. Nat Genet 44:1060-1065

Ogundero V (1988) Pectin esterase production by Rhizopus stolonifer from postharvest soft rots of potato tubers in Nigeria and its activity. Nahrung 32:59-65

Old KM, Wingfield MJ, Yuan ZQ (2003) A manual of diseases of eucalypts in South-East Asia. Centre for International Forestry Research, Jakarta, p 106

Oliva J, Samils N, Johansson U, Bendz-Hellgren M, Stenlid J (2008) Urea treatment reduced Heterobasidion annosums. 1. root rot in Piceaabies after 15 years. For Ecol Manag 255:2876-2882

Oliva R, Win J, Raffaele S, Boutemy L, Bozkurt TO, Chaparro-Garcia A, Segretin ME, Stam R, Schornack S, Cano LM, van Damme M, Huitema E, Thines M, Banfield MJ, Kamoun S (2010) Recent developments in effector biology of filamentous plant pathogens. Cell Microbiol 12:705-715

Omdal DW, Shaw CG, Jacobi WR (2004) Symptom expression in conifers infected with Armillaria ostoyae and Heterobasidion annosum. Can J For Res 34(6):1210-1219

Ortiz-Santana B, Lindner DL, Miettinen O, Justo A, Hibbett DS (2013) A phylogenetic overview of the Antrodia clade (Basidiomycota, Polyporales). Mycologia 105:1391-1411

Ota Y, Tokuda S, Buchanan PK, Hattori T (2006) Phylogenetic relationships of Japanese species of Heterobasidion-H. annosumsensulato and an undetermined Heterobasidion sp. Mycologia 98:717-725

Otrosina WJ, Garbelotto M (2010) Heterobasidion occidentale sp. nov. and Heterobasidion irregulare nom. nov.: a disposition of North American Heterobasidion biological species. Fungal Biol 114:16-25

Otrosina WJ, Chase TE, Cobb FW, Korhonen K (1993) Population structure of Heterobasidion annosum from North America and Europe. Can J Bot 71:1064-1071

Palanna KB, Shreenivasa KR, Basavaraj S, Narendrappa T (2020) Review of genus Ganoderma causing basal stem rot (coconut) and foot rot (arecanut) with respect etiology and management. Int J Curr Microbiol Appl Sci 9(4):1434-1455

Pan F, El-Kashef DH, Kalscheuer R, Müller WE, Lee J, Feldbrügge M, Mándi A, Kurtán T, Liu Z, Wu W, Proksch P (2020) Cladosins 
LO, new hybrid polyketides from the endophytic fungus $\mathrm{Cla}$ dosporium sphaerospermum WBS017. Eur J Medici Chem 191:112-159

Pande S, Sharma M, Mangla UN, Ghosh R, Sundaresan G (2011) Phytophthora blight of Pigeonpea [Cajanus cajan (L.) Millsp.]: an updating review of biology, pathogenicity and disease management. Crop Prot 30:951-957

Park DS, Sung JM, Kim YS, Yoo YB, Ryu YJ, Cha DY (1994) Analysis of interspecific Allozyme varition within genus Ganoderma by polyacrylamide Gel isoeletric focusing RDA. J Agric 36:212-221

Park YJ, Kwon OC, Son ES, Yoon DE, Han W, Nam JY, Yoo YB, Lee CS (2012) Genetic diversity analysis of Ganoderma species and development of a specific marker for identification of medicinal mushroom Ganoderma lucidum. Afr J Microbiol Res 6:5417-5425

Park SH, Choi IY, Lee WH, Lee KJ, Galea V, Shin HD (2017) Identification and characterization of Cercospora malayensis causing leaf spot on Kenaf. Mycobiology 45:114-118

Paterson RRM (2007) Ganoderma disease of oil palm-a white rot perspective necessary for integrated control. Crop Prot 26:1369-1376

Patouillard NT (1898) Champignons nouveaux ou peu connus. Bull Soc Mycol France 14:149-156

Pegler DN (2000) Taxonomy, nomenclature and description of Armillaria. In: Fox RTV (ed) Armillaria root rot: biology and control of honey fungus. Intercept Press, Andover, pp 81-93

Pennycook SR (1989) Plant diseases recorded in New Zealand. Volumes 1, 2 and 3. Plant Diseases Division, DSIR.

Pérez-Sierra A, Guillaumin JJ, Spooner BM, Bridge PD (2004) Characterization of Armillaria heimii from Africa. Plant Pathol 53:220-230

Pérez-Sierra A, Whitehead D, Whitehead M (2000) Molecular methods used for the detection and identification of Armillaria. Armillaria Root Rot: Biology and control of honey fungus. andover, Intercept, pp 95-108.

Persson Y, Ihrmark K, Stenlid J (2011) Do bark beetles facilitate the establishment of rot fungi in Norway spruce? Fungal Ecol 4:262-269

Petrak F, Deighton FC (1952) Beiträge zur Pilzeflora von Sierra Leone. Sydowia 6:309-322

Pettey TM, Shaw CG (1986) Isolation of Fomitopsis pinicola from in-flight bark beetles (Coleoptera: Scolytidae). Can J Bot 64:1507-1509

Pham NQ (2018) New Calonectria and Cylindrocladiella species from Vietnam, Malaysia and Indonesia. MSc Thesis. University of Pretoria, South Africa.

Phengsintham P, Braun U, McKenzie EHC, Chukeatirote E, Cai L, Hyde KD (2013a) Monograph of cercosporoid fungi from Thailand. Plant Pathol Quaran 3:67-138

Phengsintham P, Chukeatirote E, McKenzie EHC, Hyde KD, Braun U (2013b) Monograph of cercosporoid fungi from Laos. Curr Res Environ Appl Mycol 3:34-158

Phillips AJL, Alves A, Pennycook SR, Johnston PR, Ramaley A, Akulov A, Crous PW (2008) Resolving the phylogenetic and taxonomic status of dark-spored teleomorph genera in the Botryosphaeriaceae. Persoonia 21:29-55

Phillips AJL, Alves A, Abdollahzadeh J, Slippers B, Wingfield MJ, Groenewald JZ, Crous PW (2013) The Botryosphaeriaceae: genera and species known from culture. Stud Mycol 76:51-167

Phookamsak R, Hyde KD, Jeewon R, Bhat DJ, Jones EBG, Maharachchikumbura SSN, Raspé O, Karunarathna SC, Wanasinghe DN, Hongsanan S, Doilom M, Tennakoon DS, Machado AR, Firmino AL, Ghosh A, Karunarathna A, Mešić A, Dutta AK, Thongbai B, Devadatha B, Norphanphoun C, Senwanna C, Wei D, Pem D, Ackah FK, Wang GN, Jiang HB, Madrid H, Lee HB, Goonasekara ID, Manawasinghe IS, Kušan Cano J, Gené J, Li J,
Das K, Acharya K, Raj KNA, Latha KPD, Chethana KWT, He MQ, Dueñas M, Jadan M, Martín MP, Samarakoon MC, Dayarathne MC, Raza M, Park MS, Telleria MT, Chaiwan N, Matočec N, de Silva NI, Pereira OL, Singh PN, Manimohan P, Uniyal P, Shang QJ, Bhatt RP, Perera RH, Alvarenga RLM, Nogal-Prata S, Singh SK, Vadthanarat S, Oh SY, Huang SK, Rana S, Konta S, Paloi S, Jayasiri SC, Jeon SJ, Mehmood T, Gibertoni TB, Nguyen TTT, Singh U, Thiyagaraja V, Sarma VV, Dong W, Yu XD, Lu YZ, Lim YW, Chen Y, Tkalčec Z, Zhang ZF, Luo ZL, Daranagama DA, Thambugala KM, Tibpromma S, Camporesi E, Bulgakov T, Dissanayake AJ, Senanayake IC, Dai DQ, Tang LZ, Khan S, Zhang H, Promputtha I, Cai L, Chomnunti P, Zhao RL, Lumyong S, Boonmee S, Wen TC, Mortimer PE, Xu J (2019) Fungal diversity notes 929-1036: taxonomic and phylogenetic contributions on genera and species of fungal taxa. Fungal Divers 95:1-273

Photita W, Taylor PW, Ford R, Hyde KD, Lumyong S (2005) Morphological and molecular characterization of Colletotrichum species from herbaceous plants in Thailand. Fungal Divers 18:117-133

Pildain MB, Coetzee MPA, Rajchenberg M, Petersen RH, Wingfield MJ, Wingfield BD (2009) Molecular phylogeny of Armillaria from the Patagonian Andes. Mycol Prog 8:181

Pilotti CA, Sanderson FR, Aitken AB, Armstrong W (2004) Morphological variation and host range of two Ganoderma species from Papua New Guinea. Mycopathologia 158:251-265

Pinho DB, Firmino AL, Ferreira-junior WG, Pereira OL (2012) An efficient protocol for DNA extraction from Meliolales and the description of Meliola centellae sp. nov. Mycotaxon 122:333-345

Pinho DB, Junior JH, Firmino AL, Junior BTH, Mizubuti ESG, Pereira OL (2014) Reappraisal of the black mildews (Meliolales) on Hevea brasiliensis. Trop Plant Pathol 39:89-94

Pinruan U, Rungjindamai N, Choeyklin R, Lumyong S, Hyde KD, Jones EBG (2010) Occurrence and diversity of basidiomycetous endophytes from the oil palm, Elaeis guineensis in Thailand. Fungal Divers 41:71-88

Pirondi A, Kitner M, Iotti M, Sedláková B, Lebeda A, Collina M (2015a) Genetic structure and phylogeny of Italian and Czech populations of the cucurbit powdery mildew fungus Golovinomyces orontii inferred by multilocus sequence typing. Plant Pathol 65:959-967

Pirondi A, Vela-Corcía D, Dondini L, Brunelli A, Pérez-Garcia A, Collina M (2015b) Genetic diversity analysis of the cucurbit powdery mildew fungus Podosphaera xanthii suggests a clonal population structure. Fungal Biol 119:791-801

Pollack FG (1987) An annotated compilation of Cercospora names. In: Cramer J (ed) Germany, Berlin.

Postma J, Willemsen-de Klein MJ, van Elsas JD (2000) Effect of the indigenous microflora on the development of root and crown rot caused by Pythium aphanidermatum in cucumber grown on rockwool. Phytopathology 90:125-133

Pringsheim N (1858) Beitrage zur morphology and systematik der Algen. 2. Die Saprolegnieen. Jb. w1'ss. Bot 1:284-306

Qiao Y, Yang Y, Dong X, Qiu M (2005) 13C NMR in the application of new Ganoderma triterpenoids. J Spectroscopy 22:437-456

Qiu PL, Liu SY, Bradshaw M, Rooney-Latham S, Takamatsu S, Bulgakov TS, Tang SR, Feng J, Jin DN, Aroge T, Li Y, Wang LL, Braun U (2020a) Multi-locus phylogeny and taxonomy of an unresolved, heterogeneous species complex within the genus Golovinomyces (Ascomycota, Erysiphales), including G. ambrosiae, G. circumfusus and G. spadiceus. BMC Microbiol 20:1-16

Qiu PL, Qi XF, Li Y, Braun U, Liu SY (2020b) Epitypification and molecular confirmation of Erysiphe cucurbitacearum as a synonym of Golovinomyces tabaci. Mycoscience 61:30-36 
Quaedvlieg W, Verkley GJM, Shin HD, Barreto RW, Alfenas AC, Swart WJ, Groenewald JZ, Crous PW (2013) Sizing up Septoria. Stud Mycol 75:307-390

Quaedvlieg W, Binder M, Groenewald JZ, Summerell BA, Carnegie AJ, Burgess TI, Crous PW (2014) Introducing the consolidated species concept to resolve species in the Teratosphaeriaceae. Persoonia 33:1

Quélet L (1886) Enchiridion fungorum in Europa media et praesertim in Gallia vigentium /scripsit L. Quelet. Lutetiae: O. Doin, p 352.

Rahman MZ, Abdelzaher HM, Mingzhu L, Motohashi K, Suga H, Kageyama K (2015) Pythium rishiriense sp. nov. from water and $P$. alternatum sp. nov. from soil, two new species from Japan. FEMS Microbiol Lett 362:086

Rajchenberg M, Pildain MB, Bianchinotti MV, Barroetavena C (2015) The phylogenetic position of poroid Hymenochaetaceae (Hymenochaetales, Basidiomycota) from Patagonia, Argentina. Mycologia 107(4):754-767

Ramaley AW (2005) The connection of Dothidotthia aspera (Botryosphaeriaceae) to a hyphomycetous anamorphic fungus, Thyrostroma negundinis. Mycotaxon 94:127-132

Ramos AR, dos Santos RL, Amaro ACE, Fumes LAA, Boaro CSF, Cardoso AII (2013) Efficiency of potassium silicate in powdery mildew control and development of summer squash. Hortic Bras $31: 432-438$

Ramzi AB, Me MLC, Ruslan US, Baharum SN, Muhammad NAN (2019) Insight into plant cell wall degradation and pathogenesis of Ganoderma boninense via comparative genome analysis. PeerJ 7:e8065

Razafinarivo J, Jany JL, Crous PW, Looten R, Gaydou V, Barbier G, Mounier J, Vasseur V (2016) Cladosporium lebrasiae, a new fungal species isolated from milk bread rolls in France. Fungal Biol 120:1017-1029

Rea AJ, Jung T, Burgess TI, Stukely MJC, Hardy GESJ (2010) Phytophthora elongata sp. nov., a novel pathogen from the Eucalyptus marginata forest of Western Australia. Australasian Plant Pathol 39:477-491

Reeser PW, Hansen EM, Sutton W (2007) Phytophthora siskiyouensis, a new species from soil, water, myrtle wood (Umbellularia californica) and tanoak (Lithocarpus densiflorus) in southwestern Oregon. Mycologia 99:639-643

Reeser PW, Sutton W, Hansen E (2013) Phytophthora pluvialis, a new species from mixed tanoak douglas-fir forests of western Oregon, U.S.A. N Am Fungi 8:1-8

Rezende JS, Zivanovic M, de Novaes MI, Chen ZY (2020) The AVR4 effector is involved in cercosporin biosynthesis and likely affects the virulence of Cercospora $\mathrm{cf}$. flagellaris on soybean. Mol Plant Pathol 21:53

Richter C, Wittstein K, Kirk MP, Stadler M (2015) An assessment of the taxonomy and chemotaxonomy of Ganoderma. Fungal Divers 71 .

Rishbeth J (1950) Observations on the biology of Fomesannosus, with particular reference to East Anglian pine plantations-I. The outbreaks of disease and ecological status of the fungus. Ann Bot $14: 365-383$

Rishbeth J (1951a) Observations on the biology of Fomesannosus, with particular reference to East Anglian pine plantations-II. Spore production, stump infection, and saprophytic activity in stumps. Ann Bot 15:1-21

Rishbeth J (1951b) Observations on the biology of Fomesannosus, with particular reference to East Anglian pine plantations - III. Natural and experimental infection of pines and some factors affecting severity of the disease. Ann Bot 15:221-246

Rizzo DM, Garbelotto M, Davidson JM, Slaughter GW, Koike ST (2002) Phytophthora ramorum as the cause of extensive mortality of Quercus spp. and Lithocarpus densiflorus in California. Plant Dis 86:205-214
Rizzo DM, Garbelotto M, Hansen EA (2005) Phytophthora ramorum: integrative research and management of an emerging pathogen in California and Oregon forests. Ann Rev Phytopathol 43:309-335

Roane CW, Roane MK (1996) Graminicolous fungi of Virginia: fungi associated with genera Aegilops to Digitaria. Vac J Sci 47:197-224

Robledo G, Urcelay C, Rajchenberg M (2003) New species causing decay on living Polylepis australis in Córdoba, central Argentina. Mycologia 95(2):347-353

Romero D, Rivera ME, Cazorla FM, De Vicente A, Perez-Garcia A (2003) Effect of mycoparasitic fungi on the development of Sphaerotheca fusca in melon leaves. Mycol Res 107:64-71

Ronquist F, Huelsenbeck JP (2003) MrBayes 3: Bayesian phylogenetic inference under mixed models. Bioinformatics 19:1572-1574

Rosado AW, Custodio FA, Pinho DB, Ferreira APS, Pereira OL (2019) Cladosporium species associated with disease symptoms on Passiflora edulis and other crops in Brazil, with descriptions of two new species. Phytotaxa 409:239-260

Ross-Davis AL, Hanna JW, Klopfenstein NB, Kim MS (2012) Advances toward DNA-based identification and phylogeny of North American Armillaria species using elongation factor-1 alpha gene. Mycoscience 53:161-165

Rossman AY, Seifert KA, Samuels GJ, Minnis AM, Schroers HJ, Lombard L, Crous PW, Põldmaa K, Cannon PF, Summerbell RC, Geiser DM, Zhuang W, Hirooka Y, Herrera C, Salgado-Salazar C, Priscila Chaverri P (2013) Genera in Bionectriaceae, Hypocreaceae, and Nectriaceae (Hypocreales) proposed for acceptance or rejection. IMA Fungus 4:41-51

Rossman AY, Crous PW, Hyde KD, Hawksworth DL, Aptroot A, Bezerra JL, Bhat JD, Boehm E, Braun U, Boonmee S, Camporesi E, Chomnunti P, Dai DQ, D'souza MJ, Dissanayake A, Jones EBG, Groenewald JZ, Hernández-Restrepo M, Hongsanan S, Jaklitsch WM, Jayawardena R, Li WJ, Kirk PM, Lawrey JD, Mapook A, McKenzie EHC, Monkai J, Phillips AJL, Phookamsak R, Raja HA, Seifert KA, Senanayake IC, Slippers B, Suetrong S, Taylor JE, Thambugala KM, Tian Q, Tibpromma S, Wanasinghe DN, Wijayawardene NN, Wikee S, Woudenberg JHC, Wu HX, Yan J, Yang T, Zhang Y (2015) Recommended names for pleomorphic genera in Dothideomycetes. IMA Fungus 6:507-523

Rungjindamai N, Pinruan U, Choeyklin R, Hattori T, Jones EBG (2008) Molecular characterization of basidiomycetous endophytes isolated from leaves, rachis and petioles of the oil palm, Elaeis guineensis, in Thailand. Fungal Divers 33:139-161

Ryvarden L (1972) Studies in the Aphyllophorales of Canary Islands with a note on the genus Perenniporia. Norweg J Bot 19:139-144

Ryvarden L (1985) Type studies in the Polyporaceae 17 species described by W.A. Murrill. Mycotaxon 23:169-198

Ryvarden L (1989) Wrightoporia perplexa nov. sp. (Polyporaceae). Opera Bot 100:225-227

Ryvarden L (2004) Neotropical polypores part 1. Syn Fung 19:1-229

Ryvarden L, Gilbertson RL (1993) European polypores. Part 1. Syn Fung 6:348-350

Ryvarden L, Gilbertson RL (1994) European polypores. Part 2. Syn Fung 7:394-743

Ryvarden L, Johansen I (1980) A preliminary polypore flora of East Africa. Fungiflora, Oslo, p 636

Ryvarden L, Melo I (2014) Poroid fungi of Europe. Syn Fung 31:1-450

Ryvarden L, Stokland J (2008) Fomitopsis ochracea nova species. Syn Fung 25:44-46

Saccardo PA (1902) Sylloge Fungorum. vol 16. In: Saccardo PA (ed) Patavii, Italy, pp 1-1291.

Saenz GS, Taylor JW (1999) Phylogeny of the Erysiphales (powdery mildews) inferred from internal transcribed spacer ribosomal DNA sequences. Can J Bot 77:150-168 
Saenz GS, Taylor JW, Gargas A (1994) 18S rRNA gene sequences and supra ordinal classification of the Erysiphales. Mycologia $86: 212-216$

Saharan GS, Mehta NK, Meena PD (2019) Infection, pathogenesis, and disease cycle. Powdery mildew disease of crucifers: biology, ecology and disease management. Springer, Singapore, pp 95-130.

Saito S, Michailides TJ, Xiao CL (2016) Mucor Rot—an emerging postharvest disease of mandarin fruit caused by Mucor piriformis and other Mucor spp. in California. Plant Dis 100:1054-1063

Salmaninezhad F, Mostowfizadeh-Ghalamfarsa R (2019) Three new Pythium species from rice paddy fields. Mycologia 111:274-290

Salvador-Montoya CA, Costa-Rezende DH, Ferreira-Lopes V, BorbaSilva MA, Popoff OF (2018) Tropicoporus drechsleri (Hymenochaetales, Basidiomycota), a new species in the "Inonotuslinteus" complex from northern Argentina. Phytotaxa 338:75-89

Samarakoon MC, Persoh D, Hyde KD, Bulgakov TS, Manawasinghe IS, Jayawardena RS, Promputtha I (2018) Colletotrichum acidae sp. nov. from northern Thailand and a new record of $C$ dematium on Iris sp. Mycosphere 9(3):583-597

Sandoval-Denis M, Gené J, Sutton DA, Wiederhold NP, Cano-Lira JF, Guarro J (2016) New species of Cladosporium associated with human and animal infections. Persoonia 36:281-298

Sautua FJ, Gonzalez SA, Doyle VP, Berretta MF, Gordó M, Scandiani MM, Rivarola ML, Fernandez P, Carmona M (2019) Draft genome sequence data of Cercospora kikuchii, a causal agent of Cercospora leaf blight and purple seed stain of soybeans. Data Brief 27:104693

Sautua FJ, Searight J, Doyle VP, Scandiani MM, Carmona MA (2020) Cercospora cf. nicotianae is a causal agent of Cercospora leaf blight of soybean. Eur J Plant Pathol 156:1227-1231

Scanu B, Linaldeddu BT, Deidda A, Jung T (2015) Diversity of Phytophthora species from declining Mediterranean maquis vegetation, including two new species, Phytophthora crassamura and P. ornamentata sp. nov. PLoS ONE 10(12): 0143234

Scattolin L, Montecchio L (2007) First report of damping-off of common oak plantlets caused by Cylindrocladiella parva in Italy. Plant Dis 91:771-771

Schipper MAA (1973) A study on variability in Mucor hiemalis and related species Centraalbureau voor Schimmelcultures, Baarn.

Schipper MAA (1984) A revision of the genus Rhizopus. 1. The $R h$. Stolonifer group and Rh. oryzae. Stud Mycol 25:1-19

Schipper MAA, Stalpers JA (1984) A revision of the genus Rhizopus. Studies in Mycology Serie No. 25. Centraalbureau voor Schimmelcultures. Baarn, The Netherlands, pp 20-34.

Schoch CL, Crous PW, Wingfield MJ, Wingfield BD (2000) Phylogeny of Calonectria and selected hypocrealean genera with cylindrical macroconidia. Stud Mycol 45:45-62

Schoch CL, Shoemaker RA, Seifert KA, Hambleton S, Spatafora JW, Crous PW (2006) A multigene phylogeny ofthe Dothideomycetes using four nuclear loci. Mycologia 98(6):1041-1052

Schubert K (2005) Taxonomic revision of the genus Cladosporium s. lat. 3. A revision of Cladosporium species described by J.J. Davis and H.C. Greene (WIS). Mycotaxon 92:55-76

Schubert K, Braun U (2004) Taxonomic revision of the genus Cladosporium s. lat. 2. Morphotaxonomic examination of Cladosporium species occurring on hosts of the families Bignoniaceae and Orchidaceae. Sydowia 56:76-97

Schubert K, Braun U (2005a) Taxonomic revision of the genus Cladosporium s. lat. 1. Species reallocated to Fusicladium, Parastenella, Passalora, Pseudocercospora and Stenella. Mycol Progr 4:101-109

Schubert K, Braun U (2005b) Taxonomic revision of the genus Cladosporium s. lat. 4. Species reallocated to Asperisporium, Dischloridium, Fusicladium, Passalora, Pseudasperisporium and Stenella. Fungal Divers 20:187-208
Schubert K, Braun U (2007) Taxonomic revision of the genus Cladosporium s. lat. 6. New species, reallocations to and synonyms of Cercospora, Fusicladium, Passalora, Septonema and Stenella. Nova Hedwigia 84(1-2):189-208

Schubert K, Ritschel A, Braun U (2003) A monograph of Fusicladium s. lat. (hyphomycetes). Schlechtendalia 9:1-132

Schubert K, Braun U, Mulenko W (2006) Taxonomic revision of the genus Cladosporium s. lat. 5. Schlechtendalia 14:55-83

Schubert K, Groenewald JZ, Braun U, Dijksterhuis J, Starink M, Hill CF, Zalar P, de Hoog GS, de Crous PW (2007) Biodiversity in the Cladosporium herbarum complex (Davidiellaceae, Capnodiales), with standard isolation of methods for Cladosporium taxonomy and diagnostics. Stud Mycol 58:105-156

Scruggs AC, Quesada-Ocampo LM (2016) Cultural, chemical, and alternative control strategies for Rhizopus soft rot of sweet potato. Plant Dis 100:1532-1540

Sell I (2008) Taxonomy of the species in the Phellinus igniarius group. Mycotaxon 104:337-347

Senwanna C, Wanasinghe DN, Bulgakov TS, Wang Y, Bhat DJ, Tang AMC, Mortimer PE, Xu J, Hyde KD, Phookamsak R (2019) Towards natural classification of Dothidotthiaand Thyrostroma in Dothidotthiaceae (Pleosporineae, Pleosporales). Mycosphere 10:701-738

Shane WW, Teng PS (1992) Impact of Cercospora leaf spot on root weight, sugar yield, and purity of Beta vulgaris. Plant Dis 76:812-820

Sharma JK, Mohanan C (1991) In vitro evaluation of fungicides against Cylindrocladium spp. causing diseases of Eucalyptus in Kerala, India. Eur J For Pathol 21:17-26

Sharma G, Shenoy BD (2016) Colletotrichum systematics: past, present and prospects. Mycosphere 7:1093-1102

Sharma G, Kumar-Pinnaka A, Shenoy BD (2015) Resolving the Colletotrichum siamense species complex using ApMat marker. Fungal Divers 71:247-264

Sharma P, Jambhulkar PP, Raja M, Javeria S (2020a) Pythium spp. on vegetable crops: research progress and major challenges. Pythium 1907.

Sharma S, Hay FS, Pethybridge SJ (2020b) Genome resource for two Stemphylium vesicarium isolates causing Stemphylium leaf blight of onion in New York. Mol Plant-Microbe Interact 33:562-564

Shenoy BD, Jeewon R, Hyde KD (2007) Impact of DNA sequencedata on the taxonomy of anamorphicfungi. Fungal Diver 26:1-54

Shim SH, Ryu J, Kim JS, Kang SS, Xu Y, Jung SH, Lee YS, Lee S, Shin KH (2004) New lanostane-type triterpenoids from Ganoderma applanatum. J Nat Prod 67:1110-1113

Shin HD, La YJ (1993) Morphology of edge lines of chained immature conidia on conidiophores in powdery mildew fungi and their taxonomic significance. Mycotaxon 26:445-451

Shin HD, Zheng RY (1998) Anamorphic morphology of Uncinula and allied genera (I). Mycotaxon 66:243-266

Shirouzu T, Takamatsu S, Hashimoto A, Meeboon J, Ohkuma M (2020) Phylogenetic overview of Erysiphaceae based on nrDNA and MCM7 sequences. Mycoscience (in press).

Shivas RG (1989) Fungal and bacterial diseases of plants in Western Australia. J Royal Soci West Austra 72:1-62

Silva DN, Talhinhas P, Varzea V, Cai L, Paulo OS, Batista D (2012) Application of the Apn2/MAT locus to improve the systematics of the Colletotrichum gloeosporioides complex: an example from coffee (Coffea spp.) hosts. Mycologia 104:396-409

Silvestro D, Michalak I (2010) RAxMLGUI: a graphical front-end for RAxML version 0.9 beta 2. http://sourceforge.net/projects/ raxmlgui.

Simmons EG (1967) Typification of Alternaria, Stemphylium, and Ulocladium. Mycologia 59(1):67-92

Simmons EG (1985) Perfect states of Stemphylium II. Sydowia $38: 284-293$ 
Sinclair JB, Dhingra OD (1995) Basic plant pathology methods. CRC Press, Boca Raton

Sinclair WA, Lyon HH (2005) Diseases of trees and shrubs, 2nd edn. Cornell University Press, Ithaca, p 680

Sipos G, Prasanna AN, Walter MC, O'Connor E, Bálint B, Krizsán K, Kiss B, Hess J, Varga T, Slot J, Riley R, Bóka B, Rigling D, Barry K, Lee J, Mihaltcheva S, LaButti K, Lipzen A, Waldron R, Moloney NM, Sperisen C, Kredics L, Vágvölgyi C, Patrignani A, Fitzpatrick D, Nagy I, Doyle S, Anderson JB, Grigoriev IV, Güldener U, Münsterkötter M, Nagy LG (2017) Genome expansion and lineage-specific genetic innovations in the forest pathogenic fungi Armillaria. Nat Ecol Evol 1:1931-1941

Sitompul A, Nasution A (2020) Screening of white-rot fungi as biological control agents against Ganoderma philippii. Inter J Oil Palm 3:23-28

Slopek SW, Labun TJ (1992) First report of halo spot of barley caused by Pseudoseptoria stomaticola in Alberta. Can Plant Dis Surv 72:5-8

Smith ML, Anderson JB (1989) Restriction fragment length polymorphisms in mitochondrial DNAs of Armillaria: identification of North American biological species. Mycol Res 93:247-256

Smith BJ, Sivasithamparam K (2000) Internal transcribed spacer ribosomal DNA sequence of five species of Ganoderma from Australia. Mycol Res 104:943-951

Soares AP, Guillin EA, Borges LL, Silva AC, Almeida ÁM, Grijalba PE, Gottlieb AM, Bluhm BH, Oliveira LO (2015) More Cercospora species infect soybeans across the Americas than meets the eye. PLoS ONE 10:e0133495

Soares AM, Nogueira-Melo G, Plautz HL Jr, Gibertoni TB (2017) A new species, two new combinations and notes on Fomitopsidaceae (Agaricomycetes, Polyporales). Phytotaxa 331:75-83

Soleimani P, Soleimani MJ, Hosseini S (2018) Phylogenetic relationship and evolution of Neodidymelliopsis isolates collected from Iran. Mycosphere 9:1235-1255

Spatafora JW, Benny GL, Lazarus K (2016) A phylum-level phylogenetic classification of zygomycete fungi based on genome-scale data. Mycologia 108:1028-1046

Spegazzini C (1910) Mycetes argentinenses (series V). Anales del Museo Nacional de Historia Natural, Buenos Aires 20:329-467

Stalpers JA (1996) The aphyllophoraceous fungi II. Keys to the species of the Hericiales. Stud Mycol 40:1-185

Stamps DJ, Waterhouse GM, Newhook FJ, Hall GS (1990) Revised tabular key to the species of Phytophthora, 2nd edn. CAB-International, Wallingford

Steddom K, Bredehoeft MW, Khan M, Rush CM (2005) Comparison of visual and multispectral radiometric disease evaluations of Cercospora leaf spot of sugar beet. Plant Dis 89:153-158

Steve A, Hurdle V, Brown J (2018) Orbitomaxillo facial Mucormycosis requiring complex multifactorial management. Plast Reconstr Surg 6:1927

Stevens NE (1926) Two species of Physalospora on citrus and other hosts. Mycologia 18:206-217

Stewart EL, Liu Z, Crous PW, Szabo LJ (1999) Phylogenetic relationships among some cercosporoid anamorphs of Mycosphaerella based on rDNA sequence analysis. Mycol Res 103:1491-1499

Steyaert RL (1972) Species of Ganoderma and related genera mainly of the Bogorand Leiden herbaria. Persoonia 7:55-118

Steyaert RL (1980) Study of some Ganoderma species. Bull Jard Bot Nat Belg Bull Nat Plantenium Belg 50:135-186

Sturrock R, Frankel S, Brown A, Hennon P, Kliejunas J, Lewis K, Worrall J, Woods A (2011) Climate change and forest diseases. Plant Pathol 60:133-149

Su X, Zhu G, Huang Z, Wang X, Guo Y, Li B, Du Y, Yang W, Gao J (2019) Fine mapping and molecular marker development of the Sm gene conferring resistance to gray leaf spot (Stemphylium spp.) in tomato. Theoret Appl Genet 132:871-882
Summerell B, Liew E (2020) Phytophthora root rot: its impact in botanic gardens and on threatened species conservation. Sibbaldia: the International Journal of Botanic Garden Horticulture, pp 89-104.

Sun SJ, Gao W, Lin SQ, Zhu J, Xie BG, Lin ZB (2006) Analysis of genetic diversity in Ganoderma populations with a novel molecular marker SRAP. Appl Microbiol Biotech 72:537-543

Sun JZ, Liu XZ, McKenzie EHC, Jeewon R, Liu JK, Zhang XL, Zhao Q, Hyde KD (2019) Fungicolous fungi: terminology, diversity, distribution, evolution and species checklist. Fungal Divers 1-94.

Sutton BC (1980) The Coelomycetes. fungi imperfecti with pycnidia, acervuli and stromata. Commonwealth Mycological Institute, Kew, Surrey, England, p 696.

Sutton BC (1997) On Stigmina, Wilsonomyces and Thyrostroma (Hyphomycetes). Arnoldia 14:33-35

Sutton BC, Pascoe IG (1989) Reassessment of Peltosoma, Stigmina and Batcheloromyces and description of Hyphothyrium gen. nov. Mycol Res 92(2):210-222

Sutton DA, Fothergill AW, Rinaldi MG (1998) Guide to clinically significant fungi, 1st edn. Williams \& Wilkins, Baltimore

Swofford DL (2002) PAUP*: phylogenetic analysis using parsimony (*and other methods) Verson 4.0b10. Sinauer, Sunderland

Takamatsu S (2004) Phylogeny and evolution of the powdery mildew fungi (Erysiphales, Ascomycota) inferred from nuclear ribosomal DNA sequences. Mycoscience 45:147-157

Takamatsu S, Kano Y (2001) PCR primers useful for nucleotide sequencing of rDNA of the powdery mildew fungi. Mycoscience 42:135-139

Takamatsu S, Hirata T, Sato Y (1998) Phylogenetic analysis and predicted secondary structures of the rDNA internal transcribed spacers of the powdery mildew fungi (Erysiphaceae). Mycoscience 39:441-453

Takamatsu S, Hirata T, Sato Y, Nomura Y (1999) Phylogenetic relationships of Microsphaera and Erysiphe sect. Erysiphe (powderymildews) inferred from the rDNA ITS sequences. Mycoscience 40:259-268

Takamatsu S, Hirata T, Sato Y (2000) A parasitic transition from trees to herbs occurred at least two times in tribus Cystotheceae (Erysiphaceae): evidence from nuclear ribosomal DNA. Mycol Res 104:1304-1311

Takamatsu S, Braun U, Limkaisang S (2005a) Phylogenetic relationships and generic affinity of Uncinula septata inferred from nuclear rDNA sequences. Mycoscience 46:9-16

Takamatsu S, Niinomi S, Cabrera de Álvarez MG, Álvarez RE, Havrylenko M, Braun U (2005b) Caespitotheca gen. nov., an ancestral genus in the Erysiphales. Mycol Res 109:903-911

Takamatsu S, Matsuda S, Niinomi S, Havrylenko M (2006) Molecular phylogeny supports a northern hemisphere origin of Golovinomyces (Ascomycota: Erysiphales). Mycol Res 110:1093-1101

Takamatsu S, Havrylenko M, Wolcan SM, Matsuda S, Niinomi S (2008) Molecular phylogeny and evolution of the genus Neoerysiphe (Erysiphaceae, Ascomycota). Mycol Res 112:639-649

Takamatsu S, Niinomi S, Harada M, Havrylenko M (2010) Molecular phylogenetic analyses reveal a close evolutionary relationship between Podosphaera (Erysiphales: Erysiphaceae) and its rosaceous hosts. Persoonia 24:38

Takamatsu S, Matsuda S, Grigaliunaite B (2013) Comprehensive phylogenetic analysis of the genus Golovinomyces (Ascomycota: Erysiphales) reveals close evolutionary relationships with its host plants. Mycologia 105:1135-1152

Tang B, Pan H, Tang W, Zhang Q, Ding L, Zhang F (2012) Fermentation and purification of cellulase from a novel strain Rhizopus stolonifer var. reflexus TP-02. Biomass Bioenergy 36:366-372

Tao G, Liu ZY, Liu F, Gao YH, Cai L (2013) Endophytic Colletotrichum species from Bletilla ochracea (Orchidaceae), with description of seven new species. Fungal Divers 61:139-164 
Taylor J, Jacobson D, Kroken S, Kasuga T, Geiser D, Hibbett D, Fisher M (2000) Phylogenetic species recognition and species concepts in fungi. Fungal Gene Biol 31:21-32

Tchoumi JMT, Coetzee MPA, Rajchenberg M, Roux J (2019) Taxonomy and species diversity of Ganoderma species in the Garden Route National Park of South Africa inferred from morphology and multilocus phylogenies. Mycologia 111:730-747

Te Beest DE, Paveley ND, Shaw MW, Van Den Bosch F (2008) Disease-weather relationships for powdery mildew and yellow rust on winter wheat. Phytopathology 98:609-617

Teng BS, Wang CD, Yang HJ, Wu JS, Zhang D, Zheng M, Fan ZH, Pan D, Zhou P (2011) A protein tyrosine phosphatase 1B activity inhibitor from the fruiting bodies of Ganoderma lucidum (Fr.) Karst and its hypoglycemic potency on streptozotocin-induced type 2 diabetic mice. J Agric Food Chem 59:6492-6500

Terashima K, Cha JY, Yajima T, Igarashi T, Miura K (1998) Phylogenetic analysis of Japanese Armillaria based on the intergenic spacer (IGS) sequences of their ribosomal DNA. Eur J For Pathol 28:11-19

Thambugala KM, Ariyawansa HA, Li YM, Boonmee S, Hongsanan S, Tian Q, Singtripop C, Bhat DJ, Camporesi E, Jayawardena R, Liu ZY, Xu JC, Chukeatirote E, Hyde KD (2014) Dothideales. Fungal Divers 68:105-158

Thines M, Choi YJ, Kemen E, Ploch S, Holub EB, Shin DH, Jones JDG (2009) A new species of Albugo parasitic to Arabidopsis thaliana reveals new evolutionary patterns in white blister rusts (Albuginaceae). Persoonia 22:23-128

Thomas E, Herrero S, Eng H, Gomaa N, Gillikin J, Noar R, Beseli A, Daub ME (2020) Engineering Cercospora disease resistance via expression of Cercospora nicotianae cercosporin-resistance genes and silencing of cercosporin production in tobacco. PLoS ONE 15:e0230362

Thompson JD, Gibson TJ, Plewniak F, Jeanmougin F, Higgins DG (1997) The ClustalX window interface: flexible strategies for multiple sequence alignment aided by quality analysis tools. Nucleic Acids Res 24:4876-4882

Tkacz B, Schmitz R (1986) Association of an endemic mountain pine beetle population with lodgepole pine infected by Armillaria root disease in Utah, USDA Forest Service Res. Note INT-353, Logan Forestry Sciences Lab, Utah State University, Logan, UT.

To-anun C, Kom-un S, Sunawan A, Fangfuk W, Sato Y, Takamatsu S (2005) A new subgenus, Microidium, of Oidium (Erysiphaceae) on Phyllanthus spp. Mycoscience 46:1-8

To-anun C, Hidayat I, Meeboon J (2011) Genus Cercospora in Thailand: taxonomy and phylogeny (with a dichotomous key to species). Plant Pathol Quaran 1:11-87

Tokuda S, Ota Y, Hattori T (2007) Root and butt rot of Todo fir (Abies sachalinensis) caused by Heterobasidion annosum s.l. in Hokkaido, Japan. For Pathol 37:155-166

Tokuda S, Hattori T, Dai YC, Ota Y, Buchanan PK (2009) Three species of Heterobasidion (Basidiomycota, Hericiales), H. parviporum, $H$. orientale sp. nov. and $H$. ecrustosum sp. nov. from East Asia. Mycoscience 50:190-202

Tomšovský M, Vampola P, Sedlák P, Byrtusová Z, Jankovský L (2010) Delimitation of central and northern European species of the Phellinus igniarius group (Basidiomycota, Hymenochaetales) based on analysis of ITS and translation elongation factor 1 alpha DNA sequences. Mycol Prog 9:431-445

Torres DE, Rojas-Martínez RI, Zavaleta-Mejia E, Guevara-Fefer P, Márquez-Guzmán GJ, Perez-Martinez C (2017) Cladosporium cladosporioides and Cladosporium pseudocladosporioides as potential new fungal antagonists of Puccinia horiana Henn., the causal agent of Chrysanthemum white rust. PLoS ONE 12:e0170782
Triki MA, Gharbi Y, Bouazizi E, Cheffi M, Krid S, Feki FA, Bouhamed J (2019) First report of branch blight of almond trees caused by Nothophoma quercina in Tunisia. J Plant Pathol 101:1277

Tsushima A, Gan P, Kumakura N, Narusaka M, Takano Y, Narusaka Y, Shirasu K (2019) Genomic plasticity mediated by transposable elements in the plant pathogenic fungus Colletotrichum higginsianum. Genome Biol Evol 11:1487-1500

Tsykun T, Rigling D, Prospero SA (2013) New multilocus approach for a reliable DNA-based identification of Armillaria species. Mycologia 105:1059-1076

Turner PD (1981) Oil palm diseases and disorders. Oxford University Press, Kuala Lumpur, p 281

Utomo C, Tanjung ZA, Aditama R, Buana RFN, Pratomo ADM, Tryono R, Liwang T (2018) Draft genome sequence of the phytopathogenic fungus Ganoderma boninense, the causal agent of basal stem rot disease on oil palm. Genome Announc 6:e00122-18

Uzuhashi S, Kakishima M, Tojo M (2010) Phylogeny of the genus Pythium and description of new genera. Mycoscience 51:337-365

Uzuhashi S, Okada G, Ohkuma M (2015) Four new Pythium species from aquatic environments in Japan. Antonie Van Leeuwenhoek 107:375-391

Valenzuela-Lopez N, Cano-Lira JF, Guarro J, Sutton DA, Wiederhold N, Crous PW, Stchigel AM (2018) Coelomycetous Dothideomycetes with emphasis on the families Cucurbitariaceae and Didymellaceae. Stud Mycol 90:1-69

Van Buyten E, Höfte M (2013) Pythium species from rice roots differ in virulence, host colonization and nutritional profile. BMC Plant Biol 13:203

Van Coller GJ, Denman S, Groenewald JZ, Lamprecht SC, Crous PW (2005) Characterization and pathogenicity of Cylindrocladiella spp. associated with root and cutting rot symptoms of grapevines in nurseries. Australas Plant Pathol 34:489-498

van der Plaäts-Niterink AJ (1981) Monograph of the genus Pythium. Stud Mycol 21:1-242

van Kan JA, Van den Ackerveken GFJM, De Wit PJGM (1991) Cloning and characterization of cDNA of avirulence gene avr9 of the fungal pathogen Cladosporium fulvum, causal agent of tomato leaf mold. Mol Plant-Microbe Interact 4:52-59

van West P, Appiah AA, Gow NA (2003) Advances in research on oomycete root pathogens. Physiol Mol Plant Pathol 62:99-113

Vánky K (2013) Illustrated genera of smut fungi, 3rd edn. APS Press, St. Paul, pp 1-288

Vebliza Y, Sjamsuridzal W, Oetari A, Santoso I, Roosheroe IG (2018) Re-identification of five strains of Rhizopus arrhizus from tempeh based on ITS regions of rDNA sequence data. AIP Conference Proceedings 2023:020167

Vencelli P, Powell AJ (2008) Chemical control of turf diseases 2008. Univ. of Kentucky Cooperative Extension Service, Publication No. PPA1.

Venkatarayan SV (1936) The biology of Ganoderma lucidum on areca nut and coconut palms. Phytopathol 22:153-175

Ventura F, Watanabe I, Castillo MB, De La Cruz A (1981) Involvement of nematodes in the soil sickness of a dryland rice-based cropping system. J Soil Sci Plant Nutr 27:305-315

Vereijssen J (2004) Cercospora leaf spot in sugar beet. Epidemiology, life cycle components and disease management. Wageningen University, Wageningen, The Netherlands, p 200.

Vettraino AM, Lucero G, Pizzuolo P, Franceschini S, Vannini A (2009) First report of root rot and twigs wilting of olive trees in Argentina caused by Phytophthora nicotianae. Plant Dis 93:765-765

Vettraino AM, Brasier CM, Brown AV, Vannini A (2011) Phytophthora himalsilva sp. nov. an unusually phenotypically variable species from a remote forest in Nepal. Fungal Biol 115:275-287 
Victor D, Crous PW, Janse BJH, van Zyl WH, Wingfield MJ, Alfenas AC (1998) Systematic appraisal of species complexes within Cylindrocladiella. Mycol Res 102:273-279

Vlasák J, Vlasák J (2017) Phellinus artemisiae sp. nov. (Basidiomycota, Hymenochaetaceae), from western USA. Phytotaxa 303:93-96

Vogel S, Alvarez B, Bässler C, Müller J, Thorn S (2017) The red-belted bracket (Fomitopsis pinicola) colonizes spruce trees early after bark beetle attack and persists. Fungal Ecol 27:182-188

Volk TJ, Burdsall HH Jr, Banik MT (1996) Armillaria nabsnona, a new species from western North America. Mycologia 88:484-491

von Arx JA, Müller E (1954) Die Gattungen der amerosporen Pyrenomyceten. Beiträge zur Kryptogamenflora der Schweiz 11:1-434

Wagner T, Fischer M (2001) Natural groups and a revised system for the European poroid Hymenochaetales (Basidiomycota) supported by nLSU rDNA sequence data. Mycol Res 105:773-782

Wagner T, Fischer M (2002) Proceedings towards a natural classification of the worldwide taxa Phellinus s. 1. and Inonotus s. 1., and phylogenetic relationships of allied genera. Mycologia 94:998-1016

Wagner L, Stielow JB, de Hoog GS, Bensch K, Schwartze VU, Voigt K, Alastruey-Izquierdo A, Kurzai O, Walther G (2019) A new species concept for the clinically relevant Mucor circinelloides complex. Persoonia 44:67-97

Walker AS, Bouguennec A, Confais J (2011) Evidence of host-range expansion from new powdery mildew (Blumeria graminis) infections of triticale ( $\times$ Triticosecale) in France. Plant Pathol 60:207-220

Walther G, Pawłowska J, Alastruey-Izquierdo A, Wrzosek M, Rodriguez-Tudela JL, Dolatabadi S, Chakrabarti A, de Hoog GS (2013) DNA barcoding in Mucorales: an inventory of biodiversity. Persoonia 30:11-47

Walther G, Wagner L, Kurzai O (2019) Updates on the taxonomy of Mucorales with an emphasis on clinically important taxa. J Fungi 5:106

Wang F, Liu JK (2008) Highly oxygenated lanostane triterpenoids from the fungus Ganoderma applanatum. Chem Pharm Bull 56:1035-1037

Wang Z, Johnston PR, Takamatsu S, Spatafora JW, Hibbett DS (2006) Toward a phylogenetic classification of the Leotiomycetes based on rDNA data. Mycologia 98:1065-1075

Wang DM, Wu SH, Su CH, Peng JT, Shih YH, Chen LC (2009) Ganoderma multipileum, the correct name for 'G. lucidum' in tropical Asia. Botani Stud 50:451-458

Wang B, Cui BK, Li HJ, Du P, Jia BS (2011) Wood-inhabiting fungi in eastern China. 5. Polypore diversity in Jiangxi Province. Ann Bot Fenn 48:237-246

Wang Y, Cheng X, Shan Q, Zhang Y, Liu J, Gao C, Qiu JL (2014) Simultaneous editing of three homoeoalleles in hexaploid bread wheat confers heritable resistance to powdery mildew. Nat Biotechnol 32:947

Waterhouse GM (1963) Key to the species of Phytophthora de Barry. Mycol Paper 92:1-22

Watling R, Kile GA, Burdsall HH (1991) Nomenclature, taxonomy, and identification. In: Miller OK, Shaw CG, Kile GA (eds) Armillaria root disease agriculture handbook no. 691, USDA, Washington, $\mathrm{p} 1-9$.

Weiland JE, Beck BR, Davis A (2012) Pathogenicity and virulence of Pythium species obtained from forest nursery soils on douglas-fir seedlings. Plant Dis 97:744-748

Weir BS, Johnston PR, Damm U (2012) The Colletotrichum gloeosporioides species complex. Stud Mycol 73:115-180

Weir BS, Paderes EP, Anand N, Uchida JY, Pennycook SR, Bellgard SE, Beever RE (2015) A taxonomic revision of Phytophthora Clade 5 including two new species, Phytophthora agathidicida and P. cocois. Phytotaxa 205:21-38
White TJ, Bruns T, Lee S, Taylor JW (1990) Amplification and direct sequencing of fungal ribosomal RNA genes for phylogenetics. In: Innis MA, Gelfand DH, Sninsky JJ, White TJ (eds) PCR protocols: a guide to methods and applications. Academic Press Inc, New York, pp 315-322

Wijayawardene NN, McKenzie EHC, Hyde KD (2012) Towards incorporating anamorphic fungi in a natural classification-checklist and notes for 2011. Mycosphere 3(2):157-228

Wijayawardene NN, Hyde KD, Rajeshkumar KC, Hawksworth DL, Madrid H, Kirk PM, Braun U, Singh RV, Crous PW, Kukwa M, Lücking R, Kurtzman CP, Yurkov A, Haelewaters D, Aptroot A, Lumbsch HT, Timdal E, Ertz D, Etayo J, Phillips AJL, Groenewald JZ, Papizadeh M, Selbmann L, Dayarathne MC, Weerakoon G, Jones EBG, Suetrong S, Tian Q, Castañeda-Ruiz RF, Bahkali AH, Pang K-L, Tanaka K, Dai DQ, Sakayaroj J, Hujslová M, Lombard L, Shenoy BD, Suija A, Maharachchikumbura SSN, Thambugala KM, Wanasinghe DN, Sharma BO, Gaikwad S, Pandit G, Zucconi L, Onofri S, Egidi E, Raja HA, Kodsueb R, Cáceres MES, Pérez-Ortega S, Fiuza PO, Monteiro JS, Vasilyeva LN, Shivas RG, Prieto M, Wedin M, Olariaga I, Lateef AA, Agrawal Y, Fazeli SAS, Amoozegar MA, Zhao GZ, Pfliegler WP, Sharma G, Oset M, Abdel-Wahab MA, Takamatsu S, Bensch K, de Silva NI, De Kese A, Karunarathna A, Boonmee S, Pfister DH, Lu Y-Z, Luo Z-L, Boonyuen N, Daranagama DA, Senanayake IC, Jayasiri SC, Samarakoon MC, Zeng X-Y, Doilom M, Quijada L, Rampadarath S, Heredia G, Dissanayake AJ, Jayawardana RS, Perera RH, Tang LZ, Phukhamsakda C, HernándezRestrepo M, Ma X, Tibpromma S, Gusmao LFP, Weerahewa D, Karunarathna SC (2017a) Notes for genera-Ascomycota. Fungal Divers 86:1-594

Wijayawardene NN, Hyde KD, Tibpromma S, Wanasinghe DN, Thambugala KM, Tian Q, Wang Y (2017b) Towards incorporating asexual fungi in a natural classification: checklist and notes 2012-2016. Mycosphere 8:1457-1555

Wijayawardene NN, Pawłowska J, LetcherP KirkP, HumberR Schüßler A, Wrzosek M, Muszewska A, Okrasińska A, Istel Ł, Gęsiorska A, MungaiP Lateef A, Rajeshkumar K, Singh R, Radek R, Walther G, Wagner L, Walker C, Wijesundara D, Papizadeh M, Dolatabadi S, Shenoy B, Tokarev Y, Lumyong S, Hyde K (2018) Notes for genera: basal clades of Fungi (including Aphelidiomycota, Basidiobolomycota, Blastocladiomycota, Calcarisporiellomycota, Caulochytriomycota, Chytridiomycota, Entomophthoromycota, Glomeromycota, Kickxellomycota, Monoblepharomycota, Mortierellomycota, Mucoromycota, Neocallimastigomycota, Olpidiomycota, Rozellomycota and Zoopagomycota). Fungal Divers 92:43-129

Wijayawardene NN, Hyde KD, Al-Ani LKT, Tedersoo L, Haelewaters D, Rajeshkumar KC, Zhao RL, Aptroot A, Leontyev DV, Saxena RK, Tokarev YS, Dai DQ, Letcher PM, Stephenson SL, Ertz D, Lumbsch HT, Kukwa M, Issi IV, Madrid H, Phillips AJL, Selbmann L, Pfliegler WP, Horváth E, Bensch K, Kirk PM, Kolaříková K, Raja HA, Radek R, Papp V, Dima B, Ma J, Malosso E, Takamatsu S, Rambold G, Gannibal PB, Triebel D, Gautam AK, Avasthi S, Suetrong S, Timdal E, Fryar SC, Delgado G, Réblová M, Doilom M, Dolatabadi S, Pawłowska JZ, Humber RA, Kodsueb R, Sánchez-Castro I, Goto BT, Silva DKA, de Souza FA, Oehl F, da Silva GA, Silva IR, Błaszkowski J, Jobim K, Maia LC, Barbosa FR, Fiuza PO, Divakar PK, Shenoy BD, Castañeda-Ruiz RF, Somrithipol S, Lateef AA, Karunarathna SC, Tibpromma S, Mortimer PE, Wanasinghe DN, Phookamsak R, Xu J, Wang Y, Tian F, Alvarado P, Li DW, Kušan I, Matočec N, Mešić A, Tkalčec Z, Maharachchikumbura SSN, Papizadeh M, Heredia G, Wartchow F, Bakhshi M, Boehm E, Youssef N, Hustad VP, Lawrey JD, Santiago ALCMA, Bezerra JDP, Souza-Motta CM, Firmino AL, Tian Q, Houbraken J, Hongsanan S, Tanaka K, Dissanayake AJ, Monteiro JS, Grossart HP, 
Suija A, Weerakoon G, Etayo J, Tsurykau A, Vázquez V, Mungai P, Damm U, Li QR, Zhang H, Boonmee S, Lu YZ, Becerra AG, Kendrick B, Brearley FQ, Motiejūnaitė J, Sharma B, Khare R, Gaikwad S, Wijesundara DSA, Tang LZ, He MQ, Flakus A, Rodriguez-Flakus P, Zhurbenko MP, McKenzie EHC, Stadler M, Bhat DJ, Liu JK, Raza M, Jeewon R, Nassonova ES, Prieto M, Jayalal RGU, Erdoğdu M, Yurkov A, Schnittler M, Shchepin ON, Novozhilov YK, Silva-Filho AGS, Gentekaki E, Liu P, Cavender JC, Kang Y, Mohammad S, Zhang LF, Xu RF, Li YM, Dayarathne MC, Ekanayaka AH, Wen TC, Deng CY, Pereira OL, Navathe S, Hawksworth DL, Fan XL, Dissanayake LS, Kuhnert E, Grossart HP, Thines M (2020) Outline of fungi and funguslike taxa. Mycosphere 11:1060-1456

Woodward S, Stenlid J, Karjalainen R, Hüttermann A (1998) Preface. In: Woodward S, Stenlid J, Karjalainen R, Hüttermann A (eds) Heterobasidion annosum: biology, ecology, impact and control. CAB International, Wallingford, pp 11-12

Worrall J (2004) Armillaria root disease. The plant health instructor. The American Phytopathological Society (APS), St. Paul

Woudenberg JHC, Hanse B, van Leeuwen GCM, Groenewald JZ, Crous PW (2017) Stemphylium revisited. Stud Mycol 87:77-103

Wrather A, Shannon G, Balardin R, Carregal L, Escobar R, Gupta GK, Ma Z, Morel W, Ploper D, Tenuta A (2010) Effect of diseases on soybean yield in the top eight producing countries in 2006. Plant Health Prog 11:29

Xing JH, Song J, Decock C, Cui BK (2016) Morphological characters and phylogenetic analysis reveal a new species within the Ganoderma lucidum complex from South Africa. Phytotaxa 266:115-124

Xing JH, Sun YF, Han YL, Cui BK, Dai YC (2018) Morphological and molecular identification of two new Ganoderma species on Casuarina equisetifolia from China. MycoKeys 34:93-108

Xiong Q, Qian Y, Zhang C, Shi N, Zheng X (2019) First report of Phytophthora hydropathica causing wilting and shoot blight on Bixa orellana in China. Plant Dis 103:163

Yan JY, Jayawardena MMRS, Goonasekara ID, Wang Y, Zhang W, Liu M, Huang JB, Wang ZY, Shang JJ, Peng YL, Bahkali A, Hyde KD, Li XH (2015) Diverse species of Colletotrichum associated with grapevine anthracnose in China. Fungal Divers 71:233-246

Yang X, Copes WE, Hong CX (2014a) Two novel species representing a new clade and cluster of Phytophthora. Fungal Biol 118:72-82

Yang X, Gallegly ME, Hong CX (2014b) A high-temperature tolerant species in clade 9 of the genus Phytophthora: P. hydrogena sp. nov. Mycologia 106:57-65

Yang X, Balci Y, Brazee NJ, Loyd AL, Hong C (2016) A unique species in Phytophthora clade 10, Phytophthora intercalaris sp. nov., recovered from stream and irrigation water in the eastern USA. Int J Syst Evol Microbiol 66:845-855

Yang X, Tyler BM, Hong C (2017) An expanded phylogeny for the genus Phytophthora. IMA Fungus 8(2):355-384

Yao YJ, Wang XC, Wang B (2013) Epitypification of Ganoderma sichuanense J. D. Zhao and X.Q. Zhang (Ganodermataceae). Taxon 62:1025-1031

Yarwood CE (1957) Powdery mildews. Bot Rev 13:235-301

Ye L, Karunarathna SC, Mortimer PE, Li H, Qiu M, Peng XR, Luangharn T, Li YJ, Promputtha I, Hyde KD, Xu J (2019) Ganoderma weixiensis (Polyporaceae, Basidiomycota), a new member of the G. lucidum complex from Yunnan Province, China. Phytotaxa 423(2):75-86

Yildirim I, Turhan H, Özgen B (2010) The effects of head rot disease (Rhizopus stolonifer) on sunflower genotypes at two different growth stages. Turkish J Field Crop 15:94-98

Yombiyeni P, Douanla-Meli C, Amalfi M, Decock C (2011) Poroid Hymenochaetaceae from Guineo-Congolian rainforest: Phellinus gabonensis sp. nov. from Gabon-taxonomy and phylogenetic relationships. Mycol Prog 10:351-362
Yoon HS, Hackett JD, Pinto G, Bhattacharya D (2002) The single, ancient origin of chromist plastids. J Phycol 38:40-40

Yorinori JT, Henechin M (1978) Races of Cercospora sojina in parajme Brazil. In: 3rd international congress of plant pathology. Berlin, Parey.

Yuan ZQ, Old KM (1990) A new species of Thyrostroma from Australia. Mycol Res 94:573-576

Yun YH, Oh MH (2016) First report of Nothophoma quercina causing shoot canker on Chaenomeles sinensis in Korea. Plant Dis 100:2533-2534

Zeng XY, Zhao JJ, Hongsanan S, Chomnunti P, Boonmee S, Wen TC (2017) A checklist for identifying Meliolales species. Mycosphere 8:218-359

Zeng R, Gao S, Xu L, Liu X, Dai F (2018) Prediction of pathogenesisrelated secreted proteins from Stemphylium lycopersici. BMC Microbiol 18:191

Zeng XY, Jeewon R, Hongsanan S, Hyde KD, Wen TC (2020) Unravelling evolutionary relationships between epifoliar Meliolaceae and angiosperms. J Syst Evol (in press).

Zhang H, Hyde KD, McKenzie EHC, Bahkali AH, Zhou D (2012) Sequence data reveals phylogenetic affinities of Acrocalymma aquatica sp. nov., Aquasubmersa mircensis gen. et sp. nov. and Clohesyomyces aquaticus (freshwater coelomycetes). Cryptogamie Mycol 33:333-346

Zhang LX, Yin T, Pan M, Tian CM, Fan XL (2020) Occurrence and identification of Nothophoma spiraeae sp. nov. in China. Phytotaxa 430:147-156

Zhao CL, Saba M, Khalid AN, Song J, Pfister DH (2017) Heterobasidion amyloideopsis sp. nov. (Basidiomycota, Russulales) evidenced by morphological characteristics and phylogenetic analysis. Phytotaxa 317:199-210

Zheng L, Jia D, Fei X, Luo X, Yang Z (2007a) An assessment of the genetic diversity within Ganoderma strains with AFLP and ITSPCR-RFLP. Mycol Res 164:312-321

Zheng RY, Chen GQ, Huang H, Liu XY (2007b) A monograph of Rhizopus. Sydowia 59:273-372

Zheng L, Lv R, Huang J, Jiang D, Hsiang T (2010) Isolation, purification, and biological activity of a phytotoxin produced by Stemphylium solani. Plant Dis 94(10):1231-1237

Zhou LW, Cao Y, Wu SH, Vlasák J, Li DW, Li MJ, Dai YC (2015a) Global diversity of the Ganoderma lucidum complex (Ganoderma taceae, Polyporales) inferred from morphology and multilocus phylogeny. Phytochemistry 114:7-15

Zhou LW, Cao Y, Wu SH, Vlasak J, Li DW, Li MJ, Dai YC (2015) Global diversity of the Ganoderma lucidumcomplex (Ganodermataceae, Polyporales) inferred from morphology and multilocus phylogeny. Photochemistry 114.

Zhou LW, Vlasák J, Qin WM, Dai YC (2016) Global diversity and phylogeny of the Phellinus igniarius complex (Hymenochaetales, Basidiomycota) with the description of five new species. Mycologia 108:192-204

Zhou H, Wang D, Zhao J, Dong B, Zhang X, Wen C, Zhang J (2018) First report of Rhizopus head rot of sunflower caused by Rhizopus arrhizus (syn. R. oryzae) in Xinjiang and Gansu Provinces of China. Plant Dis 102:1173-1173

Zhu L, Ji X, Si J, Cui BK (2018) Morphological characters and phylogenetic analysis reveal a new species of Phellinus with hooked hymenial setae from Vietnam. Phytotaxa 356:91-99

Zoffoli JP, Latorre BA (2011) Table grape (Vitis vinifera L.). In: Yahia EM (ed) Postharvest biology and technology of tropical and subtropical fruits, vol 3. Woodhead Publishing, Sawston 


\section{Affiliations}

Ruvishika S. Jayawardena ${ }^{1,2,7} \cdot$ Kevin D. Hyde ${ }^{1,2,3,18} \cdot$ Yi Jyun Chen ${ }^{2,7} \cdot$ Viktor Papp $^{4} \cdot$ Balázs Palla $^{4} \cdot$ Dávid Papp $^{5,6}$. Chitrabhanu S. Bhunjun $^{2,7}$ • Vedprakash G. Hurdeal ${ }^{2,7} \cdot$ Chanokned Senwanna $^{2,8} \cdot$ Ishara S. Manawasinghe ${ }^{2,9,18}$. Dulanjalee L. Harischandra ${ }^{2,7,9} \cdot$ Ajay Kumar Gautam ${ }^{10} \cdot$ Shubhi Avasthi $^{11}$ • Boontiya Chuankid ${ }^{2,7}$.

Ishani D. Goonasekara ${ }^{2,7} \cdot$ Sinang Hongsanan ${ }^{12} \cdot$ XiangYu Zeng $^{2,7,19} \cdot$ Kapila K. Liyanage $^{2,17,20} \cdot$ NingGuo Liu $^{2}$. Anuruddha Karunarathna ${ }^{2,8} \cdot$ Kalani K. Hapuarachchi ${ }^{2} \cdot$ Thatsanee Luangharn $^{2,3}$. Olivier Raspé ${ }^{2,7}$. Rashika Brahmanage ${ }^{2,7,9} \cdot$ Mingkwan Doilom $^{3,16,17} \cdot$ Hyang B. Lee $^{13} \cdot$ Liu Mei $^{9} \cdot$ Rajesh Jeewon $^{14}$. Naruemon Huanraluek ${ }^{2} \cdot$ Napalai Chaiwan $^{2,7} \cdot$ Marc Stadler $^{15} \cdot$ Yong Wang $^{1}$

1 Department of Plant Pathology, Agriculture College, Guizhou University, Guiyang 550025, Guizhou, China

2 Center of Excellence in Fungal Research, Mae Fah Luang University, Chiang Rai, Thailand

3 Key Laboratory for Plant Diversity and Biogeography of East Asia, Kunming Institute of Botany, Chinese Academy of Sciences, Kunming 650201, People's Republic of China

4 Department of Botany, Szent István University, Villányi út 29-43, Budapest 1118, Hungary

$5 \quad$ Plant Pathology and Plant-Microbe Biology Section, Cornell University, Geneva, NY 6 14456, USA

6 Department of Pomology, Szent István University, Villányi út 29-43, Budapest 1118, Hungary

7 School of Science, Mae Fah Luang University, Chiang Rai 57100, Thailand

8 Department of Entomology and Plant Pathology, Faculty of Agriculture, Chiang Mai University, No. 9 of Shuguanghuayuanzhonglu, Chiang Mai 50200, Thailand

9 Institute of Plant and Environment Protection, Beijing Academy of Agriculture and Forestry Sciences, Haidian DistrictHaidian District, Beijing 100097, People's Republic of China

10 School of Agriculture, Abhilashi University, Mandi, Himachal Pradesh 175028, India

11 School of Studies in Botany, Jiwaji University, Gwalior 474011, India
12 Guangdong Provincial Key Laboratory for Plant Epigenetics, College of Life Sciences and Oceanography, Shenzhen University, Shenzhen 518055, PR China

13 Environmental Microbiology Lab, Dept. of Agricultural Biological Chemistry, College of Agriculture and Life Sciences, Chonnam National University, Gwangju 61186, Korea

14 Department of Health Sciences, Faculty of Science, University of Mauritius, Reduit, Mauritius

15 Department of Microbial Drugs, Helmholtz Centre for Infection Research, Inhoffenstraße 7, 38124 Braunschweig, Germany

16 Honghe Innovation Center for Mountain Futures, Kunming Institute of Botany, Honghe County, Yunnan 654400, People's Republic of China

17 World Agroforestry Centre, East and Central Asia, Kunming 650201, Yunnan, People's Republic of China

18 Institute of Plant Health, Zhongkai University of Agriculture and Engineering, Guangzhou 510225, China

19 Faculty of Agriculture, Natural Resources and Environment, Naresuan University, Phitsanulok 65000, Thailand

20 Rubber Research Institute of Sri Lanka, Dartonfield, Agalawatta, Sri Lanka 